\title{
Mechanismen der Entwicklung des zerebralen Kortex
}

Dissertation

zur Erlangung des Doktorgrades

der Mathematisch-Naturwissenschaftlichen Fakultäten der Georg-August-Universität zu Göttingen

vorgelegt von

Sven Mühlfriedel

aus Schleiz

Göttingen 2004 
D7

Referent:

Professor Dr. P. Gruss

Korreferent:

Privatdozent Dr. S. Hoyer-Fender

Tag der mündlichen Prüfung:

02.11.2004 
Diese Arbeit wurde am

Max-Planck-Institut für biophysikalische Chemie,

Karl-Friedrich-Bonhoefer-Institut

Abteilung: Molekulare Zellbiologie

Direktor: Prof. Dr. Peter Gruss

durchgeführt. 



\section{Inhaltsverzeichnis}

Inhaltsverzeichnis 1

Danksagung......................................................................................................................... 6

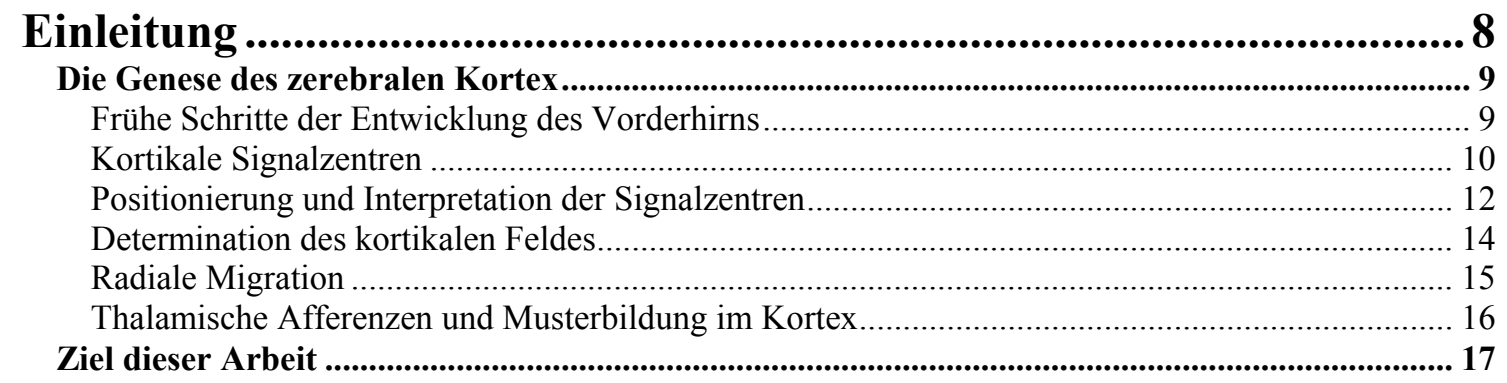

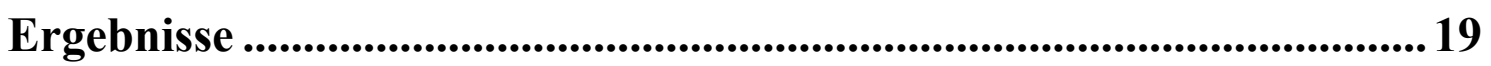

Identifikation regional exprimierter Gene im zerebralen Kortex des Embryonalstadiums 16,5 - 19 Microarray-Expressionsanalyse an RNA-Präparationen verschiedener Regionen des E16,5-Kortex 19 RNA-in situ-Hybridisierung mit ausgewählten Sequenzen ......................................................... 20

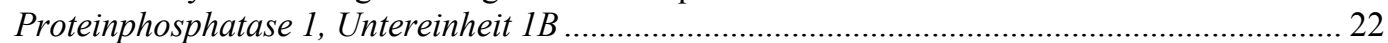

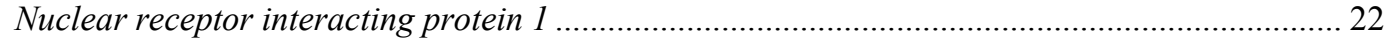

Nur-related protein 1 ........................................................................................................ 22

Fibronectin leucin rich transmembrane protein 3 ................................................................. 23

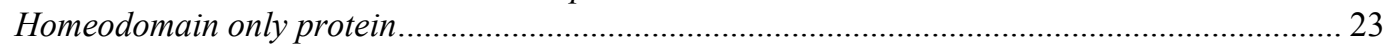

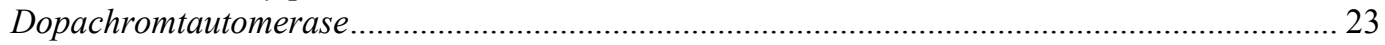

Solute carrier family 1, member 3 .......................................................................................... 23

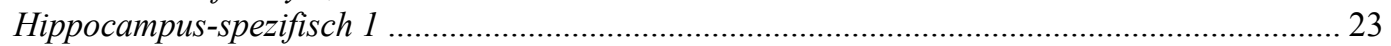

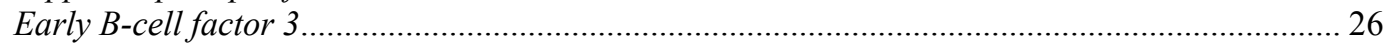

Isolation von cDNA-Klonen des Gens Hop und Expressionsstudie im zentralen Nervensystem .. 27

Isolation von cDNA-Klonen des Hop-Gens aus einer cDNA-Bibliothek........................................ 27

Analyse der Expression von Hop mittels RNA-in situ- und Northernblot-Hybridisierung .............. 27

Expression von Hop im E12,5-Embryo ..................................................................... 28

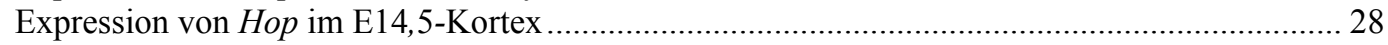

Expression von Hop im E16, 5-Kortex .................................................................................. 28

Expression von Hop im E18, 5-Kortex .................................................................................. 28

Expression von Hop im postnatalen Gehirn....................................................................... 31

Northernblot-Analyse der Hop-Expression in Organen des E16,5-Embryos.............................. 31

Expression von Hop im Lef1- und Emx2-defizienten Kortex an E16,5 ..................................... 32

Zusammenfassung der Expressionsanalyse von Hop im prä- und postnatalen Nervensystem ...... 33

Immunohistochemischer Nachweis des Proteins Serum response factor ......................................... 34

Analyse des embryonalen und adulten Gehirns einer Hop-defizienten Mauslinie........................... 35

Vergleich der Hirnanatomie von Wildtyp und Hop-Knock out ..................................................... 35

Vergleich früher Markergen-Expression im Wildtyp- und Hop-defizienten Gehirn ......................... 37

Expression von Markergenen der embryonalen Fimbria im Wildtyp und Hop-Knock out........... 37

Expression von Markergenen der Ventrikulärzone im Wildtyp und Hop-Knock out................... 37

Expression von Markergenen des Hippocampus im Wildtyp und Hop-Knock out ...................... 37

Expression von Markergenen der Marginalzone im Wildtyp und Hop-Knock out........................ 39 
Identifikation LacZ-positiver Zellen im Hop-Knock out-Gehirn .................................................. 39

BrdU-Markierung mitotischer Zellen im Vorderhirn von Wildtyp und Hop-Knock out .................. 40

Analyse eines regulatorischen Sequenzelementes "upstream" des Genlokus von Hop ................. 42

Identifikation und bioinformatische Analyse des E1-Elementes durch Vergleich genomischer

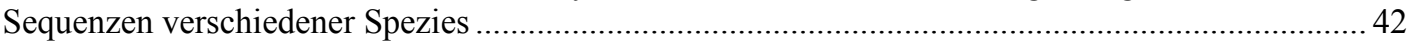

Nachweis regionaler Reporteraktivität unter Kontrolle des E1-Elementes in vivo .......................... 44

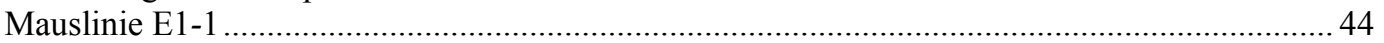

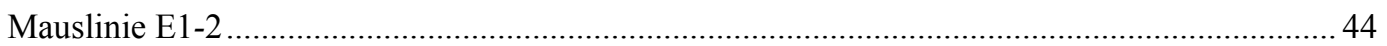

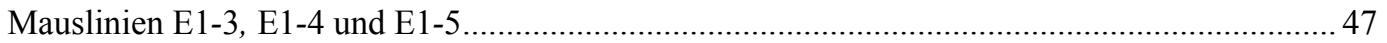

Induktion von E1-bedingter Reporteraktivität durch Transplantation der Deckplatte in vitro ........... 47

Etablierung einer in vitro-Methode zur Plasmidexpression in organotypischer Kultur des

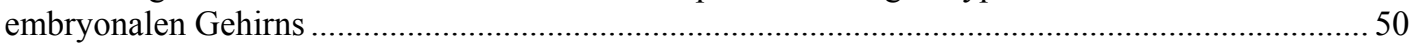

Kartierung der Aktivität des E1-Elementes in vitro .................................................................. 52

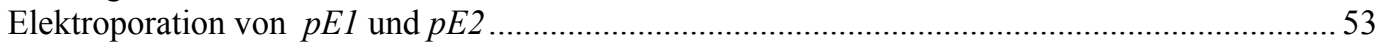

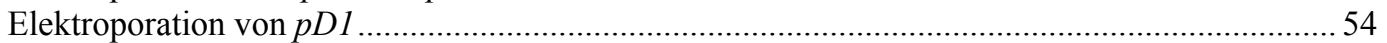

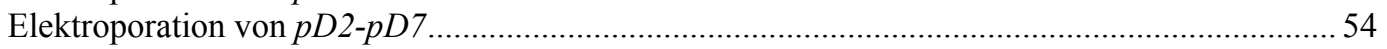

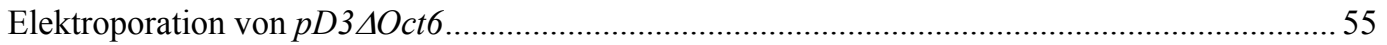

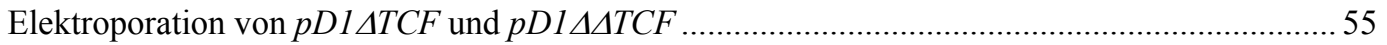

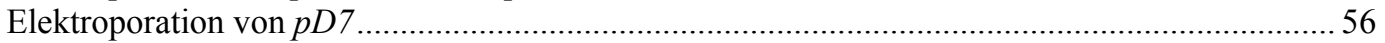

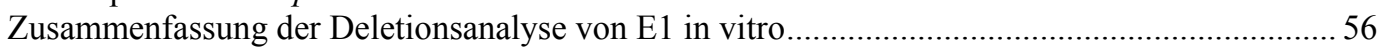

Etablierung einer Mauslinie mit Überexpression von Hop unter Kontrolle des E1-

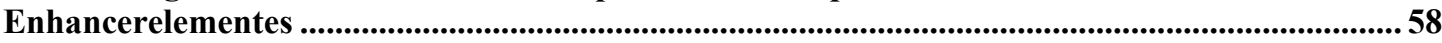

Diskussion......................................................................................................660

Microarray-Expressionsanalyse offenbart differentielle Genexpression im embryonalen Kortex

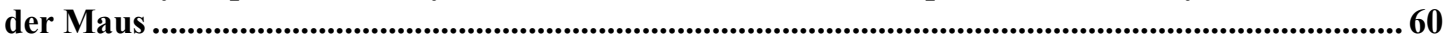

Mit Microarray-Technologie zu einem repräsentativen Überblick kortikaler Genexpression? ......... 60

Gene mit regionalisierter Expression im zerebralen Kortex des Embryonalstadiums 16,5 ..............63

Hop - ein neues Gen mit spezifischer Expression in proliferativen Zonen des medialen

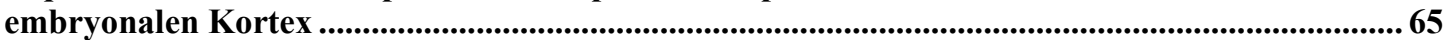

Das Hop - defiziente Gehirn zeigt keine Aberrationen, welche auf die Funktion des Gens im

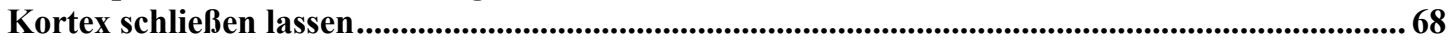

Hop - ein atypisches Homeodomäne-Protein ohne DNA-bindende Eigenschaften ......................... 68

Analyse des Kortex einer Hop-defizienten Mauslinie.......................................................................69

Das Fehlen eines Phänotyps im Hop-defizienten Gehirn ............................................................. 70

Ein Deckplatten-induzierbares Enhancerelement steuert die Expression von Hop in Strukturen

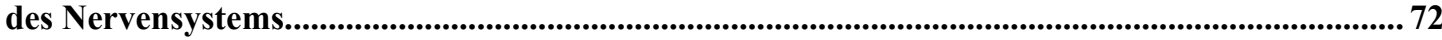

Identifikation eines Enhancerelementes "upstream" des Genlokus von Hop ................................... 72

Induktion des Hop-Enhancers durch Explantate der Deckplatte..................................................... 73

Eine in vitro-Methode kann zur Kartierung des Nervensystem-spezifischen Enhancers von Hop

eingesetzt werden .........................................................................................................................................75

Elektroporation und organotypische Kultur als effiziente Methode des Gentransfers in das

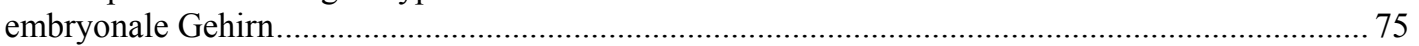

Aktivitätskartierung des E1-Elementes von Hop in vitro.......................................................... 76

Ein Konzept zur Aktivierung des E1-Elementes im Kortex.............................................................. 79

Der Nervensystem-spezifische Enhancer von Hop - ein Werkzeug zur gezielten Genexpression in

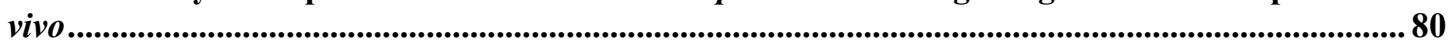

Zusammenfassung ...........................................................................................81

Material und Methoden ...........................................................................83

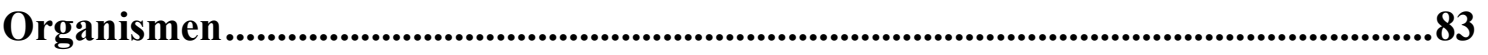

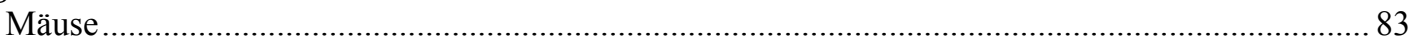

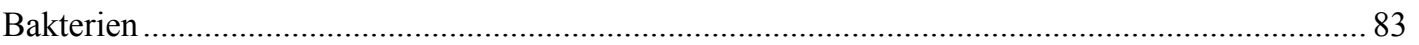




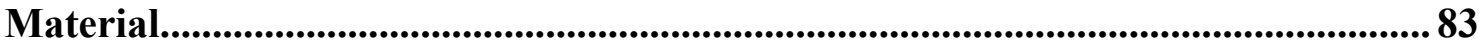

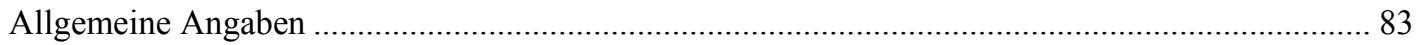

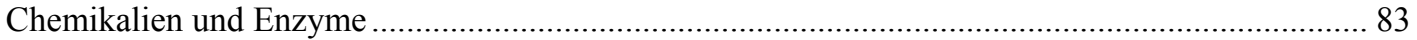

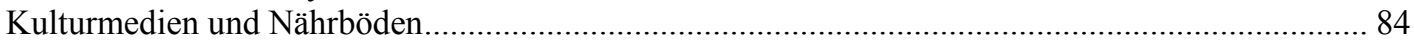

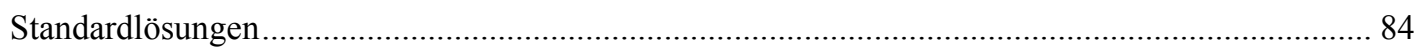

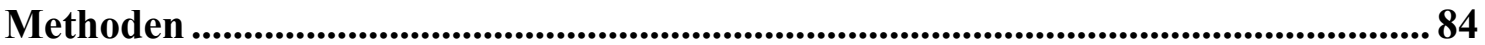

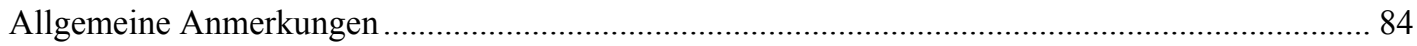

Präparative und analytische Arbeiten mit Nukleinsäuren........................................................................85

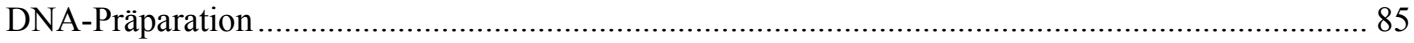

Konzentrationsbestimmung von Nukleinsäuren in Lösung ............................................................ 85

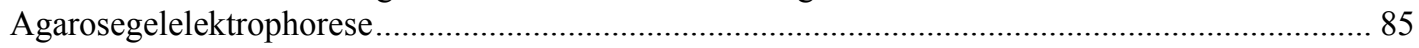

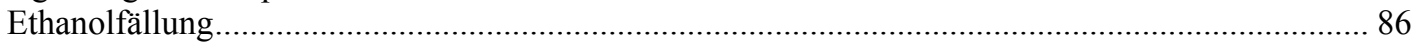

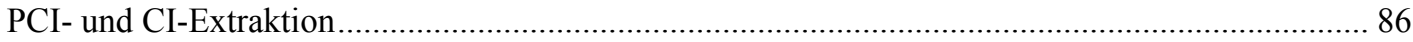

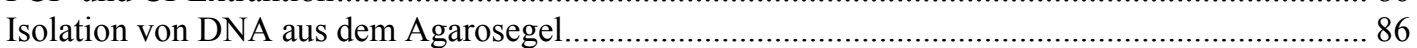

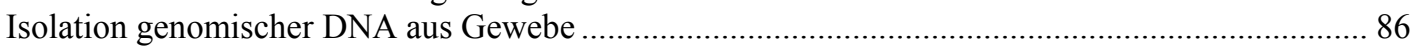

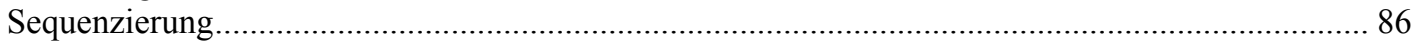

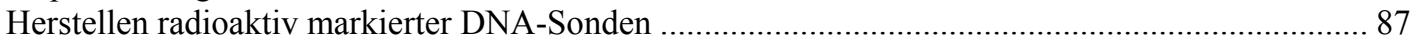

Klonierung von DNA-Fragmenten ................................................................................................................ 87

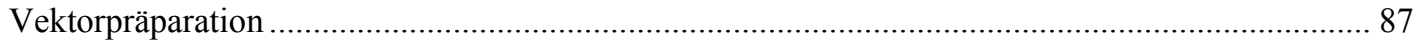

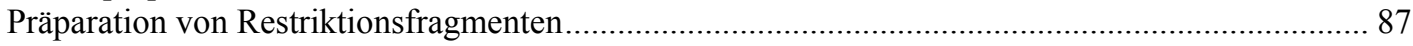

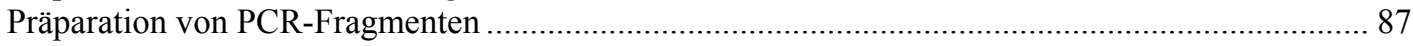

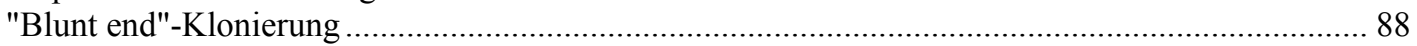

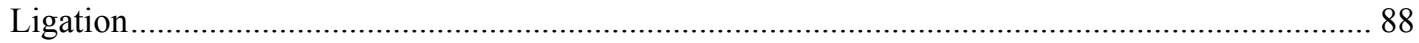

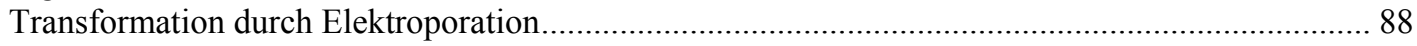

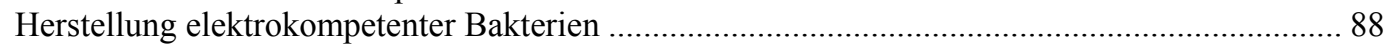

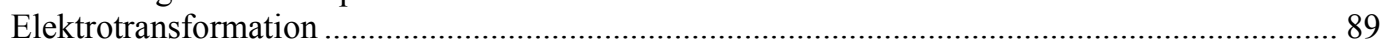

Expressionsanalyse mittels Microarray-Technologie ................................................................................ 89

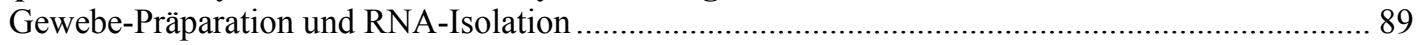

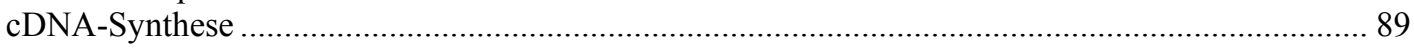

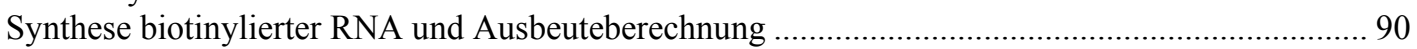

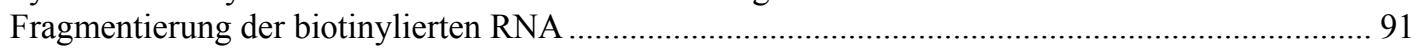

Herstellung der Hybridisierungskontrollen ................................................................................... 91

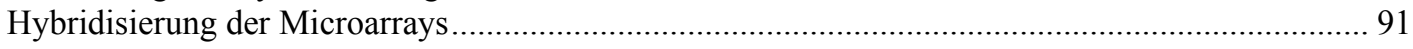

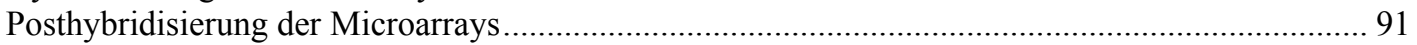

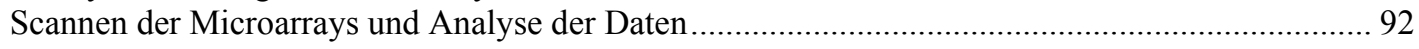

RNA-in situ-Hybridisierung................................................................................................................... 93

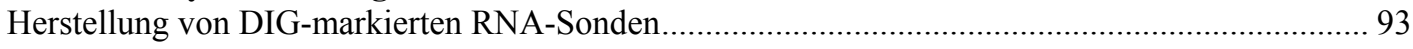

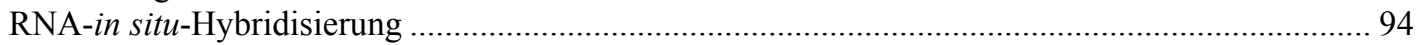

Northern Blot-Analyse ................................................................................................................................ 95

Gewebeisolation und Präparation von polyadenylierter RNA ……………………........................ 95

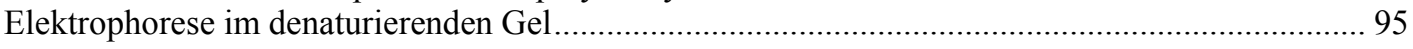

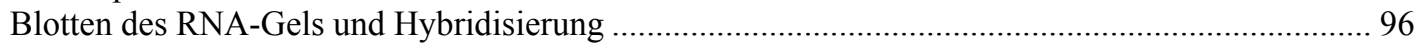

Screenen einer cDNA-Bibliothek........................................................................................................... 97

Ausplattieren der Bibliothek und Übertragen der Phagen auf Nitrozellulosemembranen .................. 97

Hybridisierung der Nitrozellulosemembranen und Autoradiographie ............................................... 97

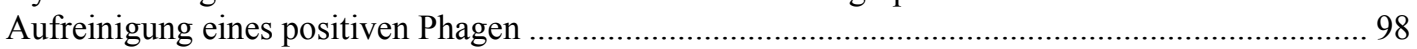

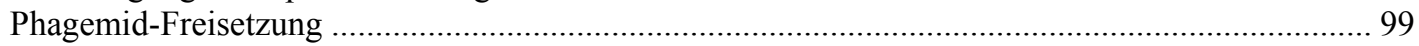

Klonierung von Enhancer- und Deletionskonstrukten...........................................................................99

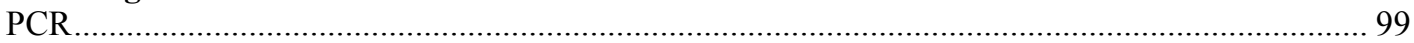

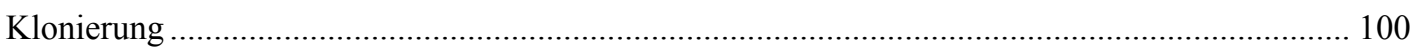

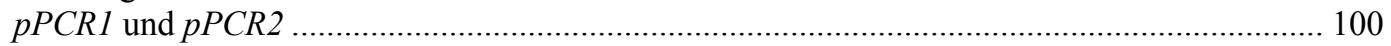

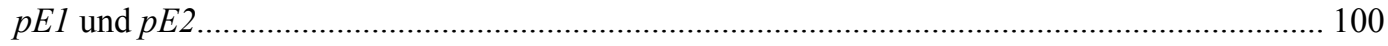

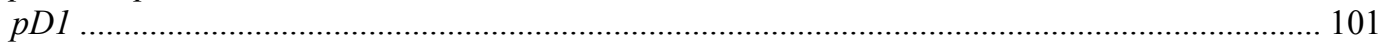

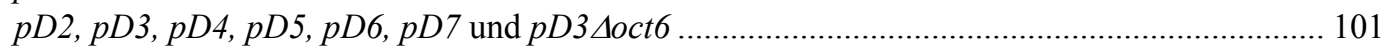

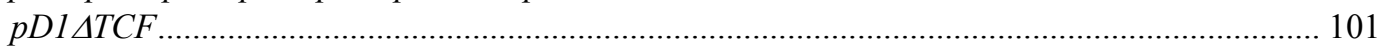

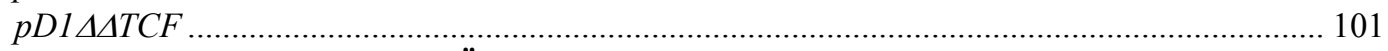

Klonierung eines Konstruktes zur Überexpression von Hop in vivo ................................................ 102 
Haltung einer Hop-defizienten Mauslinie ....................................................................................................... 102

Gewinnung Emx2- und Lef1-defizienter Gehirne .............................................................. 103

Genotypisierung Emx2-defizienter Embryonen................................................................. 103

Genotypisierung Lef1-defizienter Embryonen.................................................................... 104

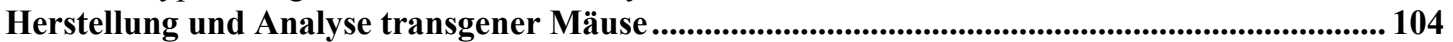

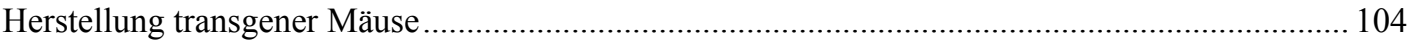

Herstellung und Analyse $p E 1$-transgener Mäuse .................................................................... 105

Herstellung und Genotypisierung $p E 1$-transgener Mäuse...................................................... 105

Analyse $p E 1$-transgener Mäuse....................................................................................... 105

Herstellung und Analyse $p E 1$-Hop-transgener Mäuse ......................................................... 105

Herstellung und Genotypisierung pE1-Hop-transgener Mäuse............................................... 105

Analyse pE1-Hop-transgener Mäuse................................................................................. 106

Histologische Methoden.................................................................................................................................... 106

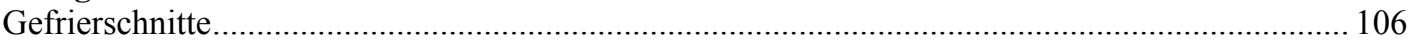

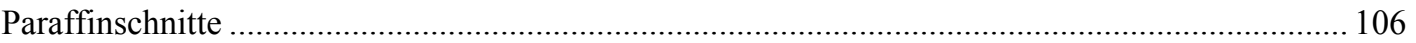

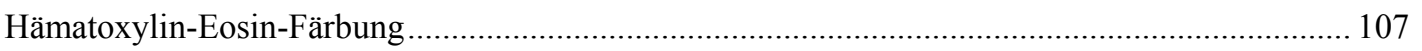

Histochemische Methoden............................................................................................................................... 107

$\beta$-Galaktosidase-Enzymhistochemie .............................................................................. 107

Immunohistochemie zum Nachweis des Proteins Serum response factor (SRF) ........................ 108

Immunhistochemischer Nachweis des FLAG-Epitops ............................................................. 108

BrdU-Markierung mitotischer Zellen und BrdU-Immunohistochemie ........................................ 108

Elektroporation embryonaler Gehirne und organotypische Kultur ............................................. 109

Herstellen der Plasmid-Lösung .............................................................................................. 109

Herstellen der Mikrokapillaren ................................................................................................... 109

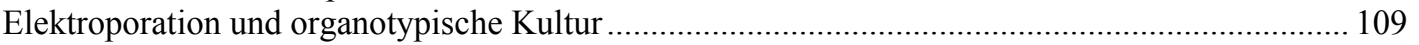

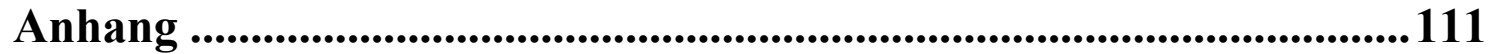

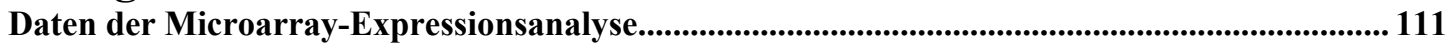

Sequenzen der cDNA-Klone und RNA-Sonde von Hop ..................................................................... 113

Nomenklatur und Abkürzungen......................................................................................... 115

Literaturverzeichnis ........................................................................................117

Lebenslauf und Publikationen .................................................................131 
"Molecular biology is not trivial aspect of biological systems. It is at the heart of the matter. Almost all aspects of life are engineered at the molecular level and without understanding molecules we can only have a sketchy understanding of life itself."

Francis Crick, 1988 


\section{Danksagung}

Mein außerordentlicher Dank gilt Herrn Prof. Dr. Peter Gruss für die Möglichkeit, in seinem Labor an diesem sehr interessanten Thema arbeiten zu können. Sein stetes Interesse an den Ergebnissen und dem Fortgang meines Projektes haben mich motiviert und begeistert. Besonders möchte ich mich auch für seine Bereitschaft bedanken, trotz Beurlaubung von seiner Funktion im Institut und Übernahme der Präsidentschaft der Max-Planck-Gesellschaft meine Promotion als Referent zu begleiten.

Besonderer Dank gilt Frau PD Dr. Sigrid Hoyer-Fender für viele freundliche und hilfreiche Gespräche, großes Interesse an meiner Arbeit und die Übernahme des Korreferates. Ich danke den Mitgliedern der Prüfungskommission für ihr Entgegenkommen.

Meinen ganz besonderen Dank möchte ich Dr. Kamal Chowdhury aussprechen, der mir stets mit fachlicher und technischer Hilfestellung zur Seite stand und meiner Arbeit ein großes Interesse entgegenbrachte. Dr. Chowdhury hat mit zahlreichen Ideen zur Gestaltung der bearbeiteten Projekte beigetragen. Besonderer Dank gilt auch PD Dr. Anastassia Stoykova zur Verfügungstellung ihres Fachwissens in vielen Diskussionen über die Aspekte der Kortikogenese.

Großer Dank gilt Friederike Kirsch für die Bereitschaft das "Microarray-Projekt" gemeinsam zu initiieren und für die enge und angenehme Zusammenarbeit während der gesamten Promotion. Ebenfalls großer Dank gilt Sabine Geisendorf für die Hilfe in zahlreichen technischen Fragen und die mehr als dreijährige freundliche und kooperative Zusammenarbeit an benachbarten Laborplätzen. Ich danke Andrea Conrad für die Hilfe in vielen technischen Fragestellungen und die Mitarbeit an durchgeführten Experimenten. Ebenso danke ich Martina Daniel für ihre freundliche Unterstützung bei technischen Fragen.

Ich danke unseren Kollaborateuren der University of Texas/ Dallas/ USA für die Erlaubnis, das Gehirn der von ihnen hergestellten Hop-defizienten Mauslinie untersuchen zu dürfen, allen voran Prof. Dr. Eric Olson. Prof. Dr. Rudolf Grosschedl danke ich für die Bereitstellung der Lef1-defizienten Mauslinie. 
Für die vielen durchgeführten Sequenzierreaktionen und die Hilfe in "schwierigen" Fällen möchte ich Sigurd Hille danken. Ich danke außerdem Ullrich Franke für die durchgeführten Mikroinjektionen, sowie Jens Krull, Kirsten Backs, Andrea Conrad und Sabine Geisendorf für die Herstellung der genomischen DNA aus Schwanzspitzen.

Zum Gelingen der vorliegenden Arbeit haben viele weitere Personen beigetragen, von denen ich die Angestellten unseres Tierhauses erwähnen möchte. Insbesondere möchte ich Dr. Ulrike Teichmann für ihre exzellente Leitung dieser Einrichtung danken, ferner Simone Brauer und Christian Dietl für hervorragende Hilfe bei der Betreuung meiner Mauskolonien.

Schließlich möchte ich Lars Wittler und Tanja Vogel für viele anregende Diskussionen und "Fachsimpeleien" danken. 


\section{Einleitung}

Bereits zu Beginn des 20. Jahrhunderts unterschieden die Neuroanatomen Korbinian Brodmann, Oskar Vogt und Cecile Vogt diskrete Areale der menschlichen Großhirnrinde aufgrund zytoarchitektonischer Charakteristika (K. Brodmann, 1909; O. Vogt und C. Vogt, 1919). Oskar und Cecile Vogt beschrieben über 200 Regionen der Hirnrinde (O. Vogt und C. Vogt, 1919), deren anatomische und funktionelle Abgrenzung bis heute Bestand hat. Schon in diesen frühen Arbeiten wurde die Hypothese formuliert, daß Neurone verschiedener Kortexareale eine bestimmte "molekulare Zusammensetzung" aufweisen, welche sich in Unterschieden in der neuronalen Entwicklung widerspiegelt (O. Vogt und C. Vogt, 1919; I. Klatzo, 2003).

Trotz großer Fortschritte der Entwicklungsbiologie in den folgenden Jahren lagen Prozesse, welche zur Regionalisierung des zerebralen Kortex führen, lange Zeit im Dunkeln. Erst die Verfügbarkeit molekularbiologischer und genetischer Methoden ermöglichte die Analyse der Entwicklung des zerebralen Kortex. Dies führte in den vergangenen 20 Jahren zu einem rasanten Erkenntniszuwachs im Verständnis zugrunde liegender Mechanismen.

Im folgenden soll ein Überblick über derzeitige Konzepte zur Embryonalentwicklung des zerebralen Kortex gegeben werden. Dabei werden offene Fragen erläutert und Ausblicke vermittelt. 


\section{Die Genese des zerebralen Kortex}

\section{Frühe Schritte der Entwicklung des Vorderhirns}

Zur Entstehung der Vorderhirnanlage am rostralen Pol der Neuralplatte müssen drei Phasen durchschritten werden: 1. ektodermale Zellen nehmen neurale Identität an, 2. rostral gelegenes Neuroektoderm bildet anteriore Charkteristika aus, 3. die Hirnanlage wird regionalisiert.

Das "neural default"1-Modell geht davon aus, daß ektodermale Zellen neurale Identität annehmen, wenn in ihnen der Bmp ${ }^{2}$-Signalweg unterdrückt wird (I. Munoz-Sanjuan und A. H. Brivanlou, 2002). Bmp-Antagonismus ist jedoch für die Ausbildung von Neuroektoderm nicht ausreichend. Vielmehr determinieren $\mathrm{Fgf}^{3}$-Proteine bereits im Prägastrulastadium das prospektive Neuroektoderm (A. Streit et al., 2000). Nach Ausbildung von Neuroektoderm ist der Erwerb anteriorer Charakteristika ein entscheidender Schritt für die Entstehung der Hirnanlage. Hierfür muß die Aktivität caudalisierender Faktoren ausgeschlossen werden. Dies geschieht durch Bewegung der anterioren Neuralplatte weg von caudalisierenden Signalen (Fgfs, Wnts ${ }^{4}$, Retinsäure, Nodal und Bmps) und rostrale Expression von Antagonisten caudalisierender Faktoren (R. S. Beddington und E. J. Robertson, 1998; A. C. Foley und C. D. Stern, 2001; A. Agathon et al., 2003). Eine wichtige Quelle für anticaudalisierende Faktoren ist das anteriore viszerale Endoderm der Maus (AVE) bzw. der extraembryonale Hypoblast des Huhns. Das AVE kommt durch Zellmigration unter der rostralen Neuralplatte zu liegen (Abb. 1). $\mathrm{Zu}$ den anticaudalisierenden Faktoren des AVE gehören Cerberus und Otx2. Das Ausschalten dieser Gene führt zum Verlust von
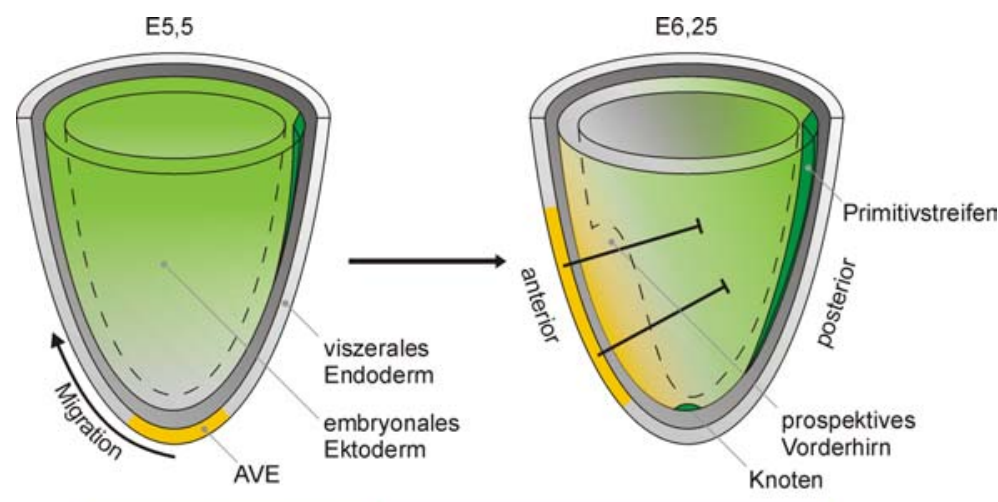

Gehirn- und Kopfstrukturen (S. L. Ang et al., 1996; T. Abb. 1: Polarisierung des embryonalen Ektoderms.

Der Organisator (Knoten) und seine Derivate bilden caudalisierende Faktoren. Durch Antagonisten des anterioren viszeralen Endoderms (AVE) entsteht eine Zone mit unterdrückter Aktivität caudalisierender Faktoren. Am anterioren Ende dieser Zone entsteht die Vorderhirnanlage. Durch Migrations- und Bouwmeester et al., 1996; S. Wachstumspozesse werden AVE und Vorderhirnanlage in Distanz zu Piccolo et al., 1999; A. C. caudalisierenden Signalen gebracht (verändert nach S. F. Gilbert, 2003; S. W. Foley und C. D. Stern, Wilson und C. Houart, 2004).

2001).

\footnotetext{
${ }^{1}$ default, engl.: Vorgabe

${ }^{2}$ Bmp: Bone morphogenic proteins, engl.: morphogene Proteine des Knochens

${ }^{3}$ Fgf: Fibroblast growth factor, engl.: Fibroblastenwachstumsfaktor
} 
Besondere Bedeutung kommt bei der Anteriorisierung der Hirnanlage der Unterdrückung des Wnt-Signalweges zu. Als Quelle von Wnt-Antagonisten tritt hierbei an der Grenze zwischen neuralem und nichtneuralem Ektoderm die sogenannte "anterior neural ridge" ${ }^{5}$ (ANR) in Erscheinung. Am nächsten zur ANR entwickelt sich im Bereich geringster Wnt-Aktivität das Telenzephalon, weiter caudal das Augenfeld und das Dienzephalon (C. Houart et al., 1998; C. P. Heisenberg et al., 2001; C. Houart et al., 2002; U. Nordstrom et al., 2002). Als Konsequenz unterdrückter Wnt-Aktivität werden wichtige Gene des anterioren Vorderhirns exprimiert. Diese Gene stabilisieren über positive Rückkopplung das anteriore Vorderhirn als Wnt-freie Zone (z. B.: Six3) und bereiten die Musterbildung im späteren Kortex vor (z. B.: Fgf8; K. Shimamura und J. L. Rubenstein, 1997; M. M. Braun et al., 2003).

\section{Kortikale Signalzentren}

An den Grenzen des kortikalen Primordiums zu benachbarten Strukturen bilden sich Signalzentren aus, die durch Ausschüttung diffusibler Moleküle charakterisiert sind (Abb. 2). Es wird vermutet, daß diese Signalmoleküle in Form morphogener Gradienten wirken und so Zellen der Vorderhirnanlage Positionsinformation entlang der anterioposterioren, mediolateralen und dorsoventralen Achsen erhalten (E. A. Grove und T. Fukuchi-Shimogori, 2003). Für das Signalmolekül Shh ${ }^{6}$ konnte im Rückenmark und Mittelhirn bereits eine Rolle als Morphogen nachgewiesen werden (S. Agarwala et al., 2001; J. Briscoe et al., 2001).

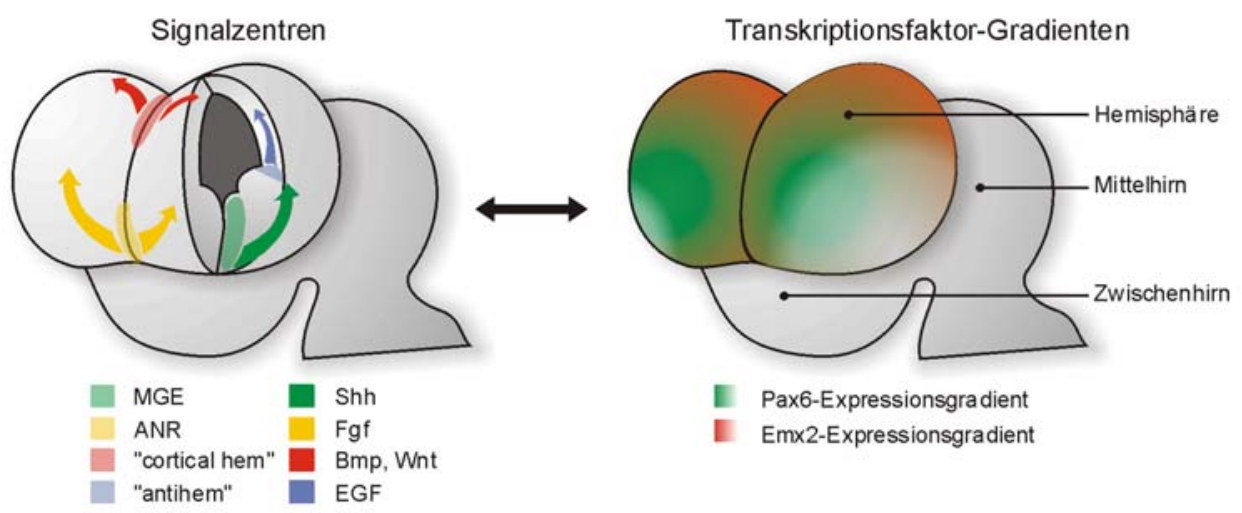

Abb. 2: Regionalisierung des zerebralen Kortex.

Signalzentren (ANR, MGE, "cortical hem", "antihem") schütten Signalmoleküle (Fgfs, Shh, Bmps, Wnts, EGFs) aus, welche das kortikale Primordium überspannende Gradienten bilden. Diese Signalmoleküle beeinflussen die Expression früher kortikaler Transkriptionsfaktoren wie Pax6 und Emx2, welche ihrerseits auf die Funktion der Signalzentren rückwirken. Die Position kortikaler Zellen innerhalb der Gradienten von Signalmolekülen und Transkriptionsfaktoren verleiht ihnen Positionsinformation (verändert und aktualisiert nach: D. D. O'Leary und Y. Nakagawa, 2002).

\footnotetext{
${ }^{4}$ Wnt: Wingless-/ Int-Proteine

${ }^{5}$ anterior neural ridge, engl.: anteriore neurale Kante

${ }^{6}$ Shh: Sonic hedgehog, nach dem Helden eines Videofilms und nach dem englischen Wort hedgehog für Igel
} 
Die ANR am anterioren Übergang von Neuroektoderm zu Epidermisektoderm ist mit Signalmolekülen der Fgf-Familie maßgeblich an der Ausbildung der anterioposterioren Achse des Kortex beteiligt. So zeigen Mausmutanten mit verringerter Fgf8-Expression eine Caudalisierung der Kortexanlage (S. K. Garel et al., 2003). Ähnliche Effekte wurden durch in utero-Elektroporation eines dominant negativen Fgf-Rezeptors (sFgfr3c) am anterioren Pol der Kortexanlage erzielt. Hier konnte neben verschobener Markergenexpression eine Verlagerung des "Barrel"7-Feldes des primären somatosensorischen Kortex nach anterior beobachtet werden. Schließlich bewirkte die Platzierung einer zweiten Fgf8-Quelle durch in utero-Elektroporation der posterioren Kortexanlage die Generierung einer zweiten anterioposterioren Achse - teilweise mit Verdopplung des Barrel-Feldes (T. Fukuchi-Shimogori und E. A. Grove, 2001).

Als eines der am besten charakterisierten Signalzentren tritt im medialen Kortex die zwischen Hippocampusanlage und Plexus choroideus gelegene, durch Bildung verschiedener Wnt- und Bmp-Proteine ausgezeichnete "cortical hem" ${ }^{8}$ in Erscheinung. Auch eine weitere Struktur der dorsalen Mittellinie des Vorderhirns, die Deckplatte, wird als Signalzentrum des dorsalen und später medialen Kortex angesehen (E. A. Grove et al., 1998; E. S. Monuki et al., 2001). Die Ausbildung der Wnt-reichen embryonalen Fimbria hängt ihrerseits von der Funktion des Transkriptionsfaktors Gli3 ab - eines Orthologs des Drosphila melanogaster-Gens "cubitus interruptus" (Ci). Ci reguliert bei Drosophila die Expression von Wingless (T. Von Ohlen et al., 1997). Eine entsprechende Beziehung besteht auch zwischen den Maus-Othologen Gli3 und Wnt. In der natürlichen Gli3-Mutante "extra toes" ${ }^{9}$ kann keine embryonale Fimbria nachgewiesen werden (E. A. Grove et al., 1998; S. Tole et al., 2000b).

Bmp-Signale aus der embryonalen Fimbria werden für die Abspaltung des Plexus choroideus vom Primordium des zerebralen Kortex verantwortlich gemacht. In der Maus führt Verlust des Bmp-Rezeptors 1a (Bmprla) zu drastischer Reduktion des Plexus choroideus. Demgegenüber führt Expression von konstitutiv aktivem Bmprla zu einer Ausdehnung des choroidalen Plexus und einer Reduktion des zerebralen Kortex (D. M. Panchision et al., 2001; J. M. Hebert et al., 2002). Schließlich ist die Aktivierung des kanonischen Wnt-Signalwegs durch Signale der embryonalen Fimbria von entscheidender Bedeutung für die Ausbildung des Hippocampus. In Wnt3a-defizienten Mäusen fehlt die Hippocampusformation nahezu vollständig. Der Aktivitätsverlust von Lef1/ TCF-Transkriptionsfaktoren als Mediatoren des

\footnotetext{
${ }^{7}$ Der sogenannte Barrel-Kortex von Nagetieren ist ein wichtiges Modellsystem in der Neurobiologie. Das Besondere am Barrel-Kortex ist, daß man mit geeigneten Gewebefärbungen tönnchenförmige Strukturen (engl.: Barrels) darstellen kann. Diese Barrels zeigen die gleiche Anordnung wie die Tasthaare auf der Nase, und jedes der Barrels erhält vornehmlich Informationen von dem ihm entsprechenden Barthaar. ${ }^{8}$ cortical hem, engl.: kortikaler Saum

${ }^{9}$ extra toes, engl.: extra Zehen
} 
Wnt-Signalweges bewirkt ähnliche Defekte im medialen Kortex. Hierbei wird davon ausgegangen, daß Wnt-Signale nicht die Spezifizierung einer hippocampalen Identität, sondern die Expansion eines bereits vorliegenden Hippocampusprimordiums bewirken (J. Galceran et al., 2000; S. M. Lee et al., 2000).

Das Signalmolekül Shh ist entlang der gesamten ventralen Mittelachse des Neuralrohrs exprimiert. In Form eines morphogenen Gradienten spezifiziert es die Identität von Neuronenklassen des ventralen Rückenmarks (H. Roelink et al., 1994; J. Briscoe et al., 2001). Es konnte gezeigt werden, daß Shh auch die Expression von Genen des ventralen Vorderhirns induziert (J. Ericson et al., 1995; K. Shimamura und J. L. Rubenstein, 1997). Als Quelle von Shh im Vorderhirn gilt die mediale ganglionäre Eminenz (MGE, Anlage des Globus pallidus der Basalganglien). Shh ist für die Ausbildung ventraler telenzephaler Strukturen von Bedeutung. So fehlt in Shh-defizienten Mäusen die MGE, auch die Ausbildung der lateralen ganglionären Eminenz (Anlage des Striatums) scheint von diesem Gen abzuhängen (C. Chiang et al., 1996; J. D. Kohtz et al., 1998).

In S. Assimacopoulos et al., 2003 wird eine Quelle verschiedener Signalmoleküle der EGF ${ }^{10}$ Familie im ventralen Pallium beschrieben. Diese als "anti-hem" bezeichnete Region scheint für die Etablierung der Grenze zwischen kortikalen/ subkortikalen Strukturen (Pallium/ Basalganglien) verantwortlich zu sein (L. Muzio et al., 2002b; S. Assimacopoulos et al., 2003).

\section{Positionierung und Interpretation der Signalzentren}

Es stellt sich die Frage, wie individuelle Zellen die Gradienten kortikaler Signalmoleküle interpretieren und ihre Positionsinformation erhalten (E. A. Grove und T. Fukuchi-Shimogori, 2003). Im Modellfall des ventralen Rückenmarks folgt auf die Ausbildung des Shh-Gradienten die Expression von Transkriptionsfaktoren, die sich gegenseitig negativ regulieren. Scharfe Expressionsgrenzen dieser Transkriptionsfaktoren und die Ausbildung begrenzter Domänen mit festgelegtem Zellschicksal sind die Folge (J. Briscoe und J. Ericson, 2001).

In mehreren Aspekten unterscheidet sich die Regionalisierung des zerebralen Kortex von der Ausbildung der Domänen des Rückenmarks. So können zwar zu frühen Stadien der Embryogenese Gradienten der Transkriptionsfaktoren Emx2 und Pax6 im Kortex beobachtet werden (K. M. Bishop et al., 2002), diese gehen aber zu keinem späteren Embryonalstadium in scharf umgrenzte Expressionsdomänen über (D. D. O'Leary und Y. Nakagawa, 2002). Begrenzte Genexpression ist in Kortexarealen erst dann zu beobachten, wenn deren Ausbildung weit fortgeschritten ist. Markergene, wie SCIP im CA1-Feld des Hippocampus und H2Z1 im somatosensorischen Kortex, werden erst zu späten Embryonalstadien bzw. postnatal exprimiert.

\footnotetext{
${ }^{10}$ EGF: Epidermal growth factor, engl.: Epidermis-Wachstumsfaktor
} 
Durch in vitro-Experimente konnte jedoch gezeigt werden, daß die Determination der späteren Expressionsbereiche schon sehr früh, nämlich zum Beginn der Neurogenese, stattfindet (Y. Gitton et al., 1999; S. Tole und E. A. Grove, 2001). Derzeit ist nicht bekannt, wie zu diesem frühen Stadium Gradienten kortikaler Transkriptionsfaktoren zur Festsetzung distinkter Arealgrenzen genutzt werden. Eine gegenseitige Repression der Transkriptionsfaktoren, wie sie im Rückenmark beobachtet wird, scheint nicht vorzuliegen. Möglicherweise werden Transkriptionsfaktorgradienten durch die Konzentrationsabhängigkeit der Enhancer- und Repressorelemente nachgeschalteter Gene in scharfe Expressionsgrenzen umgesetzt. Derartige Mechanismen wurden bei der Musterbildung von Drosophila melanogaster beschrieben (J. Rusch und M. Levine, 1996; D. D. O'Leary und Y. Nakagawa, 2002).

Pax6 und Emx2 sind in komplementären Gradienten in der Kortexanlage exprimiert, mit hoher Pax6-Expression am rostrolateralen und hoher Emx2-Expression am caudomedialen Pol (Abb. 2). Bei Verlust von Pax6 kommt es zu einer Verschiebung kortikaler Areale nach rostral, während im Emx2-defizienten Kortex ein gegensätzlicher Effekt zu beobachten ist (K. M. Bishop et al., 2000; K. M. Bishop et al., 2002). Beide Gene spielen also eine entscheidende Rolle für die Regionalisierung des Kortex entlang der anterioposterioren Achse.

Unklar ist, ob die Gradienten von Pax6 und Emx2 auf Signalmoleküle aus den Signalzentren zurückzuführen sind, oder ob Pax6 und Emx2 die Positionierung und Etablierung der Signalzentren steuern. So konnte gezeigt werden, daß einerseits Fgf8 die Expression von Emx2 negativ reguliert, andererseits aber Emx2 die Fgf8-Quelle auf den anterioren Pol der Hirnanlage beschränkt. Von beiden Interaktionen wird die letztere als primär angesehen, d. h. Emx2 reguliert die Etablierung des Fgf\&-exprimierenden anterioren Signalzentrums (T. FukuchiShimogori und E. A. Grove, 2003). Neben der Regionalisierung entlang der anterioposterioren Achse spielt Emx2 eine wichtige Rolle für die Ausprägung medialer Hirnstrukturen. Emx2defiziente Mäuse bilden nur ansatzweise einen Gyrus dentatus aus (S. Tole et al., 2000a). Im medialen Kortex scheint Emx2 dem lokalen Signalzentrum (der embryonalen Fimbria) untergeordnet zu sein. So wurde die Abhängigkeit eines Emx2-Enhancers von Bmp- und WntSignalen beschrieben. Emx2-Expression fehlt in der "extra toes"-Mutante, welche keine embryonale Fimbria ausbildet (T. Theil et al., 2002).

Die Ausbildung der "anti-hem" als Signalzentrum des ventralen Palliums hängt vom Transkriptionsfaktor Pax6 ab. Die "anti-hem" kann in Mäusen, welche homozygot für die Pax6Mutation "Sey"11 sind, nicht nachgewiesen werden (S. Assimacopoulos et al., 2003). In homozygoten Sey-Mutanten treten außerdem Defekte im Sinne einer Ventralisierung des Telenzephalons auf. Gene der Basalganglien werden im Kortex exprimiert. Es wird vermutet,

${ }^{11}$ Sey: Small eye, engl.: kleines Auge 
daß diese Defekte direkt auf den Verlust des lateralen Signalzentrums zurückzuführen sind (A. Stoykova et al., 2000; L. Muzio et al., 2002b).

Es wird deutlich, daß bei der Musterbildung im zerebralen Kortex sowohl die Signalmoleküle der Signalzentren als auch Gradienten früher Transkriptionsfaktoren eine Rolle spielen. Beide Systeme treten miteinander in Wechselwirkung und verleihen so den Zellen des kortikalen Primordiums ihre Positionsinformation.

\section{Determination des kortikalen Feldes}

Bisher wurden die Faktoren der Signalzentren und die in Gradienten exprimierten Transkriptionsfaktoren Pax6 und Emx2 in ihrer Bedeutung für die Regionalisierung des Kortex betrachtet. Dabei blieb die Frage offen, welcher Mechanismus die eigentliche Identität des kortikalen Primordiums festlegt. Ein Kandidat für die Rolle eines kortikalen Selektorgens ist Lhx2 - ein Transkriptionsfaktor mit LIM-Homeodomäne, der im kortikalen Neuroepithel, nicht in subkortikalen Strukturen oder der embryonalen Fimbria, exprimiert wird. Lhx2-defiziente Mäuse zeigen eine drastische Expansion der embryonalen Fimbria, während der zerebrale Kortex fast vollständig fehlt. Die geschilderte Beobachtung führt zur Hypothese, daß Lhx2 nicht als kortikales Selektorgen fungiert, sondern vielmehr sicherstellt, daß die embryonale Fimbria abgegrenzt wird und ihre Aktivität als Signalzentrum auf den äußersten medialen Rand des Kortex beschränkt bleibt. Obwohl Lhx2 nicht in der embryonalen Fimbria exprimiert ist, scheint Lhx2-Expression des Kortex von Bmp-Signalen der Deckplatte abzuhängen, also vom Vorläufer der embryonalen Fimbria (E. A. Grove und S. Tole, 1999; S. Bulchand et al., 2001).

Die Gene Pax6 und Emx2 werden zusammen für eine kortikale Selektorfunktion favorisiert. Mindestens ein funktionelles Allel eines dieser Gene muß vorliegen, um den zerebralen Kortex zu generieren. In doppelt homozygoten Mäusen $\left(\operatorname{Emx} 2^{-/}, \operatorname{Pax}^{S e y / \operatorname{Sey}}\right)$ wird der zerebrale Kortex durch Gewebe mit einer genetischen Ausstattung der Basalganglien ersetzt. Lediglich sehr wenige Zellen in diesem Gewebe exprimieren noch Markergene des zerebralen Kortex. Ob die kortikale Identität dieser Zellen auf die Funktionalität des Lhx2-Gens zurückgeht, ist unklar (L. Muzio et al., 2002a). Möglich scheint, daß das Zusammenspiel mehrer Gene, also Pax6, Emx2, Lhx2 und eventuell noch zu identifizierender Gene, die kortikale Identität von Zellen des dorsalen Telenzephalons determiniert (P. Rakic, 1988; E. A. Grove und T. Fukuchi-Shimogori, 2003). 


\section{Radiale Migration}

Durch die Aktivität von Signalmolekülen und Transkriptionsfaktoren ist schon in den neuralen Vorläuferzellen eine regionale Identität festgelegt (Y. Gitton et al., 1999; S. Tole und E. A. Grove, 2001; L. Muzio et al., 2002b). In diesem frühen Stadium (E12 ${ }^{12}$ bei der Maus) besteht die kortikale Anlage aus zwei Schichten, der an das Ventrikel angrenzenden Ventrikulärzone und der darüber gelegenen Präplatte. Die Ventrikulärzone enthält die als neurale Vorläuferzellen angesehenen radialen Gliazellen, welche sowohl pyramidale Neurone als auch Gliazellen des Kortex hervorbringen (D. E. Schmechel und P. Rakic, 1979; T. E. Anthony et al., 2004). Darüberhinaus stellen radiale Gliazellen in Form ihrer radialen Fortsätze das "Gerüst" bereit, an dem postmitotische Zellen entlangwandern, um ihre Postion im zerebralen Kortex zu besetzen (P. Rakic, 1972). Durch diese Migration wird die Präplatte in die Subplatte und die Marginalzone unterteilt, dazwischen kommen die Zellen der Kortikalplatte, also des späteren Kortex, zu liegen (K. L. Allendorfer und C. J. Shatz, 1994). Zunächst entsteht die tiefste Kortexschicht, Schicht 6. Später geborene Zellen siedeln sich darüber in Schicht 5 an usw. Man spricht vom inversen oder "inside out" ${ }^{13}$-Prinzip der radialen Migration, wobei die Marginalzone zu Schicht 1 wird (P. Rakic, 1974; M. B. Luskin und C. J. Shatz, 1985). Durch den Prozess der radialen Migration wird der Kortex in radiale Einheiten unterteilt, welche die entsprechenden radialen Gliazellen und deren Nachkommen enthalten. Auf diese Weise wird garantiert, daß die festgelegte Regionalisierung des kortikalen Primordiums auf die Neurone des entstehenden zerebralen Kortex übertragen wird (S. C. Noctor et al., 2001).

Die funktionelle Charakterisierung zahlreicher Gene, die in den Prozeß der radialen Migration involviert sind, hat dazu beigetragen, kortikale Fehlbildungen beim Menschen zu verstehen. Eines der ersten identifizierten Gene war Reeler, dessen Mutation zu einem invers geschichteten Kortex bei der Maus und zu einem Lissenzephalie ${ }^{14}$-Syndrom beim Menschen führt (V. S. Caviness, Jr., 1982; M. Ogawa et al., 1995; S. E. Hong et al., 2000). Die molekulare Funktion des Reeler-Gens wird nach wie vor kontrovers diskutiert (diskutiert in: O. Marin und J. L. Rubenstein, 2003). Genannt seien ferner die Gene Lis1 und Dcx, deren Mutation ebenfalls zu Lissenzephalie führt (O. Reiner et al., 1993; J. G. Gleeson et al., 1999b). Sowohl Lisl, als auch Dcx scheinen als Microtubuli-assoziierte Proteine die Dynamik des Zytoskeletts migrierender Neurone zu beeinflussen (T. Sapir et al., 1997; F. Francis et al., 1999; J. G. Gleeson et al., 1999a).

\footnotetext{
${ }^{12}$ En: Embryonalstadium $n$, mit $n$ als Anzahl der Tage nach der Befruchtung

${ }^{13}$ inside out, engl.: umgekrempelt

${ }^{14}$ Lissenzephalie, griech.: lissos, glatt; Enzephalon, Gehirn
} 


\section{Thalamische Afferenzen und Musterbildung im Kortex}

Im "Protocortex"-Modell (D. D. O'Leary, 1989) wird davon ausgegangen, daß das kortikale Primordium zunächst homogen ist und die Regionalisierung des Kortex erst durch Innervation vom Thalamus zustande kommt. Diese Hypothese basiert auf der Beobachtung verlängerter Plastizität der regionalen Identität früher Kortextransplantate und dem späten Erscheinen klassischer, morphologischer Charakteristika kortikaler Areale (D. D. O'Leary, 1989; B. L. Schlaggar und D. D. O'Leary, 1991). Wie bereits dargelegt, ist das kortikale Primordium jedoch schon zum Zeitpunkt seiner Entstehung regional determiniert, also weit vor dem Eintreffen thalamokortikaler Projektionen. Dieser Befund spiegelt sich in der "Protomap" ${ }^{15}$-Hypothese wieder (P. Rakic, 1988). Die weitgehende Unabhängigkeit der kortikalen Arealisierung wird in Gbx2- und Mash1-Mutanten mit gestörter Ausbildung thalamokortikaler Projektionen deutlich. In diesen Mutanten entwickeln sich pränatale Genexpressionsgrenzen, welche die kortikalen Arealgrenzen respektieren (E. M. Miyashita-Lin et al., 1999; Y. Nakagawa et al., 1999). Im Ebfl- und Dlxl/ 2-defizienten Gehirn kommt es zu einer Verschiebung der Topographie thalamokortikaler Projektionen, regionale kortikale Genexpression ist davon aber nicht betroffen (S. Garel et al., 2003).

Proteine, die an der Zielfindung thalamokortikaler Projektionen beteiligt sind (z. B.: Cadherine, Ephrine, LAMP), zeigen regionalisierte Lokalisation im Kortex. Die zugrunde liegende regionalisierte Genexpression ist wahrscheinlich schon im frühenn Embryo als Teil der "Protomap" determiniert. Die Regionalisierung des Kortex ist daher vielmehr die Ursache für das geordnete Einwachsen thalmokortikaler Axone, als daß thalamokortikale Projektionen den Kortex regionalisieren (M. F. Barbe und P. Levitt, 1991; S. C. Suzuki et al., 1997; T. Inoue et al., 1998; P. Vanderhaeghen et al., 2000; D. Uziel et al., 2002; J. Bolz et al., 2004). Erst beim Erreichen kortikaler Zielareale üben thalamische Axone Einfluß auf den Kortex aus. So scheinen thalamische Afferenzen durch Ausschüttung mitogener Substanzen die Proliferationsrate radialer Gliazellen zu beeinflussen (C. Dehay et al., 2001).

\footnotetext{
${ }^{15}$ Protomap, engl.: vorab angelegte Karte
} 


\section{Ziel dieser Arbeit}

Die Komplettierung des "Human Genome Project" im April 2003 (The International Human Genome Sequencing Consortium, 2003) stellt sicherlich einen Meilenstein der modernen Biowissenschaft dar. Schätzungen zufolge enthält das menschliche Genom 30'000 Gene, von denen derzeit nur 15'000 mit einer biologischen Funktion versehen sind. (E. S. Lander et al., 2001; J. C. Venter et al., 2001). Die funktionelle Charakterisierung neuer vorhergesagter Gene darf als eine der großen Herausforderungen der "Post-Genom-Ära" angesehen werden. Es wird davon ausgegangen, daß ein Großteil aller Gene (13'000 - 26'000) erhöhte oder sogar exklusive Expression im Gehirn aufweist (R. J. Milner und J. G. Sutcliffe, 1983). Demgegenüber stehen bisher nur wenige Gene, die mit der Funktion und insbesondere der Genese des Gehirns in Verbindung gebracht wurden.

Das Ziel der vorliegenden Arbeit war es, durch Microarray-Expressionsanalyse Gene mit regional spezifischer Expression im zerebralen Kortex des Embryonaltags 16,5 zu identifizieren. Regionale Expression im Vorderhirn wurde als erstes Indiz dafür angesehen, daß die betreffenden Gene möglicherweise an der Entstehung und Musterbildung des Kortex beteiligt sind. Die Expressionsmuster ausgewählter Gene sollten durch RNA-in situHybridisierung analysiert werden.

$\mathrm{Zu}$ den zahlreichen Fragen, die sich zum Verständnis der Genese des zerebralen Kortex heute stellen, gehört die Aufklärung später embryonaler Prozesse. E16,5 wurde in der vorliegenden Arbeit ausgwählt, um gezielt Gene mit möglicher Beteiligung an späten Prozessen der Kortikogenese $\mathrm{zu}$ identifizieren. Erscheinungen später Embryonalstadien sind die Umsetzung der frühen Genexpressionsgradienten in morphologisch distinkte Arealgrenzen, die Ausbildung kortikaler Schichten mit regional- und schichtspezifischer Genexpression, sowie der Übergang von intrinsischen Mechanismen der Musterbildung (dem Kortex innewohnend) zu extrinsischen Mechanismen (durch extrakortikalen Einfluß; D. D. O'Leary und Y. Nakagawa, 2002).

In der vorliegenden Arbeit wurde eines der identifizierten Gene (Homeodomain only protein) gewählt, um dessen Expression im embryonalen Nervensystem näher zu charakterisieren und seine Einbindung in Prozesse der Kortikogenese zu untersuchen. Zur Berücksichtigung funktioneller Aspekte sollte das Gehirn einer für das Gen defizienten Mauslinie analysiert werden. Darüberhinaus sollten regulatorische Elemente aufgefunden werden, die die Expression von Homeodomain only protein im Nervensystem regulieren.

Zur Funktionsanalyse von Genen und regulatorischen Elementen sollte eine in vitroMethode etabliert werden, die eine Analyse im intakten Hirngewebe ermöglicht. Die 
Anwendbarkeit einer solchen Methode sollte am Beispiel von Homeodomain only protein gezeigt werden. 


\section{Ergebnisse}

\section{Identifikation regional exprimierter Gene im zerebralen Kortex des Embryonalstadiums 16,5}

\section{Microarray-Expressionsanalyse an RNA-Präparationen verschiedener Regionen des E16,5-Kortex}

In der vorliegenden Arbeit wurde die Microarray-Technologie eingesetzt, um Gene mit regionalisierter Expression im embryonalen zerebralen Kortex der Maus (E16,5) zu identifizieren. Dazu wurde Gewebe aus fünf kortikalen Regionen isoliert. Die verwendeten Regionen waren: frontaler Kortex (Anlage des Motorkortex), rostromedialer Kortex (Anlage des anterioren Hippocampus und des Cingulums), parietaler Kortex (Anlage des primären und sekundären somatosensorischen Feldes), okzipitaler Kortex (Anlage des visuellen Kortex) und caudomedialer Kortex (Anlage des Hippocampus, siehe Abb. 3). Die identifizierten Gene sollten bevorzugt im Gehirn exprimiert sein. Deshalb wurde eine weitere Probe in die Analyse einbezogen - der Körper von E16,5-Embryonen nach Entfernung von Gehirn und Rückenmark (Probe "Restkörper"). Im Gehirn angereicherte Gene düften in dieser Probe nur geringe Expression zeigen. Viele Gene weisen
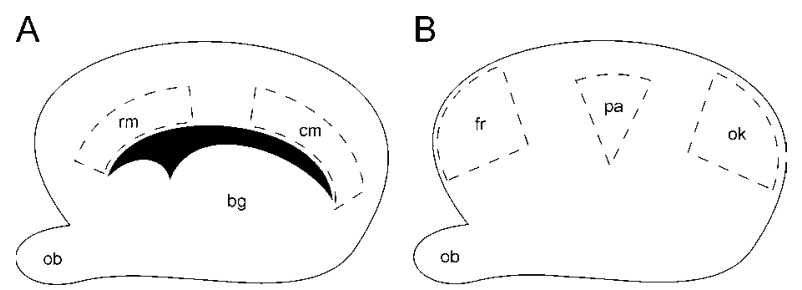

Abb. 3: Regionen des zerebralen Kortex an E16,5.

A: Schematisierte mediale Aufsicht auf eine Hirnhemisphäre. B: Laterale Aufsicht (rostral nach links). ob, Bulbus olfactorius; bg, Basalganglien; rm, rostromedialer Kortex; cm, caudomedialer Kortex; fr, frontaler Kortex; pa, parietaler Kortex; ok, okzipitaler Kortex. eine exklusive Expression im Nervensystem und männlichen Genitaltrakt auf. Um interessante Gene nicht von vornherein auszuschließen, wurde aus der Probe "Restkörper" auch die Genitalanlage entfernt.

Nach Herstellung biotinylierter RNA-Proben aus den Geweben wurden die Microarrays der Serie MGU74v2 (Affymetrix) hybridisiert, gescannt und mit der Software "MicroArray Suite 4" (Affymetrix) analysiert. Eine Sequenz auf dem Microarray (Targetsequenz) wurde als regionalisiert betrachtet, wenn sie in einer Kortexregion mindestens zweifach stärker exprimiert war als in jeder anderen Kortexregion und dreifach stärker als in mindestens einer anderen Kortexregion ("FoldChange"16 $\geq 2$, "FoldChange" ${ }_{\text {max. }} \geq 3$ ). Die Expressionsunterschiede (auch

\footnotetext{
16 "FoldChange" steht im Nomenklatursystem der Affymetrix-Software für das Verhältnis der Expressionsniveaus einer Targetsequenz in zwei Geweben.
} 
zur Probe "Restkörper") sollten als "marginal increased"17 (geringfügig erhöht) bzw. "increased" (erhöht) eingestuft sein.

Aufgrund dieser Kriterien wurden 114 Targetsequenzen ausgewählt. Davon waren 10 als Duplikate (z. B. Dct) bzw. Tripletts (z. B. Nurrl) auf dem Microarray vorhanden. Abb. 4A zeigt eine grafische Darstellung der Verteilung der ausgewählten Targetsequenzen auf die verschiedenen Kortexregionen (okzipital: 37, rostromedial: 25, caudomedial: 23, frontal: 23 , parietal: 6). Sofern dies möglich war, wurden mit Hilfe der Datenbanken "Genbank", "Ensembl" und "Celera" die Targetsequenzen bekannten Genen zugeordnet. Für 44 Sequenzen war keine Zuordnung möglich, es handelt sich hierbei um neue Gene. Eine Auflistung aller regional spezifischen Targetsequenzen mit entsprechenden Werten für "FoldChange" und "DifferenceCall" sowie den zugordneten Genen (Annotation) ist im Anhang in Tab. 5 gegeben.

Alle Gene bzw. annotierten Targetsequenzen, für die eine bekannte oder hypothetische molekulare Funktion vorlag, wurden nach den Richtlinien des Gene-Ontology-Konsortiums (M. Ashburner et al., 2000) klassifiziert. Als Quelle hierfür wurde das Internetportal "NetAffx" der Firma Affymetrix verwendet (http://www.affymetrix.com, G. Liu et al., 2003). In Abb. 4B ist diese Klassifizierung dargestellt. Aufgeführt sind die funktionellen Kategorien und die Anzahl der zugeordneten Gene (in Klammern). Verbindungslinien zeigen die hierarchische Beziehung der Kategorien zueinander. Einzelne Gene können mehreren Kategorien zugeordnet sein. Es überwogen die Kategorien "bindend" und "Signaltransduktion". Weniger Gene wurden katalytischen, enzymregulatorischen sowie Transport- und Strukturprozessen zugeordnet.

\section{RNA-in situ-Hybridisierung mit ausgewählten Sequenzen}

Die Daten der Microarray-Expressionsanalyse indizieren ein regional spezifisches Expressionsmuster der ausgewählten Sequenzen im E16,5-Kortex. Um eine Aussage über das tatsächliche räumliche Expressionsmuster treffen zu können (insbesondere schichtspezifische und extrakortikale Expression), wurde für einzelne Sequenzen eine Expressionsanalyse mittels RNA-in situ-Hybridisierung an E16,5-Hirnschnitten durchgeführt. Dieser Schritt diente auch der Verifizierung der Microarray-Daten und als Entscheidungsgrundlage für die Auswahl eines Gens, das im Verlauf der vorliegenden Arbeit näher charakterisiert werden sollte.

\footnotetext{
${ }^{17}$ Ein weiterer Terminus im Affymetrix-System ist "DifferenceCall". "DifferenceCall" steht für die Qualität des Expressionsunterschiedes und kann die Werte "marginal increased" (geringfügig erhöht), "increased" (erhöht), "marginal decreased" (geringfügig verringert), "decreased" (verringert), sowie "not changed" (nicht verändert) annehmen. Der Zuordnung dieser Prädikate liegt eine Entscheidungsmatrix zu Grunde, in die unter anderem die zugehörigen "FoldChange"-Werte eingehen. "DifferenceCall" ist ein sehr stringentes Maß für die Qualität eines Expressionsunterschiedes.
} 

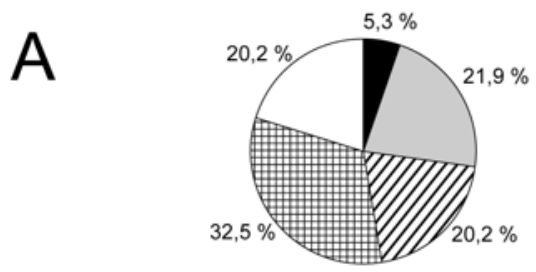

- parietaler Kortex

$\square$ rostromedialer Kortex

$\square$ caudomedialer Kortex

$\boxplus$ okzipitaler Kortex

$\square$ frontaler Kortex
6 Sequenzen

25 Sequenzen

23 Sequenzen

37 Sequenzen

23 Sequenzen

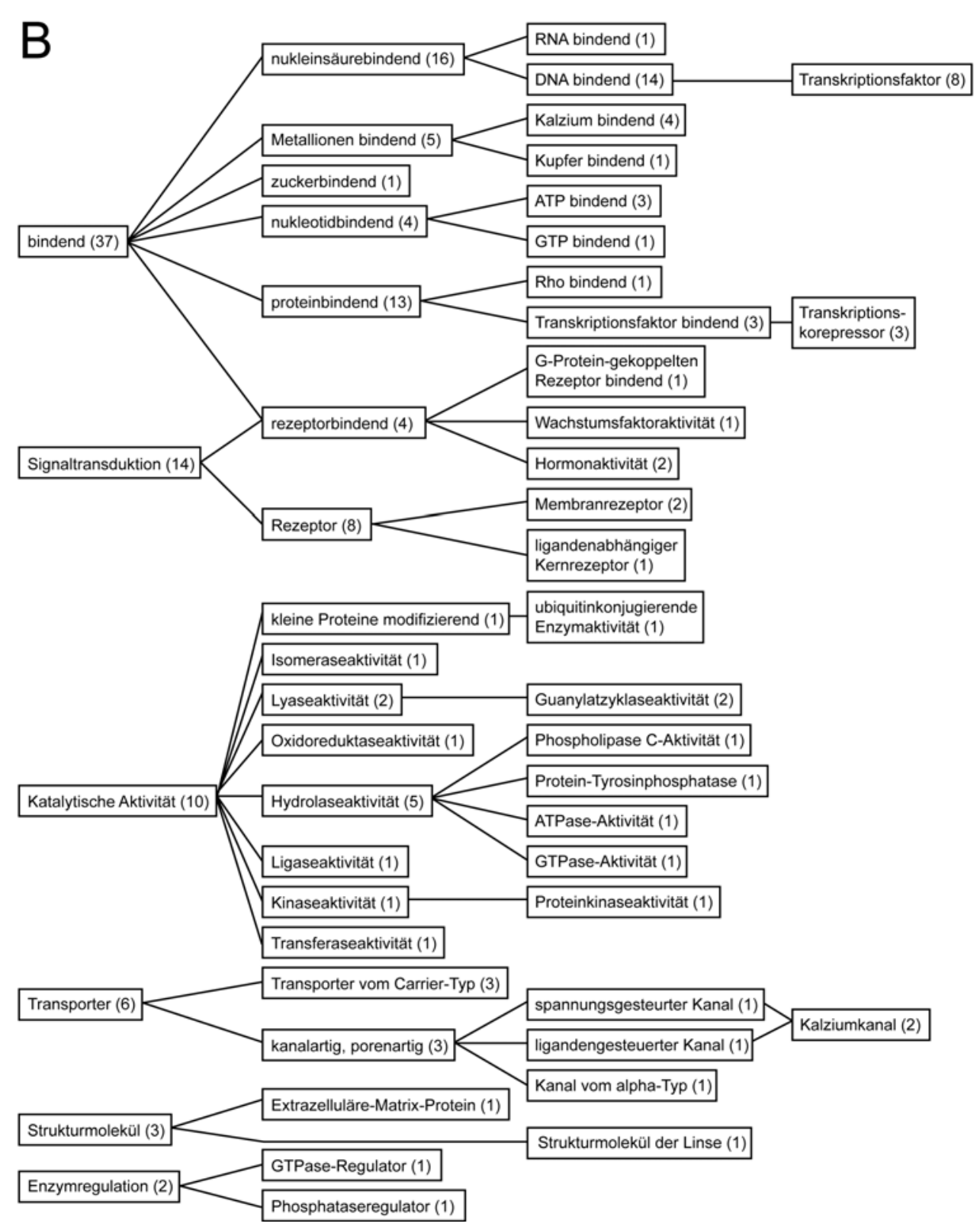

\section{Abb. 4: Klassifizierung der regional exprimierten Sequenzen.}

A: Von den Sequenzen, die der Microarray-Expressionsanalyse unterzogen wurden, erfüllten 114 die Auswahlkriterien für regionalisierte Expression im E16,5-Kortex. Die Sequenzen verteilen sich unterschiedlich auf die in die Analyse einbezogenen Kortexregionen.

B: Bekannte bzw. vorhergesagte molekulare Funktionen der den Targetsequenzen zugeordneten Gene wurden nach den Richtlinien des Gene-Ontology-Konsortiums (Ashburner et al., 2000) klassifiziert. Es überwiegen die Kategorien "bindend" und "Signaltransduktion". Katalytische, enzymregulatorische Prozesse sowie Transport- und Strukturprozesse liegen in der Minderzahl vor. 
Hier wurden zunächst neun Targetsequenzen für die RNA-in situ-Hybridisierung ausgewählt. Zum Zeitpunkt der Auswahl waren diese Sequenzen keinem bekannten Gen zuordenbar, galten also als neue Gene und waren von besonderem Interesse. Inzwischen ist eine Annotation möglich, lediglich bei den Targetsequenzen 115830_at bzw. 113738_at handelt es sich nach wie vor um ein neues Gen.

Im Rahmen einer Fortführung dieses Projektes über die vorliegende Arbeit hinaus sollen weitere Gene der RNA-in situ-Hybridisierung zugeführt werden. Die Ergebnisse sollen einen Überblick über Genexpression im E16,5-Kortex geben.

\section{Proteinphosphatase 1, Untereinheit $1 B$}

Das Gen für Proteinphosphatase 1, Untereinheit 1B (Ppp1r1b, Targetsequenz 108522_at) weist laut Microarray-Analyse die höchste Expression im frontalen Kortex auf. "FoldChange"Werte gegenüber den anderen Regionen waren: rostromedial: 2,3; caudomedial: 8,1; parietal: 2,0; okzipital: 8,3 (Abb. 5E). Für die Darstellung der Microarray-Expressionsdaten in Abb. 5 wurde das höchste Expressionsniveau der fünf Kortexregionen als $100 \%$ definiert und die relative Expression in den anderen Kortexregionen durch Division von $100 \%$ durch den "FoldChange"-Wert errechnet.

Ppplrlb ist in postmitotischen Zellen der tieferen Kortikalplatte des rostralen Kortex in einem Gradienten von lateral nach medial exprimiert. Ppplrlb-mRNA ist ferner in differenzierten Zellen des Septums, piriformen Kortex und Striatums detektierbar (Abb. 5A und B).

\section{Nuclear receptor interacting protein 1}

Auf den verwendeten Microarrays lagen zwei Targetsequenzen (103288_at/ 110650_at) für das Gen Nuclear receptor interacting protein 1 (Nrip1) vor. Stärkste Expression wurde für beide Sequenzen in der RNA-Präparation des frontalen Kortex detektiert. Es lagen folgende "FoldChange"-Werte zu anderen Regionen vor: okzipital: 3,1/ 2,9; rostromedial: 3,3/ 2,7; caudomedial: 7,4/ 5,9; parietal: 4,0/ 2,9 (Abb. 5J). RNA-in situ-Hybridisierung zeigte Nrip1Expression in der oberen Kortikalplatte des frontalen Kortex (Abb. 5F und G).

\section{$\underline{\text { Nur-related protein } 1}$}

Targetsequenzen für Nur-related protein 1 (Nurrl) waren: 92248_at, 92249_g_at und 163675_r_at. Für diese Targetsequenzen wurde die stärkste Expression im okzipitalen Kortex ermittelt. "FoldChange"-Werte zu anderen Kortexregionen: frontal: 6,1/ 3,2/ 5,6; rostromedial: 17,7/ 5,3/ 7,1; caudomedial: 4,8/ 4,8/ 2,7 und parietal: 15,4/ 5,1/ 5,9 (Abb. 5O). In situHybridisierung mit einer Nurr1-RNA-Sonde zeigte Expression im okzipitalen und temporalen 
Kortex sowie im Hippocampus (Abb. 5M und N). Schicht $6 \mathrm{~b}$ ist im gesamten Kortex positiv für Nurrl-mRNA (Abb. 5K-N). Ferner zeigt Nurrl Expression im Claustrum, Septum und dorsalen Thalamus (Abb. 5K-M).

\section{Fibronectin leucin rich transmembrane protein 3}

Es lagen zwei Targetsequenzen für Fibronectin leucin rich transmembrane protein 3 (Flrt3) vor: 110370_at und 164233_at. Flrt3 war am stärksten in der Probe aus dem okzipitalen Kortex exprimiert. "FoldChange"-Werte zu anderen Regionen: frontal: 7,0/ 5,0; rostromedial: 9,7/ 6,5; caudomedial: 3,2/ 2,4 und parietal: 2,7/ 2,1 (Abb. 5U). Flrt3-mRNA wurde in oberen Schichten des okzipitalen Kortex (Abb. 5S) und in Zellen der Marginalzone (Abb. 5T) detektiert.

\section{Homeodomain only protein}

Homeodomain only protein (Hop) zeigte in der Microarray-Analyse die stärkste Expression im rostromedialen Kortex. "FoldChange"-Werte gegenüber anderer Kortexregionen waren: okzipital: 3,7; frontal: 2,6; caudomedial: 1,9; parietal: 3,0 (Abb. 6E). Hop-mRNA wurde in der Ventrikulärzone des Kortex in einem Gradienten von rostromedial nach caudolateral detektiert (Abb. 6A-D). Starke Hop-Expression lag zudem in der embryonalen Fimbria ("cortical hem") vor (Abb. 6C).

\section{Dopachromtautomerase}

Beide Targetsequenzen für das Gen Dopachromtautomerase (Dct; 103597_at/ 164910_s_at) wiesen das höchste Expressionsniveau im rostromedialen Kortex auf - jeweils mit hohen "FoldChange"-Werten zu anderen Regionen: okzipital: 39,3/ 33,6; frontal: 3,7/ 4,8; caudomedial: 42,1/ 17,6; parietal: 11,3/ 46,9 (Abb. 6J). Dct-mRNA war exklusiv in der ventrikulären Zone des rostromedialen und frontalen Kortex detektierbar (Abb. 6F und G).

\section{Solute carrier family 1, member 3}

Solute carrier family 1, member 3 (Slcla3) zeigte in der Microarray-Analyse das stärkste Expressionssignal im rostromedialen Kortex, "FoldChange"-Werte zu anderen Regionen waren: okzipital: 3,8; frontal: 4,7; caudomedial: 2,4; parietal: 5,4 (Abb. 6Q). mRNA für Slcla3 wurde in der gesamten ventrikulären Zone des Kortex in einem Gradienten von rostrolateral nach caudomedial (Abb. 6K-O) und in Zellen der Marginalzone (Abb. 6P) detektiert.

\section{Hippocampus-spezifisch 1}

Ein neues Gen mit der vorläufigen Bezeichnung "Hippocampus-spezifisch 1" war durch zwei Targetsequenzen (113738_at/ 115830_at) auf dem Microarray repräsentiert. Höchste Expression 

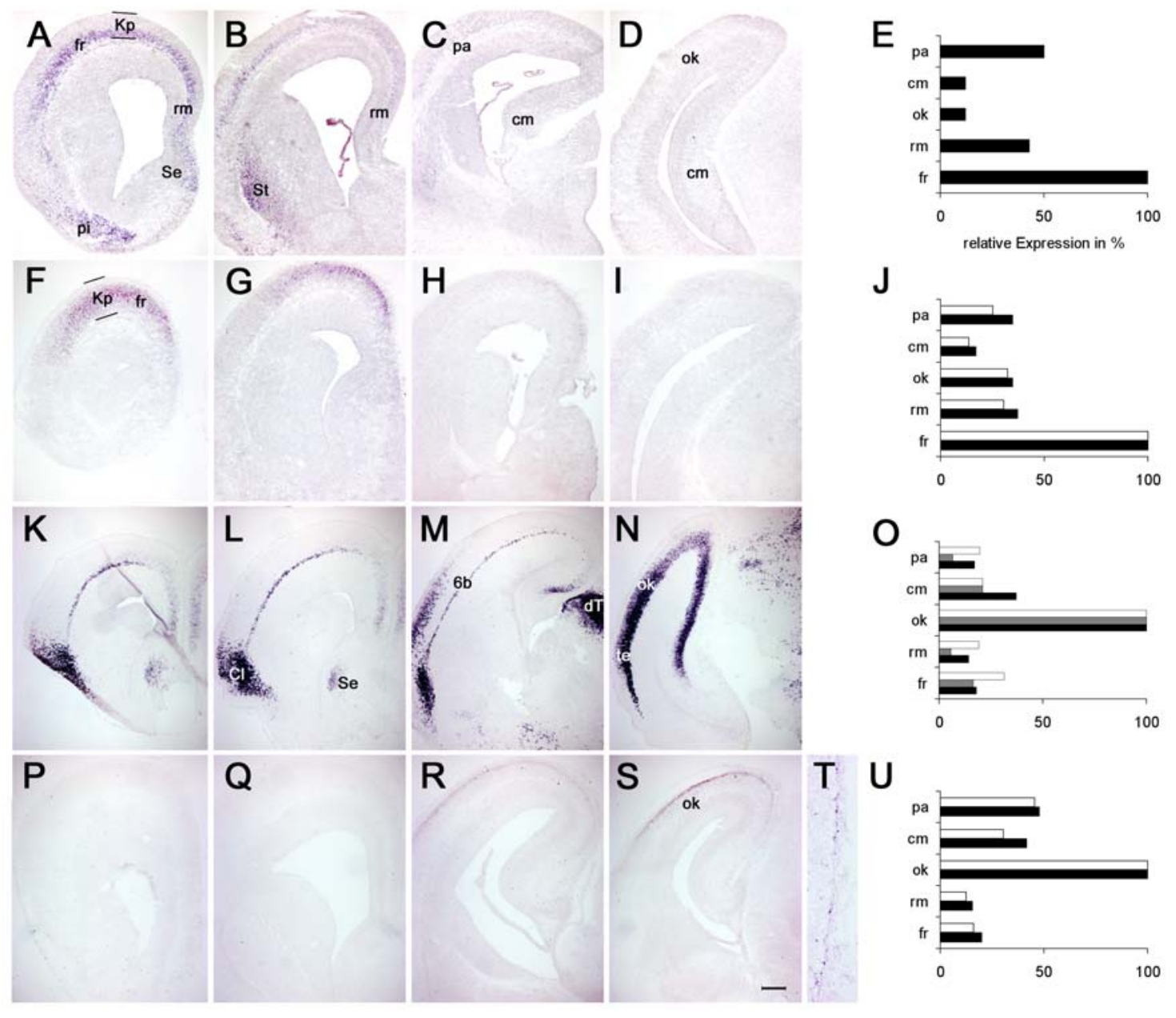

Abb. 5: Gene mit regionalisierter Expression im zerebralen Kortex an E16,5.

A-D, F-I, K-N, P-T: In situ-Hybridisierung mit antisense-RNA-Sonden zeigt Genexpression in koronalen Hirnschnitten. E, J, O, U: Quantifizierung der Genexpression in fünf Kortexregionen mittels MicroarrayExpressionsanalyse. Das höchste Expressionsniveau wurde als 100 \% definiert. Mitunter waren für ein Gen mehrere Targetsequenzen auf dem Microarray vorhanden (verschieden schattierte Balken).

A-E: Proteinphosphatase 1, Untereinheit $1 B$ zeigt Expression in tieferen Schichten des frontalen und rostromedialen Kortex. F-J: Nrip1 (Nuclear receptor interacting protein 1) mit Expressionsgradienten von rostrolateral nach caudomedial. K-O: Nurr1 (Nur-related protein 1) mit komplexem Expressionsmuster und erhöhter Expression im okzipitalen Kortex. P-U: Flrt3 (Fibronectin leucin rich transmembrane protein 3) weist erhöhte Expression in oberen Schichten des okzipitalen Kortex (S) und in Zellen der Marginalzone auf (vergrößerter Ausschnitt in T). 6b, Schicht $6 \mathrm{~b}$ des Kortex; Cl, Claustrum; Cm, caudomedialer Kortex; dT, dorsaler Thalamus; fr, frontaler Kortex; Kp, Kortikalplatte; ok, okzipitaler Kortex; pa, parietaler Kortex; pi; piriformer Kortex; rm, rostromedialer Kortex; Se, Septum; St, Striatum; te; temporaler Kortex; Eichbalken: $200 \mu \mathrm{m}$. 


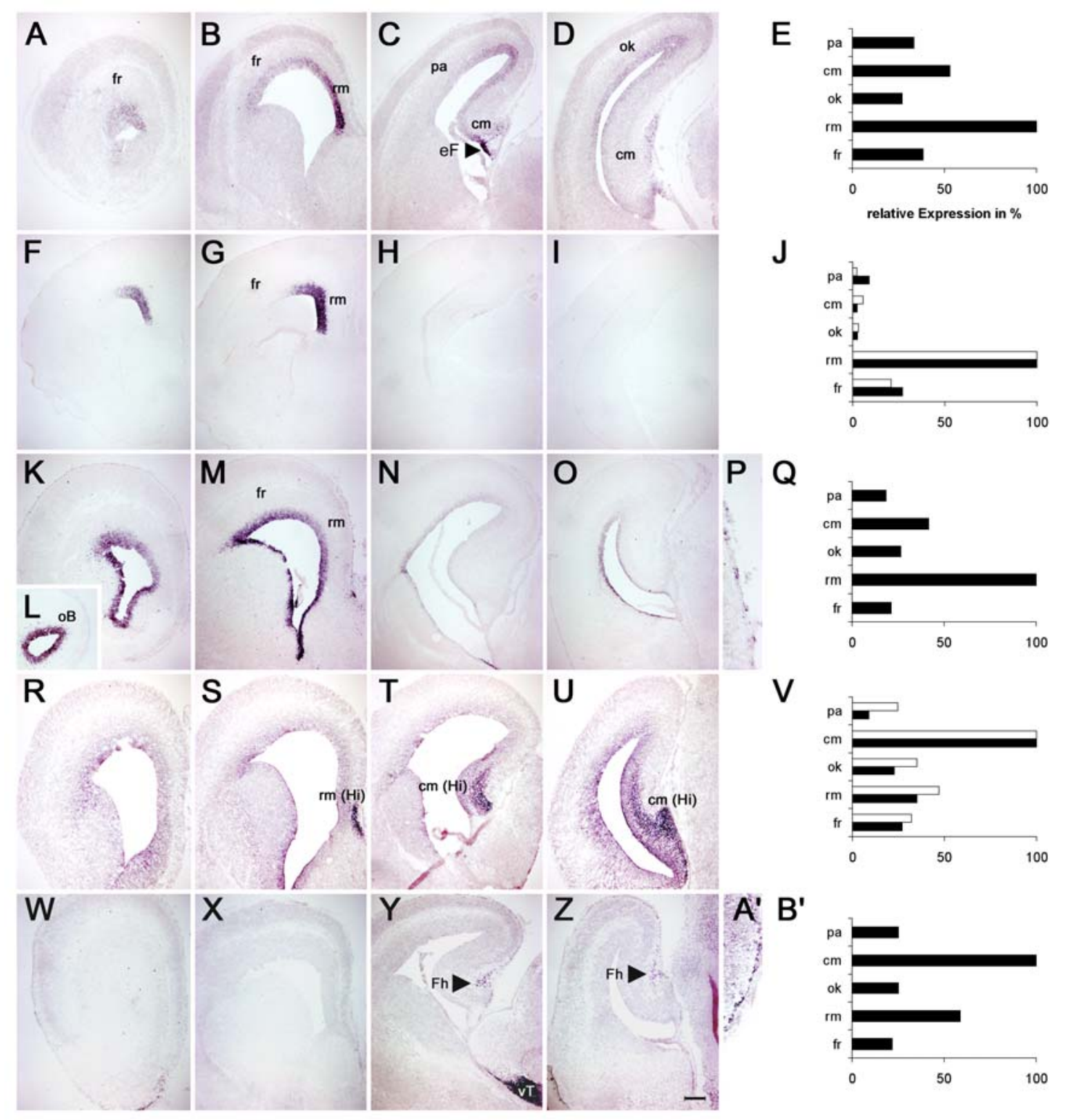

Abb. 6: Gene mit regionalisierter Expression im zerebralen Kortex an E16,5.

A-D, F-I, K-P, R-U, W-A': RNA-in situ-Hybridisierung. E, J, Q, V, B': Quantifizierung der Genexpression durch Microarray-Expressionsanalyse.

A-E: Hop (Homeodomain only protein) zeigt Expression in der kortikalen Ventrikulärzone mit einem Gradienten von rostromedial nach caudolateral. F-J: Die Expression von Dopachromtautomerase ist auf den rostromedialen Bereich der Ventrikulärzone beschränkt. K-Q: Das Gen Slcla3 (Solute carrier family 1, member 3) ist in der gesamten ventrikulären Zone in einem Gradienten von rostral nach caudal exprimiert. Ferner wurde Expression in Zellen der Marginalzone detektiert (vergrößerter Ausschnitt in P). R-V: Expression eines neuen Gens (Hippocampus-spezifisch 1) im medialen Kortex, insbesondere im Hippocampus. W-B': Ebf3 (Early B-cell factor 3) zeigt Expression in der Marginalzone (vergrößerter Ausschnitt in A'), besonders in der entstehenden Fissura hippocampi (Pfeilköpfe in Y und Z). Cm, caudomedialer Kortex; Fh, Fissura hippocampi; fr, frontaler Kortex; Hi, Hippocampus; oB, Bulbus olfactorius; ok, okzipitaler Kortex; pa, parietaler Kortex; rm, rostromedialer Kortex; vT, ventraler Thalamus; Eichbalken: $200 \mu \mathrm{m}$. 
lag im caudomedialen Kortex vor. "FoldChange"-Werte zu anderen Regionen: okzipital: 4,4/ 2,8; frontal: 3,7/ 3,1; rostromedial: 2,8/ 2,1; parietal: 11,4/ 4,0 (Abb. 6V). Eine spezifische RNA-Sonde zeigte Expression in differenzierten (postmitotischen) Zellen der Hippocampusanlage (Abb. 6S-U) und einer Subpopulation von undifferenzierten Zellen der gesamten kortikalen Ventrikulärzone (Abb. 6R-U).

\section{Early B-cell factor 3}

Die Microarray-Expressionsanalyse ergab stärkste Expression von Early B-cell factor 3 $(E b f 3)$ im caudomedialen Kortex mit folgenden Werten für "FoldChange" gegenüber den anderen Regionen: okzipital: 4,0; frontal: 4,6; rostromedial: 1,7, parietal: 4,0 (Abb. 6B'). Ebf3mRNA wurde in der gesamten Marginalzone nachgewiesen (Abb. 6W-A'), besonders im Bereich der entstehenden Fissura hippocampi (Pfeilköpfe in Abb. 6Y und Z). 


\section{Isolation von cDNA-Klonen des Gens Hop und Expressionsstudie im zentralen Nervensystem}

Von den obenstehenden Genen weckte das Gen für Homeodomain only protein (Hop) besonderes Interesse, unter anderem wegen der Kodierung einer Homeodomäne, der Expression in Form eines Gradienten in der kortikalen Ventrikulärzone und der Anreicherung in der embryonalen Fimbria - einem für die Hirnentwicklung wichtigen Signalzentrum. Die Einbindung des Hop-Gens in die Embryonalentwicklung des zerebralen Kortex, d. h. die Identifikation möglicher dem Hop-Gen vorgelagerter Regulationsmechanismen und funktionelle Aspekte des Hop-Proteins, sollten im Rahmen der vorliegenden Arbeit näher beleuchtet werden.

\section{Isolation von cDNA-Klonen des Hop-Gens aus einer cDNA-Bibliothek}

Das Durchsuchen von EST-Datenbanken nach Sequenzähnlichkeiten zur Hop-Targetsequenz (96672_at) ergab Übereinstimmung mit der EST-Sequenz AA254940 (Genbank). Ein entsprechender Klon konnte vom Deutschen Ressourcenzentrum für Genomforschung (Berlin) bezogen werden. Da dieser Klon nur eine DNA-Sequenz aus dem 3'-untranslatierten Bereich des Gens Hop enthielt, wurde die Insert-DNA zunächst zum Screenen einer cDNA-Bibliothek (J. Wijnholds et al., 1995) des E14,5-Kortex der Maus verwendet. Vollständige cDNA-Klone sollten zur Analyse der Genstruktur des Hop-Gens, zur Klonierung einer Sonde für RNA-in situ-Hybridisierung und zur Vorbereitung späterer Überexpressionsexperimente isoliert werden. Es gelang, zwei cDNA-Klone zu isolieren, deren vollständige Sequenz im Anhang dargestellt ist (Abb. 29). In J. Adu et al., 2002 wurden zwei Spleißvarianten für Hop identifiziert (Exonabfolgen Exon 1-Exon 3-Exon 4 bzw. Exon 2-Exon 3-Exon 4), wobei sich die kodierende Sequenz in den Exonen 3 und 4 befindet. Beide im Rahmen der vorliegenden Arbeit isolierten cDNA-Klone folgten der Sequenz mit Exonabfolge Exon 2-Exon 3-Exon 4 (Abb. 29).

\section{Analyse der Expression von Hop mittels RNA-in situ- und Northernblot-Hybridisierung}

Bisherige Analysen der Expression von Hop (J. Adu et al., 2002; F. Chen et al., 2002; C. H. Shin et al., 2002) bezogen sich entweder auf nichtneurale Gewebe oder frühe Embryonalstadien. Lediglich in N. Funatsu et al., 2004 findet sich eine kurze Notiz über Expression von Hop im Vorderhirn. Eine detailierte Studie zur Hop-Expression in neuralen Strukturen lag jedoch nicht vor und wurde deshalb in der vorliegenden Arbeit durchgeführt. Zur Expressionsanalyse wurde RNA-in situ-Hybridisierung zunächst mit einer aus dem Image-Klon 720084 (Genbank: AA254940) transkribierten antisense-RNA-Sonde durchgeführt. Hiermit konnten keine befriedigenden Ergebnisse erzielt werden, das Hybridisierungssignal lag kaum über dem Hintergrundniveau (nicht gezeigt). Zur Etablierung einer alternativen Sonde wurde das 255 bp große DraIII-Fragment aus cDNA-Klon 1 "blunt" in die SmaI-Schnittstelle von pBluescript II 
KS+ kloniert (siehe auch Anhang Abb. 29). Daraus wurde mit T3-Polymerase eine RNA-Sonde transkribiert, welche sich als geeignet erwies, um Hop-Expression zu detektieren (Abb. 7 und 8). Sense-Transkripte wurden mit T7-Polymerase generiert und ergaben kein Hybridisierungssignal (Abb. 7R).

\section{Expression von Hop im E12,5-Embryo}

An E12,5 wurde starke Expression im Herzen (Abb. 7A-C), im Rückenmark (Abb. 7A-D, G) und in der Anlage des Nucleus vestibularis (Abb. 7D und H) detektiert. Hop-Expression im Rückenmark lag in nahezu allen Bereichen der Ventrikulärzone vor, jedoch waren Zellen der Boden- und Deckplatte Hop-negativ. Außerdem bestand eine Expressionslücke, zu deren Lokalisation das Pax6-Gen als Marker herangezogen wurde. Hop-Expression fehlte im dorsalen Bereich der Pax6-reichen Domänen p0-pMN (Pfeilkopf in Abb. 7G). Hop-Expression im Vorderhirn war generell gering, positiv für Hop-mRNA waren die periolfaktorische Region (Abb. 7E) und das Neuroepithel des Hippocampus (Pfeilkopf in Abb. 7F).

\section{Expression von Hop im E14,5-Kortex}

An E14,5 konnte Hop-mRNA in der ventrikulären Zone des Riechkolbens und rostromedialen Kortex detektiert werden (Abb. 7I und J). Ein schwaches Hybridisierungssignal lag auch im caudomedialen Kortex, im Neuroepithel des Gyrus dentatus vor (Pfeilkopf in Abb. $7 \mathrm{~K})$. Darüberhinaus war eine Subpopulation von Zellen der ventrikulären Zone des vierten Ventrikels sowie Zellen in der Anlage des Nucleus vestibularis Hop-positiv (Abb. 7L und M).

\section{Expression von Hop im E16,5-Kortex}

Hop-Expression erstreckte sich an E16,5 in der kortikalen Ventrikulärzone in einem Gradienten von rostromedial nach caudolateral (Abb. 7N-R). Zellen im Neuroepithel des Gyrus dentatus waren stark Hop-positiv und hielten diese Expression während der Migration zum Gyrus dentatus aufrecht (Abb. 7P). Eine starke Expression von Hop war in der embryonalen Fimbria zu verzeichnen.

\section{Expression von Hop im E18,5-Kortex}

Das Expressionsmuster von Hop im Kortex an E18,5 ähnelte dem an E16,5 (Abb. 7S-V). Hop-Expression war jetzt verstärkt im Gyrus dentatus zu verzeichnen (Pfeilkopf Abb. 7V). An E18,5 war die ventrikuläre Zone des Bulbus olfactorius frei von Hop-Expression, einige Zellen der periglomerulären Schicht exprimierten Hop (Pfeilköpfe in Abb. 7S). 
Abb. 7: Expression von Hop im frühen Embryo und im embryonalen Nervensystem.

A-D: $\quad$ Im E12,5-Embryo wird Hop im Herzen (A, B), im Rückenmark (A-D) und im Nachhirn exprimiert. E-F: E12,5 ist das früheste Entwicklungsstadium, in dem Hop-RNA im Vorderhirn detektierbar ist. Hop ist in der periolfaktorischen Region (E) und in geringem Maße im medialen Kortex (Pfeilkopf in F) exprimiert. Eine starke Hop-Expression ist in der Ventrikulärzone des Rückenmarks zu verzeichnen (G). Es besteht eine Expressionslücke auf Höhe der Pax6-reichen Domäne (Pfeilkopf in G), Boden- und Deckplatte des Rückenmarks sind frei von Hop-Expression. Eine Zellpopulation im Hinterhirn, die dem späteren Kerngebiet des Nervus vestibularis zuzuschreiben ist, weist eine starke Expression von Hop auf $(\mathrm{H})$.

I-M: An E14,5 ist Hop in der Ventrikulärzone des Riechkolbens (I), im rostromedialen Kortex (J) und in einigen Zellen der Ventrikulärzone des IV. Ventrikels (L) exprimiert. Die Expression im Hinterhirn bleibt bestehen (M). Eine sehr schwache Expression im medialen Kortex auf Höhe der Hippocampus-Anlage ist $\mathrm{zu}$ verzeichnen (Pfeilkopf in $\mathrm{K})$.

N-Q: $\quad$ Hop-exprimierende

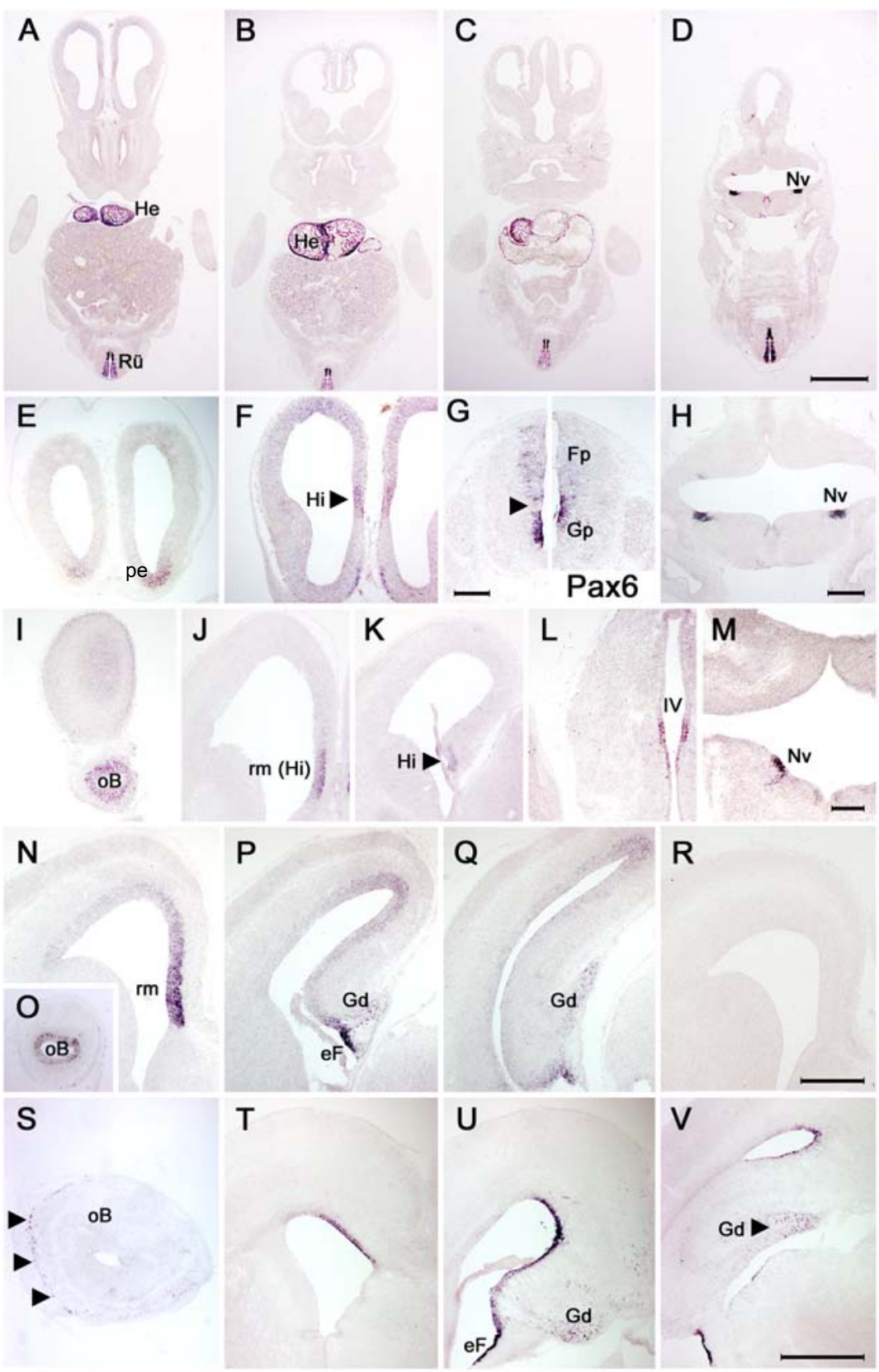

Strukturen im E16,5-Kortex sind: die Ventrikulärzone des Riechkolbens (O) und des medialen Kortex (N, P), sowie die embryonale Fimbria (P, Q). R: In situ-Hybridisierung mit einer sense-RNA-Probe ergibt kein Signal.

S-V: Auch an E18,5 ist Hop in der Ventrikulärzone des medialen Kortex exprimiert (T, U). Eine starke Expression ist in der embryonalen Fimbria (U, V) und in Zellen des Gyrus dentatus (Pfeilkopf in V) zu verzeichnen. Auch einige postmitotische Zellen im Riechkolben exprimieren Hop (Pfeilköpfe in S). eF, embryonale Fimbria; Fp, Flügelplatte; Gd, Gyrus dentatus; Gp, Grundplatte; He, Herz; Hi, Hippocampus; IV, viertes Ventrikel; Nv, Nucleus vestibularis; oB, Bulbus olfactorius; pe, periolfaktorische Region; rm, rostromedialer Kortex. Eichbalken: A-D: 1 mm; E, F, H: $400 \mu \mathrm{m} ; \mathrm{G}: 200 \mu \mathrm{m}$; I-M: $200 \mu \mathrm{m}$; N-R: $500 \mu \mathrm{m}$ : S-V: $500 \mu \mathrm{m}$. 
A

B

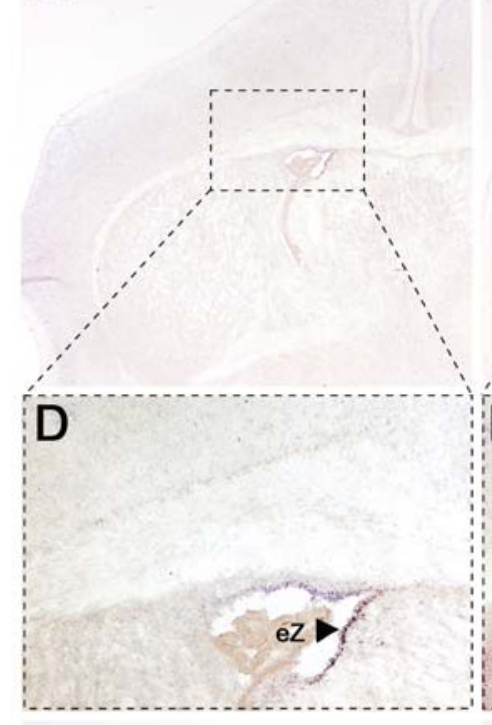

G

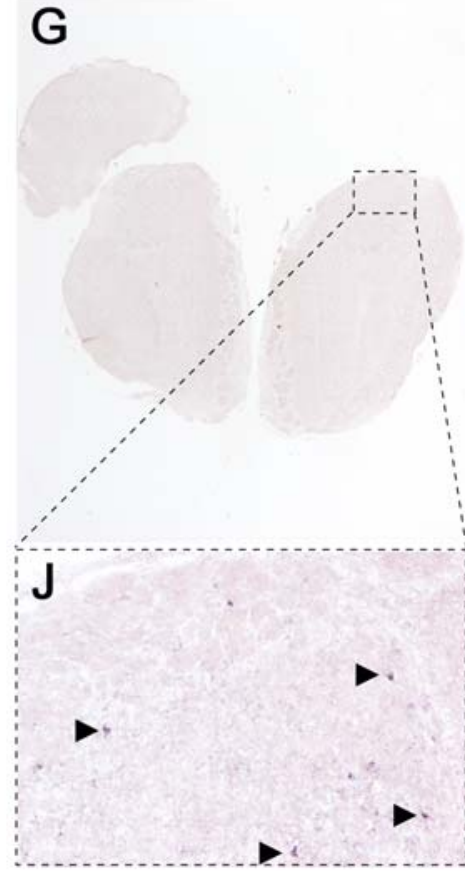

E
C
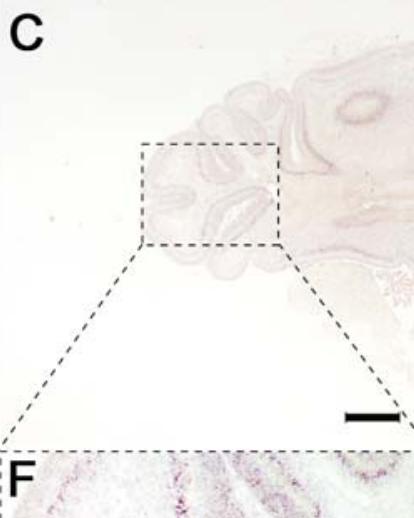

$\mathrm{Sg}$
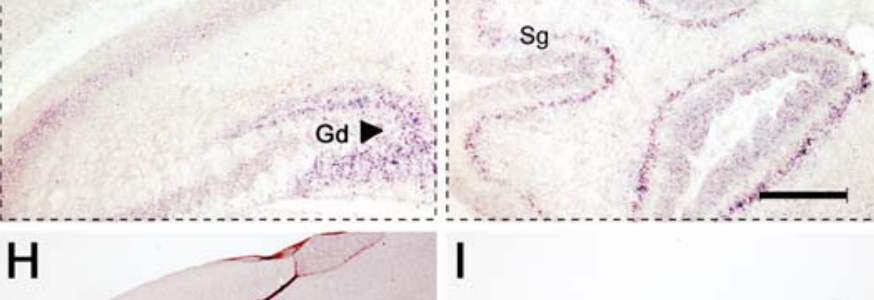

I

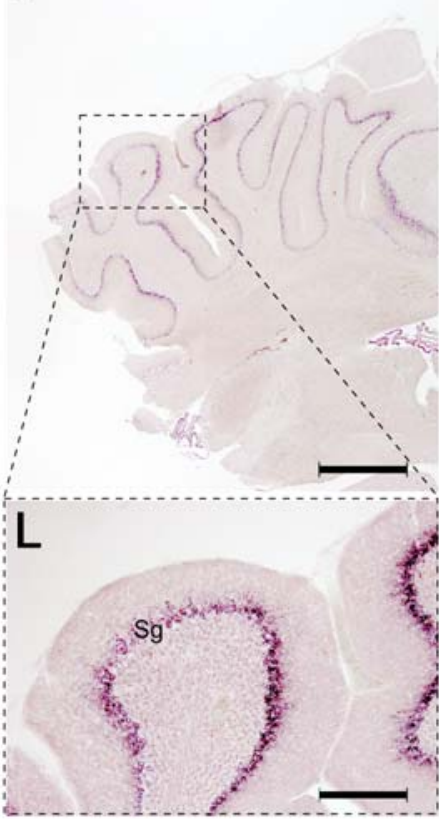

Abb. 8: Expression von Hop im postnatalen Gehirn.

A-C: Übersichtsbilder, P6-Gehirn. D-F: An P6 ist Hop in der an das laterale Ventrikel angrenzenden ependymalen Zellschicht exprimiert (Pfeilkopf in D). Ferner sind Hop-positive Zellen im Gyrus dentatus (Pfeilkopf in E) und im Stratum ganglionare des Zerebellums detektierbar.

G-I: Übersichtsbilder, P21-Gehirn. J, K: Im adulten Gehirn ist Hop in wenigen, lose verteilten Zellen des Riechkolbens (Pfeilköpfe in J) und in Zellen des Gyrus dentatus exprimiert (Pfeilkopf in K, Eichbalken: $100 \mu \mathrm{m}$ ). L: Die schon an P6 beobachtete Hop-Expression im Zerebellum bleibt auch im adulten Gehirn bestehen. eZ,

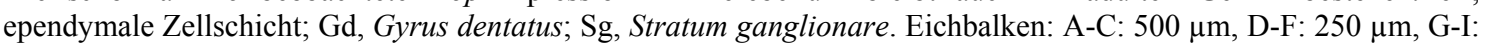
$100 \mu \mathrm{m}, \mathrm{J}-\mathrm{L}: 200 \mu \mathrm{m}$. 
Expression von Hop im postnatalen Gehirn

Sowohl an P6 (Abb. 8C und F) als auch im adulten Gehirn (Abb. 8I und L) wurde Hop im Stratum ganglionare des Zerebellums detektiert. An P6 war Hop auch in der ependymalen Zellschicht (Pfeilkopf in Abb. 8D) und im Gyrus dentatus exprimiert (Pfeilkopf in Abb. 8E). Im adulten Vorderhirn fehlte Hop-mRNA nahezu vollständig. Lediglich wenige Zellen im Riechkolben und in der subgranulären Zone des Gyrus dentatus (Pfeilköpfe in Abb. 8J bzw. K) waren Hop-positiv.

Northernblot-Analyse der Hop-Expression in Organen des E16,5-Embryos

Zur Analyse der Hop-Expression außerhalb des Gehirns wurden verschiedene Gewebe von E16,5-Embryonen entnommen, die mRNA isoliert und eine Northernblot-Analyse durchgeführt. Das ${ }^{32} \mathrm{P}$-markierte DraIII-Fragment aus cDNA-Klon 1 hybridisierte mit einem $1,2 \mathrm{~kb}$ großen RNA-Fragment, was der Größe der HopTranskripte entsprach. GAPDH diente als Ladekontrolle. Hop-Transkripte konnten im Rückenmark, der Lunge und dem Herzen detektiert werden. mRNA aus Lebergewebe

\section{Hop an E16,5.}

Hop-Transkripte wurden im Rückenmark, der Lunge, dem Herzen und nur in geringem Maße in der Leber ergab nur ein sehr schwaches Hybridisierungsdetektiert. signal (Abb. 9). 
Expression von Hop im Lef1- und Emx2defizienten Kortex an E16,5

Wie beschrieben, zeigte Hop starke Expression in Strukturen des medialen Kortex, in der embryonalen Fimbria und im Gyrus dentatus. Die unmittelbar an die embryonale Fimbria angrenzende Region des Kortex wird als primäres Neuroepithel des Gyrus dentatus beschrieben, von wo aus Zellen zum Gyrus dentatus migrieren und zwischenzeitlich das sekundäre Neuroepithel bilden (J. Altman und S. A. Bayer, 1990). Vorläuferzellen des Gyrus dentatus exprimieren während dieser Migration Hop (Abb. 7P). Es schien daher interessant, die Expression von Hop im Lefl-defizienten Kortex, welcher keinen Gyrus dentatus ausbildet (J. Galceran et al., 2000), zu untersuchen.

Im Lefl-Knock out ${ }^{18}$ ist Hop in der rostralen Ventrikulärzone und in der embryonalen Fimbria exprimiert. Auch migrierende Vorläuferzellen des Gyrus dentatus exprimieren Hop. Diese Hoppositiven Zellen verschwinden jedoch während der Migration zum Gyrus dentatus und sind somit von Lefl abhängig (Abb. $\left.10 \mathrm{~A}-\mathrm{C}, \mathrm{A}^{\prime}-\mathrm{C}^{\prime}\right)$.

Ebenfalls von Interesse erschien das Hop-Expressionsmuster im Emx2-Knock out (M. Pellegrini et al., 1996), da beide Gene überlappend in der medialen Ventrikulärzone und im Gyrus dentatus

\footnotetext{
${ }^{18}$ Knock out, engl.: das Außergefechtsetzen, im biologischen Sinne: das Ausschalten eines Gens
}

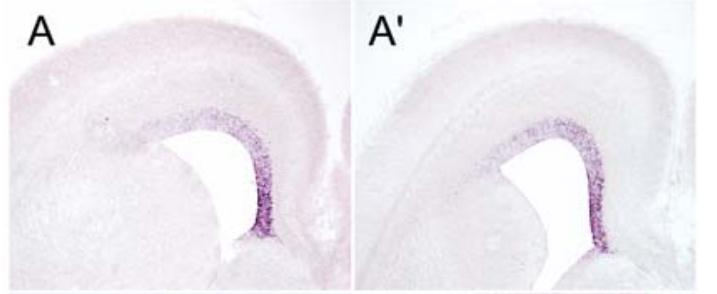

B $\quad B^{\prime}$

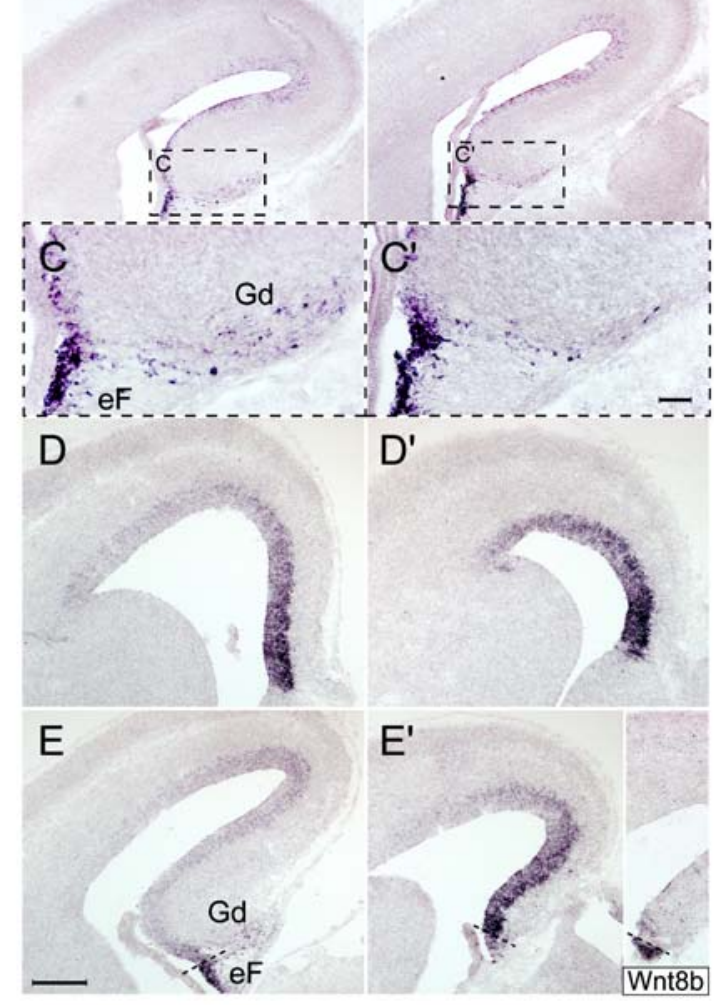

Abb. 10: Expression von Hop im Lef1- und Emx2defizienten Kortex an E16,5.

A-C: Expression von Hop im Wildtyp-Kortex. A'-C': Expression von Hop im Lefl-defizienten Kortex.

Hop ist in Vorläuferzellen des Gyrus dentatus exprimiert, die ihren Ursprung oberhalb der embryonalen Fimbria haben und zum Gyrus dentatus migrieren (C). Diese Hoppositiven Zellen werden im Lef1-Knock out angelegt, verschwinden aber auf dem Weg zum Gyrus dentatus ( $\left.\mathrm{C}^{\prime}\right)$. Hop-Expression in der kortikalen Ventrikulärzone ist nicht vom Verlust des Lef1-Gens betroffen (A, A').

D, E, D', E': Im Emx2-Knock out (D') ist der Expressionsgradient von Hop im Vergleich zum Wildtyp (D) nach lateral und caudal ausgedehnt. Ferner besteht eine Invertierung der Hop-Expression entlang der Grenze zwischen Kortex und Fimbria (Unterbrochene Linie in E und $\left.\mathrm{E}^{\prime}\right)$. Im Wildtyp ist die Hop-Expression im caudalen Kortex gering und in der embryonalen Fimbria hoch (E). Der Knock out zeigt erhöhte Expression von Hop im Kortex und verringerte Expression in der embryonalen Fimbria (E'). Zur Darstellung der Fimbria im Emx2-Knock out wurde das Markergen Wnt8b verwendet (rechts in E'). Gd: Gyrus dentatus, eF: embryonale Fimbria; Eichbalken: A-E, A'-E': $200 \mu \mathrm{m}$. 
exprimiert sind. Der Vergleich korrespondierender, koronaler Schnittebenen des Wildtyp- und Emx2-defizienten Gehirns zeigt eine Verschiebung des Hop-Expressionsgradienten nach lateral und caudal (Abb. 10D, D'). Ferner ist das Verhältnis von Hop- Expression in der embryonalen Fimbria und im Kortex invertiert, mit erhöhter Expression im Kortex und verringerter Expression in der Fimbria des Emx2-Knock outs (Abb. 10E, E').

Zusammenfassung der Expressionsanalyse von Hop im prä- und postnatalen Nervensystem

Im folgenden sollen die wichtigsten Ergebnisse der oben aufgeführten Expressionsanalyse von Hop für das prä- und postnatale Gehirn zusammengefaßt werden:

1. Von E12,5 bis P6 bestand Hop-Expression in der ventrikulären Zone (E12,5 - E18,5) bzw. in der ependymalen Zellschicht (P6) des zerebralen Kortex mit hoher Expression im rostromedialen Bereich und geringer Expression caudolateral.

2. Hop-positive Regionen im medialen Kortex waren die embryonale Fimbria und proliferative Neuroepithelien des Gyrus dentatus.

3. Von E12,5 bis hin zu adulten Stadien war Hop in Zellen der paraolfaktorischen Region $(\mathrm{E} 12,5) \mathrm{bzw}$. des olfaktorischen Bulbus $(\geq \mathrm{E} 14,5)$ exprimiert.

4. Von P6 an wurde Hop im Stratum ganglionare des Kleinhirns detektiert.

5. An E12,5 und E14,5 war Hop in der Anlage des Nucleus vestibularis detektierbar. 


\section{Immunohistochemischer Nachweis des Proteins Serum response factor}

In F. Chen et al., 2002 und C. H. Shin et al., 2002 wird eine Kolokalisation und physikalische Interaktion der Proteine Hop und SRF (Serum response factor) in Kardiozyten beschrieben. Hop tritt dabei als Modulator der Funktion des Transkriptionsfaktors SRF in Erscheinung. Kürzlich wurde das SRF-Protein auch im peri- und postnatalen Gehirn der Ratte nachgewiesen (J. L. Stringer et al., 2002). Unter diesem Aspekt stellte sich die Frage, ob SRF auch in pränatalen Stadien und insbesondere in Hop-positiven Bereichen der medialen Ventrikulärzone vorliegt. Ein solcher Befund würde die Hypothese einer Interaktion von Hop und SRF im Gehirn zulassen.

Mit einem anti-SRF-Antikörper konnte SRF auf Paraffinschnitten des Herzens von E13,5Embryonen nachgewiesen werden (positive Kontrolle, Abb. 11A). Weder an E13,5 noch an E16,5 wurde SRF-Protein in der Ventrikulärzone des medialen Kortex detektiert (Abb. 11B und C). Zur Negativkontrolle wurde Immunhistochemie ohne primären Antikörper durchgeführt (Abb. 11D-E).
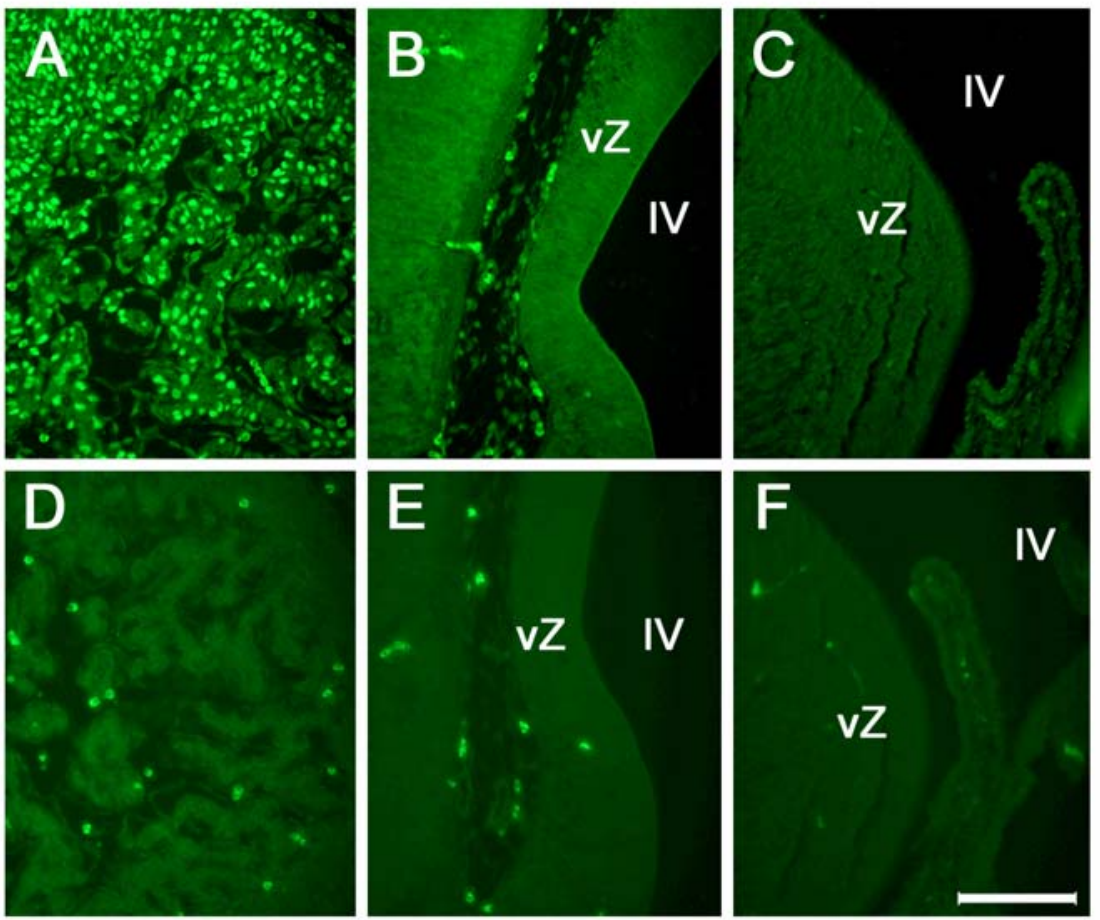

Abb. 11: Immunhistochemischer Nachweis des Proteins Serum Response Factor (SRF).

A: Das SRF-Protein kann in E13,5-Kardiozyten immunhistochemisch als grünes Fluoreszenzsignal nachgewiesen werden. B, C: Weder an E13,5 (B), noch an E16,5 (C) ist SRF in der ventrikulären Zone des Kortex detektierbar.

D, E, F: Zur Kontrolle wurden Immunfärbungen ohne primären Antikörper angefertigt. Lediglich die Eigenfluoreszenz des Gewebes, insbesondere der enthaltenen Blutgefäße ist sichtbar. D: E13,5 Herz; E: E13,5 Kortex; F: E16,5 Kortex. vZ, ventrikuläre Zone; IV, laterales Ventrikel. Eichbalken: $100 \mu \mathrm{m}$. 


\section{Analyse des embryonalen und adulten Gehirns einer Hop-defizienten Mauslinie}

Zur Funktionsanalyse von Hop im embryonalen Gehirn wurde eine Hop-defiziente Mauslinie untersucht, welche von der Arbeitsgruppe um Prof. E. N. Olson (University of Texas/ Dallas/ USA) zur Verfügung gestellt wurde. Im Hop-Knock out war bereits ein Herzphänotyp charakterisiert (F. Chen et al., 2002; C. H. Shin et al., 2002), Aspekte des Gehirns wurden nicht betrachtet. In der vorliegenden Arbeit sollte der Vergleich von Hop-defizientem Gehirn und Wildtyp-Gehirn Aufschluß über die Bedeutung des Hop-Gens für die Hirnentwicklung geben. Eine solche Rolle des Gens wurde aufgrund seines differenzierten Expressionsmusters im Kortex postuliert. Hauptaugenmerk der Analyse wurde auf die Makroanatomie des embryonalen und adulten Gehirns, auf die Expression embryonaler Markergene und die Proliferationsrate der Neuroblasten in der Ventrikulärzone gerichtet. Die jeweiligen Untersuchungen wurden an mindestens zwei Wildtyp- und Knock out-Gehirnen durchgeführt, in den zugeordneten Abbildungen sind repräsentative Ergebnisse dargestellt.

\section{Vergleich der Hirnanatomie von Wildtyp und Hop-Knock out}

Um die Anatomie des zerebralen Kortex der Genotypen Hop+/+ und Hop-/- zu vergleichen, wurde Hämatoxylin-Eosin-Färbung an koronalen Paraffinschnitten embryonaler (E16,5) und adulter Gehirne (P21) durchgeführt.

An E16,5 konnten keine offensichtlichen anatomischen Veränderungen zwischen beiden Genotypen festgestellt werden (Abb. 12A, A'). Insbesondere Strukturen des medialen Kortex, in denen starke Hop-Expression zu verzeichnen war, wie Gyrus dentatus und Fimbria, waren normal angelegt. Auch adulte Hop-defiziente Gehirne wiesen keine offensichtlichen Abweichungen vom Wildtyp auf. Hier wurde besonderes Augenmerk auf die Ausprägung des Gyrus dentatus und Hop-positive Bereiche des Kleinhirns gerichtet (Abb. 12B-D, B'-D'). Das Stratum granulosum und das Stratum ganglionare des Kleinhirns war in normaler Weise ausgebildet, Purkinje-Zellen waren in vergleichbarer Anzahl und Dichte vorhanden (Abb. 12E, $\left.E^{\prime}\right)$. 

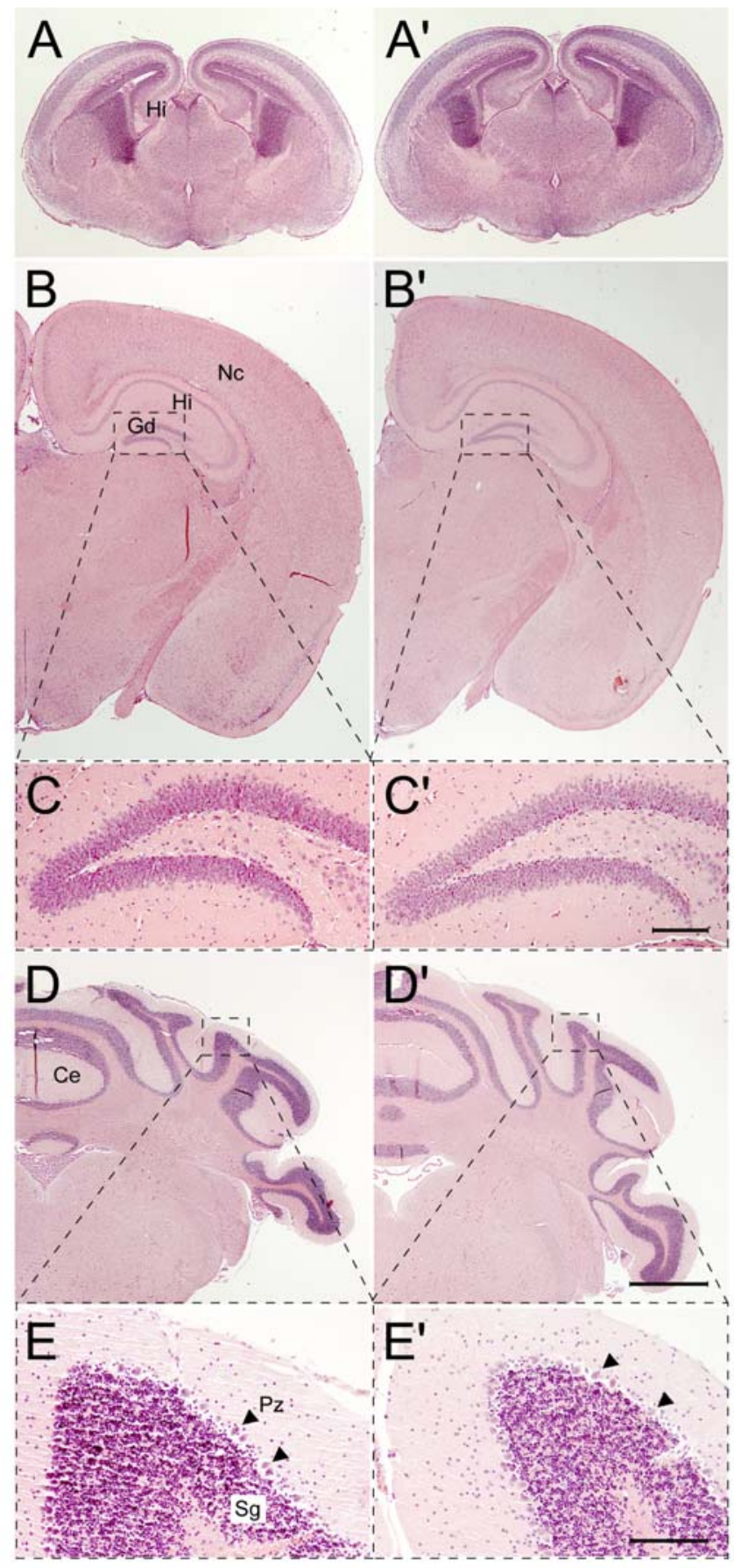

Abb. 12: Histologische Präparate embryonaler und adulter Gehirne der Genotypen Hop+/+ und Hop-/-.

A, A': Hämatoxylin-Eosin-Färbung (HE) koronaler Hirnschnitte des Embryonalstadiums 16,5 offenbarte keine anatomischen Unterschiede zwischen Wildtyp (A) und Hop-Knock out (A'). In beiden Genotypen war der medial gelegene Hippocampus (Hi) angelegt.

B-E, B'-E': HE-Färbung an koronalen Schnitten des adulten Großhirns (B, C, B', C') und Kleinhirns (D, E, D', E') der Genotypen Hop+/+ (B-E) und Hop-/- (B'-E'). Die Makroanatomie des Gehirns war vom Verlust des Hop-Gens nicht betroffen. Insbesondere Derivate der Hop-positiven medialen Ventrikulärzone, wie der Gyrus dentatus und der Hippocampus, wurden normal ausgebildet, ebenso das Kleinhirn. Ein normales Stratum granulosum lag vor, Purkinje-Zellen (Pfeilköpfe in E, E') waren in normaler Anzahl und Dichte vorhanden. Ce, Cerebellum; Gd, Gyrus dentatus, Hi, Hippocampus; Nc, Neokortex; Pz, Purkinje-Zellen; Sg, Stratum granulosum. Eichbalken: A, B, D, A', B', D': 1mm; C, E, C', E': $125 \mu \mathrm{m}$. 


\section{Vergleich früher Markergen-Expression im Wildtyp- und Hop-defizienten Gehirn}

Für eine detailiertere Analyse wurde das Embryonalstadium E16,5 gewählt, da zu diesem Zeitpunkt eine besonders starke Hop-Expression im Kortex vorlag. Durch in situHybridisierung mit Markergenen sollten bestimmte Zellpopulationen sichtbar gemacht werden, die wichtigen Hop-positiven Regionen (Bsp.: embryonale Fimbria, Gyrus dentatus) oder Prozessen (Bsp.: Regulation der Neurogenese) zugeordnet sind. Zur Kontrolle wurde in situHybridisierung auch mit der Hop-RNA-Sonde durchgeführt. Im Hop-Knock out wurde keine Hop-RNA detektiert (Abb. 13A und A').

\section{Expression von Markergenen der embryonalen Fimbria im Wildtyp und Hop-Knock out}

Neben Bmp-Faktoren stehen Proteine der Wnt-Familie für die Kapazität der embryonalen Fimbria, nach Art eines Signalzentrums die Ausbildung medialer Kortexstrukturen zu steuern (E. A. Grove et al., 1998; S. M. Lee et al., 2000). Sowohl im Wildtyp- als auch im Hopdefizienten Gehirn waren die Gene Wnt $3 a$, Wnt5a und Wnt8b in der embryonalen Fimbria exprimiert (Abb. 13 B-D, B'-D'). Obwohl Hop normalerweise hohe Expression in der embryonalen Fimbria aufweist, waren die Ausbildung und Aufrechterhaltung dieser Struktur nicht davon abhängig.

\section{Expression von Markergenen der Ventrikulärzone im Wildtyp und Hop-Knock out}

Im weiteren wurde eine Reihe von Markergenen der Hop-positiven Ventrikulärzone untersucht. $L h x 2$ ist ein solches Gen und für die Ausbildung der kortikalen Ventrikulärzone von entscheidender Bedeutung (E. S. Monuki et al., 2001). Hes5 und Ngn2 sind als negative (C. Akazawa et al., 1992) bzw. positive Regulatoren der Neurogenese (C. M. Parras et al., 2002; T. Miyata et al., 2004) in Subpopulationen von Zellen der ventrikulären Zone exprimiert. Dct wurde im Rahmen der vorliegenden Arbeit als Markergen der rostralen Ventrikulärzone beschrieben. Keines der Gene Lhx2, Hes5, Ngn2 und Dct zeigte zwischen Knock out und Wildtyp Unterschiede in seinem Expressionsmuster im Kortex (Abb. 13 E-H, E'-H').

\section{Expression von Markergenen des Hippocampus im Wildtyp und Hop-Knock out}

KA1 ist einer der frühesten Marker für das CA3-Feld des Hippocampus (P. L. Woodhams et al., 1993; E. A. Grove und S. Tole, 1999). Emx2 (M. Pellegrini et al., 1996) ist im sich entwickelnden Gyrus dentatus exprimiert. Die Expressionsmuster beider Gene gleichen sich im Wildtyp und Hop-Knock out (Abb. 13 I, J; I', J'). Der Hippocampus ist also im Knock out normal angelegt. 


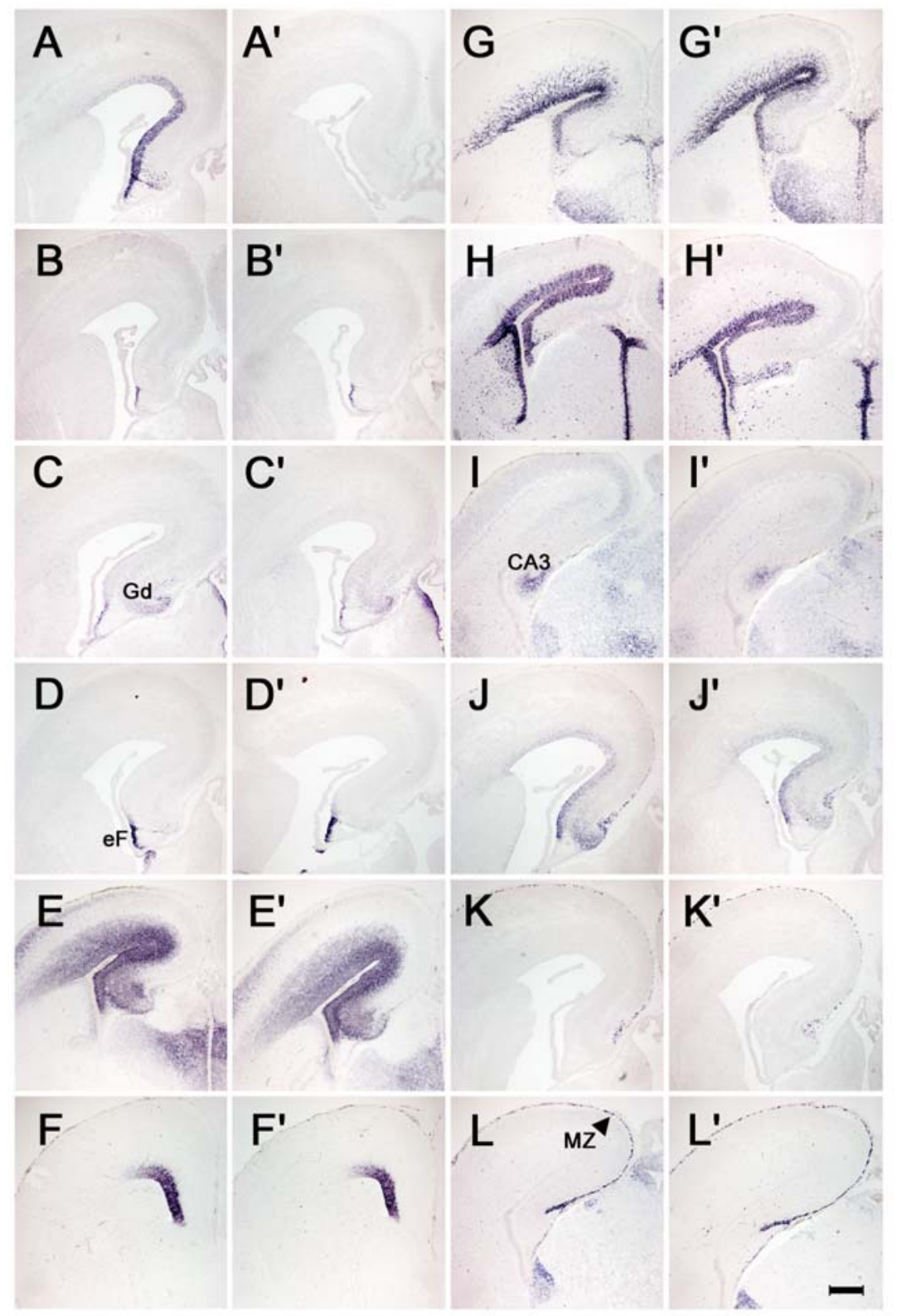

Abb. 13: Vergleich der Expression von Markergenenen im E16,5-Kortex der Genotypen Hop +/+ und Hop -/-. A-L: Markergene im Wildtyp-Kortex $(H o p+/+)$. A'-L': Expression von Markergenen im Hop-defizienten Kortex (Hop -/-).

A, A': An E16,5 ist Hop in der ventrikulären Zone des medialen Kortex, in der Fimbria und dem Gyrus dentatus exprimiert (A). Hop-RNA ist im Kortex des Genotyps Hop -/- nicht detektierbar (A'). B-D, B'-D': Gene der WntFamilie werden in gleicher Weise in der embryonlen Fimbria beider Genotypen exprimiert (B, B': Wnt3a; C, C': Wnt5a; D, D': Wnt8b). E-H, E'-H': Auch Gene mit Expression in der ventrikulären Zone sind in Abwesenheit von Hop normal exprimiert, so die Gene Lhx2 (E, E'); Dct (F, F'); Ngn2 (G, G') und Hes5 (H, H'). I, J, I', J': Im Hopdefizienten Kortex werden Hippocampus-Strukturen, wie die KA1-positive CA3-Region (I, I') und der Emx2-positive Gyrus dentatus (J, J') normal ausgebildet. K, K', L, L': Cajal-Retzius-Zellen der Marginalzone haben ihren Ursprung in der Hop-exprimierenden Fimbria. Die Ausbildung der Cajal-Retzius-Zellen ist im Hop-defizienten Kortex nicht gestört. Dies wird durch die normale Expression des Cajal-Retzius-Markers Reelin (K, K') und des MarginalzoneMarkers Lhx5 (L, L') deutlich. CA3, CA3-Feld des Hippocampus; eF, embryonale Fimbria; Gd, Gyrus dentatus; MZ, Marginalzone. Eichbalken: $150 \mu \mathrm{m}$. 


\section{Expression von Markergenen der Marginalzone im Wildtyp und Hop-Knock out}

An E12,5 ist Hop in der periolfaktorischen Region, später in der embryonalen Fimbria, exprimiert. Beide Regionen gelten als Ursprung von Cajal-Retzius-Zellen, welche die Marginalzone besiedeln (G. Meyer et al., 2002; K. Takiguchi-Hayashi et al., 2004). Es schien daher interessant, die Ausbildung von Cajal-Retzius-Zellen im Hop-defizienten Gehirn zu untersuchen. Die dafür ausgewählten Markergene Reelin und Lhx5 (M. Ogawa et al., 1995; H. Z. Sheng et al., 1997) waren sowohl im Wildtyp als auch im Hop-Knock in der Marginalzone exprimiert. Es lag kein offensichtlicher Unterschied in Quantität und Verteilung der CajalRetzius-Zellen vor (Abb. $13 \mathrm{~K}, \mathrm{~L}$; K', L').

\section{Identifikation LacZ-positiver Zellen im Hop-Knock out-Gehirn}

Im untersuchten Knock out war die kodierende Sequenz von Hop durch die cDNA von $\beta$ Galaktosidase ersetzt worden (C. H. Shin et al., 2002). Unter der Voraussetzung, daß durch die Deletion keine cis-regulatorischen Elemente des Hop-Genlokus betroffen waren, mußten normalerweise Hop-positive Zellen jetzt $\beta$-Galaktosidase-positiv sein. In Abb. 14 ist eine $\beta$ Galaktosidase-Färbung koronaler Hirnschnitte des Genotyps Hop-/- dargestellt. $\beta$ Galaktosidase-positive Zellen liegen in der normalerweise Hop-positiven embryonalen Fimbria und im Neuroepithel des Gyrus dentatus vor. Diese Zellen zeigen das gleiche Migrationsverhalten wie Hopexprimierende Zellen im Wildtyp (Besiedelung des Gyrus dentatus). In der ausgewählten Schnittebene ist Hop auch, wenngleich in geringerem Maße, in der ventrikulären Zone exprimiert. Das Fehlen von $\quad \beta$-Galaktosidase-Färbung in vergleichbaren Bereichen des Hop-Knock outs ist entweder durch die unterschiedliche Sensitivität von RNA-in situ-Hybridisierung und $\beta$-GalaktosidaseFärbung oder die Deletion regulatorischer

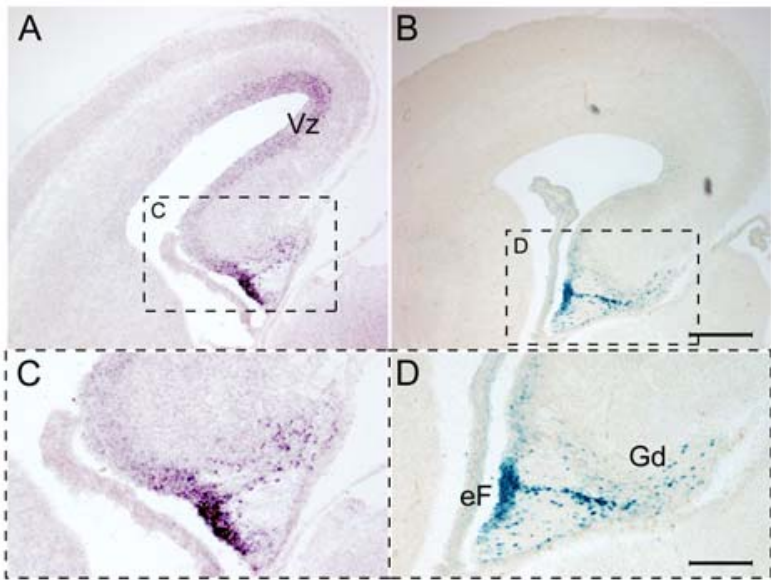

Abb. 14: Hop-Expression im Wildtyp, $\beta$-GalaktosidaseFärbung im Knock out-Gehirn.

A, C: Hop-Expression im Kortex des Wildtyps. B, D: Nachweis $\beta$-Galaktosidase-positiver Zellen im HopKnock out. eF: embryonale Fimbria, Gd: Gyrus dentatus, Vz: Ventrikulärzone; Eichbalken: A, B: 250 $\mu \mathrm{m} ; \mathrm{C}, \mathrm{D}: 125 \mu \mathrm{m}$.

Elemente im Hop-Knock out zu erklären. 


\section{BrdU-Markierung mitotischer Zellen im Vorderhirn von Wildtyp und Hop-Knock out}

Aufgrund der hohen Expression von Hop in der ventrikulären Zone, dem proliferativen Epithel des Kortex, bestand die Möglichkeit, daß Hop an der Regulation des Zellzyklus beteiligt ist und entsprechende Veränderungen im Hop-Knock out vorlagen. Es wurden deshalb Studien zur Inkorporation von BrdU in proliferierende Zellen des Wildtyp- und Hop-defizienten Kortex durchgeführt. Für diese Experimente wurde das Embryonalstadium E16,5 ausgewählt, da hier die stärkste Expression von Hop $\mathrm{zu}$ verzeichnen war. BrdU wurde trächtigen Weibchen intraperitoneal verabreicht. Nach 30 min wurden die Embryonen und deren Gehirne entnommen und genotypisiert. Es wurden Paraffinschnitte angefertigt, BrdU-Immunhistochemie und Kernfärbung mit Propidiumiodid durchgeführt. Die Analyse der BrdU-Inkorporation erfolgte im Wildtyp und Knock out in drei koronalen Schnittebenen: 1. rostral, auf Höhe des Septums (Abb. 15A und $\mathrm{A}^{\prime}$ ); 2. rostral, auf Höhe der Commissura anterior (Abb. 15B und B'); 3. im Mittelteil des Gehirns, Zwischenhirn und Hippocampusformation sind sichtbar (Abb. $15 \mathrm{C}$ und $\mathrm{C}^{\prime}$ ). In einem medial gelegenen Areal, in dem normalerweise hohe Hop-Expression vorliegt, wurde die Anzahl BrdU-positiver Zellen und die Gesamtzellzahl (Propidiumiodid) ermittelt und deren Quotient gebildet (BrdU-Markierungsindex). Entsprechende Ergebnisse sind in Abb. 15 D-F für die jeweiligen Schnittebenen dargestellt (Mittelwertbildung, $n=2$ ). Sowohl im Wildtyp als auch im Knock out schwankten die Werte des BrdU-Markierungsindex um die 25 \%-Marke. Es konnten keine signifikanten Unterschiede in der Proliferationsrate in der Ventrikulärzone beider Genotypen festgestellt werden. 

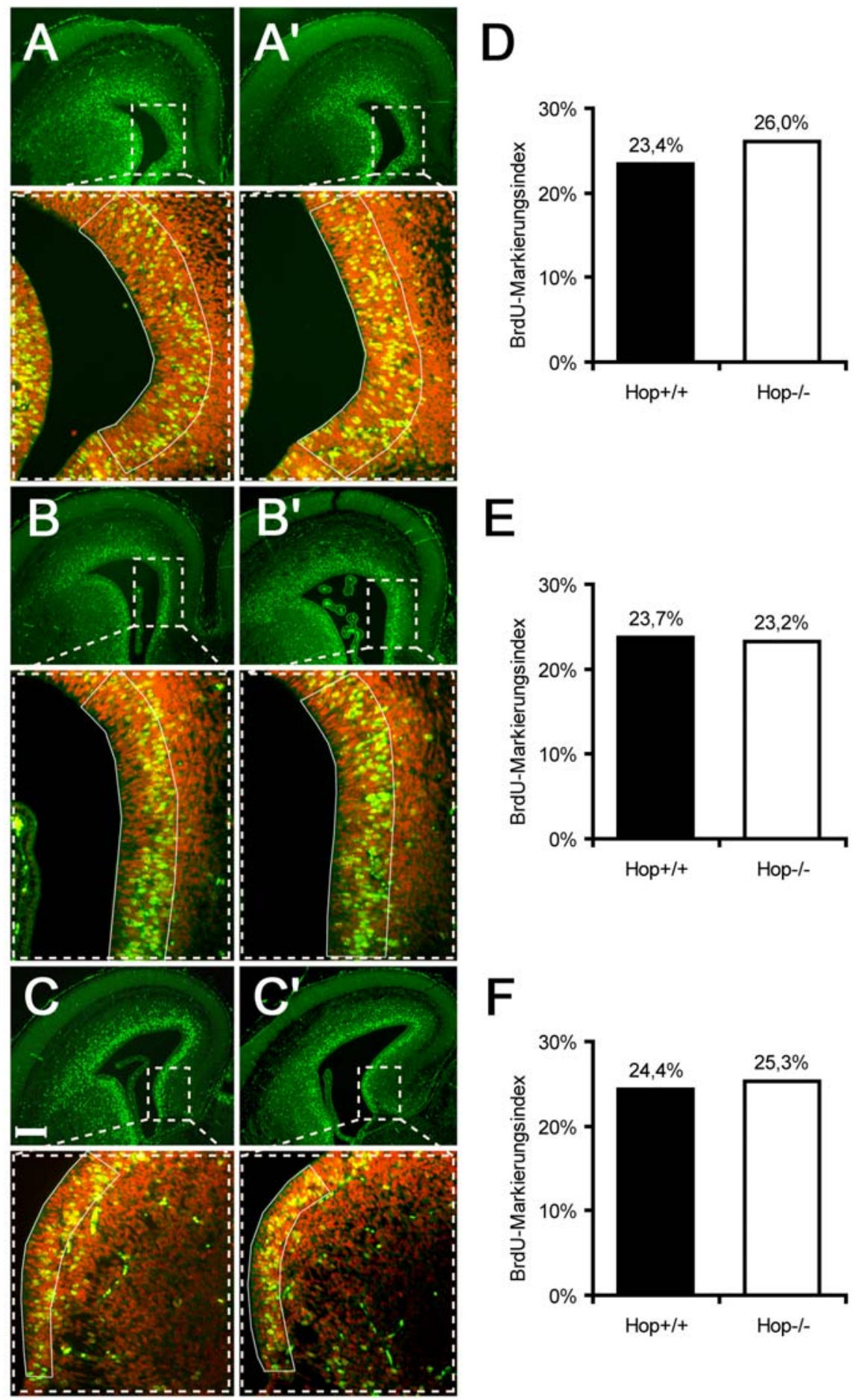

Abb. 15: Vergleich der BrDU-Inkorporation im E16,5-Kortex der Genotypen Hop +/+ und Hop -/-.

A-C, A'-C': Im immunhistochemischen Nachweis von BrdU fluoreszieren BrdU-positive Zellen grün. Dem überlagert wurden in den vergrößerten Ausschnitten alle Zellkerne durch eine rote Propidiumiodid-Färbung sichtbar gemacht. Das durch eine durchgezogene weiße Linie begrenzte Gebiet wurde zur Bestimmung des BrdUMarkierungsindex verwendet. Sowohl im Wildtyp (A, B, C) als auch im Hop-defizienten Kortex (A', B', C') sind BrdU-positive Zellen in der Ventrikulärzone des Kortex nachzuweisen (Eichbalken: $200 \mu \mathrm{m}$ ).

D-F: Der BrdU-Markierungsindex wurde als Quotient der Anzahl BrdU-positiver Zellen und der Gesamtzellzahl berechnet und für beide Genotypen grafisch dargestellt. Die Analyse erfolgte auf drei Ebenen entlang der rostralcaudal-Achse des Gehirns. Die Darstellungen in D, E und F entsprechen den Ebenen A/ A', B/ B' und C/ C'. 


\section{Analyse eines regulatorischen Sequenzelementes "upstream" des Genlokus von Hop}

In F. Chen et al., 2002 wird ein $5 \mathrm{~kb}$ großes DNA-Element "upstream"19 des Translationsstarts (ATG) von Hop beschrieben. Das Sequenzelement reicht aus, um an E10,5 im rechten Ventrikel die Transkription des Reportergens $\beta$-Galaktosidase auszulösen. Aus persönlicher Kommunikation mit Prof. E. N. Olson (University of Texas/ Dallas/ USA) ging hervor, daß der Hop-Promotor keine Aktivität in neuralen Strukturen aufweist (unveröffentlichte Daten). Sequenzelemente, die die Regulation von Hop im Nervensystem steuern, waren demnach nicht bekannt und sollten in der vorliegenden Arbeit aufgefunden und charakterisiert werden.

\section{Identifikation und bioinformatische Analyse des E1-Elementes durch Vergleich genomischer Sequenzen verschiedener Spezies}

Zum Auffinden konservierter DNA-Elemente "upstream" des Genlokus von Hop wurden die genomischen Sequenzen von Maus und Mensch miteinander verglichen. Als Datenquelle diente die kommerzielle Sequenzdatenbank "Celera" (A. Kerlavage et al., 2002), es wurde der Algorithmus BLAST (Basic local alignment search tool; S. F. Altschul et al., 1990) angewandt.

Etwa 7 kb "upstream" des Hop-Genlokus konnte ein konserviertes Sequenzelement von 418 bp Länge (E1-Element) identifiziert werden (Abb. 16A). In Abb. 16B sind die entsprechenden genomischen Sequenzen der Maus und des Menschen gegenübergestellt, der Prozentsatz identischer Basen lag bei 80 \%. Aufgrund des Fehlens eines offenen Leserahmens im E1Element und des hohen Konservierungsgrades zwischen murinem und humanem Genom schien die Annahme gerechtfertigt, daß es sich bei E1 um eine regulatorische Sequenz handelt.

Im E1-Element lagen mehrere konservierte ATTA- bzw. TAAT-Motive vor, welche als Bindestelle der Proteine mit Homeodomäne bekannt sind (W. F. Odenwald et al., 1989). Einige dieser Motive sowie andere Motive konnten mit Hilfe der Datenbank "Transfac" (K. Quandt et al., 1995) konkreten Transkriptionsfaktoren zugeordnet werden (Abb. 16B). Es wurden alle in "Transfac" ermittelten Bindestellen weiter betrachtet, deren Kernsequenz zwischen humanem und murinem Genom konserviert war und deren Ähnlickeit mit der KonsensusBindestellenmatrix $\geq 90 \%$ war. Nach diesen Kriterien wurden in E1 potentielle Bindestellen für folgende Transkriptionsfaktoren identifiziert: Lef1/ TCF-Transkriptionsfaktoren (T. L. Haynes et al., 1996), Activator protein 1, Otx-artiges Homeoboxprotein, Oct6 (X. He et al., 1991), Nkx2.5 und Pit1.

\footnotetext{
${ }^{19}$ upstream, engl.: stromaufwärts, im molekularbiologischen Sinne: in 5'-Richtung eines Genlokus
} 
A

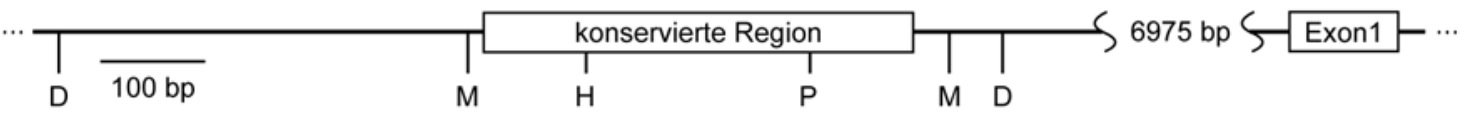

B

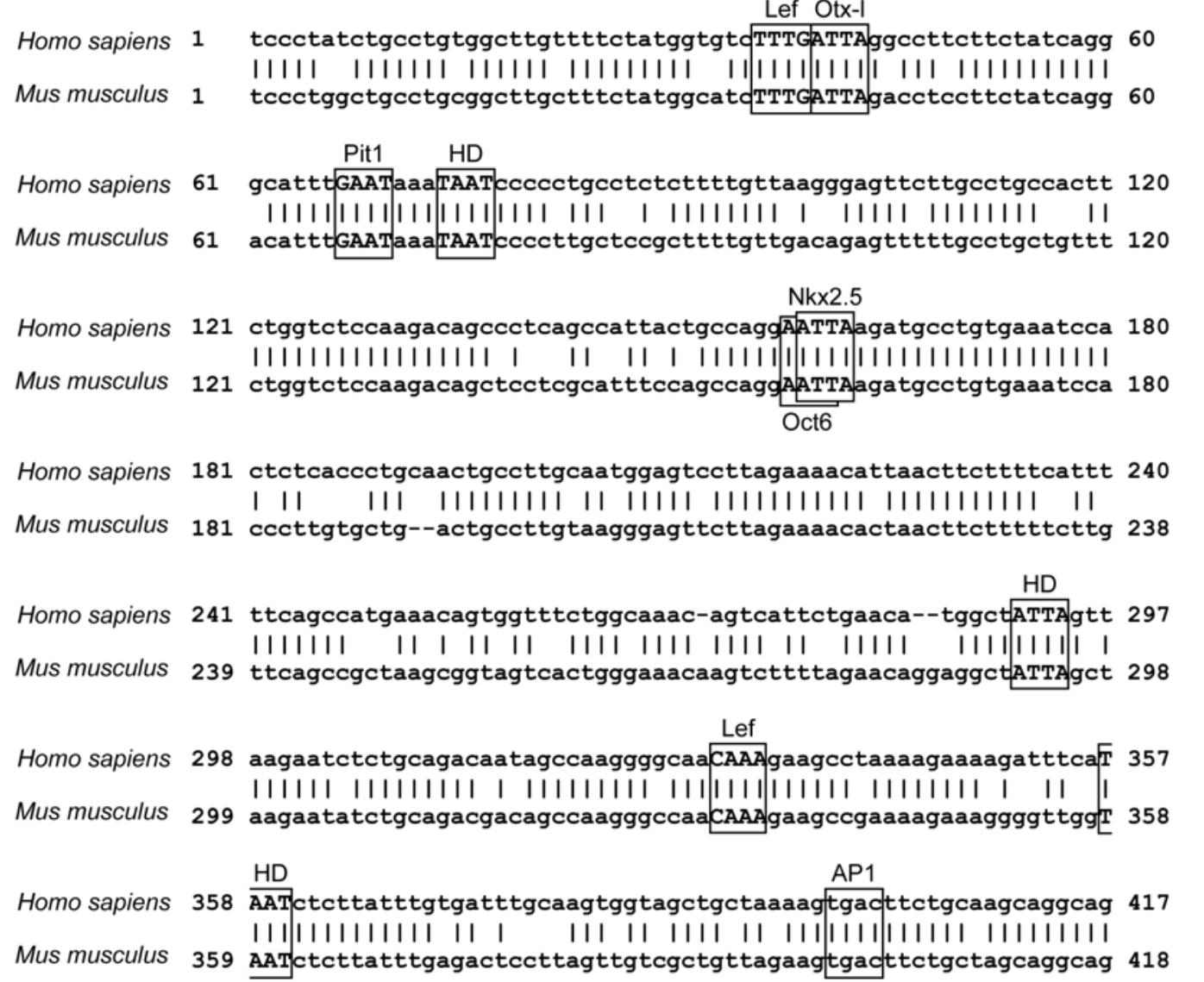

Abb. 16: Die DNA-Sequenz des E1-Elementes.

A: $7 \mathrm{~kb}$ "stromaufwärts" des Genlokus von Hop befindet sich eine DNA-Sequenz von 418 bp Länge mit hohem Konservierungsgrad im murinen und humanen Genom (E1-Element).

B: Im konservierten DNA-Element können potentielle Bindestellen für Transkriptionsfaktoren identifiziert werden. Die Kernsequenzen dieser Bindestellen sind in Großbuchstaben angezeigt (AP1: Activator protein 1, Lef: Lef1/ TCFBindestelle, Otx-1: Bindestelle für Otx-artiges Homeoboxprotein, HD: Bindestelle für Homeodomäne-Proteine, Oct6: Oct6-Bindestelle, Nkx2.5: Nkx2.5-Bindestelle, Pit1: Pituitary specific pou domain transcription factor). D: DraIII, H: HincII, M: MboI, P: PstI. 


\section{Nachweis regionaler Reporteraktivität unter Kontrolle des E1-Elementes in vivo}

Nach dem E1-Element wurde keine TATA-Box gefunden. Es konnte sich demnach nicht um eine Promotorregion, jedoch um ein Enhancerelement handeln. Zum Nachweis eventueller Enhanceraktivität von E1 wurden durch Mikroinjektion in Zygoten Mauslinien hergestellt, die transgen für das Konstrukt $p E 1$ waren. Dabei enthielt $p E 1$ das E1-Element (418 bp) mit zusätzlichen 223 bp flankierender Sequenz am 5'-Ende und 65 bp am 3'-Ende. In $p E 1$ lagen ferner vor: der $\beta$-Globin-Minimalpromotor, die kodierende Sequenz des $\beta$-Galaktosidase-Gens und ein SV40-Polyadenylierungssignal (Abb. 21) Wenn das E1-Element nach Art eines Enhancers agiert, sollten $p E 1$-transgene Mäuse regionale Reporteraktivität aufweisen.

Es konnten vier transgene Mauslinien etabliert werden (E1-1, E1-2, E1-3, E1-4). Ein fünftes transgenes Tier hatte keine Nachkommen (E1-5). Zum Nachweis von Reporteraktivität in diesen Mauslinien wurde $\beta$-Galaktosidase-Immunhistochemie an Gefrierschnitten oder ganzen Embryonen verschiedener Embryonalstadien durchgeführt. In Tab. 1 sind die Ergebnisse dieser Analyse zusammengefaßt.

\section{Mauslinie E1-1}

In der transgenen Mauslinie E1-1 konnte durch $\beta$-Galaktosidase-Färbung Reporteraktivität festgestellt werden. Diese Reporteraktivität überlappte an E12,5 mit Hop-exprimierenden Regionen im Vorder- und Hinterhirn sowie in der Flügelplatte des Rückenmarks (Abb. 17A-D, A'-D'). Andere Hop-positive Domänen, wie die Grundplatte des Rückenmarks und das Herz, waren frei von Reporteraktivität (Abb. 17D, D', E, E'). An E12,5 wurde ektopische Reporteraktivität in Teilen der Epidermis festgestellt (Pfeilkopf in Abb. 16A').

Im E16,5-Gehirn lag $\beta$-Galaktosidase-Färbung in der Ventrikulärzone des medialen Kortex und Bulbus olfactorius, in der embryonalen Fimbria und in migrierenden Zellen des Gyrus dentatus vor (Abb. 17F-I, F'-I'). Alle diese Regionen zeigen Hop-Expression. Andererseits konnte in Zellen der lateralen und caudalen ventrikulären Zone, die geringe Hop-Expression aufweisen, keine Reporteraktivität detektiert werden (Pfeilkopf in Abb. 17G, G').

\section{$\underline{\text { Mauslinie E1-2 }}$}

In dieser Mauslinie wurde das Reporteraktivitätsmuster im E12,5-Embryo analysiert. Reporteraktivität lag in Hop-exprimierenden Strukturen des Nervensystems vor: Nucleus vestibularis, medialer Kortex, Grund- und Flügelplatte des Rückenmarks (Abb. 18A-D). Das Rückenmark zeigte eine für Hop charakteristische Expressionslücke (Abb. 18 D). Im Herzen lag keine Reporteraktivität vor (Abb. 18A). Ektopische $\beta$-Galaktosidase-Färbung war in den Rippen, im ventralen Dienzephalon, im Tegmentum und Prätektum zu verzeichnen (Abb. 18 A). 
A

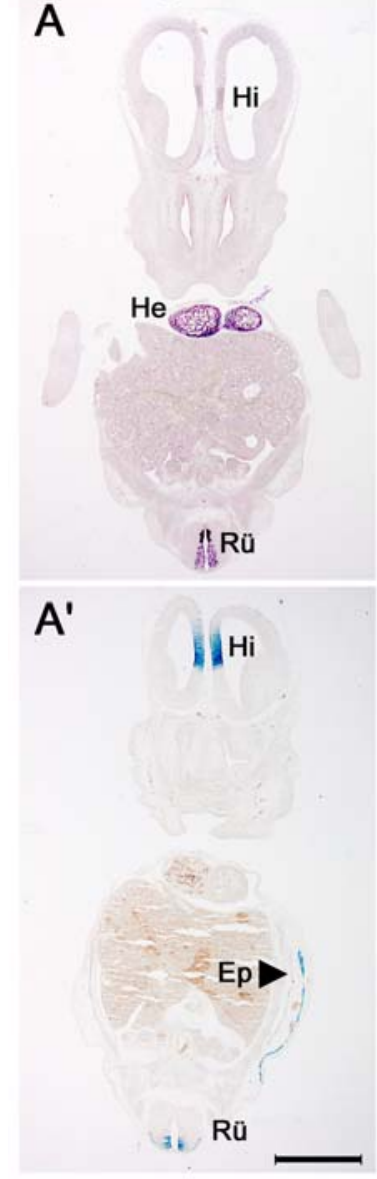

B
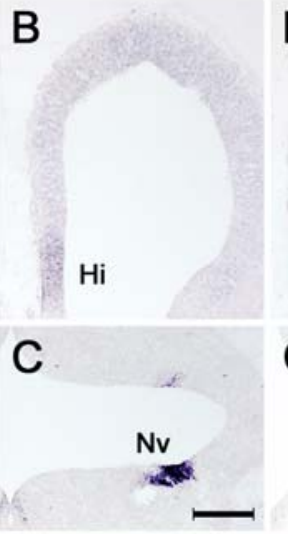

D.
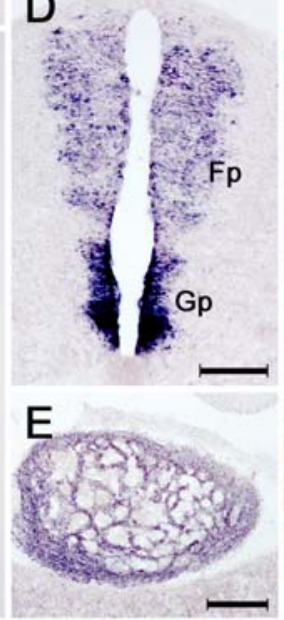
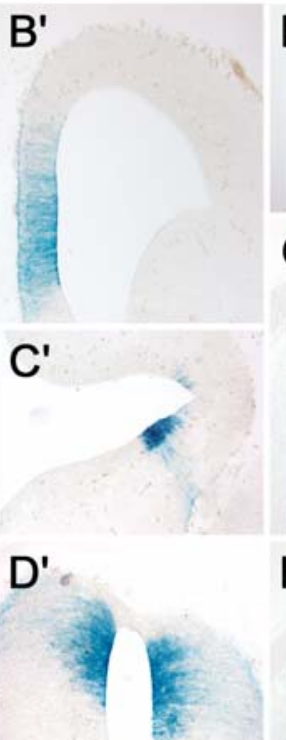

$E^{\prime}$
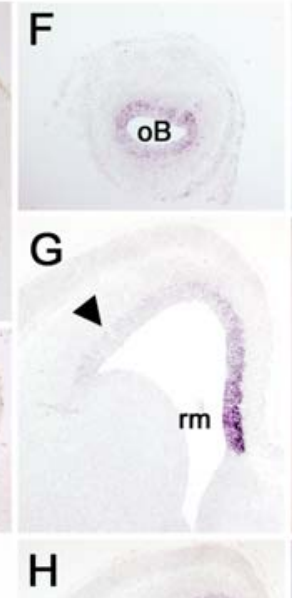

$F^{\prime}$

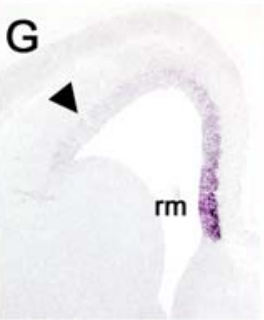

$\mathrm{H}$

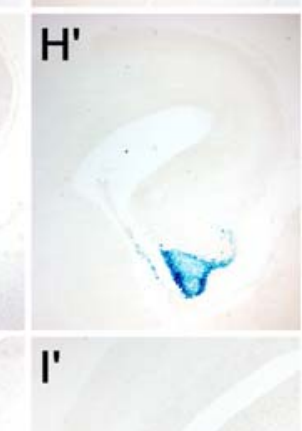

Gd

Abb. 17: Enhancerabhängige Reporteraktivität in E1-transgenen Mäusen (Mauslinie E1-1).

A-I: RNA-in situ-Hybridisierung mit einer Hop-RNA-Sonde. A'-I': Enzymhistochemischer Nachweis von $\beta$-Galaktosidase-Reporteraktivität in E1-transgenen Mäusen.

A-E, A'-E': Im E12,5-Embryo ist enhancerbedingte Reporteraktivität im rostromedialen Kortex (A', $\left.\mathrm{B}^{\prime}\right)$ und dorsalen Rückenmark (A', D') zu verzeichnen. Das ventrale Rückenmark (A', D') sowie das Herz (A', E') zeigen keine Reporteraktivität, während in diesen Regionen Hop-mRNA detektierbar ist (A, D, E). Übereinstimmende endogene Hop-Expression (C) und enhancerabhängige Reporteraktivität $\left(\mathrm{C}^{\prime}\right)$ liegen im Nucleus vestibularis vor. Ektopische Reporteraktivität ist in der normalerweise Hop-negativen Epidermis zu verzeichnen (Pfeilkopf in A').

F-I, F'-I': An E16,5 überlappen Hop-Expression und Reporteraktivität in der Ventrikulärzone des Riechkolbens (F, $\left.\mathrm{F}^{\prime}\right)$ und des medialen Kortex $\left(\mathrm{G}, \mathrm{G}^{\prime}\right)$ sowie in der embryonalen Fimbria $\left(\mathrm{H}, \mathrm{H}^{\prime}\right)$. Ferner zeigen Zellen, die in den Gyrus dentatus einwandern, Hop-Expression und Reporteraktivität (H, H', I und I'). Die schwach Hop-positive Ventrikulärzone des lateralen Kortex zeigt keine Reporteraktivität (Pfeilköpfe in G und G'). eF, embryonale Fimbria; Ep, Epiderms; Fp, Flügelplatte; Gd, Gyrus dentatus; Gp, Grundplatte; He, Herz; Hi, Hippocampus; Nv, Nucleus vestibularis; oB, Bulbus olfactorius; rm, rostromedialer Kortex. Eichbalken: A, A': 1 mm; B-C, B'-C': 200 $\mu$ m; D, D': $200 \mu \mathrm{m} ; \mathrm{E}: 100 \mu \mathrm{m} ; \mathrm{F}-\mathrm{I}, \mathrm{F}^{\prime}-\mathrm{I}^{\prime}: 500 \mu \mathrm{m}$. 
Im E16,5-Gehirn lag $\beta$-Galaktosidase-Färbung in der Ventrikulärzone des rostromedialen Kortex und Bulbus olfactorius, in der embryonalen Fimbria und in migrierenden Zellen des Gyrus dentatus vor (Abb. 18E-G).
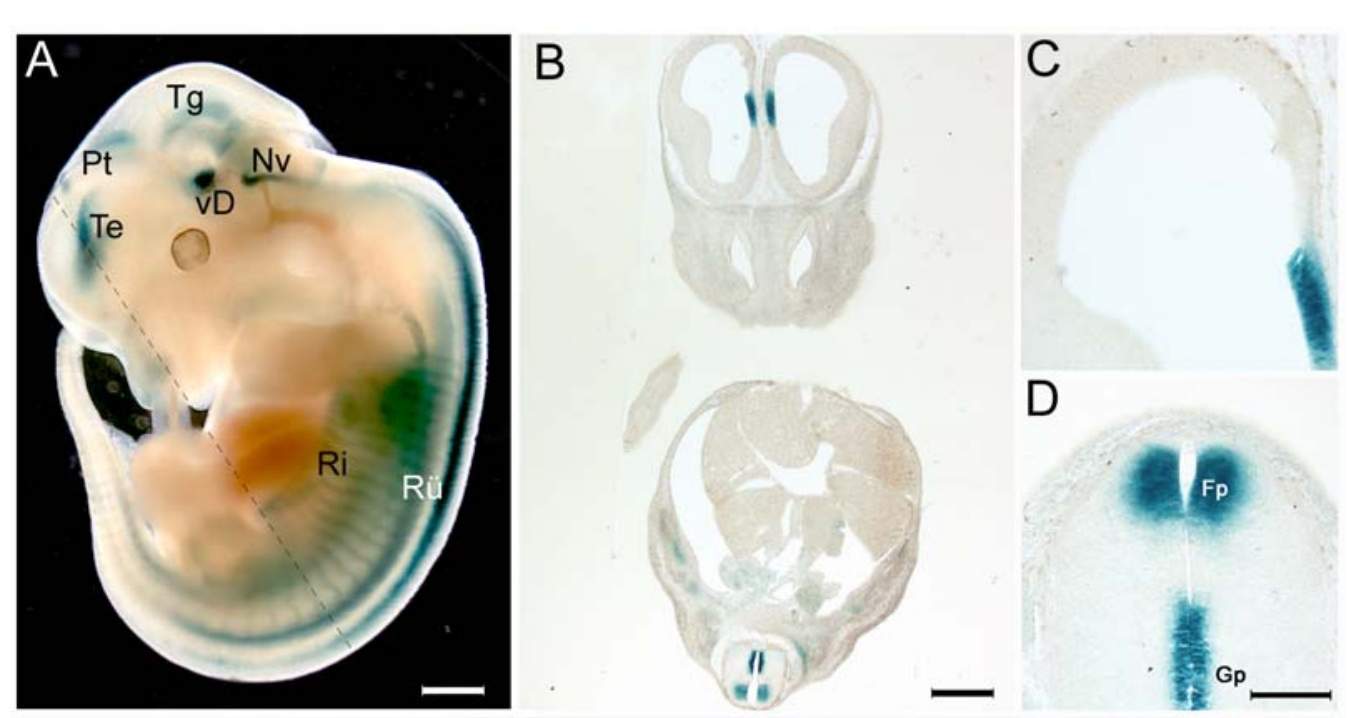

$E$
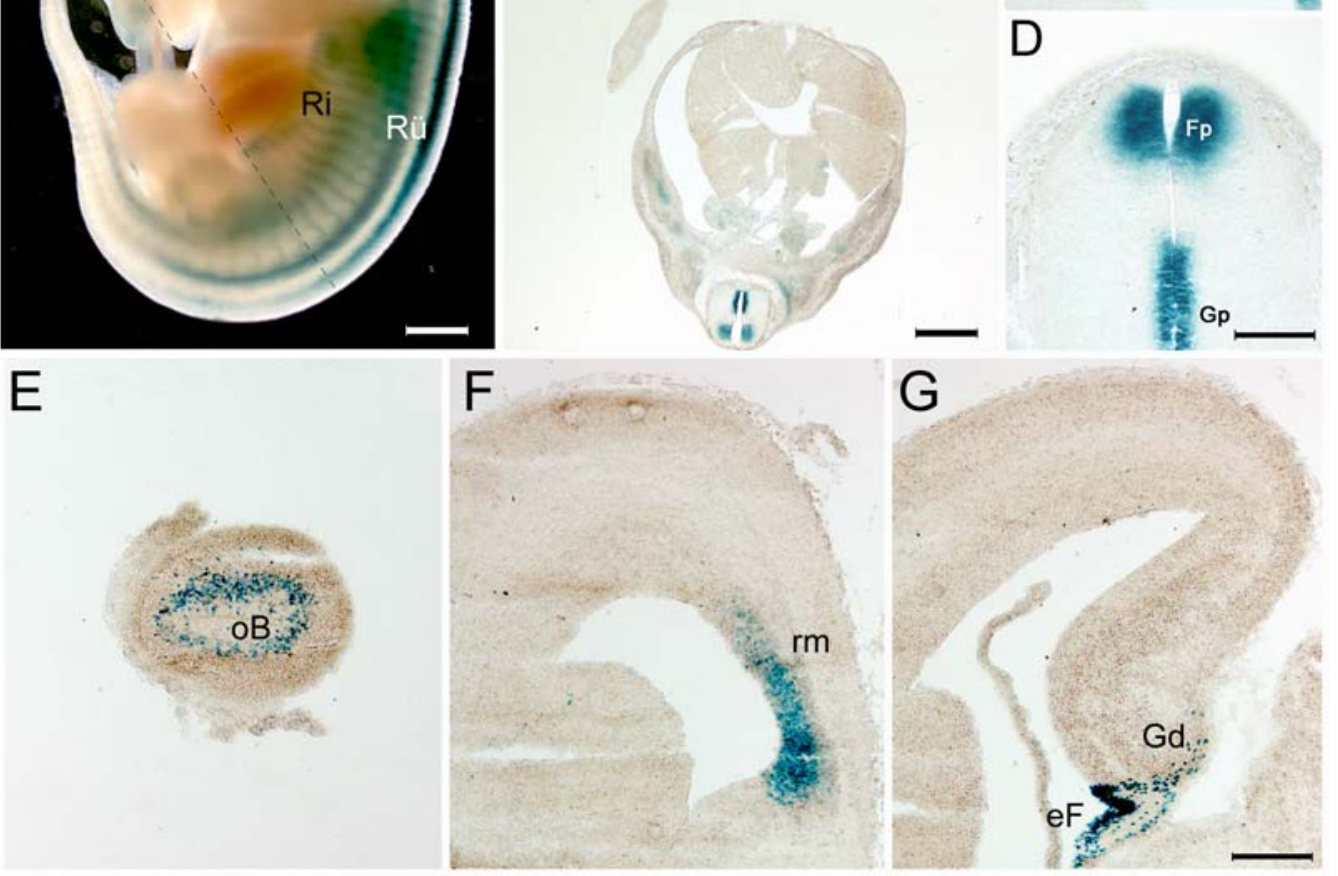

Abb. 18: Enhancerabhängige Reporteraktivität in E1-transgenen Mäusen (Mauslinie E1-2).

A: Enzymhistochemischer Nachweis von $\beta$-Galaktosidase-Reporteraktivität in ganzen Embryonen $(E 12,5)$. Starke Reporteraktivität lag in folgenden Strukturen vor: Telenzephalon (Te), Anlage des Nucleus vestibularis (Nv), ventrales Dienzephalon (vD) und Rückenmark (Rü). Schwache Reporteraktivität war zudem im Prätektum (pt), Tegmentum (Tg) und den Rippen (Ri) zu verzeichnen. Das Herz (He, halb verdeckt durch Vordergliedmaße) war frei von Reporteraktivität (Eichbalken: $400 \mu \mathrm{m}$ ). B: Schnitt entlang der unterbrochenen Linie in A mit $\beta$-GalaktosidaseFärbung im medialen Telenzephalon und Rückenmark (Eichbalken: $500 \mu \mathrm{m}$ ). C: Reporteraktivität im E12,5Telenzephalon war auf die Anlage des Hippocampus beschränkt. D: Im Rückenmark war an E12,5 Reporteraktivität in der Flügelplatte (Fp) und Grundplatte (Gp) zu verzeichnen (Eichbalken in C-G: $200 \mu \mathrm{m}$ ).

E-F: Im E16,5-Gehirn war Reporteraktivität im Bulbus olfactorius (oB, E), in der Ventrikulärzone des rostromedialen Kortex (rm in F), in der embryonalen Fimbria (eF in G) und im Gyrus dentatus zu verzeichnen (Gd in G).

Die deutliche Überlappung von E1-Enhanceraktivität und Hop-Expression in Strukturen des Vorder- und Hinterhirns sowie des Rückenmarks und die Lage des E1-Elementes in unmittelbarer Nähe zum Genlokus des Hop-Gens wurden als Indizien dafür angesehen, daß es sich beim E1-Element um die regulatorische Sequenz handelt, welche die Hop-Expression im ZNS bewirkt. 


\section{Mauslinien E1-3, E1-4 und E1-5}

In Tieren der Mauslinie E1-3 und E1-4 konnte weder an E12,5 im ganzen Embryo, noch an E16,5 im Gehirn Reporteraktivität festgestellt werden (nicht gezeigt). Das einzige transgene Tier der Mauslinie E1-5 hatte keine Nachkommen, konnte also nicht zur Analyse von Embryonen verwendet werden.

Tab. 1: Übersicht über Reporteraktivität in E1-transgenen Mäusen.

Aufgeführt sind die wichtigsten Hop-exprimierenden Strukturen des E12,5-Embryos oder E16,5-Gehirns. Reporteraktivität ist durch ein "+"-Zeichen, fehlende Reporteraktivität durch ein "-"-Zeichen angezeigt (VZ: ventrikuläre Zone, n.a.: nicht analysiert).

\begin{tabular}{|c|c|c|c|c|c|c|c|c|c|c|c|}
\hline \multirow{3}{*}{ Linie } & \multicolumn{6}{|c|}{ E12,5 } & \multicolumn{5}{|c|}{ E16,5 } \\
\hline & \multirow[b]{2}{*}{$\begin{array}{c}\text { Vorder- } \\
\text { hirn }\end{array}$} & \multirow[b]{2}{*}{$\begin{array}{l}\text { Hinter- } \\
\text { hirn }\end{array}$} & \multicolumn{2}{|c|}{ Rückenmark } & \multirow[b]{2}{*}{ Herz } & \multirow[b]{2}{*}{ ektopisch } & \multicolumn{5}{|c|}{ Kortex } \\
\hline & & & $\begin{array}{l}\text { Flügel- } \\
\text { platte }\end{array}$ & $\begin{array}{l}\text { Grund- } \\
\text { platte }\end{array}$ & & & $\begin{array}{l}\text { Bulbus } \\
\text { olfact. }\end{array}$ & $\begin{array}{c}\text { mediale } \\
\mathrm{VZ}\end{array}$ & $\begin{array}{c}\text { laterale } \\
\text { VZ }\end{array}$ & $\begin{array}{l}\text { embr. } \\
\text { Fimbria }\end{array}$ & $\begin{array}{c}\text { Gyrus } \\
\text { dentatus }\end{array}$ \\
\hline E1-1 & + & + & + & - & - & subkutan & + & + & - & + & + \\
\hline E1-2 & + & + & + & + & - & $\begin{array}{l}\text { Rippen, } \\
\text { Mittelhirn }\end{array}$ & + & + & - & + & + \\
\hline E1-3 & - & - & - & - & - & - & - & - & - & - & - \\
\hline E1-4 & - & - & - & - & - & - & - & - & - & - & - \\
\hline E1-5 & n.a. & n.a. & n.a. & n.a. & n.a. & n.a. & n.a. & n.a. & n.a. & n.a. & n.a. \\
\hline
\end{tabular}

\section{Induktion von E1-bedingter Reporteraktivität durch Transplantation der Deckplatte in vitro}

Die Deckplatte und die embryonale Fimbria gelten als entscheidende Signalzentren für die Ausbildung medialer Kortexstrukturen (E. A. Grove et al., 1998; E. A. Grove und S. Tole, 1999). Im E1-transgenen Vorderhirn war starke Enhanceraktivität im gesamten medialen Kortex $\mathrm{zu}$ verzeichnen (Abb. 17). Es lag daher nahe, eine Abhängigkeit des E1-Enhancers von medialen Signalzentren zu vermuten.

Um eine solche Abhängigkeit zu untersuchen, wurden organotypische Kokulturen von embryonalen Gehirnen E1-transgener Tiere (Linie E1-1) und Deckplatten früher Wildtypembryonen durchgeführt. Dabei wurden die Deckplatten (E10,5) des Wildtyps mit Karminrot angefärbt und in die Region des ventralen Palliums transplantiert. Als "Donor"-Gewebe wurde Gewebe des Embryonalstadiums 10,5 ausgewählt, weil dies das früheste Stadium war, an dem eine sichere Präparation der Deckplatte möglich schien. Andererseits war davon auszugehen, daß die Deckplatte an E10,5 eine starke Quelle von Signalmolekülen darstellt. Das transgene "Akzeptor"-Gewebe entstammte den Embryonalstadien E11,5; E12,5; E13,5 oder E14,5. Die Kokulturen wurden nach $48 \mathrm{~h}$ fixiert und $\beta$-Galaktosidase-Färbung durchgeführt. In fast allen 
Kokulturen mit "Akzeptor"-Gewebe des Stadiums E11,5 konnte ektopische Enhanceraktivität induziert werden (Tab. 2). Auch an E12,5 konnten $\beta$-Galaktosidase-positive Zellen im ventralen Pallium induziert werden. Transgene Gehirne der Stadien E13,5 und E14,5 zeigten keine Kompetenz gegenüber Signalen der Deckplatte (Tab. 2). Als Kontrolle wurden Kokulturexperimente mit Gewebe der ganglionären Eminenzen des Wildtyps (E10,5) und transgenen E11,5-Gehirnen durchgeführt, wobei keine ektopische Enhanceraktivität zu beobachten war. Repräsentative Ergebnisse sind in Abb. 19 dargestellt.

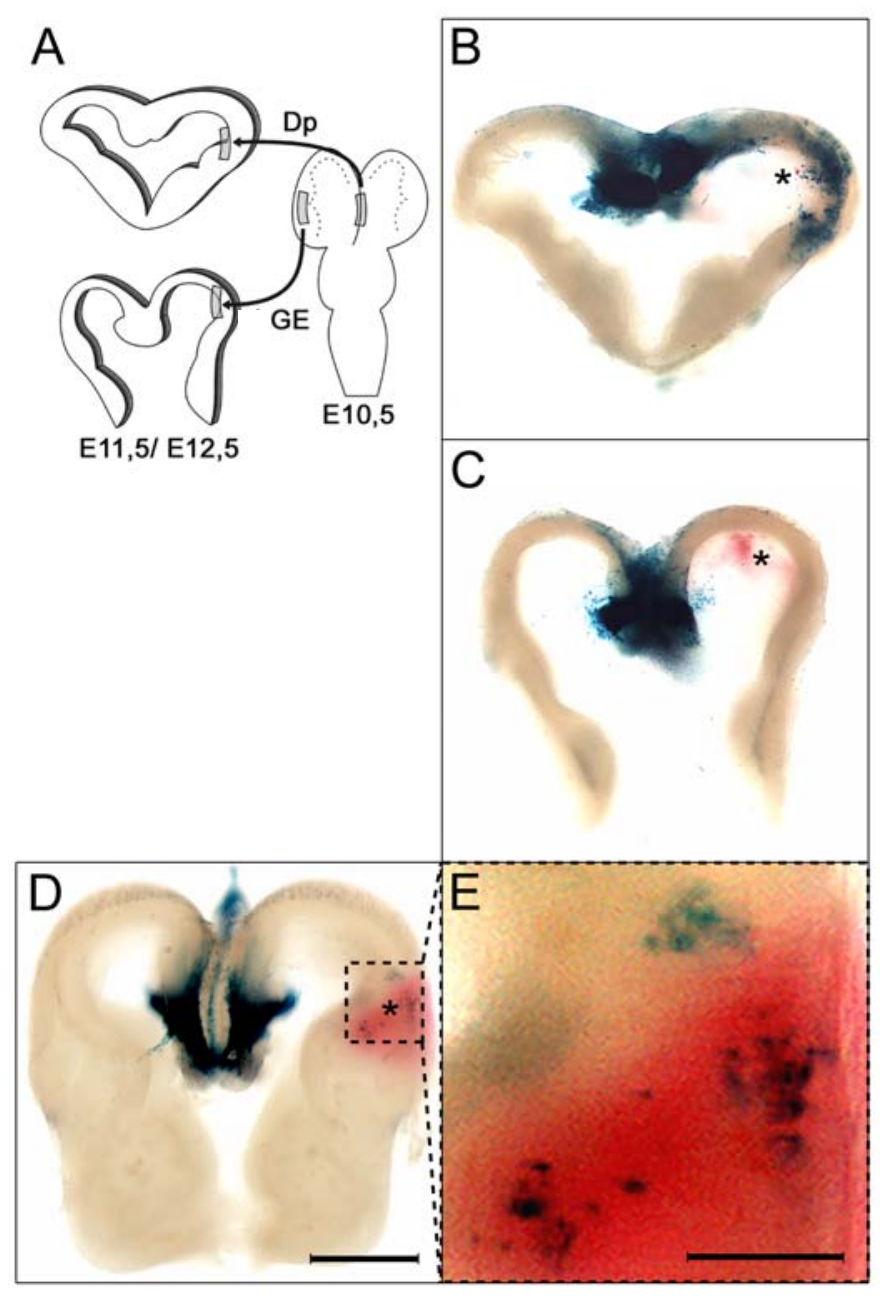

Abb. 19: Induktion ektopischer Enhanceraktivität in vitro.

A: Schematische Darstellung der Transplantationsexperimente. Explantate aus der dorsalen Mittellinie der Vorderhirnanlage (Dp, Deckplatte) bzw. der ganglionären Eminenzen (GE) von E10,5-Embryonen wurden in Kontakt mit koronalen Hirnschnitten E1-transgener Mäuse gebracht und $48 \mathrm{~h}$ organotypisch kultiviert.

B, C: In transgenen Hirnschnitten (E11,5 +48 h) konnte durch $\beta$-Galaktosidase-Färbung endogene Enhanceraktivität im medialen Kortex nachgewiesen werden. Im Gegensatz zu GE-Explantaten (*, C) induzieren Explantate der Deckplatte $(*$, B) zusätzliche Enhanceraktivität im lateralen und ventralen Pallium. D, E: Auch in transgenen Hirnschnitten des Stadiums E12,5 war nach zweitägiger Kokultur mit Deckplattenexplantaten (*, D; rot gefärbt) ektopische Enhanceraktivität im ventralen Pallium nachzuweisen. Eichbalken: B-D: $500 \mu \mathrm{m}, \mathrm{E}: 125 \mu \mathrm{m}$. 
Tab. 2: Übersicht über Kokulturexperimente mit Transplantation der Deckplatte.

Verschiedene Kombinationen aus "Donor"- und "Akzeptor"-Gewebe wurden kultiviert. Deckplattenexplantate induzierten nur an E11,5 und E12,5 Enhanceraktivität im ventralen Pallium transgener Gehirne (GE, ganglionäre Eminenzen; $\mathrm{n}_{\text {pos. }} / \mathrm{n}_{\text {ges. }}$, Anzahl an Experimenten mit ektopischer Reporteraktivität/ Gesamtanzahl der Experimente).

\begin{tabular}{ccccc}
\hline \multicolumn{2}{c}{ "Donor" (Wildtyp) } & \multicolumn{2}{c}{ "Akzeptor" (Linie E1-1) } & \multicolumn{2}{c}{ ektopische Reporteraktivität } \\
\cline { 1 - 2 } \cline { 5 - 5 } Embryonalstadium & Gewebe & Embryonalstadium & $\mathrm{n}_{\text {pos. } / \mathrm{n}_{\text {ges. }}}$ & Intensität \\
\hline E10,5 & Deckplatte & E11,5 & $6 / 9$ & hoch \\
E10,5 & Deckplatte & E12,5 & $4 / 5$ & gering \\
E10,5 & Deckplatte & E13,5 & $0 / 4$ & - \\
E10,5 & Deckplatte & E14,5 & $0 / 5$ & - \\
E10,5 & GE & E11,5 & $0 / 4$ & - \\
\hline
\end{tabular}

Mit den geschilderten Transplantationsexperimenten konnte gezeigt werden, daß Signale aus der dorsalen Mitellinie (Deckplatte) E1-Aktivität induzieren können. Die Kompetenz des E1transgenen Gewebes, auf diese Signale zu reagieren, bestand in den Embryonalstadien E11,5 und E12,5 - nicht zu späteren Zeitpunkten. Die E1-induzierenden Faktoren müssen diffusibel sein, nur so läßt sich die Wirkung des Donorgewebes (Wildtyp) auf das Akzeptorgewebe (E1transgen) erklären. 


\section{Etablierung einer in vitro-Methode zur Plasmidexpression in organotypischer Kultur des embryonalen Gehirns}

Das durch Sequenzvergleich aufgefundene und für die Herstellung transgener Mäuse verwendete DNA-Element enthielt mit 706 bp bereits eine überschaubare Sequenzinformation. Außerdem konnte davon ausgegangen werden, daß die eigentliche Enhanceraktivität im konservierten Abschnitt (E1-Element) von 418 bp lag. Um dennoch die Bedeutung einzelner Sequenzmotive im E1-Element herauszustellen, wurde eine neue Methode etabliert, die das Prinzip der Transfektion durch Elektroporation (R. Tur-Kaspa et al., 1986; T. Y. Tsong, 1991) mit dem Prinzip der organotypischen Kultur verband. Durch diese unkonventionelle Vorgehensweise sollte die Analyse mehrerer Deletionskonstrukte in kurzer Zeit ermöglicht werden.

Es erwies sich als geeignet, die zu transfizierende DNA direkt in das laterale Ventrikel isolierter E14,5-Gehirne zu injizieren, die Gehirne durch seitlich anliegende Elektroden zu elektroporieren und direkt im Anschluß in organotypische Kultur zu nehmen. Dafür wurden von den Gehirnen am Vibratom 300 - $400 \mu \mathrm{m}$ dicke koronale Schnitte angefertigt (Abb. 20A). Bei einem Elektrodenabstand von $8 \mathrm{~mm}$ wurden mit einer Spannung von $70 \mathrm{~V}$ beste Ergebnisse erzielt, d. h. hohe Transfektionseffizienz ohne Schäden am Gewebe. Weitere Parameter der Elektroporation waren: Anzahl der Pulse: 5, Pulsdauer: $50 \mathrm{~ms}$, Pause: 1 s. In den Elektroporationsexperimenten wurden verschiedene Deletionskonstrukte des E1-Elementes im 1:1-Gemisch mit dem Plasmid $C M V$-EGFP eingesetzt. $C M V$-EGFP führte zu ubiquitärer Expression eines grün fluoreszierenden Proteins und diente zur Markierung aller transfizierten Zellen. Es wurden jeweils die Zellen transfiziert, die im Gewebe zwischen injiziertem Ventrikel und Anode lagen. Auf diese Weise konnte durch die Auswahl der Injektionsseite und die Orientierung des Gehirns im elektrischen Feld eine gerichtete Transfektion erreicht werden. Zum Beispiel wurde im Experiment in Abb. 20B-E Plasmidlösung in das rechte Ventrikel injiziert und die Anode an der linken Hemisphäre angelegt. EGFP-positive Zellen im Dienzephalon (Abb. 20E) resultierten in dieser Versuchsanordnung aus einem Übertritt der Plasmidlösung aus dem lateralen Ventrikel über das Foramen interventriculare in das dritte Ventrikel. EGFP-positiv waren stets nur Zellen der ventrikulären Zone, da sie in unmittelbarem Kontakt mit der Plasmid-Lösung standen. 
A
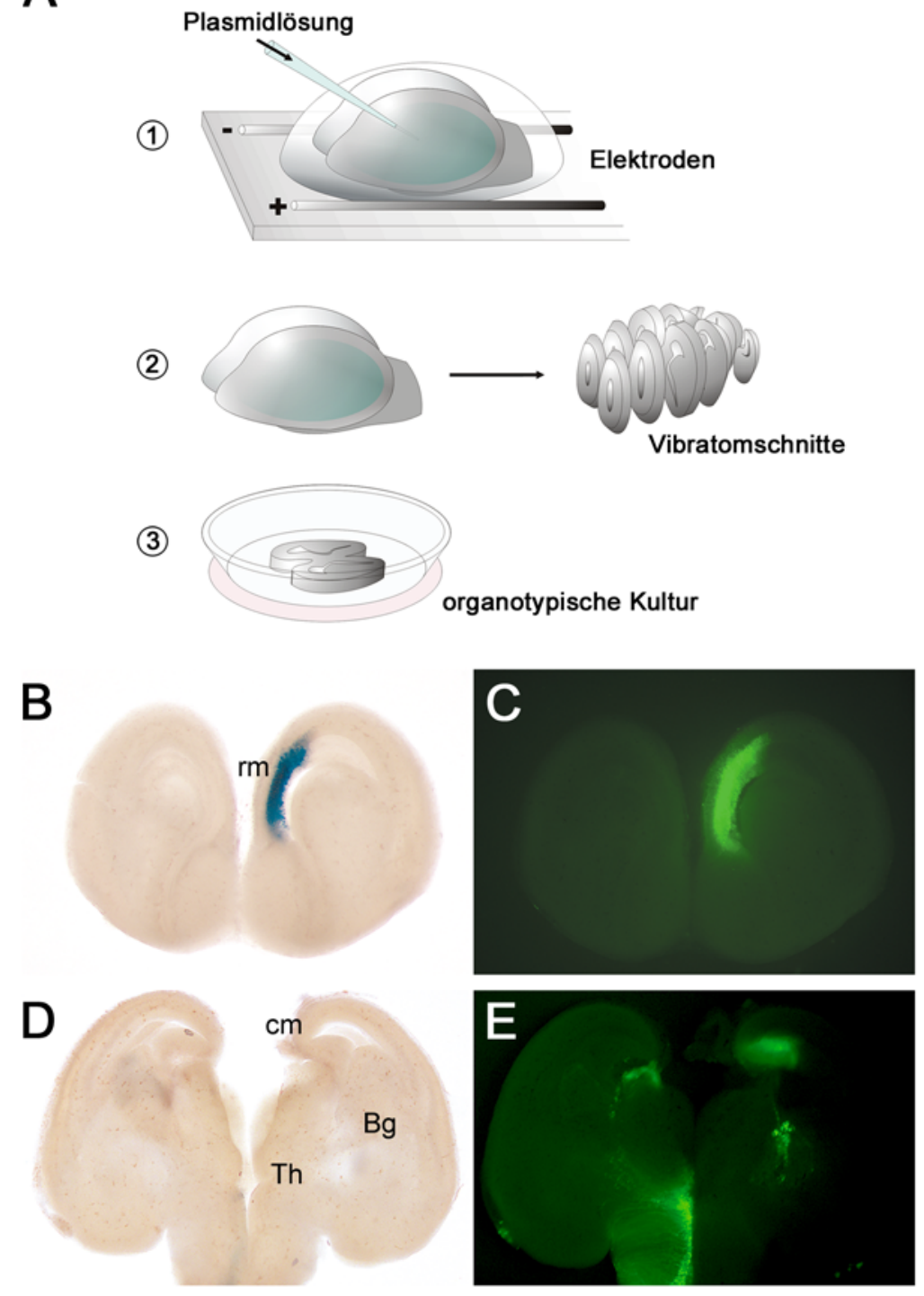

Abb. 20: Expression des Plasmides pE1 in vitro.

A: Die Expression eines Plasmides wird durch DNA-Injektion in das laterale Ventrikel eines isolierten Gehirnes und anschließende Elektroporation erreicht. Das manipulierte Gehirn kann in organotypischer Kultur mehrere Tage überleben und sich weiter entwickeln.

B-E: In einem E14,5-Gehirn wurden die Konstrukte $p E 1$ und $C M V$-EGFP koelektroporiert. Alle elektroporierten Zellen bilden das grün fluoreszierende Protein EGFP unter Kontrolle des CMV-Promotors. Durch die Elektroporation wurden Zellen im rostromedialen Kortex (C) sowie im caudomedialen Kortex, der medialen ganglionären Eminenz und der ventrikulären Zone des Thalamus und Hypothalamus (E) erreicht. Im Gegensatz dazu bewirkt das EnhancerElement E1 LacZ-Reporteraktivität nur im rostromedialen Kortex (B), nicht im caudomedialen Kortex oder anderen Hirnregionen (D). Bg: Basalganglien, cm: caudomedialer Kortex, rm: rostromedialer Kortex, Th: Thalamus. 


\section{Reproduktion der E1-Enhanceraktivität in organotypischer Kultur}

Im Rahmen der vorliegenden Arbeit wurde überprüft, inwieweit sich durch Elektroporation und organotypische Kultur die Reporteraktivität im Gehirn E1-transgener Mauslinien in vitro reproduzieren läßt. Dazu wurden die Konstrukte $p E 1$ und $C M V$-EGFP in E14,5-Gehirne des Wildtyps koelektroporiert, die kultivierten Hirnschnitte nach $24 \mathrm{~h}$ fixiert und $\beta$-GalaktosidaseFärbung durchgeführt. Wie erwähnt, wies in E1-transgenen Mäusen der rostromediale Kortex Enhanceraktivität auf, während caudomedial bis auf den Bereich der embryonalen Fimbria geringe oder keine Reporteraktivität zu verzeichnen war. Durch die Elektroporation wurden Bereiche im rostromedialen und caudomedialen Kortex erreicht (Abb. 20C), darüberhinaus einige Zellen in den Basalganglien und der Ventrikulärzone des dritten Ventrikels (Abb. 20E). $\beta$-Galaktosidase-Aktivität bestand nur im rostromedialen Kortex (Abb. 20B), nicht in den anderen elektroporierten Regionen (Abb. 20D). Es konnte somit gezeigt werden, daß nur Hirnregionen, in denen in vivo Enhanceraktivität bestand, auch in vitro enhancerbedingte Reporteraktivität aufwiesen. Der Schritt vom in vivo-System zum in vitro-System schien demnach gerechtfertigt.

\section{Kartierung der Aktivität des E1-Elementes in vitro}

Zur Kartierung der Aktivität des E1-Elementes im Kortex wurden verschiedene Deletionskonstrukte in die rostromediale Ventrikulärzone von E14,5-Gehirnen elektroporiert und das Gewebe einen Tag kultiviert. E14,5 (+ 1 Tag) wurde als Embryonalstadium gewählt, da es leicht handhabbar war und Enhanceraktivität sowie Hop-Expression in diesem Zeitraum $(\mathrm{E} 14,5$ - E16,5) in vivo eine starke Intensität erreichten. Die Deletionskonstrukte enthielten Teilbereiche des E1-Elementes oder das gesamte konservierte E1-Element mit Punktmutationen in potentiellen Bindestellen von Transkriptionsfaktoren (Abb. 21). Alle Deletionskonstrukte enthielten den $\beta$-Globin-Minimalpromotor und die kodierende Sequenz des $\beta$-GalaktosidaseGens. Nach 24-stündiger Kultur konnte $\beta$-Galaktosidase-Färbung anzeigen, ob im jeweiligen Konstrukt die für die Funktion von E1 wichtigen Sequenzelemente vorhanden waren. Die unter gleichen experimentellen Bedingungen (d. h. DNA-Konzentration: 500 ng/ $\mu \mathrm{l}$, Injektionsvolumen: $4 \mu 1$ und Dauer der $\beta$-Galaktosidase-Färbung: 5 h) erzielte Reporteraktivität wurde in semiquantitativer Weise kategorisiert (siehe auch Abb. 21). Jedes Konstrukt wurde mindestens viermal elektroporiert; dargestellt sind repräsentative Ergebnisse. 


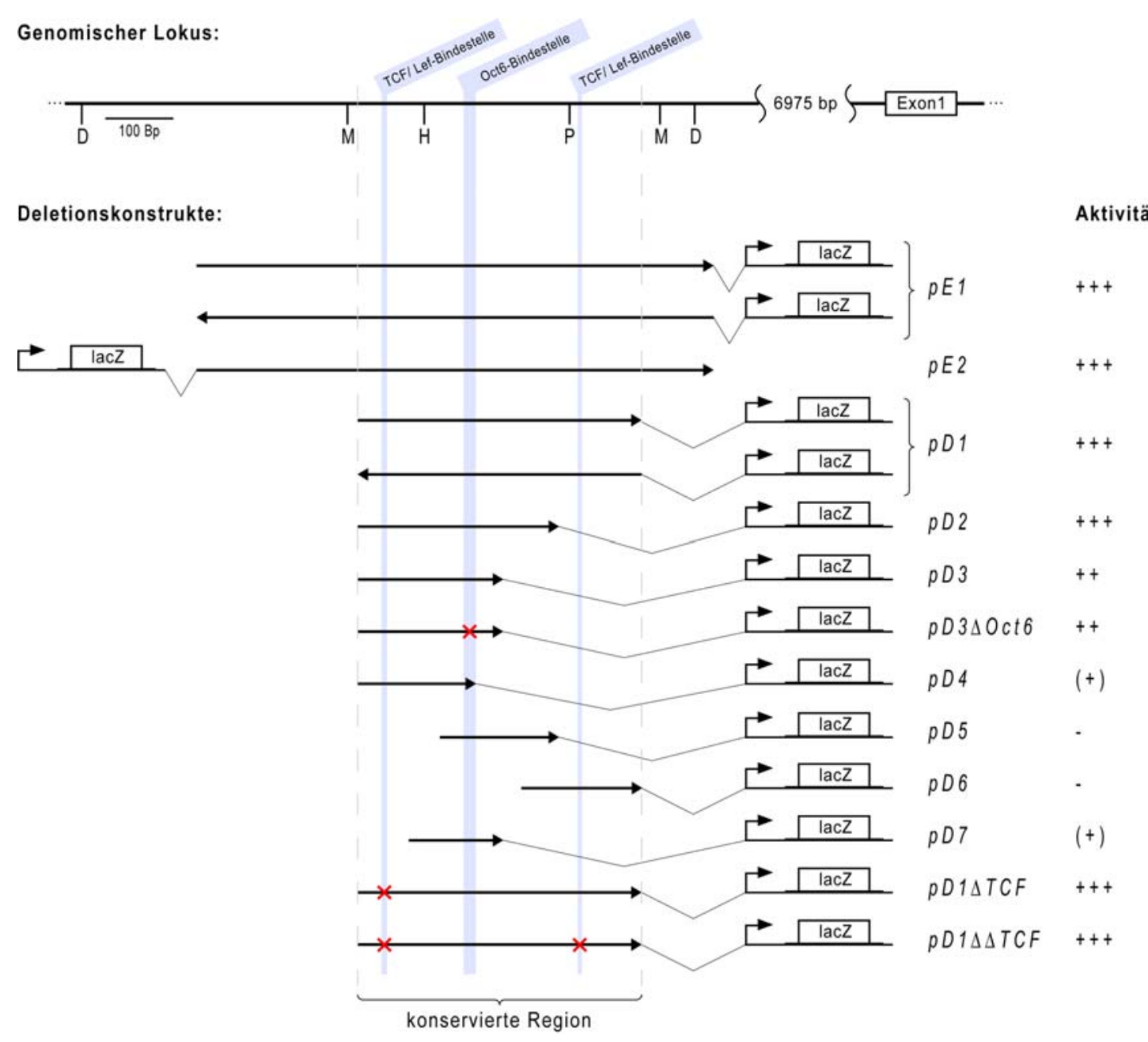

Abb. 21: Gegenüberstellung der Deletionskonstrukte für die Kartierung des E1-Elementes in vitro.

Die Deletionskonstrukte zur Kartierung der Aktivität des E1-Elementes enthielten verschiedene Teilsequenzen des E1-Elementes, den $\beta$-Globin-Minimalpromotor und die cDNA des $\beta$-Galaktosidase-Gens. Teilweise wurden Punktmutationen eingeführt (rote Kreuze). Die Reporteraktivität, die unter gleichen Bedingungen durch verschiedene Deletionskonstrukte erzielt wurde, ist vier Kategorien zugeordnet: "-": keine Aktivität; "(+)": sehr geringe Aktivität; "++": starke Aktivität, jedoch geringer als die Aktivität des vollständigen E1-Elementes, "+++": gleiche Aktivität wie das E1-Element. H: HincII, D: DraIII, M: MboI, P: PstI.

\section{Elektroporation von $p E 1$ und $p E 2$}

Die Konstrukte $p E 1$ und $p E 2$ basierten auf dem 706 bp-Fragment, also dem konservierten Bereich mit flankierender Sequenz, wie er auch für die Generierung der E1-transgenen Mauslinien eingesetzt wurde. In $p E 2$ war das 706 bp-Fragment an das 3'-Ende der $\beta$-Globin/ $\beta$ Galaktosidase-Kassette gesetzt (Abb. 21). $p E 1$ erzeugte unabhängig von der Orientierung des E1-Elementes im Plasmid Reporteraktivität im medialen Kortex. Eine gleich starke Reporteraktivität wurde auch durch Elektroporation von $p E 2$ im medialen Kortex erreicht. Das 
706 bp-Sequenzelement zeigte also die Eigenschaften eines klassischen Enhancers, nämlich Unabhängigkeit von Orientierung und Lage zum Promotor (Abb.21 und 23A-C, A'-C').

\section{Elektroporation von $p D 1$}

$p D 1$ enthielt die eigentliche zwischen murinem und humanem Genom konservierte Sequenz von 418 bp (E1-Element). Zur Elektroporation wurden zwei $p D 1$-Klone verwendet, einer mit "sense" ${ }^{21}$-Orientierung des Inserts, einer mit "antisense"22-Orientierung. Beide $p D 1$-Klone erzielten starke Reporteraktivität im medialen Kortex. Wie vermutet, reichte das konservierte E1-Element also aus, um unabhängig von seiner Orientierung Reporteraktivität auszulösen (Abb. 21 und 23D, E, D', E').

\section{Elektroporation von $p D 2-p D 7$}

Die Konstrukte $p D 4-p D 6$ enthielten 174-178 bp lange, überlappende Teilfragmente des E1Elementes, die in ihrerer Gesamtheit den Sequenzbereich von E1 abdeckten (Abb. 21). pD5 und pD6 bewirkten keine Reporteraktivität im medialen Kortex. Selbst nach verlängerter Inkubation mit dem $\beta$-Galaktosidase-Substrat konnte keine Färbung beobachtet werden (Abb. 22L, M, L', $\mathrm{M}^{\prime}$ ). Mit $p D 3$ wurde Reporteraktivität erzielt, jedoch schwach und in wenigen Zellen (Abb. $\left.22 \mathrm{~K}, \mathrm{~K}^{\prime}\right)$. Es wurde geschlußfolgert, daß sich für die Enhanceraktivität von E1 wichtige Sequenzmotive im 5'-Bereich befinden. Da diese Motive jedoch nicht die Aktivität von E1 rekonstituierten, wurden mit $p D 2$ und $p D 3$ Deletionskonstrukte analysiert, die den Sequenzbereich aus $p D 4$ einschlossen, jedoch in 3'-Richtung verlängert waren, $p D 2$ um $126 \mathrm{bp}$, pD3 um 29 bp (Abb. 21). Das 295 bp umfassende Plasmid pD2 erzeugte Reporteraktivität von gleicher Intensität wie Plasmide, die das gesamte E1-Element enthielten (Abb. 23H, H'). Das 200 bp enthaltende Plasmid $p D 3$ zeigte auch starke Enhanceraktivität, diese war jedoch im Vergleich zum gesamten E1-Element etwas reduziert (Abb. 23I, I').

Da in $p D 3$ genügend Sequenzinformation vorlag, um deutliche kortikale Expression vom $\beta$ Globin-Minimalpromotor auszulösen, kann diese Sequenz als Minimalenhancer angesehen werden. Unter den bisher erwähnten Deletionskonstrukten zeigten die Konstrukte $p D 3$ und $p D 4$ einen deutlichen Unterschied in ihrem Vermögen, Reporteraktivität auszulösen. $p D 3$ unterschied sich in nur $29 \mathrm{bp}$ von $p D 4$. Es lag nahe, in dieser Teilsequenz ein entscheidendes Sequenzmotiv zu vermuten. Der Vergleich dieser Teilsequenz mit dem entsprechenden Abschnitt im humanen Genom offenbarte jedoch einen geringen Grad der Konserviertheit (vergleiche auch Abb. 16B, 21). Darüberhinaus konnten in dieser Sequenz keine bekannten Bindestellen für Transkriptionsfaktoren identifiziert werden. Es scheint sich somit in diesem

\footnotetext{
${ }^{21}$ sense, engl.: Sinn

22 antisense, engl.: Gegensinn
} 
Aktivitätsunterschied weniger das Fehlen definierter Transkriptionsfaktor-Bindestellen, als vielmehr das Fehlen eines bestimmten Sequenz-Kontextes widerzuspiegeln.

\section{Elektroporation von $p D 3 \Delta O c t 6$}

Der im Konstrukt $p D 3$ vorliegende Sequenzbereich enthielt neben anderen Motiven eine potentielle Bindestelle für den Transkriptionsfaktor Oct6. Oct6 wird im Vorderhirn exprimiert und kann als Transkriptionsaktivator oder -repressor agieren (X. He et al., 1991). Im Konstrukt pD3AOct6 wurde die potentielle Oct6-Bindestelle mutiert (siehe auch Abb. 22). Die durch pD3AOct6 hervorgerufene Reporteraktivität unterschied sich nicht von der des nichtmutierten Konstruktes $p D 3$ (Abb. 23J, J'). Es muß deshalb davon ausgegangen werden, daß Oct6 nicht an E1-vermittelter Transkription beteiligt ist.

\section{Elektroporation von $p D 1 \triangle T C F$ und $p D 1 \triangle \triangle T C F$}

Die bisher beschriebene Deletionsanalyse ließ auf wichtige Sequenzmotive im 5'-Bereich des E1-Elementes schließen. Dort lag eine TCF/ Lef1-Bindestelle vor, die aus folgenden Gründen Aufmerksamkeit verdiente: 1. In vivo war starke Enhanceraktivität in der embryonalen Fimbria und im medialen Kortex zu verzeichnen. Beides sind Strukturen, die Wnt-Gene exprimieren, welche ihrerseits als Aktivatoren TCF/ Lef-vermittelter Transkription gelten. 2. Es war somit denkbar, daß E1-vermittelte Reporteraktivität durch Aktivierung des kanonischen WntSignalweges $^{23}$ gesteuert wird.

Um diesen Sachverhalt zu untersuchen, wurde im Konstrukt $p D 1 \triangle T C F$ die im 5'-Bereich von E1 gelegene TCF/ Lef-Bindestelle mutiert, während der übrige Teil des E1-Elementes unverändert blieb (Abb. 21, Abb. 22). Von dieser Mutation war auch die potentielle Bindestelle für den Otx-artigen Transkriptionsfaktor Otx-1 betroffen, da beide Bindestellen unmittelbar nebeneinander lagen. Die eingeführte Mutation hatte keinen Effekt auf die Intensität der erzielten Reporteraktivität im medialen Kortex (Abb. 23F, F'). Eine Funktionalität der TCF/ Lef-Bindestelle im 5'-Bereich von E1 mußte somit ausgeschlossen werden. Es war jedoch

denkbar, daß in diesem Experiment eine zweite TCF/ Lef-Bindestelle, welche im 3'-Bereich von E1 vorlag, die Funktion des mutierten TCF/ Lef-Motivs übernommen hatte und die mit $p D 1 \triangle T C F$ beobachtete Aktivität darauf zurückzuführen war. Hierüber sollte das Konstrukt

\footnotetext{
${ }^{23}$ Der kanonische Wnt-Signalweg beinhaltet die Aktivierung von Wnt-Rezeptor-Korezeptor-Komplexen (Frizzled-LRP5/ 6), was zur Aktivierung des Dishevelled-Proteins führt. Proteinkinasen (CKI $\alpha$, GSK3 $\beta$ ), deren Target das Protein $\beta$-Catenin ist, werden in ihrer Aktivität blockiert. Nichtphosphoryliertes $\beta$ Catenin kann nicht mehr ubiquitiniert und in Proteasomen abgebaut werden, es reichert sich im Nucleus an und löst im Komplex mit TCF/ Lef-Transkriptionsfaktoren Transkription aus (Übersichtsartikel in Huelsken J. und Behrens J., 2002).
} 
pDI $\triangle \triangle T C F$ Aufschluß geben, in dem beide TCF/ Lef-Bindestellen mutiert waren und der übrige Sequenzbereich von E1 erhalten blieb (Abb. 22). Auch mit $p D 1 \triangle \triangle T C F$ wurde eine dem gesamten E1-Element vergleichbare Reporteraktivität erzielt. Die Funktionalität und Notwendigkeit der beiden TCF/ Lef-Bindestellen in E1 konnten somit ausgeschlossen werden.

\section{Elektroporation von $p D 7$}

Die bisherige Deletionsanalyse offenbarte das 200 bp große Fragment in $p D 3$ als Minimalenhancer. Da die potentielle TCF/ LefBindestelle im 5'-Bereich nicht von Bedeutung schien, wurde der in $p D 3$ enthaltene Sequenzbereich vom 5'-Ende her verkleinert, um zu überprüfen, ob die darin enthaltene Sequenzinformation überhaupt erforderlich war. Es entstand das Plasmid $p D 7$ (Abb. 21). $p D 7$ zeigte im Vergleich zu $p D 3$ eine deutlich geringere Reporteraktivität (Abb. 23N, N'). Es kann somit geschlußfolgert werden, daß, obwohl die TCF/ Lef-Bindestelle im 5'-Bereich von E1 nicht funktionell war, in dieser Region

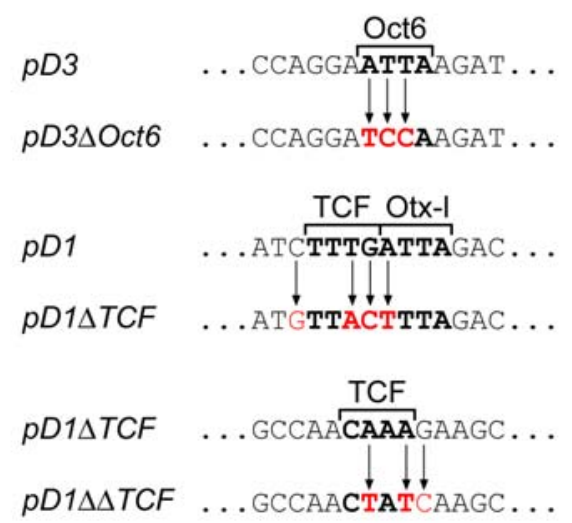

Abb. 22: Mutationen potentieller Bindestellen. Durch mutierte Primer wurden Punktmutationen in potentiellen Bindestellen von Transkriptionsfaktoren eingeführt. Die Kernsequenzen der Bindestellen sind fett gedruckt, Basenaustausche rot hervorgehoben.

Motive vorlagen, die für die Aktivität von E1

entscheidend sind.

\section{Zusammenfassung der Deletionsanalyse von E1 in vitro}

1. Das Sequenz-Element E1 zeigte die Eigenschaften eines klassischen Enhancers, nämlich Unabhängigkeit von Orientierung und Lage zum Promotor.

2. Durch ein 295 bp-Fragment (pD2) ist die Aktivität des 706 bp-Elementes (E1 + flankierende Sequenz) vollständig repräsentiert.

3. Ein 200 bp-Fragment am 5'-Ende von E1 ( $p D 3)$ repräsentiert die Aktivität von E1 nahezu vollständig und kann als Minimalenhancer angesehen werden.

4. Die Ausschaltung von Bindestellen der im zerebralen Kortex vorhandenen Transkriptionsfaktoren Oct6, Otx-1 sowie Faktoren der TCF/ Lef-Familie führte nicht zum Verlust der Enhanceraktivität. 

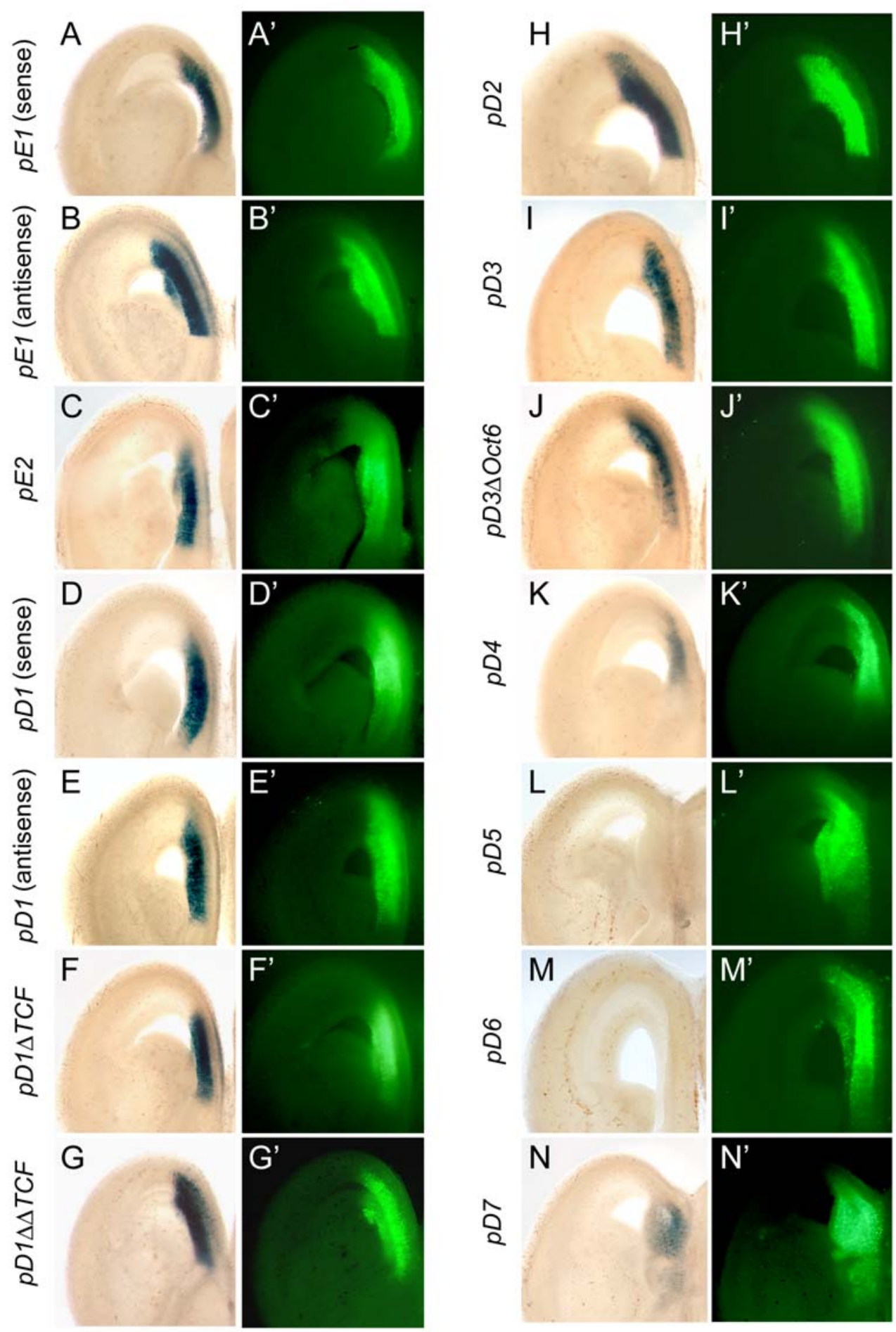

Abb. 23: Deletionsanalyse des E1-Elementes in vitro.

A-N: $\beta$-Galaktosidase-Färbung der organotypisch kultivierten Hirnschnitte $($ E14,5 $+24 \mathrm{~h})$ nach Elektroporation verschiedener Deletionskonstrukte. A'-N': Visualisierung der elektroporierten Bereiche durch EGFP-Fluoreszenz. A-G: Das 706 bp-Fragment (E1 + flankierende Sequenz, A-C) sowie das E1-Element (D, E) bewirkten unabhängig von Orientierung und Lage zum Minimalpromotor Reporteraktivität im medialen Kortex. Punktmutationen in potentiellen TCF-Bindestellen zeigten keinen Effekt (F, G). H-N: Verkleinerung des E1-Elementes vom 3'-Ende führt zu abnehmender Enhanceraktivität (H, I, K, L, N). Eine Sequenz von 200 bp des 5'-Bereiches von E1 bewirkt als Minimalenhancer starke Reporteraktivität (I), diese hängt nicht von der enthaltenen Oct6-Bindestelle ab (J). 


\section{Etablierung einer Mauslinie mit Überexpression von Hop unter Kontrolle des E1-Enhancerelementes}

Trotz des Vorhandenseins einer Homeodomäne ist Hop kein Transkriptionsfaktor, sondern ein Protein, das mit anderen Proteinen interagiert und deren Funktion moduliert. Durch Interaktion mit dem Protein SRF scheint Hop an der Balance zwischen Proliferations- und Differenzierungsprozessen im Herzen beteiligt zu sein (F. Chen et al., 2002; C. H. Shin et al., 2002). Ein Interaktionspartner von Hop im Nervensystem steht nicht fest.

Wie beschrieben, zeigte die untersuchte Hop-defiziente Mauslinie weder phänotypische Abweichungen in der Anatomie des embryonalen und adulten Gehirns, noch Veränderungen in der frühen Expression kortikaler Markergene und der Mitoserate kortikaler Neuroblasten. Um einen anderen Zugang zur Funktion des Hop-Proteins im embryonalen Kortex zu finden, wurden Mauslinien etabliert, welche transgen für das Konstrukt $p E 1-H o p$ waren. Mit dieser genetischen Manipulation sollten unter der Kontrolle des E1-Enhancerlementes zusätzlich zur endogenen Hop-Expression physiologische Mengen eines FLAG-markierten Hop-Proteins gebildet werden. Das für Protein-Protein-Interaktionen wichtige Equilibrium zwischen Hop und seinem hypothetischen Interaktionspartner wäre dann gestört, und die Analyse der Hopüberexprimierenden Zellen in vivo könnte Aufschluß über die Funktion von Hop geben. Außerdem könnte in einer solchen Mauslinie das gebildete Hop-Protein aufgrund seines FLAGEpitops immunhistochemisch nachgewiesen werden, was weitere Möglichkeiten der Analyse eröffnet (bisher fehlt ein kommerziell erhältlicher Hop-Antikörper). Zellen, in denen unter

A
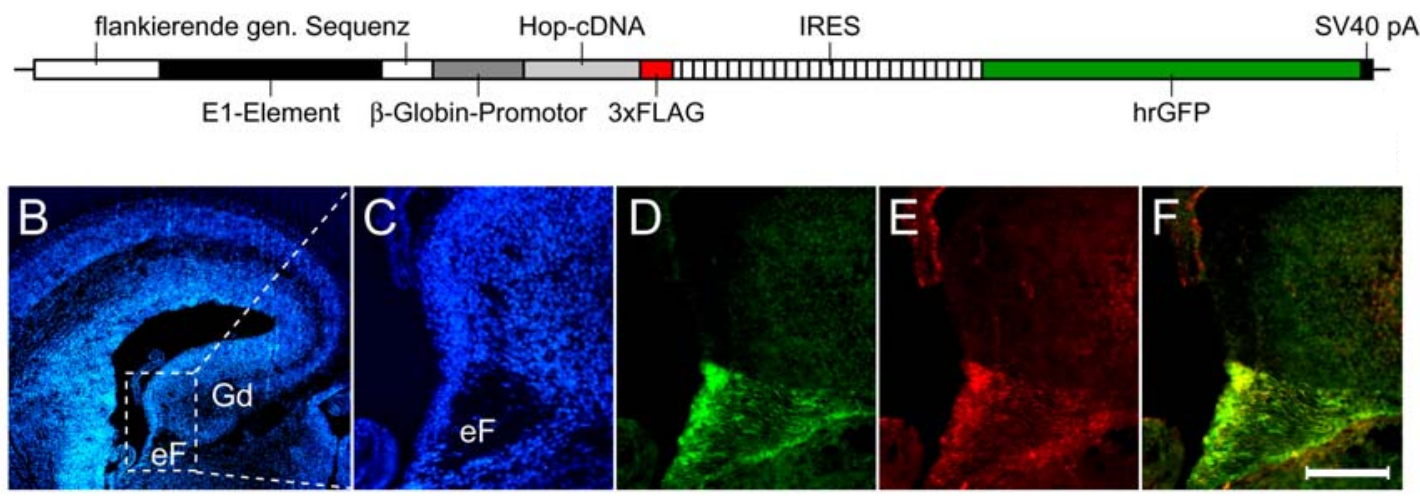
Kontrolle des E1-Enhancers Transkription stattfindet, sollten ferner positiv für das Reporterprotein hrGFP ${ }^{24}$ sein (Abb. 24A).

Es konnten zwei $p E 1$-Hop-transgene Mauslinien etabliert werden, von denen eine hrGFPReporteraktivität und FLAG-Immunreaktivität in der embryonalen Fimbria des E16,5-Kortex aufwies. Reporteraktivität und FLAG-Immunreaktivität waren kolokalisiert (Abb. 24B-F). HopFLAG-positive Zellen der embryonalen Fimbria bildeten den radialen Gliazellen ähnliche Fortsätze. Neben den Zellkörpern waren diese Fortsätze ebenfalls FLAG-immunreaktiv. HopFLAG ist demnach im Zytoplasma dieser Zellen lokalisiert.

Zukünftige Analysen der pE1-Hop-transgenen Mauslinie sollten 1. die Anatomie und Zelldichte des Gyrus dentatus, 2. die Proliferationsrate von Zellen der embryonalen Fimbria und des Gyrus dentatus, sowie 3. das Migrationsverhalten der Zellen des primären und sekundären Neuroepithels des Gyrus dentatus betrachten.

\footnotetext{
${ }^{24}$ hrGFP: humanised red shifted green fluorescent protein, engl.: humanisiertes rot-verschobenes grün fluoreszierendes Protein
} 


\title{
Diskussion
}

\section{Microarray-Expressionsanalyse offenbart differentielle Genexpression im embryonalen Kortex der Maus}

\author{
Mit Microarray-Technologie zu einem repräsentativen Überblick kortikaler \\ Genexpression?
}

Die Mikroarray-Technologie ist weithin als Methode zur Expressionsanalyse akzeptiert und bietet bekannte Vorteile, wie die simultane Analyse einer Vielzahl von Proben (Targetsequenzen) und den hohen Grad der Standardisierung (D. J. Lockhart und E. A. Winzeler, 2000). In der vorgelegten Arbeit wurde Microarray-Technologie eingesetzt, um Gene mit regionalisierter Expression im zerebralen Kortex der embryonalen Maus (E16,5) zu identifizieren. Hierfür wurde die Expression der ca. 36'000 Targetsequenzen der MicroarraySerie MGU74v2 (Chip A, B, C; Affymetrix) in fünf Regionen des Kortex analysiert. Eine Targetsequenz der Microarrays wurde als regional spezifisch betrachtet, wenn sie in einer Kortexregion mit einem "DifferenceCall" von "increased" bzw. "marginal increased" mindestens zweifach stärker exprimiert war, als in allen anderen Regionen und dreifach stärker als in mindestens einer anderen Region. Außerdem sollte die Targetsequenz als "increased" bzw. "marginal increased" im Vergleich zur Probe "Restkörper" eingestuft sein. 114 Targetsequenzen, davon 10 redundant, erfüllten diese Kriterien.

Kürzlich wurde in N. Funatsu et al., 2004 eine ähnliche Studie präsentiert, ebenfalls mit Geweben des E16,5-Kortex und Microarrays der Firma Affymetrix. In dieser Arbeit wurden allerdings nur Microarrays des Typs A hybridisiert. Ein weiterer Unterschied zur vorliegenden Arbeit bestand in der Auswahl der Kortexregionen. So wurde auf eine Unterteilung des medialen Kortex in einen rostralen und caudalen Bereich verzichtet, stattdessen kam eine weitere Kortexregion hinzu - der laterale Kortex. Obwohl Microarrays des Typs A auch Bestandteil der vorliegenden Studie waren, ist die Anzahl der Gene, die in beiden Arbeiten identifiziert wurden, gering. Es handelt sich lediglich um die Gene Hop, Crystallin, Tachykinin, Secretogranin, Visinin like 1 und eine EST-Sequenz (161050_at). Dieser Unterschied ist sicherlich auf die verschiedene Art der Gewebepräparation und insbesondere auf die andere Vorgehensweise bei der Datenanalyse zurückzuführen. In N. Funatsu et al., 2004 wurden Experimente in Duplikaten durchgeführt, der gesetzte "FoldChange"-Grenzwert für regionalisierte Expression betrug 1,5. In der vorliegenden Arbeit wurden keine Experiment- 
Duplikate durchgeführt. Es mußten deshalb höhere "FoldChange"-Grenzwerte gesetzt werden, um eine verläßliche Aussage treffen zu können.

Trotz der weniger stringenten Auswahlkriterien wird bereits in N. Funatsu et al., 2004 eine Nichterfassung zahlreicher bekannter Markergene (z. B.: EphrinA5, Wnt3a, Wnt5a, Neuropillin2, GABAa, LAMP) festgestellt. Auch in der vorliegenden Arbeit fällt auf, daß bekannte kortikale Markergene nicht die Auswahlkriterien für regional spezifische Expression erfüllten. Anhand der Beispiele Cadherin 6 und Cadherin 8 soll dies verdeutlicht werden. Beide Gene gelten als klassische Marker kortikaler Regionalisierung und wurden als solche in zahlreichen Studien verwendet. Cadherin 6 zeigt hohe Expression im parietalen Kortex, während Cadherin 8 eine Expressionsdomäne im frontalen Kortex und eine mit geringerer Expression im okzipitalen Kortex aufweist (S. C. Suzuki et al., 1997; T. Inoue et al., 1998; K. M. Bishop et al., 2000; K. M. Bishop et al., 2002). Weder Cadherin 6 noch Cadherin 8 wurden in der vorliegenden Arbeit erfaßt. Dies lag zunächst daran, daß die Expressionsunterschiede für alle paarweisen Vergleiche als nicht verändert ("DifferenceCall" = "not changed") eingestuft wurden (Abb. 25). Ferner zeigte keiner der paarweisen Vergleiche einen mehr als dreifachen Expressionsunterschied an, wie er vom zugrunde liegenden Auswahlalgorithmus gefordert

\begin{tabular}{|c|c|c|c|c|c|}
\hline $\mathrm{B}^{A}$ & $\mathrm{~cm}$ & $\mathrm{fr}$ & ok & pa & $\mathrm{rm}$ \\
\hline $\mathrm{cm}$ & & $\mathrm{nc}$ & $\mathrm{nc}$ & $\mathrm{nc}$ & $\mathrm{nc}$ \\
\hline $\mathrm{fr}$ & $\mathrm{nc}$ & $x$ & $\mathrm{nc}$ & $\mathrm{nc}$ & $\mathrm{nc}$ \\
\hline ok & $\mathrm{nc}$ & $\mathrm{nc}$ & & nc & nc \\
\hline pa & $\mathrm{nc}$ & $\mathrm{nc}$ & $\mathrm{nc}$ & & $\mathrm{nc}$ \\
\hline $\mathrm{rm}$ & $\mathrm{nc}$ & $\mathrm{nc}$ & $\mathrm{nc}$ & $\mathrm{nc}$ & \\
\hline
\end{tabular}

"FoldChange" Gewebe A versus B

\begin{tabular}{|c|c|c|c|c|c|}
\hline $\mathrm{B}^{A}$ & $\mathrm{~cm}$ & $\mathrm{fr}$ & ok & pa & $\mathrm{rm}$ \\
\hline $\mathrm{cm}$ & & 1,2 & 1,3 & 2,8 & 1,3 \\
\hline $\mathrm{fr}$ & $-1,2$ & . & 1,1 & 2,7 & 1,1 \\
\hline ok & $-1,3$ & $-1,1$ & & 2,5 & -1 \\
\hline pa & $-2,8$ & $-2,7$ & $-2,5$ & & $-2,6$ \\
\hline $\mathrm{rm}$ & $-1,3$ & $-1,1$ & 1 & 2,6 & \\
\hline
\end{tabular}

\begin{tabular}{|c|c|c|c|c|c|}
\hline & $\mathrm{cm}$ & $\mathrm{fr}$ & ok & pa & $\mathrm{rm}$ \\
\hline $\mathrm{cm}$ & & $\mathrm{nc}$ & $\mathrm{nc}$ & $\mathrm{nc}$ & $\mathrm{nc}$ \\
\hline $\mathrm{fr}$ & $\mathrm{nc}$ & & $\mathrm{nc}$ & $\mathrm{nc}$ & $\mathrm{nc}$ \\
\hline $\mathrm{ok}$ & $\mathrm{nc}$ & $\mathrm{nc}$ & & $\mathrm{nc}$ & $\mathrm{nc}$ \\
\hline $\mathrm{sa}$ & $\mathrm{nc}$ & $\mathrm{nc}$ & $\mathrm{nc}$ & & $\mathrm{nc}$ \\
\hline $\mathrm{rm}$ & $\mathrm{nc}$ & $\mathrm{nc}$ & $\mathrm{nc}$ & $\mathrm{nc}$ & \multicolumn{1}{|c}{} \\
\hline
\end{tabular}

\begin{tabular}{|c|c|c|c|c|c|}
\hline $\mathrm{B}^{A}$ & $\mathrm{~cm}$ & $\mathrm{fr}$ & ok & $\mathrm{pa}$ & $\mathrm{rm}$ \\
\hline $\mathrm{cm}$ & & 2,5 & 1,3 & 1,8 & 1,4 \\
\hline $\mathrm{fr}$ & $-2,5$ & & 2 & $-1,4$ & $-1,8$ \\
\hline ok & $-1,3$ & -2 & & 1,5 & 1,1 \\
\hline $\mathrm{pa}$ & $-1,8$ & 1,4 & $-1,5$ & & $-1,3$ \\
\hline $\mathrm{rm}$ & $-1,4$ & 1,8 & $-1,1$ & 1,3 & \\
\hline
\end{tabular}

Abb. 25: Daten der Microarray-Analyse für die Gene Cadherin 6 und Cadherin 8.

"DifferenceCall" und "FoldChange" für paarweise Vergleiche der Expression von Cadherin 6 und Cadherin 8 in fünf Kortexregionen: caudomedial (cm), frontal (fr), okzipital (ok) parietal (pa) und rostromedial (rm).

"DifferenceCall": In allen paarweisen Vergleichen wurden beide Gene als "not changed" (nc) eingestuft. "FoldChange": Fett gedruckt sind die Werte des Gewebes, das sich gegenüber den meisten anderen Geweben durch erhöhte Genexpression auszeichnete, entsprechend viele positive "FoldChange"-Werte aufwies. Für Cadherin 6 war diese Region der parietale Kortex, für Cadherin 8 der frontale Kortex. 
wurde (Abb. 25). Die Kortexregionen mit den meisten positiven "FoldChange"-Werten zu anderen Regionen waren der parietale Kortex für Cadherin 6 und der frontale Kortex für Cadherin 8 - also die Regionen, für die die höchste Expression beschrieben wurde (siehe Abb. 25). Es wird deutlich, daß sich die für beide Gene bekannten Expressionsmuster in den Daten der vorliegenden Microarray-Analyse widerspiegeln, die strengen Auswahlkriterien für regionalisierte Expression aber nicht erfüllt werden. Die Festlegung strikter Auswahlkriterien war jedoch gerechtfertigt, ja zwingend, um den Anteil falsch positiver Ergebnisse zu minimieren. Schließlich mußte auch dem Fakt Rechnung getragen werden, daß keine Experiment-Wiederholungen durchgeführt wurden. $\mathrm{Zu}$ den Markergenen, die in der vorliegenden Arbeit erfaßt wurden, gehören Lhx $9 a$, Lhx5, Neuropeptid Y und Crystallin.

Wenngleich die strengen Auswahlkriterien zum Ausschluß vieler Gene führten, so weisen die ausgewählten Gene eine sehr gute Korrelation zwischen vorhergesagtem Expressionsmuster (Microarray-Daten) und tatsächlicher Expression auf. Von den neun Genen, deren Expressionsmuster mittels RNA-in situ-Hybridisierung analysiert wurden, zeigte nur das Gen Slcla3 Abweichungen von der vorhergesagten Expression (Microarray-Daten). Für die Gene Ppp1r1b, Nurr1, Flrt3, Hop, Dct, NRIP1, Hippocampus spezifisch 1 und Ebf3 lag jeweils die höchste Expression in der Region vor, für die auch die Microarray-Analyse höchste Expression anzeigte. Die Expression in anderen Kortexregionen reflektierte fast immer die MicroarrayDaten.

Aufgrund strenger Auswahlkriterien vermittelt die Microarray-Expressionsanalyse der vorliegenden Arbeit keinen repräsentativen Überblick über Genexpression im E16,5-Kortex. Trotzdem charakterisiert die funktionelle Klassifizierung der identifizierten Gene den E16,5Kortex als sich entwickelndes und differenzierendes Gewebe, in dem Prozesse der Genregulation (Transkriptionsregulation) und Signaltransduktion in bestimmten Regionen stattfinden. Mit 104 regional spezifischen Sequenzen, davon 44 potentiell neuen Genen, wurde eine vergleichsweise hohe Anzahl von Genen mit regionalisierter Expression identifiziert (vergleiche auch N. Funatsu et al., 2004).

Abschließend sei auf generelle Limitationen der Microarray-Expressionsanalyse hingewiesen. So konnten bis vor kurzem Gene mit geringer Expression sowie geringe Expressionsunterschiede nicht erfaßt werden. Gerade solche Expressionscharakteristika scheinen aber für viele biologisch relevante Gene vorzuliegen. Neue Analysealgorithmen, die Fehlermodelle einschließen, sowie neue Microarray-Technologien mit erhöhter Sensitivität beseitigen die bestehenden Limitationen in zunehmendem Maße (J. M. Claverie, 1999; P. Baldi und A. D. Long, 2001; D. M. Mutch et al., 2002; D. Rajagopalan, 2003). 


\section{Gene mit regionalisierter Expression im zerebralen Kortex des Embryonalstadiums 16,5}

In dieser Arbeit wurden die Expressionsmuster von neun Genen im E16,5-Kortex beschrieben. Eines dieser Gene galt als neues Gen und erhielt die vorläufige Bezeichnung Hippocampus-spezifisch 1. Dieses Gen zeigte starke Expression im Hippocampus und moderate Expression in der gesamten Ventrikulärzone des Kortex. Das hypothetische, von Hippocampusspezifisch 1 abgeleitete Protein weist eine Histidin-Threonin-Domäne auf, ähnlich der des Proteins Prosaposin. Auch Prosaposin ist ein Nervensystem-assoziiertes Gen, seine Expression nimmt nach Verletzung des peripheren oder zentralen Nervensystems zu (Q. P. Cao und W. R. Crain, 1995; C. Gillen et al., 1995; M. Hiraiwa et al., 2003). Die Histidin-Threonin-Domäne wird durch poly-(CA) $)_{n}$-Repeats kodiert und stellt ein Motiv mit Bindefähigkeit des Kernlokalisationssignals dar (N. B. Elkind et al., 1995; T. Miyamoto et al., 2003). Aufgrund des Expressionsmusters wird eine Bedeutung von Hippocampus-spezifisch 1 für die Entwicklung bzw. Funktion des Hippocampus vorgeschlagen.

Die Expression von Proteinphosphatase 1, Untereinheit 1B (Synonyme: Dopamine and cAMP regulated phosphoprotein 32, DARPP-32) im embryonalen und adulten Gehirn ist schon seit längerer Zeit dokumentiert. Ppp1r1b-Transkripte wurden unter anderem im Striatum, im piriformen Kortex und im frontalen Kortex detektiert, also in Regionen, die auch in der vorliegenden Arbeit als Ppp1r1b-positiv beschrieben wurden (G. A. Foster et al., 1987; R. G. Perez und R. M. Lewis, 1992). Das frühe und definierte Auftreten von Ppplrlb während der Embryogenese ließ vermuten, daß dieses Gen Einfluß auf die Entwicklung verschiedener Bereiche des Gehirns hat. Mäuse, bei denen Ppplrlb gezielt ausgeschaltet wurde, zeigten jedoch keine Abweichungen, die auf eine Rolle des Gens während der Embryogenese hinweisen (A. A. Fienberg et al., 1998). Vielmehr konnte Ppplrlb in einer Vielzahl von Arbeiten als entscheidender Mediator biochemischer, elektrophysiologischer, transkriptioneller sowie verhaltensbiologischer Aspekte des Neurotransmitters Dopamin charakterisiert werden (Übersichtsartikel in P. Svenningsson et al., 2004).

Auch das im Rahmen der vorliegenden Arbeit identifizierte Gen Nur-related protein 1 (Nurrl) wird mit dem dopaminergen System in Verbindung gebracht. In Nurrl-defizienten Mäusen fehlt die Ausbildung dopaminerger Neurone der Substantia nigra (R. H. Zetterstrom et al., 1997). Die Expression von Nurr1 wurde im neonatalen, perinatalen und adulten Gehirn der Ratte beschrieben (R. H. Zetterstrom et al., 1996). In der vorgelegten Arbeit wird erstmals die Expression von Nurrl im embryonalen Vorderhirn betrachtet. Nurrl-positiv waren: das Claustrum, Zellen des Septums, Schicht $6 \mathrm{~b}$ im gesamten Kortex, der dorsale Thalamus, sowie tiefere Schichten des okzipitalen Kortex. Die frühe und deutlich abgegrenzte Expression dieses Gens läßt auf eine Bedeutung für die Genese von Vorderhirnstrukturen schließen. 
Das Gen Dopachromtautomerase (Dct, Synonym: Tyrosin-related protein 2) ist in Zellen der Pigmentzellinie und im Pigmentepithel der Retina exprimiert. Auch Dct-Expression im Telenzephalon wurde beschrieben (K. P. Steel et al., 1992; M. A. Mackenzie et al., 1997; S. Zhao und P. A. Overbeek, 1999). Dct ist in die Melaninsynthese involviert. Dct-defiziente Mäuse zeigen Pigmentierungsdefekte, während die Morphologie des Telenzephalons nicht verändert ist (L. Guyonneau et al., 2004). Die Bedeutung von Dct im Vorderhirn ist unklar. In L. Guyonneau et al., 2004 wird sogar eine fehlende physiologische Relevanz der telenzephalen Dct-Expression erwogen. In der vorliegenden Arbeit wird Dct an E16,5 als Markergen mit streng begrenzter Expression in der rostromedialen Ventrikulärzone charakterisiert. Als solches dürfte es zukünftig Anwendung finden, zum Beispiel zur Identifikiation und Definition dieser Region in Knock out-Mäusen mit veränderter Kortexarchitektur.

Ein im Rahmen dieser Arbeit vorgestelltes Gen mit Expression in der Kortikalplatte des frontalen Kortex war Nuclear receptor interacting protein 1 (Nrip1 oder Rip140). Nrip1 wurde als Retinsäure-aktivierbarer Korepressor des nukleären Rezeptors TR2 und als Interaktionspartner von Histondeazetylasen beschrieben (C. H. Lee et al., 1998; L. N. Wei et al., 2000; J. S. Kerley et al., 2001). Der Kernrezeptor TR2 ist im embryonalen Kortex exprimiert (W. J. Young et al., 1998). Somit ist die Möglichkeit Nrip1-vermittelter Transkriptionsrepression auch hier gegeben. Die regionalisierte Nrip1-Expression im E16,5Kortex legte eine Bedeutung für die Kortikogenese nahe. Ein Nrip1-Knock out mit Phänotyp im weiblichen Reproduktionssystem liegt vor, Aussagen über den zerebralen Kortex wurden nicht gemacht (R. White et al., 2000).

Fibronectin leucin rich transmembrane protein 3 (Flrt3) gehört zu einer Familie von drei Genen, welche für membranintegrierte Proteine mit Leuzin-reichen und Fibronektin-/ Kollagenartigen Domänen kodieren. Northernblotanalyse zeigte Expression aller drei Flrt-Gene im Gehirn an (S. E. Lacy et al., 1999). Für Flrt3 wurde darüberhinaus die Expression im adulten Gehirn mittels RNA-in situ-Hybridisierung analysiert. Expression lag in den Basalganglien, in der Körnerzellschicht des Cerebellums und im Hippocampus vor (L. Tsuji et al., 2004). Interessant ist unter diesem Aspekt, daß Flrt3 in der vorliegenden Arbeit an E16,5 als Gen mit spezifischer Expression in oberen Schichten des okzipitalen Kortex und der gesamten Marginalzone identifiziert wurde. Das Expressionsmuster von Flrt3 muß also während der Entwicklung einer hohen Dynamik unterliegen. Über die Funktion von Flrt3 ist wenig bekannt, eine Interaktion von Flrt3 mit dem FGF-Signalweg und eine positive Beeinflussung des Neuritenwachstums durch Flrt3 wurden gezeigt (R. T. Bottcher et al., 2004; L. Tsuji et al., 2004). Hier wird erstmals eine regionalisierte Expression des Flrt3-Gens im embryonalen Kortex beschrieben. Bei den Flrt3-positiven Zellen der Marginalzone könnte es sich um Cajal- 
Retzius-Zellen handeln, die in ähnlicher Anzahl und Dichte vorliegen. In jedem Falle ist eine Implikation des Gens in Prozesse der Kortikogenese denkbar.

Auch für das Gen Ebf3 wurde hier eine spezifische Expression in der Marginalzone des E16,5-Kortex beschrieben. Wiederum ist ein Zusammenhang mit der Ausbildung und Funktion der Cajal-Retzius-Zellen denkbar. Eine Beteiligung von Ebf-Faktoren an neuronaler Differenzierung wird diskutiert (S. Garel et al., 1997; O. Pozzoli et al., 2001).

Das Gen Solute carrier family 1, member 3 (Slcla3) ist unter zahlreichen Synonymen bekannt (EAAT1, GLAST, GluT-1). Slcla3 kodiert einen hochaffinen Glutamat-Transporter, dessen Expression in allen radialen Gliazellen des embryonalen Gehirns charaktersisiert wurde (M. L. Sutherland et al., 1996; T. Shibata et al., 1997; E. Hartfuss et al., 2001). Dem hier beschriebenen rostrocaudalen Expressionsgradienten scheint der rostrocaudale Gradient der Neurogenese (S. A. Bayer und J. Altman, 1991) zugrunde zu liegen. Slca3 ist kein regionspezifisches Gen im engeren Sinne.

\section{Hop - ein neues Gen mit spezifischer Expression in proliferativen Zonen des medialen embryonalen Kortex}

In der vorliegenden Arbeit wurde Homeodomain only protein mittels MicroarrayExpressionsanalyse und RNA-in situ-Hybridisierung als differentiell exprimiertes Gen des E16,5-Kortex identifiziert. Hop galt zunächst als neues Gen, wurde aber bald auch von anderen Arbeitsgruppen beschrieben (J. Adu et al., 2002; F. Chen et al., 2002; C. H. Shin et al., 2002). In diesen Studien wurde die früheste Expression von Hop an E7,75 in extraembryonalen Membranen detektiert. An E8,0 war Hop erstmals im Embryo, nämlich in den Kopffalten und im Herzen exprimiert. $\mathrm{Zu}$ den wichtigsten Regionen, die außerdem als Hop-exprimierend beschrieben wurden, gehören das Lungenepithel, das nasale Epithel und die Ventrikulärzone des Rückenmarks (J. Adu et al., 2002; H. Kook und J. A. Epstein, 2003). Bis auf eine kurze Notiz zur Expression im E16,5-Kortex (N. Funatsu et al., 2004) ist Hop-Expression im Gehirn nicht untersucht oder gar übersehen worden (J. Adu et al., 2002).

Im Rahmen der vorliegenden Arbeit wurde ein detailierter Überblick über die Expression von Hop im prä- und postnatalen Nervensystem, insbesondere im Vorderhirn, gegeben. Hop war an E12,5 in der ventrikulären Zone der Grund- und Flügelplatte des Rückenmarks exprimiert, es bestand ein Hop-freier Bereich auf Höhe der Pax6-exprimierenden Domäne. An E12,5 war die Expression der Grundplatte stärker als die der Flügelplatte. Deck- und Bodenplatte waren frei von Hop-Expression. Es ist bekannt, daß im Rückenmark Transkriptionsfaktoren als Folge morphogener Faktoren der Deck- und Bodenplatte in deutlich begrenzten Domänen exprimiert werden. Die Kombination der Transkriptionsfaktoren in den einzelnen Domänen bestimmt, welches Zellschicksal die daraus hervorgehenden Neurone 
eingehen (J. Briscoe und J. Ericson, 2001). Die für die Spezifikation der neuronalen Subtypen entscheidenden Transkriptionsfaktoren gehören zu den Proteinen mit Homeodomäne. Auch Hop kodiert für eine Homeodomäne und ist in distinkten Bereichen des Rückenmarks exprimiert. Trotzdem kann Hop nicht für die Rolle eines klassischen Zellschicksal-determinierenden Faktors favorisiert werden, da die Homeodomäne in Hop keine DNA-bindenden Eigenschaften aufweist und nicht von einer transaktivierenden Domäne begleitet wird, Hop also keinen Transkriptionsfaktor verkörpert (C. H. Shin et al., 2002). Hop scheint daher im embryonalen Rückenmark eher eine modulatorische Rolle zu besitzen. Eine solche Funktion wurde im Herzen nachgewiesen, wo Hop als Transkriptions-Kofaktor auftritt (F. Chen et al., 2002; C. H. Shin et al., 2002).

Im Vorderhirn konnte Hop-mRNA, wenn auch in geringem Maße, erstmals an E12,5 detektiert werden. In diesem Stadium waren die periolfaktorische Region und die Anlage des Hippocampus Hop-positiv. An E14,5 wurde die Expression von Hop im Vorderhirn stärker und erreichte schließlich an E16,5 ein Maximum. Hop war jeweils im medialen Kortex exprimiert in der Anlage des Hippocampus und Gyrus dentatus. Hop-positiv waren darüberhinaus der Bulbus olfactorius und die embryonale Fimbria. Hop-Expression trat sowohl im medialen Kortex als auch im Bulbus olfactorius in der ventrikulären Zone auf, also in proliferierenden, undifferenzierten Zellen. Die Expression von Hop im E18,5-Kortex war ähnlich, jedoch verschwand Hop in der ventrikulären Zone des Bulbus olfactorius, wo nunmehr Zellen der periglomerulären Schicht Hop-positiv waren. Die Expression von Hop in der ventrikulären Zone bildete an E16,5 und E18,5 einen Gradienten mit höchster Expression im rostromedialen Bereich.

Erstmals an E16,5 war zu beobachten, daß Hop-positive Zellen aus dem Bereich oberhalb der embryonalen Fimbria zum Gyrus dentatus migrieren und dabei die Expression von Hop aufrechterhalten. Ein Großteil dieser Zellen hatte an E18,5 den Gyrus dentatus erreicht. Es handelte sich hierbei um Zellen des als "dentate notch" ${ }^{25}$ bezeichneten primären Neuroepithels des Gyrus dentatus, die während ihrer Migration ein sekundäres und im Zielgebiet ein tertiäres Neuroepithel etablieren (J. Altman und S. A. Bayer, 1990). Im Gyrus dentatus ist Hop auch an P6 exprimiert, zu einem Zeitpunkt da die Neurogenese des Gyrus dentatus noch nicht abgeschlossen ist (K. Y. Reznikov, 1991). Im adulten Gyrus dentatus war Hop schließlich nur in wenigen Zellen zu finden. Für die Klärung der Identität dieser Zellen wäre eine immunhistochemische Kolokalisation des Hop-Proteins mit Marker-Proteinen verschiedener Zelltypen nötig, was aufgrund des Fehlens eines erhältlichen Hop-Antikörpers vorerst nicht realisierbar war. Die Lage und Anzahl der Hop-exprimierenden Zellen im adulten Gyrus

\footnotetext{
${ }^{25}$ dentate notch, engl.: gezahnte Einkerbung
} 
dentatus läßt jedoch den Schluß zu, daß es sich um Stammzellen der subgranulären Zone handelt, die auch im adulten Gehirn der Neurogenese dienen (J. Altman und G. D. Das, 1965; N. Picard-Riera et al., 2004). K. Jin et al. zeigten 2001, daß nach induziertem Schlaganfall im Gyrus dentatus der Ratte eine erhöhte Neurogenese $\mathrm{zu}$ beobachten ist. Von derselben Arbeitsgruppe wurde das zu Hop orthologe Gen der Ratte unter dem Namen Global ischemia induced gene $15 B$ patentiert (K. Jin et al., 1999). Hop-Expression scheint somit nach Schlaganfall erhöht zu sein, was indirekt auf eine Verbindung des Gens zu Stammzellen des adulten Gyrus dentatus hinweist. Eine wissenschaftliche Publikation zu diesem Thema liegt noch nicht vor. Fest steht, daß Hop in vielen (vielleicht allen) Vorstufen von Gyrus dentatusZellen exprimiert wird. Dieser Aspekt spiegelt sich auch im Lefl-defizienten Kortex wider, wo die Zellen des Gyrus dentatus angelegt sind, aber nicht proliferieren, was schließlich zur Agenese dieser Struktur führt (J. Galceran et al., 2000). Im Lefl-Knock out sind Hop-positive Zellen im primären und sekundären Neuroepithel des Gyrus dentatus vorhanden, verschwinden jedoch während der Migration zum tertiären Proliferationsgebiet.

Wenngleich Hop in Stammzellen des Gyrus dentatus exprimiert zu sein scheint, handelt es sich bei diesem Gen nicht um einen allgemeinen Marker adulter neuraler Stammzellen. Die wichtigste neuroproliferative Region des adulten Gehirns, die subventrikuläre Zone (A. D. Tramontin et al., 2003), war frei von Hop-Expression. Zu keinem der untersuchten Stadien lag Hop-Expression in subkortikalen Strukturen des Vorderhirns vor. Hop trat immer im Kortex und hier nur in proliferierenden Zellen auf. Die Funktion von Hop dürfte demanch mit der Proliferation der kortikalen Neuroblasten verbunden sein.

Neben seiner Expression im medialen Kortex wurde Hop auch im Hinterhirn detektiert. Die erste Expression wurde an E12,5 im Nucleus vestibularis des Pons beobachtet und blieb in späteren Stadien bestehen. Von P6 an bis hin zu adulten Stadien war Hop außerdem im Stratum ganglionare des Kleinhirns exprimiert.

In der vorliegenden Arbeit wurde die Expression von Hop im Emx2-Knock out untersucht. Wie beschrieben, gilt Emx2 als einer der wichtigsten Regulatoren für die Genese medialer Kortexstrukturen (S. Tole et al., 2000a; K. Shinozaki et al., 2004). Hop und Emx2 zeigen überlappende Expression in der Ventrikulärzone des medialen Kortex. Es bestand daher die Möglichkeit, daß Hop-Expression direkt vom Transkriptionsfaktor Emx2 reguliert wird. Im Emx2-defizienten Gehirn war Hop an E16,5 in der Ventrikulärzone des Kortex exprimiert. Hop stellt also kein Zielgen von Emx2 dar. Es kam jedoch zu einer Verschiebung des HopGradienten nach lateral und insbesondere nach caudal. Genau diese Art der Expressionsverschiebung wurde für zahlreiche Markergene im Emx2-Knock out beschrieben und widerspiegelt den Regionalisierungsdefekt dieser Mutante (K. M. Bishop et al., 2002). 
Interessant war der Befund, daß Hop im Emx2-defizienten Kortex nicht das charakteristische Expressionsmuster am Übergang vom Archikortex zur embryonalen Fimbria ausbildete. Während Hop im Wildtyp geringe Expression im caudomedialen Kortex zeigte, jedoch stark in der Fimbria exprimiert war, lag im Emx2-Knock out verstärke kortikale Expression im Vergleich zur Fimbria vor.

\section{Das Hop - defiziente Gehirn zeigt keine Aberrationen, welche auf die Funktion des Gens im Kortex schließen lassen}

\section{Hop - ein atypisches Homeodomäne-Protein ohne DNA-bindende Eigenschaften}

Das Gen Homeodomain only protein gilt aus evolutionärer Sicht als junges Gen, HopOrthologe wurden im Genom aller bisher untersuchten Wirbeltierklassen gefunden (Zebrafisch, Krallenfrosch, Huhn, Maus, Ratte, Rind, Schwein und Mensch), Hop fehlt dagegen in der Fruchtfliege und im Fadenwurm (J. Adu et al., 2002; F. Chen et al., 2002). Hop kodiert eine Homeodomäne mit 57 \% Ähnlichkeit zur Homeodomäne des Pax6-Proteins. Obwohl Hop den typischen Aufbau der Homeodomäne aus drei $\alpha$-Helices aufweist, sind zahlreiche Aminosäuren der dritten $\alpha$-Helix nicht konserviert. Da diese Aminosäuren aber für die Bindung der Homeodomäne an die große Furche des DNA-Doppelstranges zuständig sind, wurde zunächst vorhergesagt - später experimentell bewiesen, daß Hop keine DNA-bindenden Eigenschaften aufweist (F. Chen et al., 2002; C. H. Shin et al., 2002). Homeodomäne-Proteine gelten im klassischen Sinne als Transkriptionsfaktoren, die an spezifische DNA-Elemente in Promotoroder Enhancer-Regionen binden und so die Transkription der nachgeschalteten Gene regulieren. Darüberhinaus wurde aber gezeigt, daß einige Homeodomäne-Proteine als Kofaktoren an andere Transkriptionsfaktoren binden und deren Aktivität modulieren (D. A. Grueneberg et al., 1995). Eine solche Funktion wurde für Hop beschrieben, das im Herzen als Korepressor des MADS-Transkriptionsfaktors Serum response factor auftritt (F. Chen et al., 2002). Im Hopdefizienten Herzen zeigen SRF-regulierte Gene wie ANF, Myoglobin, Myosin light chain $v 2$ und $\alpha$-Cardiac actin als Folge fehlender Korepression durch Hop eine erhöhte Expression. Es kommt zu einem partiell penetranten, früh letalen Phänotyp (F. Chen et al., 2002; C. H. Shin et al., 2002).

Die hier dargelegte Studie zur Expression von Hop im prä- und postnatalen Vorderhirn legte eine Funktion des Gens in der Genese des zerebralen Kortex nahe. Zunächst stellte sich die Frage, welche molekulare Funktion Hop im Kortex ausübt. In peri- und postnatalen Entwicklungsstadien ist $S R F$ im Gehirn der Ratte exprimiert, über embryonale Stadien wurden keine Aussagen gemacht (J. L. Stringer et al., 2002). In der vorliegenden Arbeit konnte SRF weder an E13,5 noch an E16,5 in Hop-positiven Bereichen der kortikalen Ventrikulärzone 
detektiert werden. Eine Interaktion von Hop und SRF scheidet demnach für den embryonalen Kortex aus. Generell wird davon ausgegangen, daß Hop mit anderen Proteinen als SRF, z. B.: mit anderen MADS-Transkriptionsfaktoren oder Histondeacetylasen der Klasse I interagieren kann (Y. Hamamori und M. D. Schneider, 2003; H. Kook und J. A. Epstein, 2003).

Bemerkenswert sind die unterschiedlichen Aussagen über die subzelluläre Lokalisation des Hop-Proteins. So wird in Chen et al., 2002 eine Kernlokalisation (Daten nicht gezeigt!), in Adu et al., 2002 eine zytoplasmatische Lokalisation beschrieben. Möglich ist, daß Hop je nach Zelltyp und -zustand in verschiedenen Zellkompartimenten vorliegt. Dies hätte jedoch weitreichende Konsequenzen für mögliche Funktionen des Proteins. Hier wurde eine FLAGmarkierte Variante des Hop-Proteins unter Kontrolle eines Hop-Enhancers (E1) in der embryonalen Fimbria des E16,5 Kortex exprimiert. FLAG-Immunreaktivität lag im Plasma und Fortsätzen der betreffenden Zellen vor. Eine Funktion von Hop als Transkriptions-Kofaktor wäre demnach in Zellen der embryonalen Fimbria unwahrscheinlich. Nicht auszuschließen ist eine Lokalisation in beiden Kompartimenten, also im Kern und im Zytoplasma.

Atypische Homeodomäne-Proteine können als Translationsfaktoren auftreten. Zum Beispiel wird in Drosophila melanogaster die Translation der Caudal-mRNA durch das HomeodomäneProtein Bicoid reprimiert. Der Arginin-Rest an Position 54 der Homeodomäne ist hierfür von entscheidender Bedeutung (D. Niessing et al., 2000). Auch Hop besitzt in Position 54 der Homeodomäne einen Arginin-Rest und wurde in einer Datenbanksuche nach atypischen Homeodomänen mit potentiellen RNA-Bindeeigenschaften aufgefunden (persönliche Kommunikation mit Dr. R. Rivera-Pomar/ MPI für biophysikalische Chemie/ Göttingen).

\section{Analyse des Kortex einer Hop-defizienten Mauslinie}

Um die Funktion des Hop-Gens für die Genese des zerebralen Kortex zu verstehen, wurde hier das Gehirn einer Hop-defizienten Mauslinie (C. H. Shin et al., 2002) analysiert. Hohe HopExpression lag in der medialen ventrikulären Zone des späten embryonalen Kortex und in Zellen des Neuroepithels des Gyrus dentatus vor. Es war also denkbar, daß Hop für die korrekte Ausbildung von Derivaten der medialen Ventrikulärzone (Hippocampus und Gyrus dentatus) notwendig ist. Die Makroanatomie des Gehirns, insbesondere des Hippocampus und Gyrus dentatus, war jedoch im Knock out weder an E16,5 noch im adulten Alter verändert. Auch die Expression verschiedener Markergene des E16,5-Kortex blieb vom Verlust des Hop-Gens unberührt. So zeigten Gene der Wnt-Familie (Wnt3a, Wnt5a, Wnt $8 b$ ) eine normale Ausbildung der embryonalen Fimbria an. Auch Markergene verschiedener Subpopulationen von Zellen der Ventrikulärzone (Lhx2, Dct, Ngn2, Hes5, Emx2) und des Hippocampus (KA1, Emx2) waren unverändert. Hop ist in der periolfaktorischen Region, später in der embryonalen Fimbria, exprimiert - Regionen, die als Ursprung von Cajal-Retzius-Zellen gelten (G. Meyer et al., 2002; 
K. Takiguchi-Hayashi et al., 2004). Cajal-Retzius-Zellen der Marginalzone (Reelin, Lhx5) lagen in normaler Anzahl im Hop-Knock out vor.

Durch Detektion des $\beta$-Galaktosidase-Proteins, das im Knock out vom Hop-Lokus exprimiert wurde, konnten die normalerweise Hop-positiven Zellen schließlich direkt visualisiert werden. Diese Zellen lagen im Knock out vor und zeigten das typische Migrationsverhalten zum Gyrus dentatus. Die Funktion des Hop-Gens war also zur Ausbildung und Aufrechterhaltung dieser Zellen nicht nötig.

Die Beobachtung einer erhöhten Proliferation von Kardiozyten im Hop-defizienten Herzen (F. Chen et al., 2002; C. H. Shin et al., 2002) und einer verringerten Expression von Hop in krebsartig veränderten Zellen (Chorionkarzinomzellen: K. Asanoma et al., 2003/ Lungenkrebszellen: Genbank-Eintrag gi21264585) führte zur Vermutung, daß die Kontrolle von Proliferation versus Differenzierung eine generelle endogene Funktion von Hop darstellt. Eine solche Funktion von Hop wird auch im Vorderhirn und Rückenmark vorgeschlagen, wo Hop ausschließlich in proliferierenden, nicht in differenzierten Zellen exprimiert ist. Um diesen Sachverhalt zu untersuchen, wurde die Proliferationsrate von Neuroblasten des E16,5-Kortex im Wildtyp und Hop-Knock out in drei verschiedenen Ebenen entlang der rostrocaudalen Achse untersucht. In jeder dieser Ebenen hatten nach dreißigminütiger Einwirkzeit 23-26\% der Zellen der medialen Ventrikulärzone das markierte Nukleotid BrdU inkorporiert. Der BrdUMarkierungsindex zeigte keine signifikanten Unterschiede zwischen Wildtyp- und Hopdefizientem Gehirn.

Zusammenfassend muß festgestellt werden, daß mit den hier durchgeführten Analysen keine phänotypischen Veränderungen im Hop-defizienten Gehirn identifiziert werden konnten. Eine Aussage über die Funktion des Gens im embryonalen Kortex ist nicht möglich.

\section{Das Fehlen eines Phänotyps im Hop-defizienten Gehirn}

Für das Fehlen eines Phänotyps nach Inaktivierung von Genen können verschiedene Ursachen vorliegen. So ist zunächst vorstellbar, daß redundante Mechanismen den Verlust eines einzelnen Gens kompensieren. Zum Beispiel bewirkt der Verlust des kortikalen Gens Emxl keine phänotypischen Veränderungen, führt aber im Doppel-Knock mit Emx2 zu drastischen Veränderungen im medialen Kortex, die viel stärker ausfallen, als die des Emx2-Knock outs alleine (M. Yoshida et al., 1997; K. Shinozaki et al., 2004). Eine Datenbanksuche zeigte, daß das Hop-Protein nicht zu einer Familie strukturell verwandter Proteine gehört. Als Homeodomäne-Protein weist Hop Ähnlichkeit und Verwandtschaft zu anderen Proteinen mit Homeodomäne auf, am stärksten zu den Transkriptionsfaktoren Pax6 und Goosecoid mit 40 \% Identität und 57 \% Ähnlichkeit der Aminosäuren der Homeodomäne (F. Chen et al., 2002). Obwohl eine Redundanz zwischen diesen Homeodomäne-Transkriptionsfaktoren und dem Hop- 
Protein möglich ist, scheint dies aufgrund der zugehörigen Expressionsmuster unwahrscheinlich. Zum Beispiel zeigen Pax6 und Hop sowohl im Rückenmark als auch im Vorderhirn eher komplementäre, als überlappende Expressionsmuster. Während Pax6 als Regulator des lateralen kortikalen Signalzentrums ("anti-hem") des Kortex fungiert, ist Hop im gegenüberliegenden Bereich der embryonalen Fimbria aktiv. Möglich ist die Existenz noch nicht identifizierter Gene, die in Hinsicht auf Struktur und Expression Ähnlichkeiten zu Hop aufweisen.

Der im Herzen beobachtete früh letale Phänotyp des Hop-Knock outs trat sowohl in einem gemischten, als auch im isogenen genetischen Hintergrund mit partieller Penetranz auf. Für diese partielle Penetranz wird hauptsächlich ein stochastischer Effekt verantwortlich gemacht, nämlich die mit einer bestimmten Wahrscheinlichkeit auftretende Ruptur des ausgedünnten Myokardiums zwischen E10,5 und E12,5. Haben Hop-defiziente Embryonen diesen Zeitraum überstanden, können andere Mechanismen den Aufbau des Herzmuskels unterstützen und ein Überleben ermöglichen (F. Chen et al., 2002; C. H. Shin et al., 2002). Trotzdem ist der Einfluß modifizierender Gene, der die Ausprägung des Phänotyps vom genetischen Hintergund abhängig macht, nicht auszuschließen. Solche Abhängigkeiten sind für andere Gene bekannt (K. S. Wittman und M. Hamburgh, 1968; J. H. Nadeau, 2001). Sollte partielle Penetranz des HopKnock outs auch im Gehirn vorliegen und von den selben modifizierenden Genen wie im Herzen abhängen, dann wäre die Analyse der Kortizes mit phänotypischer Veränderung nicht möglich, da die entsprechenden Embryonen einer frühen Letalität erliegen. In diesem Falle wäre es nötig, eine konditionelle Aktivierung des Gens nur im Gehirn vorzunehmen.

In Bai et al., 2003 wurde für die Ratte und die Maus gezeigt, daß der zeitlich begrenzte Knock down ${ }^{26}$ des Doublecortin-Gens durch RNA-Interferenz in utero einen Phänotyp hervorruft, der dem humanen Lissenzephalie-/ Doppelkortex-Syndroms ähnelt. Eben dieses Syndrom kann bekanntermaßen beim Menschen durch Mutationen im Doublecortin-Gen verursacht werden (J. G. Gleeson et al., 1999b). Bei Knock out des Doublecortin-Gens in der Maus treten überraschenderweise nicht die erwarteten Migrationsdefekte des DoppelkortexSyndroms auf. Der Neokortex gestaltet sich normal, nur milde Defekte im Hippocampus wurden beobachtet (J. C. Corbo et al., 2002). Diese Diskrepanz zwischen erwiesener Funktion des Gens im Menschen und Entbehrlichkeit des Gens in der Maus wird in Bai et al., 2003 ausführlich diskutiert. Dabei werden zwei Aspekte deutlich, die möglicherweise auch für Hop relevant sind: 1. Obwohl ein Gen zwischen verschiedenen Wirbeltierklassen konserviert ist, kann seine Funktion in einzelnen Spezies verzichtbar sein. Für Hop wäre in diesem Sinne das

\footnotetext{
${ }^{26}$ Knock down, engl.: das Niederschmettern, im biologischen Sinne: das Verringern der Expression eines Gens
} 
Studium der kortikalen Funktion in anderen Modellorganismen wie Zebrafisch, Ratte oder Primaten interessant. 2. Kompensatorische Mechanismen können den Verlust eines Genes ausgleichen, insbesondere, wenn es von Anfang der Embryogenese an fehlt und sich adaptive Prozesse über einen langen Zeitraum etablieren können. Durch die Verwendung der RNAInterferenz-Methode wird ein vollständiges Ausschalten des Doublecortin-Gens verhindert, was offensichtlich zur Unterdrückung kompensatorischer Mechanismen führt. Es wäre demnach interessant, Hop-Expression nur zu einem bestimmten Zeitpunkt und in einem bestimmten Maße zu verringern und daraus resultierende Veränderungen zu analysieren. Auch hier wären RNAi-Ansätze denkbar.

Mit der etablierten Mauslinie mit Bildung des Hop-FLAG-Fusionsproteins unter Kontrolle des Hop-Enhancers E1 wird ein anderer Ansatz verfolgt. Hierbei soll eine moderate Überexpression in Hop-positiven Zellen erreicht werden. Zukünftige Analysen dieser Mauslinie werden zeigen, inwieweit sich diese Vorgehensweise phänotypisch manifestiert und eine Funktion des Hop-Gens im Kortex offenlegt.

\section{Ein Deckplatten-induzierbares Enhancerelement steuert die Expression von Hop in Strukturen des Nervensystems}

\section{Identifikation eines Enhancerelementes "upstream" des Genlokus von Hop}

Durch Vergleich muriner und humaner genomischer Sequenzen "upstream" des Genlokus von Hop wurde hier ein konservierter Bereich aufgefunden, der eine Größe von 418 bp und einen Konservierungsgrad von 80 \% zwischen beiden Genomen aufwies. Der konservierte Bereich enthielt keinen offenen Leserahmen und war nicht als exprimierte Sequenz (EST) in EST-Datenbanken vertreten. Es war zu vermuten, daß es sich bei diesem Element um eine regulatorische Sequenz des Genlokus von Hop handelte.

In der Tat war eine genomische Sequenz von 706 bp, die das E1-Element und flankierende Bereiche enthielt, in der Lage, in vivo vom $\beta$-Globin-Minimalpromotor Transkription des Reporters $\beta$-Galaktosidase auszulösen. In zwei unabhängigen transgenen Mauslinien trat Reporteraktivität in Hop-positiven Bereichen im medialen Kortex (Ventrikulärzone, Gyrus dentatus, embryonale Fimbria), Hinterhirn (Nucleus vestibularis) und dorsalen Rückenmark auf. Die Aktivität des Enhancers deckte somit fast alle neuralen Expressionsdomänen von Hop ab und darf als Nervensystem-spezifisches Enhancerelement des Gens betrachtet werden. Eine Aussage, ob es auch die ventrale Expressionsdomäne von Hop im Rückenmark abdeckt, ist nicht sicher. Eine transgene Mauslinie zeigte Aktivität, eine andere nicht. Die Analyse weiterer transgener Linien kann hierüber Klarheit schaffen. 
Bereiche der lateralen Ventrikulärzone, die geringe Hop-Expression an E16,5 zeigten, waren negativ für E1-abhängige Enhanceraktivität. Diesem Unterschied können technische Ursachen zugrunde liegen, so diskutieren einige Autoren eine geringere Sensitivität von enzymhistochemischen Nachweismethoden von $\beta$-Galaktosidase im Vergleich zur Methode der RNA-in situ-Hybridisierung (A. Aguzzi und F. Theuring, 1994; D. Mahony et al., 2002). Interessant ist unter diesem Aspekt, daß auch die hier gezeigte $\beta$-Galaktosidase-Färbung im Genotyp Hop-/- (beide Hop-Allele sind durch das $\beta$-Galaktosidase-Gen ersetzt) negativ für die laterale Ventrikulärzone ausfiel. Wiederum mag dies einen methodischen Unterschied zwischen RNA- und Protein-Detektion widerzuspiegeln. Denkbar ist aber auch die Existenz anderer schwächerer Hop-Enhancer, welche für die Expression des Gens in der lateralen Ventrikulärzone verantwortlich sind und die im dritten Intron von Hop liegen, also im Bereich, der im Knock out deletiert ist. Es kann jedoch davon ausgegangen werden, daß E1 der wichtigste Enhancer ist, der die Expression von Hop im Nervensystem steuert. Trotz geringer ektopischer Enhanceraktivität in vivo (Epidermis, Rippen, Mittelhirn) lag in keiner untersuchten Linie Enhanceraktivität in nichtneuralen Hop-positiven Organen, wie Herz und Lunge, vor. Expression in diesen Regionen dürfte durch andere Enhancer oder alleine durch den Promotor des Hop-Gens gesteuert werden, wie es für die Expression im rechten Herzventrikel gezeigt wurde (F. Chen et al., 2002).

\section{Induktion des Hop-Enhancers durch Explantate der Deckplatte}

Sowohl Hop-mRNA als auch E1-abhängige Reporteraktivität wurden an E16,5 in der rostralen Ventrikulärzone in einem Gradienten von medial nach lateral detektiert. Zahlreiche Gene (z. B.: Emx2, $L h x 2$ ) weisen ähnliche Expressionsgradienten auf, wobei vermutet wird, daß diesen Gradienten die Aktion diffusibler Signalmoleküle aus der Deckplatte und der embryonalen Fimbria, zugrunde liegt (E. S. Monuki et al., 2001; E. A. Grove und T. FukuchiShimogori, 2003). In der Tat konnte für einen Enhancer des Emx2-Gens eine Abhängigkeit von Wnt- und Bmp-Signalen gezeigt werden - beides Proteinfamilien, die in der Deckplatte bzw. Fimbria gebildet werden (T. Theil et al., 2002). Auch der im Kortex beobachtete Lhx2-Gradient wurde auf Signale des medialen Signalzentrums zurückgeführt, namentlich auf Proteine der Bmp-Familie (E. S. Monuki et al., 2001). Schließlich ist die Deckplatte im Rückenmark und Mittelhirn als Signalzentrum etabliert, das für die Spezifizierung dorsaler Neuronenklassen notwendig ist (K. J. Lee et al., 2000; J. H. Millonig et al., 2000). Die Rolle der Deckplatte als Organisator dorsaler bzw. medialer Strukturen scheint im gesamten zentralen Nervensystem konserviert zu sein.

In der vorliegenden Arbeit wurde überprüft, inwieweit auch die Aktivität des Hop-Enhancers E1 von Deckplatten-Signalen abhängt. Dazu wurden E1-transgene Kortizes verschiedener 
Embryonalstadien in organotypischer Kultur gehalten und mit Transplantaten aus der dorsalen Mittellinie von E10,5-Embryonen des Wildtyps zusammengebracht. E10,5 ist ein Stadium, an dem der Schluß des Neuralrohrs vollzogen ist und die Deckplatte beginnt, sich zwischen den beiden Hemisphären einzusenken. Die Differenzierung des sekundären Signalzentrum (embryonale Fimbria) und des Plexus choroideus steht noch am Anfang (S. A. Bayer und J. Altman, 1991; E. S. Monuki et al., 2001). Die transplantierte Region enthielt demnach die Deckplatte sowie Anteile der frühen Fimbria. Als Transplantationsstelle wurde die Region des ventralen Palliums gewählt, wo keine endogene Enhanceraktivität vorlag.

Zunächst wurden E1-transgene Hirnschnitte des Stadiums E11,5 mit Gewebe der dorsalen Mittellinie von E10,5-Wildtypembryonen kultiviert. Nach zweitägiger Kultur zeigte $\beta$ Galaktosidase-Färbung eine ektopische Enhanceraktivität im ventralen Pallium an. E1abhängige Reporteraktivität konnte also tatsächlich durch Gewebe der dorsalen Mittellinie induziert werden. Auch E1-transgene Hirnschnitte des Stadiums E12,5 konnten ektopische Enhanceraktivität entwickeln, diese war jedoch geringer als die induzierte Aktivität in E11,5Gehirnen. Gehirne der Stadien E13,5 und E14,5 zeigten keine Kompetenz gegenüber Signalen der dorsalen Mittellinie, es konnte keine ektopische Enhanceraktivität erzeugt werden.

Der kritische Zeitraum, in dem E1-Aktivität von Signalen der Deckplatte/ Fimbria abhängt, endet demnach mit dem Embryonalstadium E12,5. Dies ist gleichzeitig der Zeitpunkt, an dem erstmals Hop-Expression im medialen Kortex sichtbar wird. Die Induktion E1-vermittelter Expression des Hop-Gens im Kortex scheint also vom medialen Signalzentrum abzuhängen, während die Aufrechterhaltung der Hop-Expression zu späteren Zeitpunkten eine intrinsische Eigenschaft der betroffen Zellen wird.

In der vorliegenden Arbeit wurde erstmals eine direkte induktive Kapazität von Gewebe der dorsalen Mittellinie des Vorderhirns gezeigt. Gewebe der dorsalen Mitellinie war in der Lage, im lateralen Pallium einen medialen Marker (E1-Aktivität) anzuschalten. Es handelte sich hierbei um einen spezifischen Effekt, da er nicht durch Transplantate der Shh-bildenden ganglionären Eminenzen nachgeahmt werden konnte.

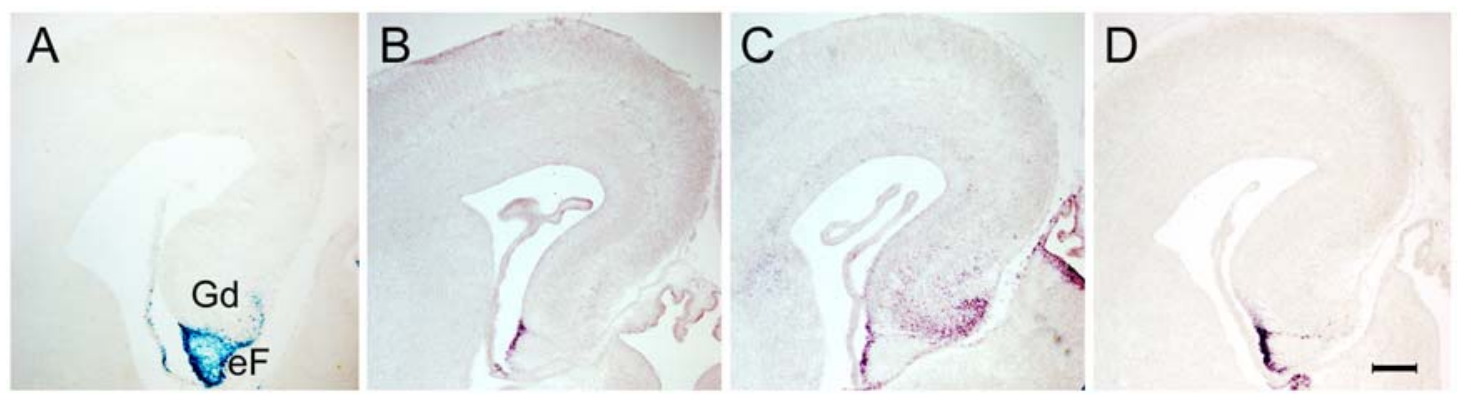

Abb. 26: Vergleich von E1-bedingter Reporteraktivität und Expression verschiedener Wnt-Gene im E16,5Kortex.

A: E1-bedingte $\beta$-Galaktosidase-Aktivität in der embryonalen Fimbria (eF) und Zellen des Gyrus dentatus (Gd).

B-D: Expression der $W n t$-Gene $W n t 3 a(B), W n t 5 a(C)$ und $W n t 8 b(\mathrm{D})$. Eichbalken: $200 \mu \mathrm{m}$. 
Es stellt sich die Frage nach den Faktoren, welche die beobachteten Effekte bewirken. Im gesamten Nervensystem ist die Deckplatte durch die Bildung von Bmp-Faktoren gekennzeichnet (K. F. Liem, Jr. et al., 1995; Y. Furuta et al., 1997; K. J. Lee et al., 1998). In Transplantationsexperimenten am Rückenmark konnte eine Induktion dorsaler Neuronentypen durch Deckplatten beobachtet werden. Dieser Effekt war durch Bmp-Faktoren nachzuahmen (K. F. Liem, Jr. et al., 1997). Auch die embryonale Fimbria ist durch Bmp-Expression ausgezeichnet. Darüberhinaus stellt die Fimbria wie erwähnt eine starke Quelle für WntProteine dar (E. A. Grove et al., 1998). Da die Wildtyp-Explantate eine Art "Fernwirkung" auf transgene Kortizes ausübten (beide Gewebe hatten lediglich Oberflächenkontakt), können die hier beobachteten Effekte am besten durch diffusible Faktoren erklärt werden. Als sezernierte Faktoren erfüllen Bmp- und Wnt-Proteine dieses Kriterium. Aus mehreren Gründen sind von beiden Proteinklassen Faktoren der Wnt-Familie zu favorisieren. So zeigte E1-Aktivität insbesondere in der embryonalen Fimbria und im Gyrus dentatus eine starke Überlappung mit Expression verschiedener Wnt-Gene (Abb. 26). Hop-Expression, E1-Aktivität und WntExpression fehlten im Plexus choroideus, der Bmp-positiv ist. Ferner lagen im E1-Element potentielle Bindestellen der TCF/ Lef-Transkriptionsfaktoren vor, welche als Vermittler des Wnt-Signalwegs gelten.

\section{Eine in vitro-Methode kann zur Kartierung des Nervensystem- spezifischen Enhancers von Hop eingesetzt werden}

\section{Elektroporation und organotypische Kultur als effiziente Methode des Gentransfers in das embryonale Gehirn}

Als Bestandteil der vorgelegten Arbeit sollte eine Methode entwickelt werden, die einen gezielten und effizienten Gentransfer in das embryonale Gehirn sowie die Analyse der daraus resultierenden Effekte erlaubt. Im hier verfolgten Ansatz wurde eine Kombination aus Transfektion durch Elektroporation und organotypischer Kultur realisiert.

R. Tur-Kaspa et al. führten 1986 die Elektroporation als Verfahren zum Transfer von Plasmiden in primäre Hepatozyten ein. Durch Verabreichung elektrischer Pulse kommt es zum vorübergehenden Verlust der Semipermeabilität der Zellmembran und zur Ausbildung von Nanometer großen Poren. Die Aufnahme von DNA-Molekülen durch die Zelle wird ermöglicht (T. Y. Tsong, 1991). In den folgenden Jahren wurde die Methode weiterentwickelt und fand als in ovo-Elektroporation breite Anwendung im Studium molekularer Mechanismen der Embryogenese des Huhnes (N. Itasaki et al., 1999; exemplarisch: A. Bach et al., 2003; M. Bylund et al., 2003; R. Scardigli et al., 2003). Auch Methoden zum Gentransfer in Mausembryonen nutzen das Prinzip der Elektroporation und werden erfolgreich zur 
Erforschung der Embryonalentwicklung des Gehirns eingesetzt. Dabei wird das Leben elektroporierter Embryonen entweder durch Embryokultur erhalten (N. Osumi und T. Inoue, 2001; M. Takahashi und N. Osumi, 2002; M. Takahashi et al., 2002) oder die Elektroporation wird ohne Unterbrechung der Schwangerschaft in utero durchgeführt (T. Fukuchi-Shimogori und E. A. Grove, 2001; H. Tabata und K. Nakajima, 2001; T. Fukuchi-Shimogori und E. A. Grove, 2003).

In der hier beschriebenen Methode zur Genexpression im embryonalen Gehirn werden hohe Effizienz und Gerichtetheit der Elektroporationstechnik und leichte Handhabbarkeit der organotypischen Kultur vereint. Ein Zugewinn zu den Möglichkeiten der Embryokultur wird im erweiterten Zeitfenster, in dem Manipulationen möglich sind, gesehen. Embryokultur: E7,0 bis E12,0 (Takahashi et al., 2002), organotypische Kultur: ab E11,0. Als Vorteile gegenüber der in utero-Elektroporation sind die höhere Effizienz und die leichtere Zugänglichkeit des Zielgewebes (zerebraler Kortex) zu nennen. Die Sterberate bei in utero-Manipulationen liegt bei ca. $40 \%$ (M. Takahashi et al., 2002).

Eine ähnliche wie die hier beschriebene Methode wurde von der Arbeitsgruppe um J. L. Rubenstein entwickelt und wurde zum Studium der Funktion von Dlx-Genen und Lhx6 in GABAergen Neuronen des Vorderhirns eingesetzt (T. Stühmer et al., 2002; P. Alifragis et al., 2004). In der vorliegenden Arbeit wurde die Methode der in vitro-Elektroporation erstmals zur Analyse eines Enhancerelementes der Maus verwendet.

\section{Aktivitätskartierung des E1-Elementes von Hop in vitro}

Durch Elektroporation und organotypische Kultur wurde das Plasmid, welches zur Generierung E1-transgener Mäuse verwendet wurde, im Thalamus, Hypothalamus, in den Basalganglien sowie in der medialen Ventrikulärzone des E14,5-Kortex exprimiert. Nach $24 \mathrm{~h}$ organotypischer Kultur zeigte $\beta$-Galaktosidase-Färbung ein starkes Signal im rostromedialen Kortex, also in der Region, die auch in vivo E1-bedingte Reporteraktivität aufwies. In anderen elektroporierten Hirnregionen, wie der caudomedialen Ventrikulärzone, dem Thalamus sowie den Basalganglien, waren weder in vivo noch in vitro Reporteraktivität nachzuweisen. Die regional spezifische Aktivität des Enhancerelementes E1 konnte in vitro rekapituliert werden. Der Schritt vom in vivo-System zum in vitro-System zur weiteren Charakterisierung von E1 war demnach gerechtfertigt. Arbeiten am Huhn bestätigten ebenfalls den Erhalt der Spezifität von Enhancerelementen nach Elektroporation (J. Timmer et al., 2001; D. Spieler et al., 2004).

Hier wurde in vitro gezeigt, daß das E1-Element, also die 418 bp große konservierte Region "upstream" des Hop-Genlokus, ausreicht, um im medialen Kortex Reporteraktivität vom Minimalpromotor auszulösen. Die Vermutung der eigentlichen Enhanceraktivität des 706 bpFragmentes im konservierten Bereich wurde bestätigt. Das E1-Element bewies dabei die 
Eigenschaften eines klassischen Enhancers, wie sie ursprünglich am SV40-Enhancer definiert wurden (J. Banerji et al., 1981; M. Fromm und P. Berg, 1983; B. Wasylyk et al., 1983). Diesen Charakteristika entsprechend war E1-Aktivität unabhängig von Orientierung ("sense" oder "antisense") und Lage (5' oder 3') vom Minimalpromotor.

Die Kartierung von E1 durch Deletionsanalyse in vitro offenbarte eine komplexe Natur dieses regulatorischen Elementes. Eine systematische Vorgehensweise zeigte, daß weder am 5'Ende gelegene, noch zentrale oder am 3'-Ende lokalisierte überlappende Teilfragmente von 170180 bp Länge die Aktivität von E1 rekonstituierten. Lediglich das 5'-Fragment zeigte Aktivität, diese war jedoch sehr stark vermindert im Vergleich zum Gesamtfragment.

Fragmente von 295 bzw. 200 bp Länge am 5'-Ende zeigten zum Gesamtbereich identische bzw. leicht verringerte Reporteraktivität. Das 200 bp-Fragment wurde als Minimalenhancer angesehen, es enthielt offensichtlich alle für die Enhancerfunktion nötigen Elemente. Der Aktivitätsunterschied zwischen dem 295 bp- und dem 200 bp-Fragment war sehr gering und kaum auf den Verlust spezifischer Bindestellen zurückzuführen. Im Differenzbereich von 95 bp lagen keine längeren konservierten Motive vor, auch wurden keine TranskriptionsfaktorBindemotive identifiziert.

Ein deutlicher Aktivitätsunterschied bestand zwischen dem 200 bp-Minimalfragment und einem vom 3'-Ende her um 29 bp verkleinerten Fragment. Jedoch konnte auch hierfür kein Verlust von Transkriptionsfaktor-Bindemotiven verantwortlich gemacht werden, da im Differenzbereich keine solchen Motive identifiziert wurden und außerdem ein sehr geringer Konservierungsgrad zwischen murinem und humanem Genom vorlag. Vielmehr schien ein erforderlicher Sequenzkontext vorzuherrschen, der nach Entfernung der fraglichen Sequenz fehlte. Solche Kontextabhängigkeit ist eine bekannte Erscheinung von Enhancerelementen (R. Grosschedl et al., 1994; M. Carey, 1998).

Die Verringerung des 200 bp-Minimalfragmentes vom 5'-Ende um 84 bp führte zu einer sehr starken Aktivitätsminderung. In diesem Bereich lagen potentielle TranskriptionsfaktorBindestellen und längere konservierte Abschnitte vor. Es handelte sich hierbei um Bindestellen der TCF/ Lef-Proteine sowie der Proteine Otx-1 und Pit1. Ferner lag eine nicht spezifizierte Bindestelle der Homeodomäne (TAAT-Motiv) vor.

Punktmutationen im TCF/ Lef-Otx-1-Motiv des 5'-Bereichs führten nicht zur Verringerung der Enhanceraktivität, ebensowenig die Kombination von Punktmutationen im TCF/ Lef-Otx-1Motiv des 5'-Bereichs und im TCF/ Lef-Motiv des 3'-Bereichs. Die in E1 vorliegenden TCF/ Lef-Bindemotive erwiesen sich nicht als funktionell. Dieser Befund überraschte, da die oben beschriebene ektopische Aktivierung des Enhancers durch Explantate der dorsalen Mittellinie in vitro auf eine Abhängigkeit des E1-Elementes vom Wnt/ TCF-Signalweg hindeutete. Ein drittes 
Motiv, das an E1-bedingter Enhanceraktivität beteiligt sein konnte, war das Oct6-Bindemotiv. Oct6 wird in der Ventrikulärzone des Gehirns exprimiert (N. Suzuki et al., 1990). Punktmutationen in dieser potentiellen Bindestelle wurden im Kontext des 200 bpMinimalenhancers gesetzt und führten nicht zu einer Aktivitätsminderung.

Zwei im Minimalenhancer lokalisierte potentielle Bindestellen wurden bisher nicht betrachtet, es handelt sich um die Pit1-Bindestelle sowie das nicht spezifizierte TAAT-Motiv. Pit1 kann kaum mit dem E1-Element in Verbindung gebracht werden, da es sich hierbei um einen Epiphysen-spezifischen Transkriptionsfaktor handelt (A. McCormick et al., 1990). Die mögliche Relevanz des TAAT-Motivs bleibt offen.

Lef Otx-1

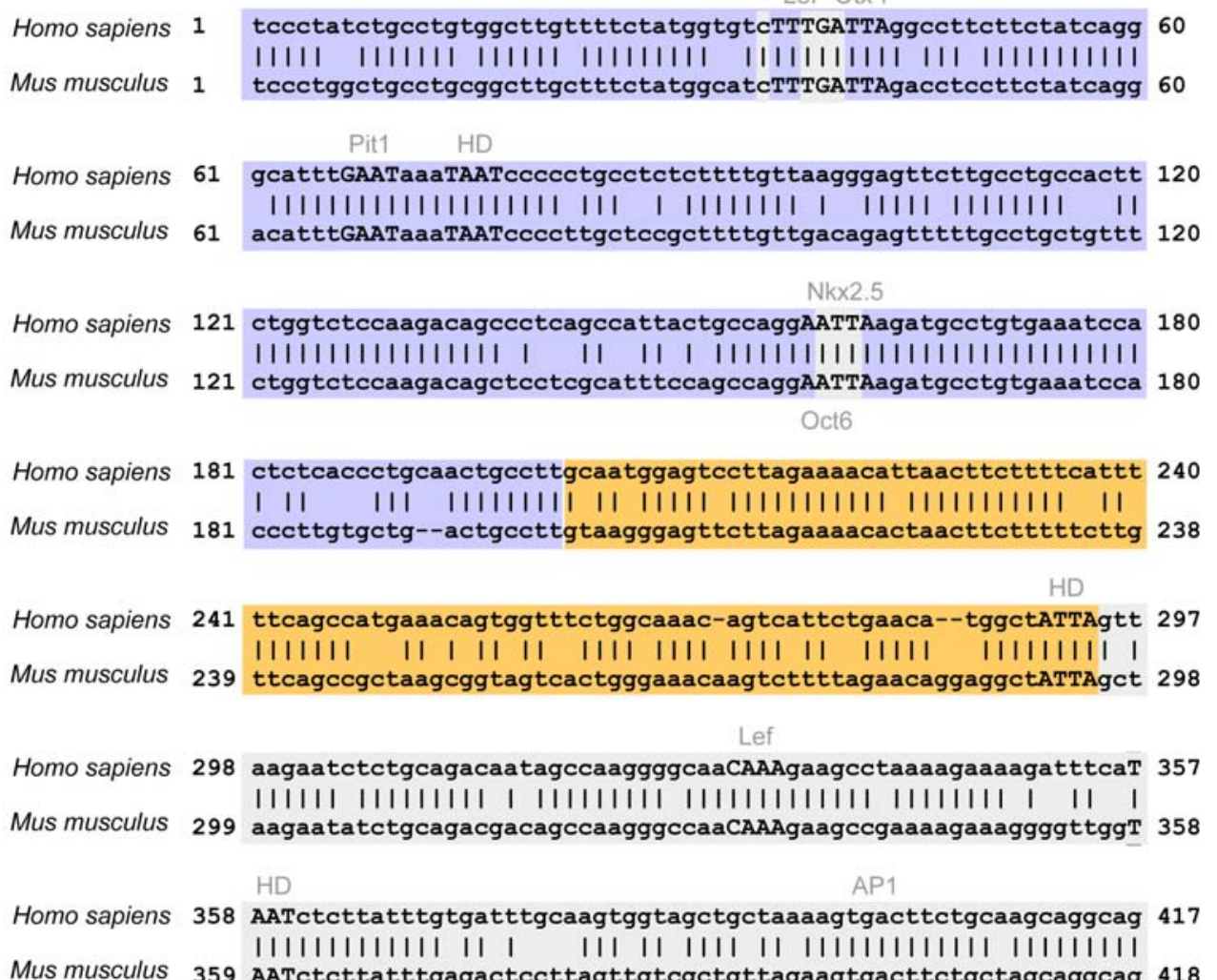

vollständige Enhanceraktivität

geringfügig verringerte Enhanceraktivität (Minimalenhancer)

nicht notwendig für Enhanceraktivität

Abb. 27: Kartierung des E1-Elementes:

Eine Sequenz von 200 bp am 5'-Ende des E1-Elementes ist ausreichend für starke Enhanceraktivität im medialen Kortex und wird als Minimalenhancer betrachtet (hellblauer Bereich). Sequenzinformation des 3'Bereiches (grauer Bereich) ist für die Enhanceraktivität nicht notwendig. 
Die Ergebnisse der hier durchgeführten Deletionsanalyse sind in Form einer Aktivitätskarte des E1-Elementes in Abb. 27 zusammengefaßt. Dabei erwies sich die Methode der in vitroElektropration als geeignet, die Sequenzinformation von 418 bp (ursprünglich 706 bp) auf einen 200 bp-Minimalenhancers zu reduzieren. Die Funktionalität der im Minimalenhancer vorliegenden Bindestellen für TCF/ Lef, Otx-1 und Oct6 konnte ausgeschlossen werden. Ebenso erwies sich der 3'-Bereich von mehr als 200 bp als nicht notwendig für E1-Enhanceraktivität. Es fällt auf, daß einige der verwendeten Deletionskonstrukte weder die vollständige E1-Aktivität noch einen völligen Aktivitätsverlust aufwiesen. Diese graduellen Unterschiede deuten darauf hin, daß die Enhanceraktivität des Elementes durch mehr als einen Transkriptionsfaktor bewirkt wird. Synergistische Effekte mehrer Faktoren sind häufig und erschweren die Kartierung der betreffenden regulatorischen Elemente (D. N. Arnosti et al., 1996; M. Carey, 1998; H. Skala et al., 1998; A. Iwahori et al., 2004; S. Lei et al., 2004). Darüberhinaus scheint ein Großteil des Sequenzkontextes von E1 für die Bindefähigkeit der beteiligten Faktoren notwendig zu sein.

\section{Ein Konzept zur Aktivierung des E1-Elementes im Kortex}

Obwohl hier keine Aussage über die Identität der E1-aktivierenden Transkriptionsfaktoren gemacht wird, kann ein generelles Konzept zum Mechanismus E1-abhängiger Expression von Hop im zerebralen Kortex entworfen werden. Zunächst bleibt festzustellen, daß E1-Aktivität während einer kritischen Phase, welche mit dem Embryonalstadium E12,5 endet, vom medialen Signalzentrum, der Deckplatte, induziert werden kann. Spätere Enhanceraktivität ist vom medialen Signalzentrum unabhängig. Der Expressioninitiation und -aufrechterhaltung könnten demnach verschiedene Mechanismen unterliegen. Für die Induktion von E1-Aktivität im Kortex kommen insbesondere Faktoren der Bmp- und Wnt-Familie in Frage. Auch wenn die in E1 vorliegenden Bindestellen der Wnt-Mediatoren TCF und Lef1 für die spätere (>E14,5) Aktivität des E1-Elementes ausgeschlossen wurden, besteht doch die Möglichkeit, daß sie in frühen Phasen eine Rolle spielen. Eine alleinige Abhängigkeit der Hop-Expression und E1-Aktivität vom Lef1-Transkriptionsfaktor kann ausgeschlossen werden, da Hop-Expression im medialen Lefl-defizienten Kortex bestehen bleibt. Andere Tcf-Faktoren sind jedoch denkbare Vermittler von E1-Aktivität, so $T c f 3$, daß in der kortikalen Ventrikulärzone und in der embryonalen Fimbria exprimiert wird (J. Galceran et al., 2000).

E1-Aktivität im E14,5-Kortex bedarf eines Minimalenhancers von 200 bp. TCF/ Lef-, Otx-1und Oct6-Bindemotive werden dafür nicht benötigt. Eine starke Kontextabhängigkeit und die mögliche Beteiligung mehrere Transkriptionsfaktoren-Bindemotive kennzeichnen die Enhanceraktivität des Minimalfragmentes. 


\section{Der Nervensystem-spezifische Enhancer von Hop - ein Werkzeug zur gezielten Genexpression in vivo}

In der vorliegenden Arbeit wurde anhand transgener Mauslinien gezeigt, daß Transkription, die unter Kontrolle des E1-Enhancerelementes vom $\beta$-Globin-Minimalpromotor ausgeht, auf Strukturen des medialen Kortex sowie des Rückenmarks und Hinterhirns beschränkt ist. So wurden das Reportergen $\beta$-Galaktosidase und eine für das Fusionsprotein Hop-FLAG kodierende cDNA unter Kontrolle von E1 exprimiert. In allen transgenen Mauslinien trat E1abhängige Expression unabhängig von Integrationseffekten in der embryonalen Fimbria auf (Abb. 28A).

Die Abgrenzung der als Signalzentrum auftretenden embryonalen Fimbria vom benachbarten Archikortex gilt als wichtiger Prozeß der Kortikogenese und ist in Lhx2defizienten Mäusen gestört. Im Lhx2-Knock out kommt es zur Agenese des Archikortex und einer Vergrößerung der embryonalen Fimbria (S. Bulchand et al., 2001). Als ungeklärt gilt hierbei die Frage, ob Lhx2 die kortikale Identität bestimmter Neurone determiniert, dessen Wegfall also zum Verlust des Kortex führt, oder ob Lhx2 die Ausbildung des Kortex ermöglicht, weil es die embryonale Fimbria in ihrer Ausdehnung beschränkt. Es wurde zur Klärung dieser Frage vorgeschlagen, Lhx2 ektopisch in der embryonalen Fimbria zu exprimieren und die Folgen dieser Manipulation zu analysieren (E. A. Grove und T. FukuchiShimogori, 2003). Für dieses Experiment darf die Generierung transgener Mäuse, welche Lhx2 unter Kontrolle des E1-Elementes exprimieren, als besonders geeignet und leicht realisierbar gelten (vergleiche Abb. 28A und B).

Schließlich könnte das E1-Elementes zur Generierung einer Mauslinie mit spezifischer Expression des Proteins Cre-Rekombinase im medialen Kortex und Bereichen des embryonalen Rückenmarks eingesetzt werden. Eine solche Mauslinie wäre eine hilfreiche Ergänzung zum derzeit begrenzten Repertoire an Mauslinien mit Cre-Expression im Kortex.

Diese als Ausblick angegebenen Anwendungen (ektopische Lhx2Expression, Cre-Linie) sollen in weiterführenden Projekten realisiert werden.

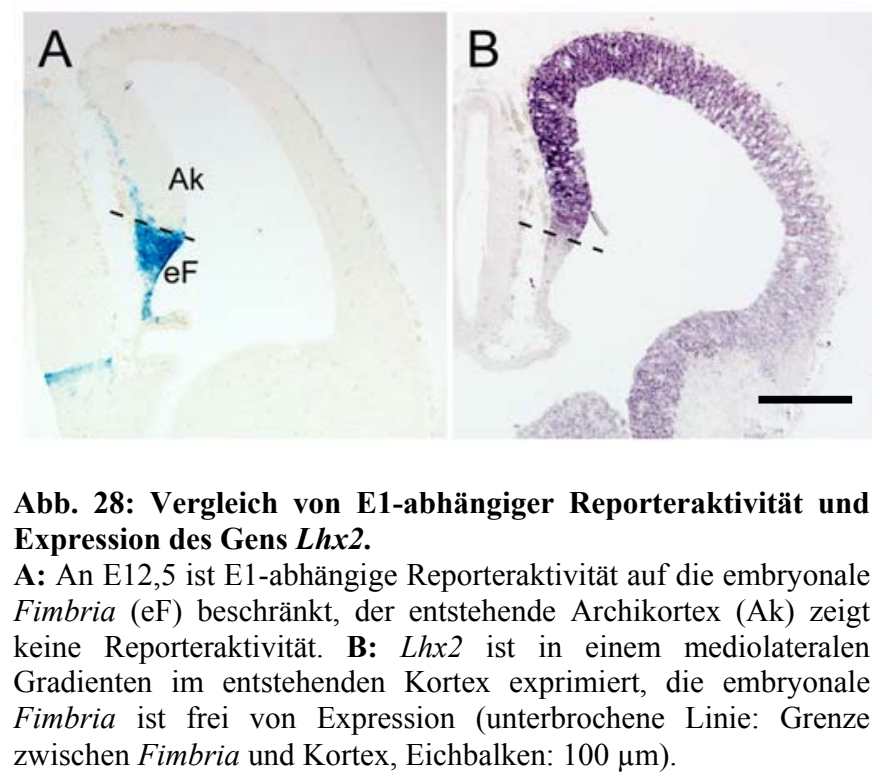




\section{Zusammenfassung}

In der vorliegenden Arbeit wurden mittels Microarray-Expressionsanalyse 114 Targetsequenzen identifiziert, die regional spezifische Expression im zerebralen Kortex des Embryonaltags 16,5 (E16,5) der Maus aufwiesen. 44 dieser Targetsequenzen konnten keinem bekannten Gen zugeordnet werden und galten als neue Gene. Eine funktionelle Klassifizierung der bekannten Gene charakterisierte den E16,5-Kortex als Struktur, in der Prozesse der Transkriptionsregulation und Signaltransduktion in regional spezifischer Weise ablaufen. Die Expressionsmuster von neun ausgewählten Genen (Ppp1r1b, Nurr1, Flrt3, Hop, Hippocampusspezifisch 1, Dct, Ebf3, NRIP1, Slcla3) wurden durch RNA-in situ-Hybridisierung im E16,5Gehirn analysiert und beschrieben. Hippocampus-spezifisch 1 ist ein neues Gen und kodiert ein hypothetisches Protein mit Bindeeigenschaften des nukleären Lokalisationssignals. Hippocampus-spezifisch 1 zeigte spezifische Expression in postmitotischen Zellen der Hippocampusformation.

Hier wurde das Gen Hop (Homeodomain only protein) ausgewählt, um dessen Expressionsmuster und Funktion im prä- und postnatalen Nervensystem zu analysieren. Ferner sollten regulatorische Elemente, welche für die Expression von Hop im Nervensystem verantwortlich zeichnen, aufgefunden und charakterisiert werden.

Expression von Hop konnte erstmals an E12,5 im medialen zerebralen Kortex identifiziert werden. Expression bestand fortan in der Ventrikulärzone des medialen Kortex und Neuroepithelien des Gyrus dentatus sowie der embryonalen Fimbria. Andere Hopexprimierende Strukturen des Nervensystems waren pränatal das Rückenmark und der Nucleus vestibularis, postnatal die Körnerzellschicht des Kleinhirns. Das räumlich und zeitlich dynamische Expressionsmuster des Hop-Gens wies auf eine Funktion während der Genese des zerebralen Kortex hin.

Das Studium einer Hop-defizienten Mauslinie offenbarte keine phänotypischen Veränderungen im prä- und postnatalen Gehirn, die auf eine Funktion des Gens schließen lassen. Hierzu wurden folgende Eigenschaften untersucht: Makroanatomie des embryonalen und adulten Gehirns, Markergen-Expression und Proliferationsrate der Neuroblasten im embryonalen Kortex (E16,5).

Bioinformatische Analyse offenbarte eine konservierte Region "upstream" des HopGenlokus, welche einen hohen Konservierungsgrad zwischen murinem und humanem Genom aufwies. Diese als E1-Element bezeichnete Region hatte eine Länge von 418 bp. Das E1- 
Element war in der Lage in vivo Expression des Reportergens $\beta$-Galaktosidase vom $\beta$-GlobinMinimalpromotor auszulösen. $\beta$-Galaktosidase-positive Bereiche waren mit den wichtigsten Expressionsdomänen von Hop im Nervensystem identisch. E1-getriebene Reporteraktivität bestand nicht in anderen Hop-exprimierenden Organen wie Herz und Lunge.

In vitro-Experimente zeigten eine Induzierbarkeit kortikaler E1-bedingter Reporteraktivität durch Gewebe der dorsalen Mittellinie des Vorderhirns. Diese Induzierbarkeit endete mit dem Embryonalstadium E12,5 (einschließlich), also dem Sichtbarwerden von Hop-Expression im Kortex.

Hier wurde eine neue Methode zur Plasmidexpression im embryonalen Kortex etabliert. Diese Methode machte sich die Verfahren der Transfektion durch Elektroporation und der organotypischen Kultur zu nutze. Durch Elektroporation konnte E1-bedingte Reportearktivität in regional spezifischer Weise in vitro reproduziert werden. Das neue Verfahren wurde zur Aktivitätskartierung des Elementes E1 eingesetzt. Unter Ausschluß der funktionellen Relevanz von Bindestellen der Transkriptionsfaktoren TCF/ Lef- Otx-1 und Oct6 konnte ein Minimalenhancer von 200 bp etabliert werden.

Die hohe Spezifität des E1-Elementes in vivo und in vitro erlaubt die gezielte Expression von Proteinen im medialen Kortex und in der embryonalen Fimbria. Hier wurde eine Mauslinie mit Bildung eines Hop-FLAG-Fusionsproteins unter Kontrolle von E1 etabliert. Die zukünftige Analyse dieser Mauslinie soll im Sinne eines "gain of function"27-Experimentes einen Zugang zur Funktion von Hop im embryonalen Kortex geben. Durch Experimente, wie die ektopische Expression von kortikalen Transkriptionsfaktoren (z. B.: BF1 und Lhx2) im Bereich der embryonalen Fimbria, könnte der Einsatz des E1-Elementes zukünftig zum Verständnis der Musterbildung im medialen Kortex beitragen.

\footnotetext{
${ }^{27}$ gain of function, engl.: Zugewinn an Funktion
} 


\section{Material und Methoden}

\section{Organismen}

\section{Mäuse}

Eine Hop-defiziente Mauslinie wurde im Rahmen einer Kollaboration von der Arbeitsgruppe um Prof. E. N. Olson (Department of Molecular Biology, University of Texas Southwestern Medical Center at Dallas, 6000 Harry Hines Boulevard, Dallas, TX 75390, USA) zur Verfügung gestellt. Lef1-defiziente Mäuse zur Untersuchung der Hop-Expression stammten aus dem Labor von Prof. R. Grosschedl (Gene Center and Institute of Biochemistry, Universität München). Tiere des Mausstammes FVB wurden von Harlan Winkelmann (Borchen), CD1-Mäuse von Charles River (Sulzfeld) bezogen.

\section{Bakterien}

Es wurden Bakterien des im Labor vorliegenden Stammes E. coli DH5 $\alpha$ verwendet. Bakterien der Stämme E. coli NP66 und NM522 wurden von Pharmacia bezogen.

\section{Material}

\section{Allgemeine Angaben}

Im weiteren Text sind Prozentangaben für Feststoffe als Masseprozent, für Flüssigkeiten und Gase als Volumenprozent zu verstehen. Lösungen wurden in Wasser angesetzt, andernfalls ist das Lösungsmittel ausgewiesen. Verwendetes Wasser wurde im Ionenaustauscher (MilliQ synthesis, Millipore) entmineralisiert.

\section{Chemikalien und Enzyme}

Chemikalien wurden von den Firmen Difco, Fluka, Gibco, Merck, Roth und Sigma bezogen. Es wurden Chemikalien des Reinheitsgrades "p.a." (zur Analyse) verwendet. DNA-Primer wurden von der IBA-GmbH Göttingen bezogen.

Sofern nicht anders ausgewiesen, wurden verwendete Enzyme von Boehringer-Mannheim, Promega und GeneCraft bezogen. 


\section{Kulturmedien und Nährböden}

\begin{tabular}{|c|c|}
\hline \multicolumn{2}{|l|}{ STI-Medium: } \\
\hline$\overline{\mathrm{NaCl}}$ & $1 \%$ \\
\hline Trypton & $1 \%$ \\
\hline $\begin{array}{l}\text { Hefeextrakt } \\
\text { pH 7,0 }\end{array}$ & $0,5 \%$ \\
\hline \multicolumn{2}{|l|}{ STI ${ }^{\mathrm{A}}$-Medium: } \\
\hline \multicolumn{2}{|c|}{ STI-Medium mit Zusatz von: } \\
\hline Ampizillin & $50 \mu \mathrm{g} / \mathrm{ml}$ \\
\hline \multicolumn{2}{|c|}{ STI ${ }^{\mathrm{A}}$-Bakterienagarplatten: } \\
\hline \multicolumn{2}{|c|}{ STI ${ }^{A}$-Medium mit Zusatz von: } \\
\hline Bakterienagar & $1,5 \%$ \\
\hline \multicolumn{2}{|l|}{ 2xYT ${ }^{\mathrm{S}}$-Medium: } \\
\hline $\mathrm{NaCl}$ & $0,5 \%$ \\
\hline Trypton & $1,6 \%$ \\
\hline Hefeextrakt & $1 \%$ \\
\hline $\begin{array}{l}\text { Spektinomycin } \\
\text { pH } 7,0\end{array}$ & $50 \mu \mathrm{g} / \mathrm{ml}$ \\
\hline
\end{tabular}

2xYT ${ }^{\mathrm{CSM}}$-Medium:

$2 x Y T^{S}$-Medium mit Zusatz von:

Maltose $\quad 0,2 \%$

Chloramphenikol $\quad 50 \mu \mathrm{g} / \mathrm{ml}$

NZCYM ${ }^{\mathrm{S}}$-Medium:

Kaseinhydrolysat $\quad 1 \%$

$\mathrm{NaCl} \quad 0,5 \%$

Casaminosäuren $\quad 0,1 \%$

Hefeextrakt $\quad 0,5 \%$

$\mathrm{MgSO}_{4} \quad 8 \mathrm{mM}$

Maltose $\quad 0,2 \%$

Spektinomycin $\quad 50 \mu \mathrm{g} / \mathrm{ml}$

pH 7,0

$\mathrm{pH} 7,0$

\section{Standardlösungen}

PBS:

$\mathrm{NaCl}$

$\mathrm{Na}_{2} \mathrm{HPO}_{4}$

$\mathrm{NaH}_{2} \mathrm{PO}_{4}$

$\mathrm{pH} \mathrm{7,2}$

PFA:

Paraformaldehyd $\quad 40 \mathrm{~g}$

PBS

bei $62{ }^{\circ} \mathrm{C}$ gelöst, filtriert

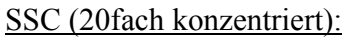

$\mathrm{NaCl} \quad 3 \mathrm{M}$

Natriumzitrat $\quad 0,3 \mathrm{M}$

pH 4,5 bzw. pH 7,5

$130 \mathrm{mM}$

$7 \mathrm{mM}$

$3 \mathrm{mM}$

11

MOPS-Puffer:

3-(N-Morpholino)propansulfonsäure

Natriumazetat

$200 \mathrm{mM}$

$50 \mathrm{mM}$

$\mathrm{pH} 7,0$
TE:

Tris-Cl $10 \mathrm{mM}$

pH 7,5 oder 8,0

$\underline{T}_{1 / 10}$ E:

Tris-Cl $\quad 10 \mathrm{mM}$

EDTA $\quad 0,1 \mathrm{mM}$

$\mathrm{pH} 7,5$

TBE (einfach konzentriert):

Tris-Borat $\quad 89 \mathrm{mM}$

Borsäure $\quad 89 \mathrm{mM}$

EDTA $2 \mathrm{mM}$

$\mathrm{pH} 8,0$

\section{Methoden}

\section{Allgemeine Anmerkungen}

Sofern nicht anders ausgewiesen, wurden Versuche bei Raumtemperatur (RT) ausgeführt. Zentrifugationsschritte von Lösungen mit kleinem Volumen $(<2 \mathrm{ml})$ erfolgten in 1,5 ml - oder $2,0 \mathrm{ml}$ - Reaktionsgefäßen in Tischzentrifugen (Eppendorf) bei $13000 \mathrm{U} / \mathrm{min}$. Für große 
Volumina wurden 50 ml-Gefäße in HS4-Rotoren und RC50-Zentrifugen der Firma Sorvall bei bis zu $7000 \mathrm{U} / \mathrm{min}$ eingesetzt.

\section{Präparative und analytische Arbeiten mit Nukleinsäuren}

\section{DNA-Präparation}

Das Plasmid enthaltende Bakterien wurden auf $\mathrm{STI}^{\mathrm{A}}$-Bakterienagarplatten ausgestrichen und über Nacht bei $37{ }^{\circ} \mathrm{C}$ inkubiert. Zur Vorkultur wurden Einzelkolonien in $5 \mathrm{ml} \mathrm{STI}{ }^{\mathrm{A}}$-Medium inokuliert und 6-8 h bei $37^{\circ} \mathrm{C}$ schüttelnd inkubiert. Es folgten das Animpfen von $100 \mathrm{ml} \mathrm{STI}{ }^{\mathrm{A}}$ Medium mit $1 \mathrm{ml}$ Vorkultur und Inkubation unter Schütteln über Nacht bei $37{ }^{\circ} \mathrm{C}$. Zur Präparation von Plasmid-DNA kam das "QIAfilter Plasmid Maxi Kit" (Qiagen) zur Verwendung. Dabei wurde nach den Angaben des Herstellers verfahren. Gewonnene PlasmidDNA wurde in $200 \mu 1$ TE-Puffer (pH 7,5) gelöst.

Zur analytischen DNA-Präparation wurde das "QIAfilter Plasmid Mini Kit" (Qiagen) verwendet.

\section{Konzentrationsbestimmung von Nukleinsäuren in Lösung}

Die Konzentration von DNA bzw. RNA wurde in einem Spektrophotometer (Bio Photometer, Eppendorf; UV-Küvetten, Brand) bestimmt. Dazu wurde die DNA/ RNA-Lösung 1:100 in Wasser verdünnt und die optische Dichte bei $260 \mathrm{~nm}\left(\mathrm{OD}_{260}\right)$ ermittelt. Eine $\mathrm{OD}_{260}$ von 1 entspricht einer Konzentration von $50 \mu \mathrm{g}$ doppelsträngiger DNA bzw. $40 \mu \mathrm{g}$ RNA pro ml Lösung.

Geringe DNA-Konzentrationen wurden im Agarosegel durch den Vergleich der Fluoreszenzintensitäten der unbekannten mit einer bekannten DNA-Probe abgeschätzt.

\section{Agarosegelelektrophorese}

$\mathrm{Zu}$ analytischen und präparativen Zwecken wurden DNA-Fragmente im Agarosegel nach ihrer Größe aufgetrennt. Je nach aufzutrennender Fragmentgröße wurden 0,5 - 2 \% Agarose und $0,1 \mathrm{mg} / \mathrm{ml}$ Ethidiumbromid (Sigma) in einhalbfach konzentriertem TBE-Puffer verwendet. Einhalbfach konzentrierter TBE-Puffer diente auch als Laufpuffer. DNA-Proben wurden 1:5 in Ladepuffer verdünnt eingesetzt. Die Detektion der DNA-Banden erfolgte im UV-Licht $(\lambda=258$ $\mathrm{nm}$ ), die Dokumentation mittels Fotografie. Zur Vermeidung von DNA-Strangbrüchen und der Bildung von Thymidindimeren wurden präparative Gele nur langwelligem UV ausgesetzt $(\lambda>$ $300 \mathrm{~nm})$.

\begin{tabular}{ll} 
Ladepuffer: & \\
\hline Ficoll & $15 \%$ \\
EDTA, pH 8 & $60 \mathrm{mM}$ \\
Bromphenolblau & $0,01 \%$ \\
Xylencyanat & $0,03 \%$
\end{tabular}




\section{Ethanolfällung}

Ein Volumenanteil DNA-haltiger Lösung wurde mit 0,1 Volumenanteilen $3 \mathrm{M}$ Natriumazetat und 2,5 Volumenanteilen Ethanol versetzt und mindestens $2 \mathrm{~h}$ bei $-20{ }^{\circ} \mathrm{C}$ inkubiert. Das DNA-Präzipitat wurde durch Zentrifugation bei höchster Umdrehungszahl abgeschieden und in $75 \%$ Ethanol gewaschen. Nach Trocknung des DNA-Pellets wurde es in einem geeigneten Volumen Wasser oder TE-Puffer gelöst.

\section{PCI- und CI-Extraktion}

Extraktionen mit PCI (Phenol-Chloroform-Isoamylakohol; TE-gesättigt; pH 7,5; Roth) und CI (Chloroform-Isoamylakohol) wurden zur Entfernung von Proteinrückständen aus DNAhaltigen Lösungen durchgeführt. Die DNA-Lösung wurde mit einem äquivalenten Volumen des PCI-Gemisches ( $\mathrm{vol} / \mathrm{vol} / \mathrm{vol}=24 / 24 / 1) \mathrm{bzw}$. der CI-Mischung $(\mathrm{vol} / \mathrm{vol}=24 / 1)$ versetzt, $30 \mathrm{~s}$ kräftig geschüttelt und die Phasen durch Zentrifugation getrennt. Die wässrige Phase wurde abgenommen und die DNA durch Ethanolfällung gewonnen.

\section{Isolation von DNA aus dem Agarosegel}

DNA-Fragmente wurden im präparativen Agarosegel nach ihrer Größe aufgetrennt, die gewünschte DNA-Bande unter langwelligem UV-Licht lokalisiert und das Gelstück ausgeschnitten. Mit Hilfe der Option Gelextraktion des "QIAquick Kit" (Qiagen) wurde die DNA aus dem Gelstück isoliert und in $30 \mu 1$ TE-Puffer eluiert.

\section{Isolation genomischer DNA aus Gewebe}

Gewebe aus Schwanzspitzen wurde über Nacht bei $56{ }^{\circ} \mathrm{C}$ in $500 \mu$ Proteinase K-Lysepuffer verdaut. Gewebereste wurden durch Zentrifugation abgetrennt und der Überstand mit PCI extrahiert. Die genomische DNA wurde mit $400 \mu 1$ Isopropanol gefällt, einmal in $70 \%$ Ethanol gewaschen, getrocknet und $1 \mathrm{~h}$ bei $60^{\circ} \mathrm{C}$ in $1 \mathrm{ml} \mathrm{T} \mathrm{T}_{1 / 10}$ E-Puffer gelöst.

$\begin{array}{ll}\text { Proteinase K-Lysepuffer: } & \\ \text { Tris-Cl; pH 8,5 } & 100 \mathrm{mM} \\ \text { EDTA } & 5 \mathrm{mM} \\ \text { SDS } & 0,2 \% \\ \mathrm{NaCl} & 200 \mathrm{mM} \\ \text { Proteinase K } & 1 \mathrm{mg} / \mathrm{ml}\end{array}$

\section{Sequenzierung}

Zur Sequenzierung wurde das Verfahren der kontrollierten Unterbrechung der DNASynthese nach Sanger et al., 1977 eingestzt. Die Bestimmung der Nukleotidsequenzen wurde auf einem ABI PRISM-377 DNA-Sequencer durchgeführt. Im Reaktionsansatz wurden 300 400 ng DNA, 10 pmol Primer und 4,5 ml Big Dye Terminator Cycle Sequencing Kit-Lösung zugegeben. Die Reaktion fand in einem Gesamtvolumen von 11,5 - 13,5 ml statt. Das Cycle 
sequencing-Programm $\left(30 \mathrm{~s}, 95{ }^{\circ} \mathrm{C} ; 10 \mathrm{~s}, 50{ }^{\circ} \mathrm{C} ; 4 \mathrm{~min}, 60^{\circ} \mathrm{C} ; 25\right.$ Zyklen) wurde in einem Biometra Trio-Thermoblock durchgeführt. Nach der Reaktion wurde der Ansatz mit Ethanol gefällt und in Big Dye-Auftragspuffer gelöst. Die Analyse erfolgte auf dem Sequenziergel und wurde mit der Computersoftware "Sequencher" ausgewertet.

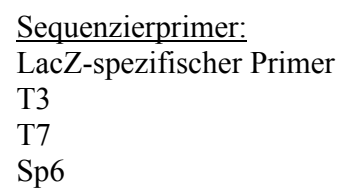

\author{
AGCGGCTGATGTTGAACTG \\ AATTAACCCTCACTAAAGG \\ CTAATACGACTCACTATAGGGC \\ ATTTAGGTGACACTATAG
}

\section{Herstellen radioaktiv markierter DNA-Sonden}

50 - 100 ng DNA wurden in $45 \mu 1$ TE-Puffer für 5 min bei $95{ }^{\circ} \mathrm{C}$ denaturiert, auf $4{ }^{\circ} \mathrm{C}$ abgekühlt und unter Zuhilfenahme des Kit "RediPrime II" (Amersham) mit $50 \mu \mathrm{Ci}{ }^{32} \mathrm{P}$-dCTP (Amersham) 15 min bei $37^{\circ} \mathrm{C}$ radioaktiv markiert. Die Reaktion wurde mit $5 \mu$ EDTA $(0,2 \mathrm{M})$ beendet, nichtinkorporierte Nukleotide durch Gelfiltration an G50-Säulen (Amserham) entfernt. Zur Überprüfung der Qualität der radioaktiven Markierung wurde die spezifische Aktivität der Sonde im Szintillationszähler (Beckmann) gemessen. Die DNA-Sonde sollte eine spezifische Aktivität von mindestens $5 \times 10^{8}$ Zerfällen $/ \mathrm{min} / \mu \mathrm{g}$ aufweisen.

\section{Klonierung von DNA-Fragmenten}

\section{Vektorpräparation}

Vektor-DNA wurde für $3 \mathrm{~h}$ mit einem Überschuß des entsprechenden Restriktionsenzyms (3-5 Units/ $\mu \mathrm{g}$ Plasmid-DNA) bei $37{ }^{\circ} \mathrm{C}$ in geeignetem Puffer inkubiert. Das linearisierte Plasmid wurde durch Gelelektrophorese und Elution aus dem Gel aufgereinigt und für 30 min bei $37{ }^{\circ} \mathrm{C}$ in CIP-Puffer der Behandlung mit alkalischer Phosphatase aus dem Kälberdarm (CIP) unterzogen. Die DNA wurde PCI-extrahiert, mit Ethanol gefällt und in $10 \mu 1$ TE resuspendiert. Vektoren, die mit zwei verschiedenen Restriktions-Enzymen geschnitten wurden, wurden nicht mit CIP behandelt.

\section{Präparation von Restriktionsfragmenten}

$\mathrm{Zu}$ klonierende DNA-Fragmente (Inserts) wurden durch Restriktionsverdau aus bereits vorhandenen Plasmiden ausgeschnitten. Das DNA-Fragment wurde durch Gel-Elektrophorese (1 \% Agarose) und Elution aus dem Gel ("QIAquick Gel Extraction Kit", Qiagen) aufgereinigt, es folgten Fällung mit Ethanol und Resuspension in $10 \mu 1 \mathrm{TE}$.

\section{Präparation von PCR-Fragmenten}

Einige klonierte Fragmente wurden durch Polymerase-Kettenreaktion aus genomischer DNA amplifiziert. Die PCR-Produkte wurden aufgereinigt ("QIAquick PCR Purification Kit", 
Qiagen), mit Ethanol gefällt und in geeignetem Volumen TE aufgenommen. Um in den Vektor "pGEM-T Easy" (Promega) zu klonieren, konnte aufgrund des A-Überhanges der PCRProdukte direkt zur Ligation übergegangen werden.

Sollten PCR-Produkte als Restriktionsfragmente kloniert werden, so wurden in der PCR Primer verwendet, welche Überhänge mit entsprechenden Restriktions-Schnittstellen enthielten.

\section{"Blunt end"28-Klonierung}

Zur Klonierung in "blunt end"-Vektoren wurden 5'-Überhänge von Restriktionsfragmenten mittels Klenow-Fragment aufgefüllt (15 min bei RT; $50 \mu \mathrm{M}$ dNTP; $10 \mathrm{mM} \mathrm{MgCl}$; 5 Units/ $\mu \mathrm{l}$ Klenow). 3'-Überhänge wurden durch T4-DNA-Polymerase entfernt (15 min bei RT; $100 \mu \mathrm{M}$ dNTP; T4-DNA-Polymerase-Puffer). Beide Reaktionen wurden für 10 min bei $65{ }^{\circ} \mathrm{C}$ hitzeinaktiviert, das Enzym durch PCI-Extraktion abgetrennt.

\section{Ligation}

Die Konzentrationen von Insert und Vektor wurden im Agarosegel abgeschätzt. Zur Ligation wurde angestrebt, Insert und Vektor im Stoffmengenverhältnis von 3:1 einzusetzen. Die Ligation erfolgte bei Raumtemperatur, über Nacht.

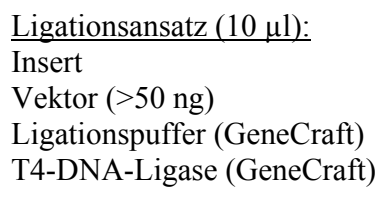

\author{
3 Stoffmengenanteile \\ 1 Stoffmengenanteile \\ einfach konzentriert \\ 10 Units/ Ansatz
}

\section{Transformation durch Elektroporation}

\section{Herstellung elektrokompetenter Bakterien}

Zur Herstellung elektrokompetenter Bakterien wurde eine Einzelkolonie des Bakterienstammes E. coli DH5 $\alpha$ in $50 \mathrm{ml}$ STI-Medium inokuliert und über Nacht bei $37{ }^{\circ} \mathrm{C}$ schüttelnd inkubiert. 2,5 $\mathrm{ml}$ dieser Starterkultur wurden in $250 \mathrm{ml}$ STI-Medium überimpft und weiter kultiviert, bis die Kultur bei $600 \mathrm{~nm}$ eine optischen Dichte von 0,5 - 0,6 aufwies. Die Kultur wurde auf Eis abgekühlt (15 min) und die Bakterien pelletiert. Nacheinander wurden die Bakterien durch Resuspension und Zentrifugation dreimal in sterilem Wasser und dreimal in $10 \%$ Glycerol gewaschen. Alle Waschschritte erfolgten bei $4{ }^{\circ} \mathrm{C}$. Schließlich wurden die Bakterien in einem dem Volumen des Pellets equivalenten Volumen $10 \%$ Glycerol resuspendiert, aliquotiert und auf Trockeneis eingefroren. Die Lagerung erfolgte bei $-80^{\circ} \mathrm{C}$.

\footnotetext{
${ }^{28}$ blunt end, engl.: glattes Ende
} 


\section{Elektrotransformation}

Für die Elektrotransformation wurden $50 \mu$ lektrokompetente Bakterien und 1 - 5 ng Plasmid-DNA oder $1 \mu 1$ Ligationsansatz 10 min auf Eis inkubiert. Die Elektroporation erfolgte in Küvetten mit 0,1 cm Elektrodenabstand (Gene Pulser Cuvette, Bio-Rad) bei 1,8 kV und einer Kapazität von $25 \mu \mathrm{F}$ im Elektroporationsgerät (Gene Pulser, Bio-Rad). Die Bakteriensuspension wurde in $1 \mathrm{ml}$ STI-Medium aufgenommen und für eine Stunde schüttelnd bei $37{ }^{\circ} \mathrm{C}$ inkubiert. Schließlich wurden $100 \mu 1$ der Bakterienkultur auf $\mathrm{STI}^{\mathrm{A}}$-Bakterienagarplatten ausplattiert und über Nacht bei $37^{\circ} \mathrm{C}$ inkubiert.

\section{Expressionsanalyse mittels Microarray-Technologie}

Zur Expressionsanalyse wurde die "GeneChip"-Technologie der Firma Affymetrix eingesetzt. Es wurden die Microarrays Test3 Array, MGU74Av2, MGU74Bv2 und MGU74Cv2 verwendet.

\section{Gewebe-Präparation und RNA-Isolation}

Tris-freie Lösungen wurden mit DEPC $\left(0,1 \%\right.$; Sigma) bei $37{ }^{\circ} \mathrm{C}$ über Nacht behandelt und autoklaviert. Tris enthaltende Puffer wurden autoklaviert. Alle Arbeitsschritte erfolgten unter RNase-freien Bedingungen

Gewebe aus fünf Regionen des zerebralen Kortex 16 Tage alter Embryonen wurde isoliert (rostromedial, caudomedial, dorsofrontal, dorsocaudal, parietal). Als zusätzliche Probe wurde der Körper nach Entfernung von Rückenmark und Genitalanlage verwendet ("Restkörper"). Die Präparation erfolgte in eiskaltem DEPC-PBS. Isoliertes Gewebe wurde bis zur weiteren Verwendung in RNAlater (Ambion) bei $4^{\circ} \mathrm{C}$ aufbewahrt.

Das Gewebe wurde mit Hilfe eines Homogenisators (Polytron PT1200, Kinematica) homogenisiert und die Gesamt-RNA mit Hilfe des "RNeasy Mini Kit" (Qiagen) isoliert. Die Integrität der RNA wurde im nativen Agarosegel (1 \%) überprüft, deren Konzentration in einem Spektrophotometer bestimmt.

\section{cDNA-Synthese}

Zur Synthese von doppelsträngiger cDNA aus Gesamt-RNA wurde das "SuperScript Choice System" der Firma Invitrogen Life Technologies verwendet. Dabei wurden $9 \mu$ g Gesamt-RNA pro Gewebeprobe eingesetzt. Das Protokoll begann mit der Primerhybridisierung (10 min, 70 $\left.{ }^{\circ} \mathrm{C}\right)$, es folgten Temperatureinstellung $\left(2 \mathrm{~min}, 42^{\circ} \mathrm{C}\right)$, Synthese der einzelsträngigen cDNA $(1 \mathrm{~h}$, $\left.42{ }^{\circ} \mathrm{C}\right)$, Syntheses der doppelsträngigen cDNA $\left(2 \mathrm{~h}, 16^{\circ} \mathrm{C}\right)$ und "blunt"-machen der cDNAEnden $\left(5 \mathrm{~min}, 16^{\circ} \mathrm{C}\right)$. Alle Teilschritte erfolgten in einem Reaktionsansatz unter sukzessiver Zugabe der Komponenten. 


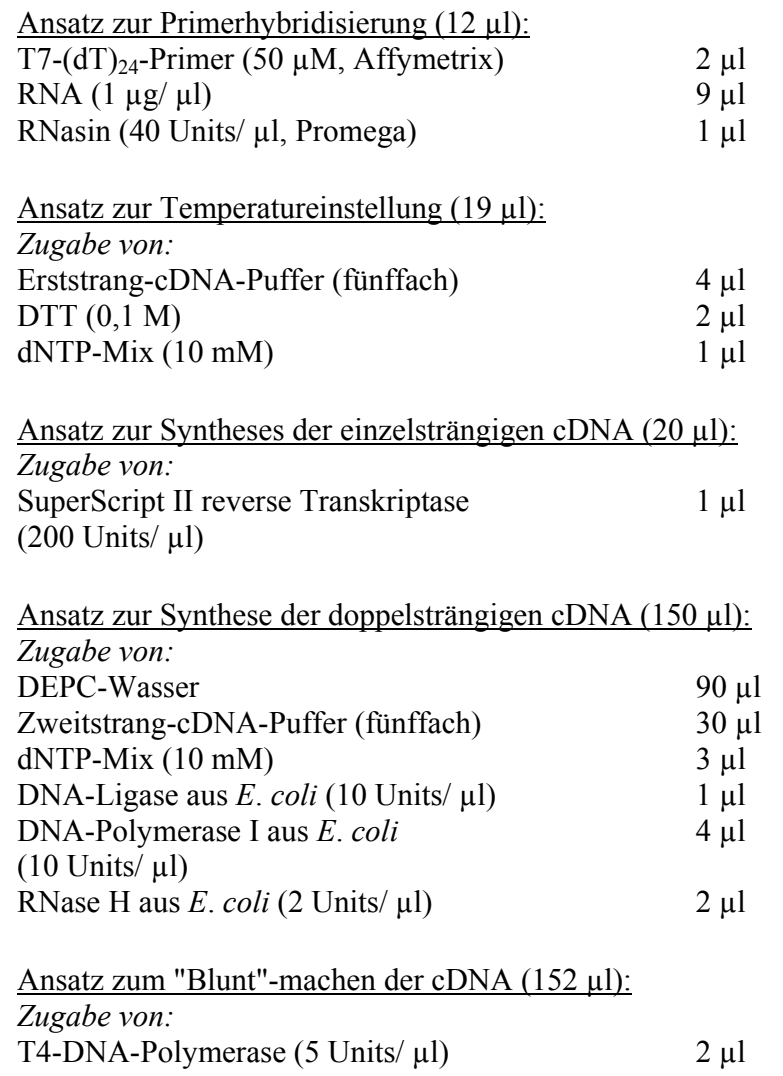

Die Reaktion wurde unter Zugabe von $10 \mu$ EDTA (0,5 M) abgestoppt und die cDNA durch PCI-Extraktion gereinigt, mit Ethanol präzipitiert und in $12 \mu 1$ DEPC-Wasser aufgenommen.

\section{Synthese biotinylierter RNA und Ausbeuteberechnung}

Die in vitro-Transkription der cDNA zur Herstellung biotinylierter RNA-Sonden wurde für $5 \mathrm{~h}$ bei $37^{\circ} \mathrm{C}$ durchgeführt. Dazu wurde das "RNA Transcript Labeling Kit" der Firma Enzo verwendet.

Ansatz zur in vitro-Transkription $(40 \mu \mathrm{l})$ :

$\begin{array}{ll}\text { cDNA (ca. } 100 \mathrm{ng} / \mu \mathrm{l}) & 12 \mu \mathrm{l} \\ \text { DEPC-Wasser } & 10 \mu \mathrm{l} \\ \text { HY-Reaktionspuffer (zehnfach) } & 4 \mu \mathrm{l} \\ \text { Biotin-markierte Ribonukleotide (zehnfach) } & 4 \mu \mathrm{l} \\ \text { DTT (100 mM) } & 4 \mu 1 \\ \text { RNase-Inhibitor (20 Units/ } \mu \mathrm{l}) & 4 \mu \mathrm{l} \\ \text { T7-RNA-Polymerase }(50 \mathrm{Units} / \mu \mathrm{l}) & 2 \mu \mathrm{l}\end{array}$

Zur Extraktion der RNA aus dem Reaktionsansatz wurde die Option "RNA Clean-up" des "RNeasy Mini Kit" (Qiagen) genutzt. Die Elution erfolgte mit $30 \mu 1$ DEPC-Wasser. Die Konzentration der erhaltenen RNA $\left(\mathrm{c}_{0}\right)$ wurde im Spektrophotometer bestimmt. Zur Berechnung der Konzentration an biotinylierter RNA $\left(c_{1}\right)$ wurde von einem vollständigen Übertrag der ursprünglich eingesetzten Gesamt-RNA $(9 \mu \mathrm{g})$ ausgegangen und eine entsprechende Korrektur vorgenommen $\left(\mathrm{c}_{1}=\mathrm{c}_{0}-9 \mu \mathrm{g} / 30 \mu \mathrm{l}, \mathrm{c}_{1}=\mathrm{c}_{0}-0,3 \mu \mathrm{g} / \mu \mathrm{l}\right)$. 


\section{Fragmentierung der biotinylierten RNA}

Die Fragmentierung der biotinylierten RNA wurde für 35 min bei $94^{\circ} \mathrm{C}$ ausgeführt. Die Qualität fragmentierter RNA wurde im nativen Agarosegel (1\%) überprüft, es sollten RNAFragmente von 35 bis 200 Basen vorliegen.

\begin{tabular}{lc} 
Ansatz zur Fragmentierung biotinylierter RNA $(40 \mu \mathrm{l}):$ \\
\hline biotinylierte RNA & $0,625 \mu \mathrm{g} / \mu \mathrm{l}$ \\
Tris-Azetat; pH 8,1 & $40 \mathrm{mM}$ \\
Kaliumazetat & $100 \mathrm{mM}$ \\
Magnesiumazetat & $30 \mathrm{mM}$
\end{tabular}

\section{Herstellung der Hybridisierungskontrollen}

Auf den Microarrays vom Typ MGU74v2 sind Proben der prokaryotischen Gene bioB, bioC, bioD und Cre repräsentiert. Entsprechende antisense-RNAs wurden als Hybridisierungskontrollen dem Hybridisierungscocktail zugefügt. Plasmide mit den cDNAs bioB, bioC, bioD und $\mathrm{Cre}$ wurden von American Type Culture Collection bezogen. Plasmid-DNA wurde mit dem "QIAfilter Plasmid Maxi Kit" (Qiagen) präpariert, mit Xho I linearisiert und PCI-extrahiert. Die in vitro-Transkription wurde mit 0,75 $\mu$ g Plasmid-DNA durchgeführt (RNA Transcript Labeling Kit, Enzo). Es wurde T7-RNA-Polymerase verwendet.

\section{Hybridisierung der Microarrays}

Zur Prähybridisierung wurde der Microarray 10 min bei $45{ }^{\circ} \mathrm{C}$ mit MES-Puffer $(74 \mathrm{mM}$ $\left[\mathrm{Na}^{+}\right], 100 \mathrm{mM}$ MES) inkubiert. Die Inkubation erfolgte unter Rotation (60 U/ min) im Hybridisierungsofen (Affymetrix). Zur Hybridisierung wurden $300 \mu 1$ Hybridisierungscocktail mit $15 \mu \mathrm{g}$ fragmentierter RNA vorbereitet, 5 min bei $99{ }^{\circ} \mathrm{C}$ denaturiert und auf $45{ }^{\circ} \mathrm{C}$ temperiert. Die Hybridisierung erfolgte über $16 \mathrm{~h}$ bei $45{ }^{\circ} \mathrm{C}$ und $60 \mathrm{U} / \mathrm{min} \mathrm{im}$ Hybridisierungsofen.

$\begin{array}{ll}\text { Hybridisierungscocktails }(300 \mu \mathrm{l}) \text { : } & \\ \text { fragmentierte, biotinylierte RNA } & 0,05 \mu \mathrm{g} / \mu \mathrm{l} \\ \text { Kontroll-Oligonukleotide B2 (Affymetrix) } & 50 \mathrm{pM} \\ \text { Hybridisierungskontrolle bioB } & 1,5 \mathrm{pM} \\ \text { Hybridisierungskontrolle bioC } & 5 \mathrm{pM} \\ \text { Hybridisierungskontrolle bioD } & 25 \mathrm{pM} \\ \text { Hybridisierungskontrolle cre } & 100 \mathrm{pM} \\ \text { Heringsspermien-DNA (Promega) } & 0,1 \mathrm{mg} / \mathrm{ml} \\ \text { azetyliertes BSA (Gibco) } & 0,5 \mathrm{mg} / \mathrm{ml} \\ \text { MES } & 100 \mathrm{mM} \\ \left.\text { Na }^{+}\right] & 1 \mathrm{M} \\ \text { EDTA } & 20 \mathrm{mM} \\ \text { Tween-20 } & 0,01 \%\end{array}$

\section{Posthybridisierung der Microarrays}

Die Posthybridisierung der Microarrays wurde in der "GeneChip Fluidics Station 400" (Affymetrix) durchgeführt und durch die Software "Microarray suite 4.0" (Affymetrix) gesteuert. Dazu wurde zunächst der Hybridiserungscocktail entfernt und durch Puffer A ersetzt. 
Anschließend wurde zehnmal mit Puffer A bei $25^{\circ} \mathrm{C}$ und viermal mit Puffer B bei $50^{\circ} \mathrm{C}$ gewaschen. Es folgten: Inkubation mit Streptavidin-Phycoerythrin-Lösung (10 min, $\left.25^{\circ} \mathrm{C}\right)$, zehnmal Waschen mit Puffer A bei $25^{\circ} \mathrm{C}$, Inkubation mit Biotin-anti-Streptavidin-Antikörper $\left(10 \mathrm{~min}, 25^{\circ} \mathrm{C}\right)$, Inkubation mit Streptavidin-Phycoerythrin-Lösung $\left(10 \mathrm{~min}, 25^{\circ} \mathrm{C}\right)$ und 15 Waschschritte mit Puffer A bei $30^{\circ} \mathrm{C}$.

\begin{tabular}{ll} 
Puffer A: & \\
\hline $\mathrm{NaCl}$ & $0,9 \mathrm{M}$ \\
$\mathrm{NaH}_{2} \mathrm{PO}_{4}$ & $60 \mathrm{mM}$ \\
EDTA & $6 \mathrm{mM}$ \\
Tween-20 & $0,01 \%$ \\
Antifoam 0-30 (Sigma) & $0,005 \%$ \\
& \\
Puffer B: & $100 \mathrm{mM}$ \\
MES & $0,1 \mathrm{M}$ \\
[Na $\left.{ }^{+}\right]$ & $0,01 \%$ \\
Tween-20 & \\
& \\
Streptavidin-Phycoerythrin-Lösung: & $100 \mathrm{mM}$ \\
\hline $\mathrm{MES}^{+}$ & $1 \mathrm{M}$ \\
Tween-20 & $0,05 \%$ \\
Antifoam 0-30 & $0,005 \%$ \\
azetyliertes BSA & $2 \mathrm{mg} / \mathrm{ml}$ \\
Streptavidin-Phycoerythrin (Molecular Probes) & $10 \mu \mathrm{g} / \mathrm{ml}$ \\
& \\
Lösung mit Biotin-anti-Streptavidin-Antikörper: & \\
\hline MES & $100 \mathrm{mM}$ \\
{$\left[\right.$ Na $\left.{ }^{+}\right]$} & $1 \mathrm{M}$ \\
Tween-20 & $0,05 \%$ \\
Antifoam 0-30 & $0,005 \%$ \\
IgG der Ziege (Sigma) & $0,1 \mathrm{mg} / \mathrm{ml}$ \\
Biotin-anti-Streptavidin-Antikörper aus der Ziege & $3 \mu \mathrm{g} / \mathrm{ml}$ \\
(Vector Laboratories) & \\
&
\end{tabular}

\section{Scannen der Microarrays und Analyse der Daten}

Microarrays wurden mit dem "HP GeneArray Scanner" (Affymetrix) gescannt. Die Datenanalyse wurde mit der Software "MicroArray Suite 4" (Affymetrix) vorgenommen. Die Qualität jeder RNA-Probe wurde zunächst mit einem Testchip (Test3 Array, Affymetrix) beurteilt. Der Testchip enthält Sets von Proben für murine Haushaltsgene, wie beta-Aktin und GAPDH. Für gute Hybridisierungs-Proben sollte das Verhältnis der Hybridiserungssignale von Probensets aus dem 5'- und 3'-Ende der Gene beta-Aktin und GAPDH den Wert 3 nicht überschreiten. Anderenfalls muß von einer Degradierung der RNA im Hybridisierungscocktail ausgegangen werden. Für gut befundene Hybridisierungscocktails wurden zur Hybridisierung der Microarrays vom Typ MGU74v2 weiter verwendet.

Um die Vergleichbarkeit zweier Microarrays zu gewährleisten, wurde der Algorithmus "Scaling" (Skalierung) ausgeführt. Die gewählte Targetintensität betrug 500. Computerdateien vom Typ ".chp" wurden erstellt und paarweise miteinander verglichen. Mit Hilfe der erhaltenen Daten für "FoldChange" (Expressionsverhältnis) und "DifferenceCall" (Prädikat des 
Expressionsunterschiedes) wurden Listen von Genen erstellt, deren Expression in einem der fünf Kortexgebiete erhöht war. In eine solche Liste wurde ein Gen genau dann aufgenommen, wenn es alle folgenden Kriterien erfüllte:

1. Im Vergleich zu allen anderen vier Kortexregionen sowie der Probe "Restkörper" liegt ein "DifferenceCall" von "marginal increased" (geringfügig erhöht) oder "increased" (erhöht) vor.

2. Im Vergleich zu allen anderen vier Kortexregionen ist die Expression um einen "FoldChange" von mindestens 2 erhöht.

3. Im Vergleich $\mathrm{zu}$ mindestens einer anderen Kortexregion ist die Expression um einen "FoldChange" von $\geq 3$ erhöht.

\section{RNA-in situ-Hybridisierung}

Alle zur RNA-in situ-Hybridisierung verwendeten Tris-freien Lösungen wurden mit DEPC behandelt, Tris enthaltende Puffer autoklaviert. Es wurden RNase-freie Bedingungen eingehalten.

\section{Herstellung von DIG-markierten RNA-Sonden}

Die Herstellung Digoxygenin-markierter RNA-Sonden erfolgte durch In vitro-Transkription cDNA enthaltender, linearisierter Plasmide (Tab. 3). Dazu wurde $1 \mu$ g Plasmid-DNA in $20 \mu 1$ eines In vitro-Transkriptionsansatzes $2 \mathrm{~h}$ bei $37^{\circ} \mathrm{C}$ inkubiert.

\begin{tabular}{ll} 
In vitro-Transkriptionansatz $(20 \mu 1):$ & \\
\hline Transkriptionspuffer (Boehringer) & einfach konzentriert \\
DIG-RNA-Labeling-Mix & $0,1 \mathrm{mM}$ (jeweils) \\
(ATP, CTP, GTP und & \\
UTP/ Digoxygenin-11-UTP; ENZO) & \\
RNase-Inhibitor (RNasin, Promega) & 20 Units/ Ansatz \\
RNA-Polymerase (Sp6, T3, T7; Promega) & 20 Units/ Ansatz
\end{tabular}

Die Plasmid-DNA wurde mit 2 Units DNase (RQ1-DNase, Promega) 15 min bei $37{ }^{\circ} \mathrm{C}$ verdaut und die RNA durch Zugabe von $100 \mu 1 \mathrm{TE}(\mathrm{pH}$ 8,0), $10 \mu 14 \mathrm{MLiCl}$ und $300 \mu 1$ Ethanol $2 \mathrm{~h}$ bei $-80{ }^{\circ} \mathrm{C}$ gefällt. Die erhaltene RNA wurde in $100 \mu \mathrm{TE}$ aufgenommen und deren Integrität im nativen Agarosegel (1\%) überprüft. 
Tab. 3:

Charakterisierung der zur Synthese von DIG-markierten RNA-Sonden verwendeten Plasmide (Größe der enthaltenen cDNA, Restriktionsenzym zur Plasmid-Linearisierung, verwendete RNA-Polymerase und Herkunft).

\begin{tabular}{|c|c|c|c|c|}
\hline $\begin{array}{l}\text { Enthaltene } \\
\text { cDNA }\end{array}$ & $\begin{array}{l}\text { cDNA- } \\
\text { Größe in Bp } \\
\text { (gerundet) }\end{array}$ & $\begin{array}{l}\text { Restriktions- } \\
\text { enzym }\end{array}$ & $\begin{array}{l}\text { RNA- } \\
\text { Polymerase }\end{array}$ & Referenz/ Herkunft \\
\hline $\operatorname{Em} x 2$ & 600 & HindIII & $\mathrm{T} 7$ & (A. Simeone et al., 1992) \\
\hline Flrt3 & unbekannt & EcoRI & $\mathrm{T} 3$ & Image-Klon 3972772, RZPD, Berlin \\
\hline Hes 5 & 1300 & HindIII & $\mathrm{T} 3$ & (K. Takebayashi et al., 1995) \\
\hline $\begin{array}{l}\text { Hippoc. } \\
\text { spez. } 1\end{array}$ & unbekannt & EcoRI & $\mathrm{T} 3$ & Image-klon 1248381, RZPD, Berlin \\
\hline Hop & 260 & $\begin{array}{l}\text { anti-sense: BamHI } \\
\text { sense: EcoRI }\end{array}$ & $\begin{array}{l}\mathrm{T} 3 \\
\mathrm{~T} 7\end{array}$ & $\begin{array}{l}\text { Dra III-Fragment von cDNA-Klon 1, "blunt" kloniert in SmaI- } \\
\text { Schnittstelle von pBluescript II KS+ (Stratagene) }\end{array}$ \\
\hline$K A 1$ & 3312 & KpnI & $\mathrm{T} 3$ & (B. Bettler et al., 1990) \\
\hline $\operatorname{Lhx} 2$ & 1400 & SacII & Sp6 & (G. Bernier et al., 2001) \\
\hline $\operatorname{Lhx} 5$ & 1100 & $\mathrm{XbaI}$ & $\mathrm{T} 7$ & (H. Z. Sheng et al., 1997) \\
\hline $\operatorname{Ngn} 2$ & 1400 & BamHI & $\mathrm{T} 7$ & (G. Gradwohl et al., 196) \\
\hline Nril & unbekannt & XhoI & $\mathrm{T} 3$ & Image-Klon 3376347, RZPD, Berlin \\
\hline Nurl & 3000 & NcoI & Sp6 & Plasmidbibliothek des Labors \\
\hline Pplr1b & unbekannt & EcoRI & $\mathrm{T} 3$ & Image-Klon 921764, RZPD, Berlin \\
\hline Reelin & 650 & SpeI & $\mathrm{T} 7$ & V. Tarabykin, MPI f. experimentelle Medizin, Göttigen \\
\hline Dct & 1200 & HindIII & $\mathrm{T} 7$ & (K. P. Steel et al., 1992) \\
\hline Wnt $3 a$ & 150 & EcoRI & Sp6 & (H. Roelink und R. Nusse, 1991) \\
\hline Wnt5a & 2511 & Xhol & Sp6 & (B. J. Gavin et al., 1990) \\
\hline$W n 8 b$ & unbekannt & EcoRI & Sp6 & Plasmidbibliothek des Labors \\
\hline
\end{tabular}

\section{RNA-in situ-Hybridisierung}

RNA-in situ-Hybridisierung wurde auf $18 \mu \mathrm{m}$-Gefrierschnitten durchgeführt. Nach 15 min Fixierung in 4\% PFA und zweimal 5 min Waschen in PBS wurden die Gewebeschnitte der Proteinase-K-Behandlung unterzogen $\left(20 \mu \mathrm{g} / \mathrm{ml}, 4 \mathrm{~min}, 37^{\circ} \mathrm{C}\right)$. Der Proteinase-K-Verdau wurde mit 0,2 \% Glyzin in PBS abgestoppt. Es folgten zweimal 5 min Waschen in PBS und 20 min Fixierung in $0,2 \%$ Glutaraldehyd/ 4\% PFA in PBS. Nach erneutem Waschen in PBS (zweimal 5min) wurde die Prähybridisierung (Hybridiserungslösung, $2 \mathrm{~h}, 70^{\circ} \mathrm{C}$ ) durchgeführt.

Hybridisierungslösung:

$\begin{array}{ll}\text { Formamid } & 50 \% \\ \text { SSC; pH 4,5 } & \text { fünffach konzentriert } \\ \text { Hefe-tRNA } & 1 \mathrm{mg} / \mathrm{ml} \\ \text { CHAPS } & 0,1 \% \\ \text { Tween } 20 & 0,1 \% \\ \text { EDTA; pH } 8,0 & 5 \mathrm{mM} \\ \text { Heparin } & 0,1 \mathrm{mg} / \mathrm{ml}\end{array}$


Zur anschließenden Hybridisierung (über Nacht, $70^{\circ} \mathrm{C}$ ) wurde die DIG-markierte RNA aus einer In vitro-Transkriptionsreaktion (dto.) 1:50 in Hybridisierungslösung eingesetzt. Zur Entfernung ungebundener RNA-Sonde wurde 5 min in zweifach konzentriertem SSC (pH 4,5) und dreimal je $30 \mathrm{~min}$ in 50\% Formamid/ zweifach $\mathrm{SSC}(\mathrm{pH} \mathrm{4,5)} \mathrm{gewaschen.} \mathrm{Es} \mathrm{folgten}$ zweimal 10 min Waschen in KTBT-Puffer und Inkubation mit anti-DIG-Antikörper (konjugiert mit alkalischer Phosphatase, ENZO) in KTBT (1:2000, über Nacht, $\left.4{ }^{\circ} \mathrm{C}\right)$.

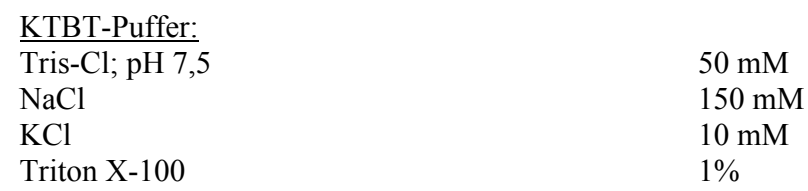

Unspezifisch gebundener Antiköper wurde durch Waschen mit KTBT-Puffer entfernt (dreimal $5 \mathrm{~min}$, dreimal $30 \mathrm{~min}$ ). Nach Equilibrieren in NTMT-Puffer (dreimal $5 \mathrm{~min}$ ) wurde die Farbreaktion (NBT-BCIP-Lösung, Roche; 1:50 in NTMT) bis zur gewünschten Farbsättigung durchgeführt. Zum Abstoppen der Farbreaktion wurde dreimal 5 min in PBS gewaschen. Die Objekte wurden in Mowiol (Kuraray Specialities) eingedeckelt.

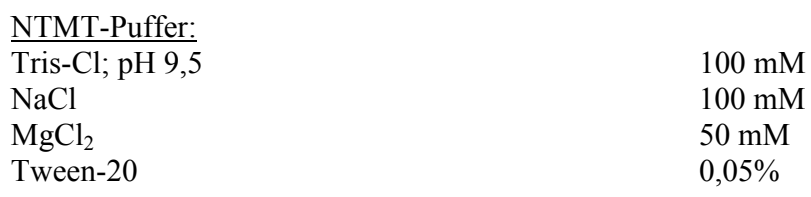

\section{Northern Blot-Analyse}

Die Arbeiten zur Northern Blot-Analyse wurden unter RNase-freien Bedingungen durchgeführt. Lösungen wurden mit DEPC behandelt und autoklaviert.

\section{Gewebeisolation und Präparation von polyadenylierter RNA}

Gewebe wurde in kaltem DEPC-PBS isoliert und bis zur weiteren Verwendung in RNAlater (Ambion) bei $4{ }^{\circ} \mathrm{C}$ aufbewahrt. Das Gewebe wurde mit Hilfe eines Homogenisators (Polytron PT1200, Kinematica) homogenisiert, die Gesamt-RNA mit dem "RNeasy Mini Kit" (Qiagen) präpariert. Die Integrität der RNA wurde anhand der Banden ribosomaler RNA im nativen Agarosegel (1 \%) überprüft. Um aus den Gesamt-RNA-Proben polyadenylierte RNA zu isolieren, wurden "Oligotex"-Säulen der Firma Qiagen verwendet. Es wurde dabei nach den Empfehlungen des Herstellers verfahren. Die Konzentration polyadenylierter RNA wurde im Spektrophotometer bestimmt.

\section{Elektrophorese im denaturierenden Gel}

Für jede RNA-Probe wurde ein Lademix vorbereitet. Der Lademix enthielt jeweils $4 \mu \mathrm{g}$ polyadenylierte RNA. Sein Gesamtvolumen wurde mit DEPC-Wasser auf $50 \mu$ l eingestellt. Der Lademix wurde 5 min bei $60{ }^{\circ} \mathrm{C}$ inkubiert und auf das denaturierende Gel aufgetragen. Als 
Größenmarker wurde eine RNA-Leiter (Gibco BRL) verwendet. Das RNA-Gel lief für 2-3 h bei $75 \mathrm{~V}$ in einfach konzentriertem MOPS-Puffer.

Lademix $(50 \mu 1)$ :

polyadenylierte RNA

MOPS-Puffer

Formaldehyd

Formamid

EDTA, pH 8

Bromphenolblau

Xylencyanat

Glycerol

Denaturierendes Gel:

Agarose

Formaldehyd

MOPS-Puffer
$2 \mu \mathrm{g} / 50 \mu 1$

einfach konzentriert

$6,5 \%$

$50 \%$

$0,2 \mathrm{mM}$

$0,05 \%$

$0,05 \%$

$10 \%$

$1 \%$

$37 \%$

einfach konzentriert

\section{Blotten des RNA-Gels und Hybridisierung}

Zunächst wurde das RNA-Gel 40 min in zehnfach konzentriertem SSC (pH 7,5) equilibriert. Zum Blotten wurde der Aufbau nach (F. Sambroock et al., 1989) verwendet. Das Blotten erfolgte für $48 \mathrm{~h}$ mit zehnfach konzentriertem SSC. Es wurden Nitrozellulosemembranen von Qiagen verwendet.

Die geblottete Nitrozellulosemembran wurde für $2 \mathrm{~h}$ bei $80{ }^{\circ} \mathrm{C}$ inkubiert und 60 min bei 60 ${ }^{\circ} \mathrm{C}$ in zweifach SSC/ $0,5 \%$ SDS gewaschen. Anschließend wurde $2 \mathrm{~h}$ bei $42{ }^{\circ} \mathrm{C}$ mit Hybridisierungspuffer vorhybridisiert, die Hybridiserungslösung erneuert und radioaktiv markierte, denaturierte DNA-Sonde zugegeben. Die Hybridisierung erfolgte unter Rotation in Glasflaschen, über Nacht bei $42{ }^{\circ} \mathrm{C}$. Es wurden $>50 \mathrm{ng}$ radioaktiv markierte Sonde in $6 \mathrm{ml}$ Hybridisierungslösung eingesetzt. Zur Entfernung ungebundener Sonde wurden folgende Waschschritte durchgeführte: zweimal 30 min bei $60{ }^{\circ} \mathrm{C}$ mit zweifach SSC/ 0,5\% SDS und zweimal $30 \mathrm{~min}$ bei $60{ }^{\circ} \mathrm{C}$ mit $0,1 \mathrm{fach} \quad \mathrm{SSC} / \quad 0,5 \%$ SDS. Die hybridisierten Nitrozellulosemembranen wurden in Folie gepackt und in Bleikassetten Röntgenfilmen (Biomax, Kodak) exponiert (3-6 d bei $-72{ }^{\circ} \mathrm{C}$ ). Die Entwicklung der Filme erfolgte in einem Entwicklerautomaten (Curix 60, Agfa).

$\begin{array}{ll}\text { Hybridisierungspuffer: } & \\ \mathrm{KPO}_{4} ; \mathrm{pH} 7,4 & 25 \mathrm{mM} \\ \mathrm{SSC}, \mathrm{pH} 7,5 & \text { fünffach konzentriert } \\ \text { Heringsspermium-DNA } & 50 \mu \mathrm{g} / \mu \mathrm{l} \\ \text { Formamid } & 50 \% \\ \text { Ficoll } & 0,02 \% \\ \text { Polyvinylpyrrolidon } & 0,02 \% \\ \text { BSA } & 0,02 \%\end{array}$




\section{Screenen einer cDNA-Bibliothek}

Zur Isolation vollständiger, das Gen Hop repräsentierender cDNA-Klone wurde eine cDNABibliothek gescreent. Die verwendete Bibliothek (J. Wijnholds et al., 1995) enthielt cDNAKlone aus dem murinen Gehirn des Embryonalstadiums E14,5.

\section{Ausplattieren der Bibliothek und Übertragen der Phagen auf Nitrozellulosemembranen}

Zunächst wurden Einzelkolonien des Bakterienstammes E. coli NM522 in $50 \mathrm{ml}$ STIMedium / $1 \%$ Maltose inokuliert und über Nacht bei $37{ }^{\circ} \mathrm{C}$ schüttelnd inkubiert. Die Bakterien wurden pelettiert und in $25 \mathrm{ml} 10 \mathrm{mM} \quad \mathrm{MgSO}_{4}$ resuspendiert. $\mathrm{Zu}$ jeweils $200 \mu \mathrm{l}$ Bakteriensuspension wurden verschiedene dezimale Verdünnungsstufen der cDNA-Bibliothek gegeben und 15 min inkubiert. Die Bakterien-Phagen-Gemische wurde jeweils mit $4 \mathrm{ml}$ geschmolzener Top-Agarose (0,7 \% Agarose in STI-Medium) auf STI-Bakterienagarplatten $(\varnothing$ $9 \mathrm{~cm}$ ) gegossen und nach dem Erkalten bei $37^{\circ} \mathrm{C}$ inkubiert. Zur Bestimmung des Titers virulenter Phagen wurde die Anzahl der Lysehöfe im Bakterienrasen ausgezählt.

In sterile Polyethylen-Testschalen (24 x $24 \mathrm{~cm}$, Nunc) wurde eine Schicht Bakterienagar (1,5 $\%$ in STI-Medium) ausgebracht und $2 \mathrm{~d}$ bei $37{ }^{\circ} \mathrm{C}$ getrocknet. $2 \mathrm{ml}$ NM522Bakteriensuspension wurden für 15 min mit 150.000 virulenten Phagen inkubiert und zusammen mit $50 \mathrm{ml}$ geschmolzener Top-Agarose $\left(50{ }^{\circ} \mathrm{C}\right)$ auf die vorbereiteten Testschalen gegossen. Auf diese Weise wurden insgesamt fünf Testschalen vorbereitet. Nach dem Erkalten der Top-Agarose erfolgte die Inkubation bei $37^{\circ} \mathrm{C}$. Nachdem sich Lysehöfe im Bakterienrasen ausgebildet hatten, wurden Nitrozellulosemembranen für 1 min aufgelegt. Dieser Vorgang wurde wiederholt, um von jeder Membran ein Duplikat zu erstellen. Die Membranen wurden mit Denaturierungspuffer benetzt, in Neutralisationspuffer neutralisiert und mit zweifach konzentriertem $\operatorname{SSC}(\mathrm{pH} \mathrm{7,5)}$ gewaschen (jeweils $1 \mathrm{~min}$ ). Um übertragene Phagen-DNA kovalent an die Membranen zu binden, wurden diese $2 \mathrm{~h}$ auf $80^{\circ} \mathrm{C}$ erhitzt.

Denaturierungspuffer:

$\begin{array}{ll}\mathrm{NaOH} & 0,2 \mathrm{M} \\ \mathrm{NaCl} & 1,5 \mathrm{M}\end{array}$

Neutralisationspuffer:

Tris-Cl, $\mathrm{pH} \mathrm{7,6} \quad 2 \mathrm{M}$

SSC, $\mathrm{pH} 7,5 \quad$ zweifach konzentriert

\section{Hybridisierung der Nitrozellulosemembranen und Autoradiographie}

Als Hybridisierungssonde wurde das Not I/ Dra III-Fragement aus Image-Klon 720084 (Image Consortium, GeneBank-Eintrag: AA254940) verwendet. Es handelte sich dabei um ein 621 bp großes Fragment aus der 3'-untranslatierten Region des Genes Hop. 
Zur Prähybridisierung wurden die Nitrozellulosemembranen $30 \mathrm{~min}$ mit zweifach konzentriertem SSC/ 0,5\% SDS equilibriert und $2 \mathrm{~h}$ bei $42{ }^{\circ} \mathrm{C}$ mit Hybridisierungslösung inkubiert. Die Hybridisierung erfolgte über Nacht bei $42{ }^{\circ} \mathrm{C}$ mit 20-50 ng radioaktiv markierter DNA-Sonde in $8 \mathrm{ml}$ Hybridisierungslösung. Ungebundene Sonde wurde bei $65^{\circ} \mathrm{C}$ durch einmal 1 min und viermal 15 min Waschen mit zweifach konzentriertem SSC/ 0,5\% SDS entfernt. Weiterhin wurde einmal für 30 min bei $65{ }^{\circ} \mathrm{C}$ mit 0,2 fach konzentriertem SSC/ $0,5 \% \mathrm{SDS}$ gewaschen.

\begin{tabular}{ll} 
Hybridisierungspuffer: & \\
\hline Formamid & $48 \%$ \\
SSC; $\mathrm{pH} 7,5$ & fünffach konzentriert \\
Tris-Cl, pH 7 & $20 \mathrm{mM}$ \\
Ficoll & $0,02 \%$ \\
Polyvinylpyrrolidon & $0,02 \%$ \\
BSA & $0,02 \%$ \\
Dextransulfat & $10 \%$ \\
SDS & $0,1 \%$
\end{tabular}

Den hybridisierten Nitrozellulosemembranen wurden in Bleikassetten Röntgenfilme (Biomax, Kodak) exponiert (3-6 d bei $-72^{\circ} \mathrm{C}$ ). Die Filme wurden in einer Entwicklermaschine (Curix 60, Agfa) entwickelt und positive Hybridisierungssignale durch Vergleich der jeweiligen Duplikate ermittelt. Durch Auflegen der Filme auf die zugehörigen Testschalen konnte die Position der Plaques bestimmt werden, welche mit der Sonde hybridisiert hatten. Solche positiven Plaques wurden mit einer Pasteurpipette ausgestochen, in Phagensuspensionsmedium überführt und über Nacht bei $37^{\circ} \mathrm{C}$ geschüttelt. Die Aufbewahrung der Phagensuspension erfolgte nach Zugabe eines Tropfens Chloroform bei $4{ }^{\circ} \mathrm{C}$.

Phagensuspensionsmedium:

\begin{tabular}{ll}
\hline $\mathrm{NaCl}$ & $100 \mathrm{M}$ \\
$\mathrm{MgSO}_{4}$ & $8 \mathrm{mM}$ \\
Tris-Cl, pH 7,5 & $50 \mathrm{mM}$ \\
Gelatine (Difco) & $0,1 \%$
\end{tabular}

\section{Aufreinigung eines positiven Phagen}

Dezimalen Verdünnungsstufen der Phagensuspension wurden in Phagensuspensionsmedium vorbereitet, 15 min mit $200 \mu \mathrm{l}$ Bakteriensuspension inkubiert und mit $4 \mathrm{ml}$ Top-Agarose auf STI-Bakterienagarplatten $(\varnothing 9 \mathrm{~cm})$ gegossen. Nach dem Erkalten wurden die Platten bis zur Ausbildung von Lysehöfen bei $37^{\circ} \mathrm{C}$ inkubiert. Nitrozellulosemembranen wurden aufgelegt und wie beschrieben denaturiert, neutralisiert, equilibriert und die Phagen-DNA bei $80{ }^{\circ} \mathrm{C}$ kovalent gebunden. Die Nitrozellulosemembranen wurden mit radioaktiver DNA-Sonde hybridisert, gewaschen und Röntgenfilmen exponiert. Anhand positiver Hybridisierungssignale auf den Filmen konnten positive Plaques bestimmt werden. Sie wurden ausgestochen und über Nacht bei $37^{\circ} \mathrm{C}$ in Phagensuspensionsmedium eluiert. Falls aufgrund hoher Plaquedichte ein positiver 
Plaque nicht sicher von den umgebenden Plaques getrennt werden konnte, wurde das Verfahren zur Aufreinigung ein weiteres Mal durchlaufen.

\section{Phagemid-Freisetzung}

Die verwendete cDNA-Bibliothek (J. Wijnholds et al., 1995) basiert auf dem Vektor $\lambda$ ExCell (Pharmacia) und enthält einen internen, linearisierten Phagemidvektor. Es war somit möglich, eine Phagemidfreisetzung durchzuführen, um die cDNA-Klone als Inserts im Vektor pExCell zu erhalten.

Zur Phagemidfreisetzung wurde eine Einzelkolonie des Bakterienstammes E. coli NP66 über Nacht bei $32{ }^{\circ} \mathrm{C}$ in $5 \mathrm{ml} 2 \mathrm{xYT}^{\mathrm{CSM}}$-Medium schüttelnd inkubiert. Aus dieser Starterkultur wurden $50 \mu 1$ in $5 \mathrm{ml} 2 \mathrm{xYT}^{\mathrm{CSM}}$-Medium überimpft und bei $32{ }^{\circ} \mathrm{C}$ solange kultiviert, bis die optische Dichte bei $600 \mathrm{~nm}\left(\mathrm{OD}_{600}\right)$ 2,0 betrug. Die Bakterien wurden pelletiert, in NZCYM ${ }^{\mathrm{S}}$ Medium resuspendiert und mit $\mathrm{NZCYM}^{\mathrm{S}}$-Medium auf $\mathrm{OD}_{600}=2,0$ eingestellt. $100 \mu \mathrm{l}$ der Bakteriensuspension wurden für $20 \mathrm{~min}$ bei $39^{\circ} \mathrm{C}$ kultiviert. Es folgten: Zugabe von $100 \mu \mathrm{l}$ Phagensuspension und Kultur für weitere $20 \mathrm{~min}$ bei $39{ }^{\circ} \mathrm{C}$. Nach Zugabe von $200 \mu 11 \mathrm{M}$ Natriumzitrat und $5 \mathrm{ml} 2 \mathrm{xYT}^{\mathrm{S}}$-Medium wurde für $1,5 \mathrm{~h}$ bei $32{ }^{\circ} \mathrm{C}$ schüttelnd inkubiert. Aus dieser Freisetzungskultur konnte nun auf $\mathrm{STI}^{\mathrm{A}}$-Agarplatten ausgestrichen werden. Einzelkolonien wurden in $\mathrm{STI}^{\mathrm{A}}$-Medium überimpft und analytische DNA-Präparationen durchgeführt.

Im pExCell-Vektor werden DNA-Inserts von T7- und Sp6-Promotorsequenzen flankiert. Entsprechende Primer konnten zur Sequenzierung verwendet werden.

\section{Klonierung von Enhancer- und Deletionskonstrukten}

Zur Aktivitätskartierung wurden das E1-Element und dessen Teilfragmente mittels PCR amplifiziert und in den Vektor pTrap kloniert. pTrap geht auf den Vektor pPolyIII-I zurück (R. Lathe et al., 1987; P. L. Pfeffer et al., 2000) und enthält den $\beta$-Globin-Minimalpromotor, das LacZ-Gen und eine SV40-Polyadenylierungssequenz.

\section{PCR}

Alle PCR-Reaktionen folgten einem allgemeinen Reaktionsschema, die AnnealingTemperatur $\left(\mathrm{T}_{\mathrm{A}}\right)$ wurde je nach Primer variiert. Eine Übersicht ist in Tab. 4 gegeben. PCRReaktionen enthielten 50-100 ng genomische DNA als Template und wurden auf dem PCRGerät "TRIO-Thermoblock" von Biometra durchgeführt.

$\left.\begin{array}{ll}\text { PCR-Reaktionsschema: } & \\ \hline 95^{\circ} \mathrm{C} & 2 \mathrm{~min} \\ \mathrm{~T}_{\mathrm{A}} & 30 \mathrm{~s} \\ 72^{\circ} \mathrm{C} & 60 \mathrm{~s} \\ 95^{\circ} \mathrm{C} & 30 \mathrm{~s}\end{array}\right\} 25$ Zyklen


PCR-Reaktionsansatz $(25 \mu 1)$ :

$\begin{array}{ll}\text { Genomische DNA } & 2-4 \mathrm{ng} / \mu \mathrm{l} \\ \text { Vorwärts-Primer } & 10 \mu \mathrm{M} \\ \text { Rückwärts-Primer } & 10 \mu \mathrm{M} \\ \text { PCR-Puffer (GeneCraft) } & \text { einfach konzentriert } \\ \text { dNTP-Mix (GeneCraft) } & 0,2 \mathrm{mM} \\ \text { DNA-Polymerase (BioTherm, GeneCraft) } & 1 \mathrm{Unit} / \text { Ansatz }\end{array}$

Tab. 4: PCR-Bedingungen zur Klonierung der Deletionskonstrukte.

Primer-Sequenzen, Annealing-Temperatur $\left(\mathrm{T}_{\mathrm{A}}\right)$ und Länge $\left(\mathrm{L}_{\mathrm{P}}{ }^{29}\right)$ der durch PCR amplifizierten DNA-Fragmente. Eingeführte Restriktionsschnittstellen sind unterstrichen, Punktmutationen grau unterlegt.

\begin{tabular}{|c|c|c|c|c|}
\hline Konstrukt & $\begin{array}{l}\text { Vorwärts-Primer } \\
\left(5^{\prime} \rightarrow 3^{\prime}\right)\end{array}$ & $\begin{array}{l}\text { Rückwärts-Primer } \\
\left(5^{\prime} \rightarrow 3^{\prime}\right)\end{array}$ & $\begin{array}{l}\mathrm{T}_{\mathrm{A}} \\
\text { in }{ }^{\circ} \mathrm{C}\end{array}$ & $\begin{array}{l}\mathrm{L}_{\mathrm{P}} \\
\text { in bp }\end{array}$ \\
\hline$p D 1$ & $\begin{array}{l}\text { AAAGTCGACTAGATCTCTTTGACACACT } \\
\text { C }\end{array}$ & AAAGTCGACAACAGCTGCCTGCTAGCAG & 65 & 459 \\
\hline$p D 4$ & AAAGTCGACTCCCTGGCTGCCTGCGGC & $\begin{array}{l}\text { AAAGTCGACAGGCATCTTAATTCCTGGCT } \\
\text { G }\end{array}$ & 64 & 188 \\
\hline$p D 5$ & $\begin{array}{l}\text { AAAGTCGACTGGTCTCCAAGACAGCTC } \\
\text { C }\end{array}$ & $\begin{array}{l}\text { AAAGTCGACTAATAGCCTCCTGTTCTAAA } \\
\text { AG }\end{array}$ & 61 & 192 \\
\hline$p D 6$ & $\begin{array}{l}\text { AAAGTCGACAGCCGCTAAGCGGTAGTC } \\
\text { AC }\end{array}$ & $\begin{array}{l}\text { AAAGTCGACTGCCTGCTAGCAGAAGTCA } \\
\text { C }\end{array}$ & 64 & 194 \\
\hline$p D 7$ & AAAGTCGACTCCGCTTTTGTTGACAGAG & $\begin{array}{l}\text { TTTGTCGACAAGGCAGTCAGCACAAGGG } \\
\text { TGGATTTC }\end{array}$ & 64 & 133 \\
\hline$p D 2$ & AAAGTCGACTCCCTGGCTGCCTGCGGC & $\begin{array}{l}\text { AAAGTCGACTAATAGCCTCCTGTTCTAAA } \\
\text { AG }\end{array}$ & 61 & 315 \\
\hline$p D 3$ & AAAGTCGACTCCCTGGCTGCCTGCGGC & $\begin{array}{l}\text { TTTGTCGACAAGGCAGTCAGCACAAGGG } \\
\text { TGGATTTC }\end{array}$ & 70 & 218 \\
\hline$p D 3 \Delta O c t 6$ & AAAGTCGACTCCCTGGCTGCCTGCGGC & $\begin{array}{l}\text { TTTGTCGACAAGGCAGTCAGCACAAGGG } \\
\text { TGGATTTCACAGGCATCTTGGATCCTG }\end{array}$ & 70 & 218 \\
\hline pPCR1 & CAACTTTCAAAGGCTTTACGTTTC & GAAGAGTGGCTTAAGGGCTCTGC & 60 & 706 \\
\hline pPCR2 & $\begin{array}{l}\text { TCCCTGGCTGCCTGCGGCTTGCTTTCTA } \\
\text { TGGCATGTTACTTTAGAC }\end{array}$ & AAATCTAGAAACAGCTGCCTGCTAGCAG & 65 & 431 \\
\hline
\end{tabular}

\section{Klonierung}

\section{$p P C R 1$ und $p P C R 2$}

Zur Klonierung der Plasmide $p P C R 1$ und $p P C R 2$ wurde das entsprechende PCR-Produkt mit A-Überhang direkt in den Vektor $p G E M-T$ Easy (Promega) kloniert. Die Plasmide dienten als Basis zur Klonierung der Deletionskonstrukte.

\section{$\underline{p E 1 \text { und } p E 2}$}

Das Eco RI-Fragment von $p P C R l$ wurde "blunt" in die Xbal-Schnittstelle von $p T R A P$ kloniert. Die Orientierung des Fragmentes wurde durch Sequenzierung mit einem LacZspezifischen Primer bestimmt. Es wurden sowohl $p E 1$-Klone, die das E1-Enhancerelement $\left(^{+}\right.$ flankierende Sequenz) in "sense"-Richtung enthielten, als auch solche mit "antisense"Orientierung verwendet. In $p E 2$ wurden E1-Element und flankierende Sequenz in die XhoISchnittstelle nach der $\beta$-Galaktosidase-cDNA von $p T R A P$ kloniert (Partialverdau).

\footnotetext{
${ }^{29}$ Einschließlich Überhang der eingeführten Restriktionsschnittstellen.
} 
$\underline{p D 1}$

Das PCR-Produkt enthielt durch den Primer eingeführte SalI-Schnittstellen. Die SalIFragmente wurden in die SalI-Schnittstelle von pTrap kloniert, die Orientierung durch Sequenzierung mit einem LacZ-spezifischen Primer bestimmt. pD1-Klone wurden in "sense"und "antisense"-Orientierung verwendet.

$p D 2, p D 3, p D 4, p D 5, p D 6, p D 7$ und $p D 3 \Delta o c t 6$

Die PCR-Produkte enthielen durch den Primer eingeführte SalI-Schnittstellen. Die SalIFragmente wurden in die SalI-Schnittstelle von pTrap kloniert, die Orientierung durch Sequenzierung mit einem LacZ-spezifischen Primer bestimmt. In pD3Aoct6 ist die potentielle Bindungsstelle des Transkriptionsfaktors Oct6 mutiert.

$\underline{p D 1 \triangle T C F}$

Das Eco RI-Fragment von pPCR2 wurde "blunt" in die XbaI-Schnittstelle von pTRAP kloniert. Die Orientierung des Fragmentes wurde durch Sequenzierung mit einem LacZspezifischen Primer bestimmt. In $p D 1 \triangle T C F$ ist die potentielle Bindungsstelle von TCF/ LefTranskriptionsfaktoren mutiert.

$p D 1 \triangle \triangle T C F$

Um die TCF/ Lef-Bindestelle im 3'-Bereich des E1-Elementes zu mutieren, wurden zunächst zwei unabhängige PCR-Rekationen durchgeführt, welche das Konstrukt $p D 1 \triangle T C F$ als Template verwendeten:

\begin{tabular}{|c|c|}
\hline \multicolumn{2}{|l|}{ PCR-Reaktionsschema: } \\
\hline$\overline{95^{\circ} \mathrm{C}}$ & $2 \min$ \\
\hline $64^{\circ} \mathrm{C}$ & $30 \mathrm{~s}$ \\
\hline $72^{\circ} \mathrm{C}$ & 25 Zyklen \\
\hline $95^{\circ} \mathrm{C}$ & $30 \mathrm{~s} J$ \\
\hline $72{ }^{\circ} \mathrm{C}$ & $5 \min$ \\
\hline \multicolumn{2}{|l|}{ PCR-Reaktionsansatz $(25 \mu 1)$ : } \\
\hline$\overline{p D 1 \Delta T C F}$ & $2 \mathrm{ng} / \mu \mathrm{l}$ \\
\hline Vorwärts-Primer & $10 \mu \mathrm{M}$ \\
\hline Rückwärts-Primer & $10 \mu \mathrm{M}$ \\
\hline PCR-Puffer (GeneCraft) & einfach konzentriert \\
\hline dNTP-Mix (GeneCraft) & $0,2 \mathrm{mM}$ \\
\hline DNA-Polymerase (BioTherm, GeneCraft) & 1 Unit/ Ansatz \\
\hline \multicolumn{2}{|c|}{ Primersequenzen (Punktmutationen grau unterlegt, Schnittstellen unterstrichen): } \\
\hline \multicolumn{2}{|c|}{ PCR I: } \\
\hline Vorwärts-Primer & AAAGTCGACTCCCTGGCTGCCTGCGGC \\
\hline Rückwärts-Primer & CTTTCTTTTCGGCTTGATAGTTGGCCCTTGGC \\
\hline \multicolumn{2}{|l|}{ PCR II: } \\
\hline Vorwärts-Primer & GCCAAGGGCCAACTATCAAGCCGAAAAGAAAG \\
\hline Rückwärts-Primer & AAAGTCGACTGCCTGCTAGCAGAAGTCAC \\
\hline
\end{tabular}


Beide PCR-Produkte wurden aufgereinigt und zusammen als Template für eine weitere PCR-Reaktion nach oben gezeigtem PCR-Programm eingesetzt.

PCR-Reaktionsansatz $(25 \mu \mathrm{l})$ :

PCR-Produkt I:

PCR-Produkt II:

Vorwärts-Primer

Rückwärts-Primer

PCR-Puffer (GeneCraft)

dNTP-Mix (GeneCraft)

DNA-Polymerase (BioTherm, GeneCraft)

Primersequenzen (Schnittstellen unterstrichen):

PCR III:

Vorwärts-Primer

Rückwärts-Primer

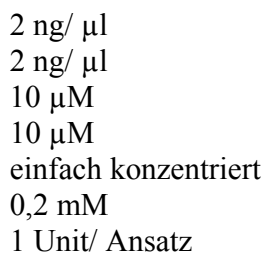

1 Unit/ Ansatz

\section{AAAGTCGACTCCCTGGCTGCCTGCGGC} AAAGTCGACTGCCTGCTAGCAGAAGTCAC

Das erhaltene PCR-Produkt wurde aufgereinigt, mit SalI geschnitten und in die Sal Schnittstelle von $p T R A P$ kloniert. Die Orientierung des Fragmentes wurde durch Sequenzierung mit einem LacZ-spezifischen Primer bestimmt. In $p D 1 \triangle \triangle T C F$ waren beide TCF/ LefBindestellen von E1 mutiert.

\section{Klonierung eines Konstruktes zur Überexpression von Hop in vivo}

Mittels PCR wurde die Hop-cDNA aus cDNA-Klon 1 amplifiziert. Die AnealingTemperatur der PCR-Reaktion betrug $52^{\circ} \mathrm{C}$. Durch Überhänge in den verwendeten Primern wurde eine Eco RI-Schnittstelle am 5'-Ende und eine XhoI-Schnittstelle am 3'-Ende des PCRProduktes eingeführt.

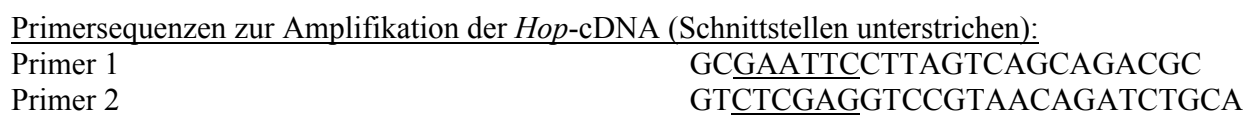

Das EcoRI-XhoI-geschnittene PCR-Produkt wurde in die entsprechenden Schnittstellen des Plasmids pIRES-hrGFP-1a (Stratagene) kloniert. Durch die XhoI-Schnittstelle wurde ein "in fram"-Übergang der kodierenden Sequenz von Hop in das FLAG-Epitop von pIRES-hrGFP-1a gewährleistet. Aus dem resultierenden Konstrukt wurde durch BamHI-NsiI-Verdau der CMVPromotor entfernt und durch das XhoI-BamHI-Fragment, welches das E1-Eelement, die flankierende Sequenz und den $\beta$-Globin-Minimalpromoter enthielt, ersetzt ("Blunt"Klonierung). Es entstand das Konstrukt mit der Bezeichnung pE1-Hop.

\section{Haltung einer Hop-defizienten Mauslinie}

Hop-defiziente Mäuse wurden im genetischen Hintergrund des Mausstammes SV129 von der Arbeitsgruppe um Prof. E. N. Olson bezogen (C. H. Shin et al., 2002). Heterzygote Männchen (Hop+/-) wurden mit Weibchen des Mausstammes C57/ BL6 verpaart, die resultierenden Nachkommen in Geschwisterverpaarung zur Etablierung der Mauskolonie 
verwendet. Die Kolonie wurde im gemischten genetischen Hintergrund SV129/ C57/ BL6 aufrechterhalten und die Tiere zur Analyse herangezogen.

Die Genotypisierung erfolgte durch PCR mit genomischer DNA aus Schwanzbiopsien. Es wurden die Primer Hop I (CCAGCCAAGCCATCACTTTACAC), Hop II (GAACCTTCCCAGCATCCTTTG) und Hop III (AGGACATAGCGTTGGCTACC CGTG) verwendet. Das Wildtypallel gab ein PCR-Produkt von 430 bp, das rekombinante Allel ein 600 bp-Produkt. Die Analyse der PCR-Reaktionen erfolgte im Agarosegel (1 \%).

\begin{tabular}{|c|c|c|}
\hline PCR-Reaktionsschema: & & \\
\hline$\overline{95^{\circ} \mathrm{C}}$ & $3 \min$ & \\
\hline $95{ }^{\circ} \mathrm{C}$ & $1 \mathrm{~min}$ & \\
\hline $56{ }^{\circ} \mathrm{C}$ & $1 \mathrm{~min}$ & 30 Zyklen \\
\hline $72{ }^{\circ} \mathrm{C}$ & $2 \min$ & \\
\hline $72{ }^{\circ} \mathrm{C}$ & $10 \mathrm{~min}$ & \\
\hline PCR-Reaktionsansatz $(25 \mu 1):$ & & \\
\hline Genomische DNA & $2-4 \mathrm{ng}$ & \\
\hline Hop I & $10 \mu \mathrm{M}$ & \\
\hline Hop II & $10 \mu \mathrm{M}$ & \\
\hline Hop III & $10 \mu \mathrm{M}$ & \\
\hline PCR-Puffer (GeneCraft) & einfach & konzentriert \\
\hline dNTP-Mix (GeneCraft) & $0,2 \mathrm{mN}$ & \\
\hline DNA-Polymerase (BioTherm, GeneCraft) & 1 Unit/ & Ansatz \\
\hline
\end{tabular}

\section{Gewinnung Emx2- und Lef1-defizienter Gehirne}

Männchen und Weibchen der Genotypen Emx2+/- (M. Pellegrini et al., 1996) bzw. Lef1+/(J. Galceran et al., 2000) wurden verpaart, die Embryonen an Embryonaltag 16,5 durch Kaiserschnitt entnommen. Isolierte Gehirne der Embryonen wurden in 4 \% PFA in PBS fixiert und für Gefrierschnitt vorbereitet. Zur Genotypisierung der Embryonen wurde genomische DNA aus Schwanzbiopsien verwendet. Die Genotypisierung erfolgte mittels PCR.

\section{Genotypisierung Emx2-defizienter Embryonen}

Für die PCR wurden die Primer Emx2-I (CACAAGTCCCGAGAGTTTCC), Emx2-II (CGTAAGACTGAGACTGTGAGCC) und Emx2-III (CCAGAGGCCATTTGTGTAGC) verwendet. Das Wildtypallel gab ein PCR-Produkt von 200 bp, das rekombinante Allel ein 300 bp-Produkt. Die Analyse der PCR-Reaktionen erfolgte im Agarosegel (2 \%).

$\left.\begin{array}{ll}\text { PCR-Reaktionsschema: } & \\ \hline 95^{\circ} \mathrm{C} & 5 \mathrm{~min} \\ 80^{\circ} \mathrm{C} & 2 \mathrm{~min} \\ 95^{\circ} \mathrm{C} & 30 \mathrm{~s} \\ 58^{\circ} \mathrm{C} & 30 \mathrm{~s} \\ 72^{\circ} \mathrm{C} & 30 \mathrm{~s}\end{array}\right\} 30$ Zyklen


PCR-Reaktionsansatz $(25 \mu 1)$ :

$\begin{array}{ll}\text { Genomische DNA } & 2-4 \mathrm{ng} / \mu \mathrm{l} \\ \text { Emx2-I } & 20 \mu \mathrm{M} \\ \text { Emx2-II } & 10 \mu \mathrm{M} \\ \text { Emx2-III } & 10 \mu \mathrm{M} \\ \text { PCR-Puffer (GeneCraft) } & \text { einfach konzentriert } \\ \text { dNTP-Mix (GeneCraft) } & 0,2 \mathrm{mM} \\ \text { DNA-Polymerase (BioTherm, GeneCraft) } & 1 \mathrm{Unit} / \text { Ansatz }\end{array}$

Genotypisierung Lef1-defizienter Embryonen

Es wurden die Primer D8 (CCGTTTCAGTGGCACGCCCTCTCC), LPP2.2 (TGTCTC TCTTTCCGTGCTAGTTC) und Neo1 (ATGGCGATGCCTGCTTGCCGAATA) verwendet. Das Wildtypallel gab ein PCR-Produkt von ca. 120 bp, das rekombinante Allel ein ca. 300 bp-Produkt. Die Analyse der PCR-Reaktionen erfolgte im Agarosegel (2.2 \%).

\begin{tabular}{|c|c|c|}
\hline \multicolumn{3}{|l|}{ PCR-Reaktionsschema: } \\
\hline $95^{\circ} \mathrm{C}$ & \multicolumn{2}{|l|}{$4 \mathrm{~min}$} \\
\hline $95^{\circ} \mathrm{C}$ & $30 \mathrm{~s}$ & \multirow{3}{*}{25 Zyklen } \\
\hline $69^{\circ} \mathrm{C}$ & $30 \mathrm{~s}$ & \\
\hline $72^{\circ} \mathrm{C}$ & $30 \mathrm{~s}$ & \\
\hline $72{ }^{\circ} \mathrm{C}$ & \multicolumn{2}{|c|}{$10 \mathrm{~min}$} \\
\hline \multicolumn{3}{|l|}{ PCR-Reaktionsansatz $(20 \mu 1)$ : } \\
\hline Genomische DNA & \multicolumn{2}{|c|}{$2-4 \mathrm{ng} / \mu \mathrm{l}$} \\
\hline D8 & \multicolumn{2}{|c|}{$20 \mu \mathrm{M}$} \\
\hline Lpp2.2 & \multicolumn{2}{|c|}{$10 \mu \mathrm{M}$} \\
\hline Neol & \multicolumn{2}{|c|}{$10 \mu \mathrm{M}$} \\
\hline PCR-Puffer (GeneCraft) & \multicolumn{2}{|c|}{ einfach konzentriert } \\
\hline dNTP-Mix (GeneCraft) & \multicolumn{2}{|c|}{$0,2 \mathrm{mM}$} \\
\hline DNA-Polymerase (BioTherm, GeneCraft) & \multicolumn{2}{|c|}{1 Unit/ Ansatz } \\
\hline
\end{tabular}

\section{Herstellung und Analyse transgener Mäuse}

\section{Herstellung transgener Mäuse}

Zur Superovulation wurden sechs Wochen alte weibliche Mäuse (FVB) intraperitoneal mit 4 Units PMS (Stutenserum-Gonadotropin, Sigma) und nach 48 h mit weiteren 4 Units chorionischen Gonadotropins injiziert. Die Tiere wurden mit männlichen Mäusen (FVB) verpaart, die befruchteten Eizellen nach $24 \mathrm{~h}$ entnommen, anhaftende Cumulus-Zellen mit Hyaluronidase $(300 \mathrm{mg} / \mathrm{ml})$ entfernt und der männliche Vorkern mit $2 \mathrm{pl}(2 \mathrm{ng} / \mu \mathrm{l}) \mathrm{der}$ entsprechenden Plasmid-DNA mikroinjiziert. Die manipulierten einzelligen Embryonen wurden in scheinschwangere Ammen-Mütter transferiert. Als Ammen-Mütter dienten FVB-Weibchen, die durch intraperitoneale Injektion von 3 Units Gonadotropin und nach $48 \mathrm{~h}$ mit 2 Units chorionischen Gonadotropins superovuliert wurden. Die von den Ammen-Müttern geborenen transgenen Tiere (F0-Generation) wurden zur Etablierung transgener Maus-Linien und zur Analyse der Embryonen mit FVB-Mäusen verpaart. 


\section{Herstellung und Analyse $p E 1$-transgener Mäuse}

Herstellung und Genotypisierung pE1-transgener Mäuse

Als pEl-transgene Mäuse wurden jene Mäuse bezeichnet, die durch Mikroinjektion des Xho I-Inserts aus dem Plasmid $p E 1$ in befruchtete Eizellen hervorgingen. $p E 1$-transgene Mäuse wurden im genomischen Hintergrund des FVB-Mausstammes gehalten

Die Bestimmung des Genotypes erfolgte durch PCR mit genomischer DNA aus SchwanzBiopsien. Im Falle des transgenen Genotyps war ein PCR-Produkt von 400 bp mit den $\beta$ Galaktosidase-spezifischen Primern LacZ-F (CGTCACACTACGTCTGAACGTCG) und LacZ-R (CAGACGATTCATTGGCACCATGC) zu erwarten. Die Analyse der PCRReaktionen erfolgte im Agarosegel (1\%).

\begin{tabular}{|c|c|c|}
\hline \multicolumn{3}{|l|}{ PCR-Reaktionsschema: } \\
\hline $95^{\circ} \mathrm{C}$ & \multicolumn{2}{|c|}{$4 \min$} \\
\hline $95^{\circ} \mathrm{C}$ & $30 \mathrm{~s}$ & \multirow{4}{*}{30 Zyklen } \\
\hline $65^{\circ} \mathrm{C}$ & $30 \mathrm{~s}$ & \\
\hline $72{ }^{\circ} \mathrm{C}$ & $40 \mathrm{~s}$ & \\
\hline $72{ }^{\circ} \mathrm{C}$ & $5 \mathrm{mil}$ & \\
\hline \multicolumn{3}{|l|}{ PCR-Reaktionsansatz $(25 \mu 1):$} \\
\hline Genomische DNA & \multicolumn{2}{|c|}{$2-4 \mathrm{ng} / \mu \mathrm{l}$} \\
\hline LacZ-F & \multicolumn{2}{|c|}{$10 \mu \mathrm{M}$} \\
\hline LacZ-R & \multicolumn{2}{|c|}{$10 \mu \mathrm{M}$} \\
\hline PCR-Puffer (GeneCraft) & \multicolumn{2}{|c|}{ einfach konzentriert } \\
\hline dNTP-Mix (GeneCraft) & \multicolumn{2}{|c|}{$0,2 \mathrm{mM}$} \\
\hline DNA-Polymerase (BioTherm, GeneCraft) & \multicolumn{2}{|c|}{1 Unit/ Ansatz } \\
\hline
\end{tabular}

Analyse $p E 1$-transgener Mäuse

Embryonen des Embryonalstadiums 12,5 und Gehirne von E16,5 wurden entnommen und für $2 \mathrm{~h}$ bei $4{ }^{\circ} \mathrm{C}$ in PFA (4 \% in PBS) fixiert. Von den Embryonen bzw. Gehirnen wurden Gefrierschnitte $(20 \mu \mathrm{m})$ angefertigt und der $\beta$-Galaktosidase-Färbung unterzogen. Einige Embryonen wurden als Ganzpräparat für $\beta$-Galaktosidase-Aktivität gefärbt und anschließend am Vibratom (Leica Instruments) in $30 \mu \mathrm{m}$ dicke Schnitte geschnitten.

\section{Herstellung und Analyse $p E$ 1-Hop-transgener Mäuse}

Herstellung und Genotypisierung pE1-Hop-transgener Mäuse

Mäuse, welche transgen für das Konstrukt $p E 1-H o p$ waren, gingen durch Mikroinjektion des Xho I-Fragmentes des Plasmid pE1-Hop in befruchtete Eizellen hervor. Die pE1-Hoptransgene Mauslinie wurde im genetischen Hintergrund C57/ BL6 gehalten.

Die Genotypisierung erfolgte durch PCR mit genomischer DNA aus Schwanz-Biopsien. Im Falle des transgenen Genotyps war ein PCR-Produkt von 450 bp mit den hrGFP-spezifischen Primern hrGFP-f (GAACAACCACGTGTTCACCATGG) und hrGFP-r (CGTTCATG 
TACACCACCTCGAAG) zu erwarten. Die Analyse der PCR-Reaktionen erfolgte im $1 \%$ igen Agarosegel.

\begin{tabular}{|c|c|c|}
\hline \multicolumn{3}{|l|}{ PCR-Reaktionsschema: } \\
\hline $95^{\circ} \mathrm{C}$ & \multicolumn{2}{|l|}{$4 \min$} \\
\hline $95^{\circ} \mathrm{C}$ & $1 \mathrm{~min}$ & \\
\hline $65^{\circ} \mathrm{C}$ & $1 \mathrm{~min}$ & 30 Zyklen \\
\hline $72^{\circ} \mathrm{C}$ & $1 \mathrm{~min}$ & \\
\hline $72{ }^{\circ} \mathrm{C}$ & $10 \mathrm{~min}$ & \\
\hline \multicolumn{3}{|l|}{ PCR-Reaktionsansatz $(25 \mu 1)$ : } \\
\hline Genomische DNA & \multicolumn{2}{|c|}{$2-4 \mathrm{ng} / \mu \mathrm{l}$} \\
\hline hrGFP-f & \multicolumn{2}{|c|}{$10 \mu \mathrm{M}$} \\
\hline hrGFP-r & \multicolumn{2}{|c|}{$10 \mu \mathrm{M}$} \\
\hline PCR-Puffer (GeneCraft) & \multicolumn{2}{|c|}{ einfach konzentriert } \\
\hline dNTP-Mix (GeneCraft) & \multicolumn{2}{|c|}{$0,2 \mathrm{mM}$} \\
\hline DNA-Polymerase (BioTherm, GeneCraft) & \multicolumn{2}{|c|}{1 Unit/ Ansatz } \\
\hline
\end{tabular}

\section{Analyse $p E 1-H o p$-transgener Mäuse}

Gehirne des Embryonalstadiums 16,5 wurden entnommen, für $2 \mathrm{~h}$ bei $4{ }^{\circ} \mathrm{C}$ in PFA $(4 \%$ in PBS) und für Gefrierschnitt vorbereitet. Es wurden $10 \mu \mathrm{m}$-Gefrierschnitte angefertigt und das FLAG-markierte Hop-Protein mittels Immunhistochemie nachgewiesen.

\section{Histologische Methoden}

\section{Gefrierschnitte}

Für Gefrierschnitte wurden embryonale Gehirne oder ganze Embryonen $2 \mathrm{~h}$ in kaltem PFA (4 \% in PBS) fixiert, zweimal 30 min in kaltem PBS gewaschen und über Nacht bei $4{ }^{\circ} \mathrm{C}$ in $30 \%$ Sucrose in PBS gegen Gefrierartefakte geschützt. Das Einfrieren erfolgte in Einbettmedium (Leica Instruments) auf Trockeneis. Gefrierschnitte wurden am Kryostaten (S3000, Leica Instruments) angefertigt und auf beschichtete Objektträger (SuperFrost Plus, Menzel-Gläser) aufgeschmolzen.

\section{Paraffinschnitte}

Embryonale oder adulte Gehirne wurden isoliert, über Nacht in kaltem PFA (4 \% in PBS) fixiert und jeweils über Nacht bei $4{ }^{\circ} \mathrm{C}$ in PBS und $0,86 \% \mathrm{NaCl}$ gewaschen. Das Gewebe wurde in aufsteigender Ethanol- und Lösungsmittel-Reihe entwässert, dreimal über Nacht mit flüssigem Paraffin (Tycon heealth care) infiltriert und in Paraffin eingebettet. Paraffinschnitte wurden am Mikrotom (Leica Instruments) angefertigt und auf beschichtete Objektträger (SuperFrost Plus, Menzel-Gläser) aufgenommen. 
Aufsteigende Ethanol- und Lösungsmittel-Reihe zur Gewebeentwässerung:

\begin{tabular}{lll}
\hline Lösungsmittel & $\begin{array}{l}\text { Einwirkdauer für } \\
\text { embryonale Gehirne }\end{array}$ & $\begin{array}{l}\text { Einwirkdauer für } \\
\text { adulte Gehirne }\end{array}$ \\
Ethanol $(50 \%)$ & $2 \times 15 \mathrm{~min}$ & über Nacht, $4{ }^{\circ} \mathrm{C}$ \\
Ethanol $(70 \%)$ & $2 \times 15 \mathrm{~min}$ & über Nacht, $4{ }^{\circ} \mathrm{C}$ \\
Ethanol $(80 \%)$ & $3 \times 20 \mathrm{~min}$ & über Nacht, $4{ }^{\circ} \mathrm{C}$ \\
Ethanol $(90 \%)$ & $3 \times 30 \mathrm{~min}$ & über Nacht, $4{ }^{\circ} \mathrm{C}$ \\
Ethanol $(96 \%)$ & $4 \times 30 \mathrm{~min}$ & über Nacht, $4{ }^{\circ} \mathrm{C}$ \\
Ethanol $(100 \%)$ & $5 \times 20 \mathrm{~min}$ & über Nacht, $4{ }^{\circ} \mathrm{C}$ \\
Isopropanol & über Nacht, $4{ }^{\circ} \mathrm{C}$ & über Nacht, $4{ }^{\circ} \mathrm{C}$ \\
Toluol : Isopropanol $(25 \%: 75 \%)$ & $30 \mathrm{~min}$ & - \\
Toluol : Isopropanol $(50 \%: 50 \%)$ & $30 \mathrm{~min}$ & - \\
Toluol : Isopropanol $(75 \%: 25 \%)$ & $30 \mathrm{~min}$ & - \\
Toluol & $3 \times 60 \mathrm{~min}$ & über Nacht, $4{ }^{\circ} \mathrm{C}$
\end{tabular}

\section{Hämatoxylin-Eosin-Färbung}

Die Hämatoxylin-Eosin-Färbung wurde an Paraffinschnitten $(8 \mu \mathrm{m})$ durchgeführt. Die Schnitte wurden dreimal in Histoclear XEM200 (Vogel GmbH, Giessen) entwachst und über eine absteigende Ethanol-Reihe (100\%, $90 \%, 70 \%, 50 \%$ Ethanol) in Wasser überführt. Anschließend wurde 8 min in Hämatoxylin-Lösung (modifiziert nach Harris; 7,5 \%; Sigma) gefärbt, dreimal 3 min mit Wasser gewaschen und $12 \mathrm{~s}$ mit 3,5\% $\mathrm{HCl} / 70 \%$ Ethanol differenziert. Nach zweimal Waschen mit Wasser wurde mit essigsaurem Eosin ( $0,1 \%$; Merck) gegengefärbt und für $40 \mathrm{~s}$ mit $50 \%$ Ethanol differenziert. Es folgten eine aufsteigende EthanolReihe $(70 \%, 90 \%, 100 \%$ Ethanol) und Überführung in Histoclear. Die Präparate wurden in Eukitt (O. Kindler GmbH) eingedeckelt.

\section{Histochemische Methoden}

\section{$\beta$-Galaktosidase-Enzymhistochemie}

Gefrierschnitte $(20 \mu \mathrm{m})$ wurden 10 min in kaltem Glutaraldehyd $(0,2 \%$ in PBS) fixiert, dreimal 5 min in Puffer A gewaschen und über Nacht bei $37{ }^{\circ} \mathrm{C}$ in Puffer B gefärbt. Die Reaktion wurde in PBS abgestoppt.

$\begin{array}{ll}\text { Puffer A: } & \\ \mathrm{MgCl}_{2} & 2 \mathrm{mM} \\ \text { Natrium-Desoxycholat } & 0,01 \% \\ \mathrm{NP} \mathrm{40} & 0,02 \% \\ \text { PBS; } \mathrm{pH} 7,5 & \text { einfach konzentriert } \\ & \\ \text { Puffer B: } & \\ \mathrm{MgCl}_{2} & 2 \mathrm{mM} \\ \mathrm{Natrium}-D e s o x y c h o l a t & 0,01 \% \\ \mathrm{NP} \mathrm{40} & 0,02 \% \\ \mathrm{~K}_{3} \mathrm{Fe}(\mathrm{CN})_{6} & 5 \mathrm{mM} \\ \mathrm{K}_{4} \mathrm{Fe}(\mathrm{CN})_{6} & 5 \mathrm{mM} \\ 5-\mathrm{Bromo}-4-C h l o r o-3-\text { Indolyl- } \beta-D-G a l a k t o s i d & 0,5 \mathrm{mg} / \mathrm{ml} \\ \mathrm{PBS} ; \mathrm{pH} 7,5 & \text { einfach konzentriert }\end{array}$

Zum Nachweis der $\beta$-Galaktosidase-Aktivität in organotypisch kultivierten Gehirnschnitten oder ganzen Embryonen (E12,5) wurden diese für $30 \mathrm{~min}$ in kalter Fixierlösung fixiert und 
zweimal mit PBS gewaschen. Es folgte die Inkubation in Färbelösung bei $37^{\circ} \mathrm{C}$ über Nacht. Die Färbereaktion wurde in PBS gestoppt.

$\begin{array}{ll}\text { Fixierlösung: } & \\ \text { Formaldehyd } & 1 \% \\ \text { Glutaraldehyd } & 0,2 \% \\ \text { NP 40 } & 0,02 \% \\ \text { PBS; } \mathrm{pH} 7,5 & \text { einfach konzentriert } \\ & \\ \text { Färbelösung: } & 2 \mathrm{mM} \\ \mathrm{MgCl}_{2} & 5 \mathrm{mM} \\ \mathrm{K}_{3} \mathrm{Fe}(\mathrm{CN})_{6} & 5 \mathrm{mM} \\ \mathrm{K}_{4} \mathrm{Fe}(\mathrm{CN})_{6} & 1 \mathrm{mg} / \mathrm{ml} \\ 5-\mathrm{Bromo}-4-\mathrm{Chloro}-3-\text { Indolyl- } \beta-D-G a l a k t o s i d & \\ (\mathrm{Gibco} \mathrm{BRL}) & \text { einfach konzentriert }\end{array}$

\section{Immunohistochemie zum Nachweis des Proteins Serum response factor (SRF)}

Paraffinschnitte $(8 \mu \mathrm{m})$ wurden in Histoclear entwachst, in einer absteigenden Ethanol-Reihe (100\%, $90 \%, 70 \%, 50 \%$ Ethanol) rehydriert und unspezifische Protein-Bindungsstellen für 30 min in $3 \%$ Ziegenserum (Vector) und 0,5\% BSA (Sigma) in PBS blockiert. Als primärer Antikörper wurde Kaninchen-anti-SRF (Santa Cruz) $1: 100$ in 1,5 \% Ziegenserum und 0,5\% BSA in PBS eingesetzt. Die Inkubation erfolgte bei $4{ }^{\circ} \mathrm{C}$ über Nacht. Nach dreimaligem Waschen in PBS wurden die Schnitte für $30 \mathrm{~min}$ mit einem Alexa 488-konjugierten antiKaninchen-IgG-Antikörper (Molecular Probes) $1: 500$ in 0,5 \% BSA/ PBS inkubiert. Nach drei weiteren Waschschritten in PBS wurden die Präparate in Vectashield (Vectabound) eingedeckelt.

\section{Immunhistochemischer Nachweis des FLAG-Epitops}

Gefrierschnitte $(10 \mu \mathrm{m})$ wurden dreimal $5 \mathrm{~min}$ in PBS gewaschen, für $30 \mathrm{~min}$ in $3 \%$ Ziegenserum und 0,5 \% BSA in PBS blockiert. Der primäre Antikörper (Kaninchen-anti-FLAG, Sigma) wurde $1: 300$ verdünnt in 1,5\% Ziegenserum/ 0,5\% BSA in PBS eingesetzt. Die Inkubation mit primärem Antikörper erfolgte über Nacht bei $4{ }^{\circ} \mathrm{C}$. Anschließend wurde dreimal $5 \mathrm{~min}$ in PBS gewaschen und für $30 \mathrm{~min}$ mit einem Alexa 594-konjugierten anti-Kaninchen IgG-Antikörper (Molecular Probes) 1:500 in 0,5 \% BSA/ PBS inkubiert. Nach drei weiteren Waschschritten in PBS wurde eine DAPI-Gegenfärbung (2 min, 0,05 $\mu \mathrm{g} / \mathrm{ml}$ PBS; Calbiochem) durchgeführt, weiter zweimal mit PBS gewaschen und die Präparate in Vectashield eingedeckelt.

\section{BrdU-Markierung mitotischer Zellen und BrdU-Immunohistochemie}

Weibliche und männliche Mäuse des Genotyps Hop+/- wurden verpaart und den trächtigen Weibchen an E16,5 intraperitoneal $100 \mu \mathrm{g}$ BrdU (in PBS, Sigma) pro g Körpergewicht verabreicht. Nach 30 min wurden die Embryonen entnommen, deren Gehirne isoliert und 
Gewebe aus dem Schwanz zur Genotypisierung bereitgestellt. Die Gehirne wurden fixiert und für Paraffinschnitt vorbereitet. Es wurden $6 \mu \mathrm{m}$-Paraffinschnitte angefertigt.

Die Gewebeschnitte wurden in Histoclear entwachst und in einer aufsteigenden EthanolReihe rehydriert. Anschließend wurde die DNA für 30 min in $2 \mathrm{~N} \mathrm{HCl}$ denaturiert. Die Schnitte wurden zweimal 10 min in $0,1 \mathrm{M} \mathrm{Na}_{2} \mathrm{~B}_{4} \mathrm{O}_{7}(\mathrm{pH} 8,5)$ neutralisiert und zweimal 5 min in PBS gewaschen. Zur Proteinase K-Behandlung wurden $20 \mu \mathrm{g} / \mathrm{ml}$ Proteinase $\mathrm{K}$ in $20 \mathrm{mM}$ Tris-Cl, pH 7,5 und $1 \mathrm{mM}$ EDTA eingesetzt. Die Proteinase K-Behandlung dauerte $7 \mathrm{~min}$. Es wurde zweimal 5 min mit PBS gewaschen, unspezifische Protein-Bindungsstellen wurden $1 \mathrm{~h}$ in $0,2 \%$ Tween 20 und 0,2 \% Gelatine in PBS blockiert. Nach Waschen in PBS wurde über Nacht bei 4 ${ }^{\circ} \mathrm{C}$ mit Fluoreszin-konjugiertem anti-BrdU-Antikörper (1:10 in PBS, Boehringer Mannheim) inkubiert. Es schlossen sich an: dreimal 5 min Waschen mit PBS und 1 min Gegenfärbung mit Propidiumiodid (0,33 $\mu \mathrm{g} / \mathrm{ml}$ PBS; Molecular Probes). Nach vier weiteren PBS-Waschschritten wurden die Präparate in Vectashield eingedeckelt.

\section{Elektroporation embryonaler Gehirne und organotypische Kultur}

\section{Herstellen der Plasmid-Lösung}

Plasmid-DNA wurde mit Hilfe des "QIAfilter Plasmid Maxi Kit" (Qiagen) präpariert, PCI und CI extrahiert und in 0,01 \% Fast green (Sigma) in PBS gelöst. Die verwendete DNAKonzentration betrug $500 \mathrm{ng} / \mu 1$. Der Plasmid-Lösung war ferner das Konstrukt CMV-EGFP (L. Luo et al., 2004) in einer Endkonzentration von $600 \mathrm{ng} / \mu 1$ zugesetzt.

In der Literatur werden DNA-Konzentration von 2-5 $\mu \mathrm{g} / \mu \mathrm{l}$ (N. Osumi und T. Inoue, 2001) und sogar 5-10 $\mu \mathrm{g} / \mu \mathrm{l}$ (H. Tabata und K. Nakajima, 2001) empfohlen. Die hier verwendete Konzentration von $500 \mathrm{ng} / \mu \mathrm{l}$ erwies sich als geeignet, graduelle Unterschiede der Reporteraktivität zu erkennen.

\section{Herstellen der Mikrokapillaren}

Mikrokapillaren (Clark Electromedical Instruments) wurden mit Hilfe eines vertikalen Kapillarenziehers (Modell 720, David Kopf Instruments) gezogen (Solenoid $=0$, Heater $=$ $18,5)$.

\section{Elektroporation und organotypische Kultur}

Embryonale Gehirne (E14,5) wurden in kaltem EBSS isoliert (Gibco BRL). Die

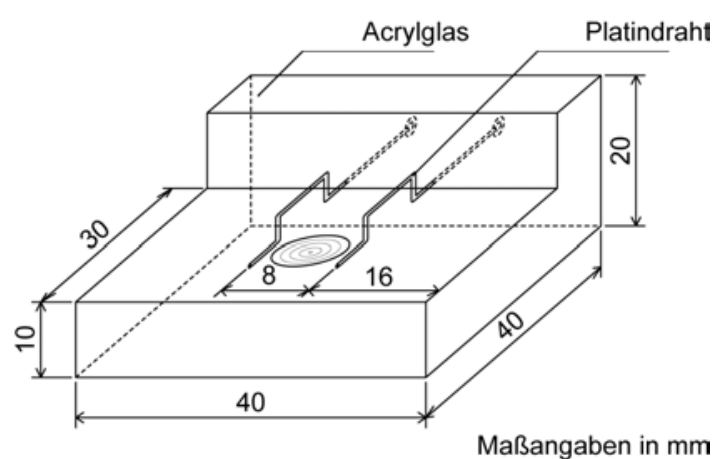

Abb. 28: Apparatur zur Elektroporation Der Elektroporationstisch trägt eine zentrale Vertiefung (Ø $8 \mathrm{~mm}$, Tiefe $1 \mathrm{~mm}$ ), die zur Aufnahme des zu elektroporierenden Gehirns dient. Daran angrenzend befinden sich die Elektroden aus Platindraht. 
Elektroporation erfolgte auf einem Elektroporationstisch (Abb. 28). Dazu wurden $100 \mu 1$ steriles, kaltes PBS auf die zentrale Vertiefung gegeben, so daß beide Elektroden benetzt waren. Im PBS wurde das zu elektroporierende Gehirn mit dem Zielareal zur Anode orientiert und 2-3 $\mu 1$ Plasmid-Lösung durch Mikrokapillaren (Mikroinjector 5242, Eppendorf) in das zur Anode gerichtete laterale Hirnventrikel injiziert. Es folgte die Verabreichung von fünf elektrischen Pulsen (Spannung $=70 \mathrm{~V}$, Pulsdauer $=50 \mathrm{~ms}$, Pause $=1 \mathrm{~s}$; Rechteckspannungs-Generator ECM 830, BTX). Elektroporierte Gehirne wurden in kaltem Gewebekulturmedium aufbewahrt und anschließend in $2 \%$ niedrigschmelzender Agarose (Gibco BRL) in EBSS eingebettet. Koronale Schnitte $(300-400 \mu \mathrm{m})$ der eingebetteten Gehirne wurden am manuellen Vibratom (TSE Systems) in kaltem PBS angefertigt. Zur Gewebekultur wurden die Hirnschnitte auf Gewebekultureinsätze (Polykarbonat; 0,3 $\mu \mathrm{m}$-Poren; Nunc) in 6-Well-Platten mit 1,5 ml Kulturmedium pro Kammer platziert. Die Kultur erfolgte im Inkubator (BBD 6220, Heraeus) in feuchter $\mathrm{CO}_{2}$-Atmosphäre $\left(\left[\mathrm{CO}_{2}\right]=5 \%\right.$, Luftfeuchte $\left.=95 \%, \mathrm{~T}=37^{\circ} \mathrm{C}\right)$.

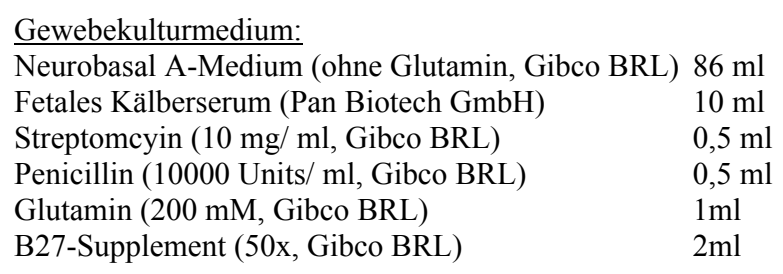

In Y. Gitton et al., 1999 wird eine ähnliche Methode der organotypischen Kultur verwendet. Insbesondere wird darauf hingewiesen, daß die zum Schneiden der Gehirne nötige AgaroseEinbettung nicht entfernt werden muß. In der Tat führt das Belassen der Agarose-Matrix zu einem guten Erhalt der Morphologie des kultivierten Schnittes. So können auch noch nach 48stündiger Kultur deutlich Strukturen wie Hippocampus, Septum, ganglionäre Eminenzen und laterales Ventrikel unterschieden werden. Da das kultivierte Gewebe weiter wächst und nicht nach außen, in Richtung zur Agarose expandieren kann, kommt es zur Expansion in Richtung des Ventrikels, welches nach viertägiger Kultur verschwindet. Dann ist auch die maximale Dauer einer solchen Kultur erreicht. 


\section{Anhang}

\section{Daten der Microarray-Expressionsanalyse}

Tab. 5: Daten der durch Microarray-Expressionsanalyse identifizierten Gene.

Alle Sequenzen (Proben-Sets), deren Microarray-Expressionsdaten die Auswahlkriterien erfüllten, sind nach der jeweiligen Kortexregion gruppiert und ihre Probenkennummern ausgewiesen. DC bezeichnet das Prädikat des Expressionsunterschiedes ("DifferenceCall") und FC das Expressionsverhältnis ("FoldChange") zu anderen Regionen des Kortex und der Probe "Restkörper". Sofern eine Zuordnung des Proben-Sets zu einem bekannten oder hypothetischen Protein vorlag, sind Name und Symbol des Gens angegeben.

\begin{tabular}{|c|c|c|c|c|c|c|c|c|c|c|c|c|c|}
\hline \multirow{2}{*}{\multicolumn{2}{|c|}{$\begin{array}{l}\text { Affymetrix } \\
\text { Proben- } \\
\text { kennummer }\end{array}$}} & \multicolumn{2}{|c|}{ Okzipitaler Korlex } & \multicolumn{2}{|c|}{ Frontaler Kortex } & \multicolumn{2}{|c|}{$\begin{array}{l}\text { Caudomedialer } \\
\text { Kontex }\end{array}$} & \multicolumn{2}{|c|}{ Parietaler Kortex } & \multicolumn{2}{|c|}{ |"Restkörper" } & \multirow[t]{2}{*}{ Genname } & \multirow[t]{2}{*}{ Gensymbol } \\
\hline & & $\mathrm{DC}$ & FEC & $\mathrm{DC}$ & FC & $D C$ & TFC & $\mathrm{DC}$ & FC & $\mathrm{DC}$ & IFC & & \\
\hline & 92995_at & & 5,2 & & 3,3 & & 5,6 & 1 & 5,4 & 1 & 2,9 & Visinin like 1 & Vsnl1 1 \\
\hline & 93372_at & & 5,3 & & 7,4 & $\mathrm{MI}$ & 5,6 & 1 & 7,6 & 1 & 3,9 & Acidic nuclear phosphoprotein 32a & Anp32a \\
\hline & 96672 at & & 3,7 & & 2,6 & & 1,9 & 1 & 3.0 & $\pi$ & 2,4 & Homeodomain only protein & Hop \\
\hline & 97721 at & & 3,5 & I & 57 & I & 4,1 & 1 & 6,3 & 1 & 4,2 & Fibroblastenwachstumsfaktor 15 & Fgf15 \\
\hline & 98330 at & & 6,0 & & 5,0 & & 5,4 & 1 & 7.9 & 1 & 7.8 & Zinkfingerprotein des Zerebellums 3 & Zic3 \\
\hline & 103597 at & & 39,3 & & 3,7 & & 42,1 & 1 & 11,3 & 1 & 14,7 & Dopachrom tautomerase & Dot \\
\hline & 104169 at & & 30,8 & 1 & 8,2 & 1 & 4,2 & 1 & 35,1 & 1 & 67,8 & Zinkfingerprotein des Zerebellums 1 & Zic1 \\
\hline 䒽 & 104299_at & & 9,7 & & 1,4 & $\mathrm{MI}$ & 1,6 & $T$ & 6,4 & 1 & 3,5 & DHHC-Zinkfingerprotein 14 & Zdhhc14 \\
\hline $\begin{array}{c}3 \\
\text { o }\end{array}$ & 105606 at & & 3,4 & & 2,2 & & 2,3 & 1 & 2.7 & 1 & 4,0 & Ras homolog gene family, member $E$ & Arhe \\
\hline & 109653 at & & 4,3 & T & 5,7 & & 2,3 & 1 & 5,5 & 1 & 2,6 & Neurotensin & Nis \\
\hline$\frac{\mathrm{w}}{\frac{5}{2}}$ & 112211 at & & 1,7 & 1 & 1,4 & & 4,0 & 1 & 1,3 & $t$ & 6,9 & nicht ammotient & \\
\hline 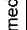 & 114630 at & & 6,8 & I & 4,8 & & 2,5 & 1 & 2.2 & 1 & 1.4 & nicht amnotiert & - \\
\hline E & 115573 at & & 3.6 & & 4,3 & & 4,3 & 1 & 4.1 & 1 & 2,2 & Guanindeaminase & Gda \\
\hline 密 & 133830 at & & 6,3 & I & 3,7 & 1 & 2,9 & 1 & 7,2 & 1 & 2,4 & nicht ammotiert & - \\
\hline 迎 & 134526 __at & & 2,3 & I & 3,9 & & 3.8 & 1 & 2.6 & 1 & 1.9 & nicht ammotiert & - \\
\hline & 135902 at & & 1,9 & $\sqrt{1}$ & 4,2 & & 1,6 & 1 & 3.4 & 1 & 6,1 & Hypothetisches Protein mit CCHC-Zinkfinger & - \\
\hline & 137669 at & & 8,8 & 1 & 3,0 & & 2,8 & 1 & 10,0 & 1 & 6,6 & Solute carrier familie 14, member 2 & Slc14a2 \\
\hline & 138947_at & & 9,1 & MI & 2,4 & & 15,9 & 1 & 14.4 & 1 & 5,0 & Kalium kanal-interagierendes Protein 2 & Konip2 \\
\hline & $161817 \mathrm{f}$ at & & 5,9 & & 20 & & 1,7 & $t$ & 2.6 & $t$ & 2.8 & SPRY enthaltendes SOCS-Box-Protein 1 & SSB1 \\
\hline & 162814 at & & 3,8 & & 4,7 & I & 2,4 & 1 & 5.4 & 1 & 10,2 & Solute carrier familie 1 , member 3 & Slc1a3 \\
\hline & 164910 s_at & & 33,6 & & 4,8 & & 17,6 & $t$ & 46.9 & $t$ & 10,9 & Dooachrom tautomerase & Dct \\
\hline & 165991 i at & & 2,2 & & 2,4 & & 2,0 & +1 & 3.0 & $\mathrm{MI}$ & 1.5 & Tdrg-TL1 & Tdrg-TL1 \\
\hline & 166858 at & & 30,3 & & 14,6 & & 7,2 & 1 & 45,2 & 1 & 22,4 & nicht ammotiert & \\
\hline & 166871 at & & 5,3 & & 21 & & 3,8 & & 2.0 & 1 & 15,3 & nicht amotient & \\
\hline & 168675 i at & $\mid \bar{M}$ & 2,9 & & 7,3 & $\mid \mathrm{M}$ & 3 & $\mid \mathrm{MI}$ & 3,6 & $\pi$ & 2,5 & Prefoldin 1 & Pidn1 \\
\hline
\end{tabular}

\begin{tabular}{|c|c|c|c|c|c|c|c|c|c|c|c|c|}
\hline \multirow{2}{*}{\begin{tabular}{|l|} 
Affymetrix \\
Proben- \\
kennummer
\end{tabular}} & \multicolumn{2}{|c|}{ Okzipitaler Kortex } & \multicolumn{2}{|c|}{ Frontaler Kortex } & \multicolumn{2}{|c|}{$\begin{array}{l}\text { Rostromedialer } \\
\text { Kortex }\end{array}$} & \multicolumn{2}{|c|}{ Parietaler Kortex } & \multicolumn{2}{|c|}{ "Restkörper" } & \multirow[t]{2}{*}{ Genname } & \multirow[t]{2}{*}{ Gensymbol } \\
\hline & $\overline{D C}$ & JFC & $D C$ & JFC & $D C$ & JFC & DC & JFC & $D C$ & JFC & & \\
\hline 92981 at & & 3,0 & 1 & 12,8 & $\frac{1}{1}$ & 2,5 & $\frac{1}{15}$ & 2.5 & $\frac{6}{1}$ & $\frac{5}{4.4}$ & nicht annotiert & \\
\hline 93643 at & & 5,5 & ti & 6,4 & MI & $\frac{4,2}{4,0}$ & $\frac{f}{1}$ & $\frac{1.2}{7.5}$ & fi & $\frac{170}{4,0}$ & LIM-Homeoboxprotein $9 \alpha$ & Lhx $9 \alpha$ \\
\hline 93913_at & & 4,0 & i & 4,6 & I & 1,7 & $t$ & 4.0 & $t$ & 1.9 & Early B-cell factor 3 & Ebf3 \\
\hline 94780 at & & 3,3 & 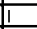 & 4,0 & 1 & 2,5 & 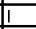 & 7,1 & 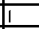 & 30,5 & Zinkfingerprotein 288 & Zfp288 \\
\hline 101192 at & & 5,0 & $t$ & 6,6 & $\mid \mathrm{Ml}$ & 6,6 & $i$ & 7,8 & $f$ & 3.5 & LIM-Homeoboxprotein 5 & Lh $\times 5$ \\
\hline 103548 at & & 21,7 & $t$ & 33,5 & 1 & 3,2 & $t$ & 27,5 & 1 & 39 & Tachykinin 2 & Tac2 \\
\hline 103916 at & 1 & 4,0 & $t$ & 7,6 & $t$ & $\frac{1,2}{2,1}$ & $t$ & 5.9 & fi & $\frac{13}{13}$ & nicht annotiert & \\
\hline 104460 at & $\mid \mathrm{Ml}$ & 3,3 & $t$ & 86 & $\mid \mathrm{MI}$ & 5,7 & $t$ & 7.5 & $i$ & 5.8 & Spannungsabh. $\mathrm{Ca}^{2+}$ Kanal_Tyo I Subunit 1G & Cacna1g \\
\hline 104580 at & & 8,3 & $t$ & 14,9 & 1 & 10,4 & $t$ & 13,8 & $t$ & 6,2 & 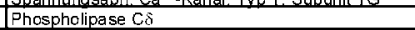 & PItó \\
\hline 109495 at & ti & $\frac{1,5}{23}$ & $t$ & 35 & $t$ & 2,1 & $t$ & $\frac{1,0}{43}$ & fi & $\frac{1,2}{80}$ & nicht annotiert & \\
\hline 113738 at & MI & 44 & $t$ & 3,7 & $f$ & $\frac{1.18}{2,8}$ & ti & 11.4 & 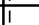 & 4.6 & nicht annotient & - \\
\hline 115830 at & & 2,8 & $t$ & 3,1 & $t$ & 2,1 & $t$ & 4,0 & $t$ & 4,5 & nicht annotient' & - \\
\hline$\frac{116382 \text { at }}{116}$ & & $\frac{1,0}{3,0}$ & $\frac{11}{11}$ & $\frac{1,1}{13,4}$ & $\frac{f 1}{11}$ & $\frac{1,1}{2,0}$ & & 13,3 & & $\frac{1.5}{2.7}$ & Neuropilin 2 & $\mathrm{Nrp} 2$ \\
\hline 116619 at & & 29 & $t$ & 3,5 & i & 2,0 & $i$ & 5,6 & $f$ & $\frac{1,1}{16,7}$ & Zinkfingerprotein 288 & Zfp288 \\
\hline 130408 at & & 9,2 & $t$ & 10,6 & MI & 2,6 & $t$ & 10,7 & $f$ & 5,0 & nicht annotiert & \\
\hline 160937 at & & $\frac{1,2}{16,0}$ & $\frac{11}{1}$ & $\frac{17,0}{17,7}$ & $\frac{1}{1}$ & $\frac{2,0}{2,9}$ & $\frac{n}{1}$ & $\frac{0,1}{19,3}$ & $\frac{f}{1}$ & $\frac{6.0}{6.9}$ & \begin{tabular}{|l} 
Crystallin mu \\
\end{tabular} & crym \\
\hline $162219 \mathrm{f}$ at & & 2,3 & | & 4,9 & i & $\frac{1.9}{1.9}$ & i & 3.8 & 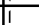 & 5.7 & Solute carrier familie 16, member 2 & $\begin{array}{l}\operatorname{sic} 16 \mathrm{a} 2 \\
\end{array}$ \\
\hline$\frac{162219 \mathrm{al}}{163120 \text { at }}$ & & $\frac{2,3}{69}$ & $\frac{\pi}{1}$ & $\frac{1,9}{8,6}$ & $\frac{11}{1}$ & $\frac{1,9}{1,8}$ & $\frac{n}{1}$ & $\frac{2.8}{8.8}$ & $\frac{1}{11}$ & $\frac{2,1}{2,2}$ & 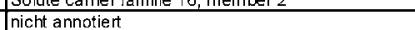 & \\
\hline 165567 at & & $\frac{\mid, 5}{15,5}$ & $\frac{t 1}{11}$ & $\frac{2,0}{25,3}$ & $\frac{\pi}{11}$ & 23,5 & $\frac{\pi}{11}$ & $\frac{10}{17.8}$ & $\frac{f}{11}$ & $\frac{1,2}{6.8}$ & Gastrin freisetzendes Peptid & Grp \\
\hline $165981 \mathrm{i}$ at & & 22,6 & $t$ & 31,2 & $\frac{\pi}{11}$ & $\frac{20,0}{2,0}$ & $t$ & 26.2 & i & $\frac{2,2}{2,2}$ & Lecukocyte cell derived chemotaxin 1 & $\begin{array}{ll}\text { Lect } 1 \\
\end{array}$ \\
\hline 166317 f at & 1 & 3,0 & $t$ & 3,7 & 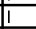 & 3,3 & $t$ & 4,2 & $f$ & 2,2 & Prolineiarginine-rich end leucine-rich repeat protein & Prelp \\
\hline $166814 \mathrm{f}$ at & ti & $\frac{10}{3,0}$ & $t$ & $\frac{11}{45}$ & ti & $\frac{1.2}{19}$ & ti & 4.2 & $t$ & $\frac{1.2}{35,4}$ & nicht annotiert & \\
\hline 168744 at & & 3,3 & 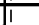 & $\frac{4,8}{4.8}$ & 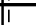 & $\frac{10}{2.8}$ & 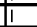 & 4.2 & 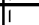 & 2.0 & micht annotiert & \\
\hline
\end{tabular}



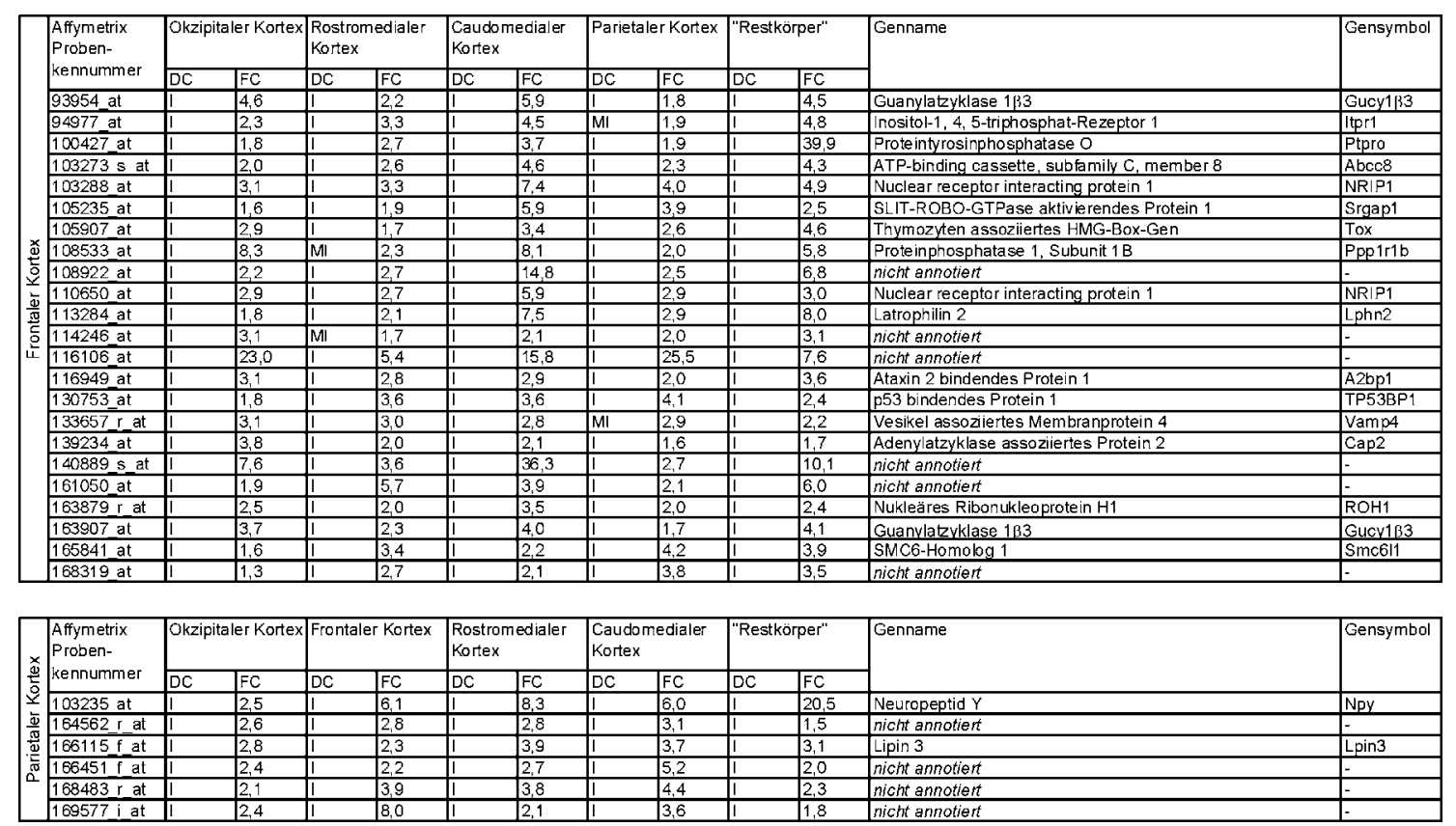

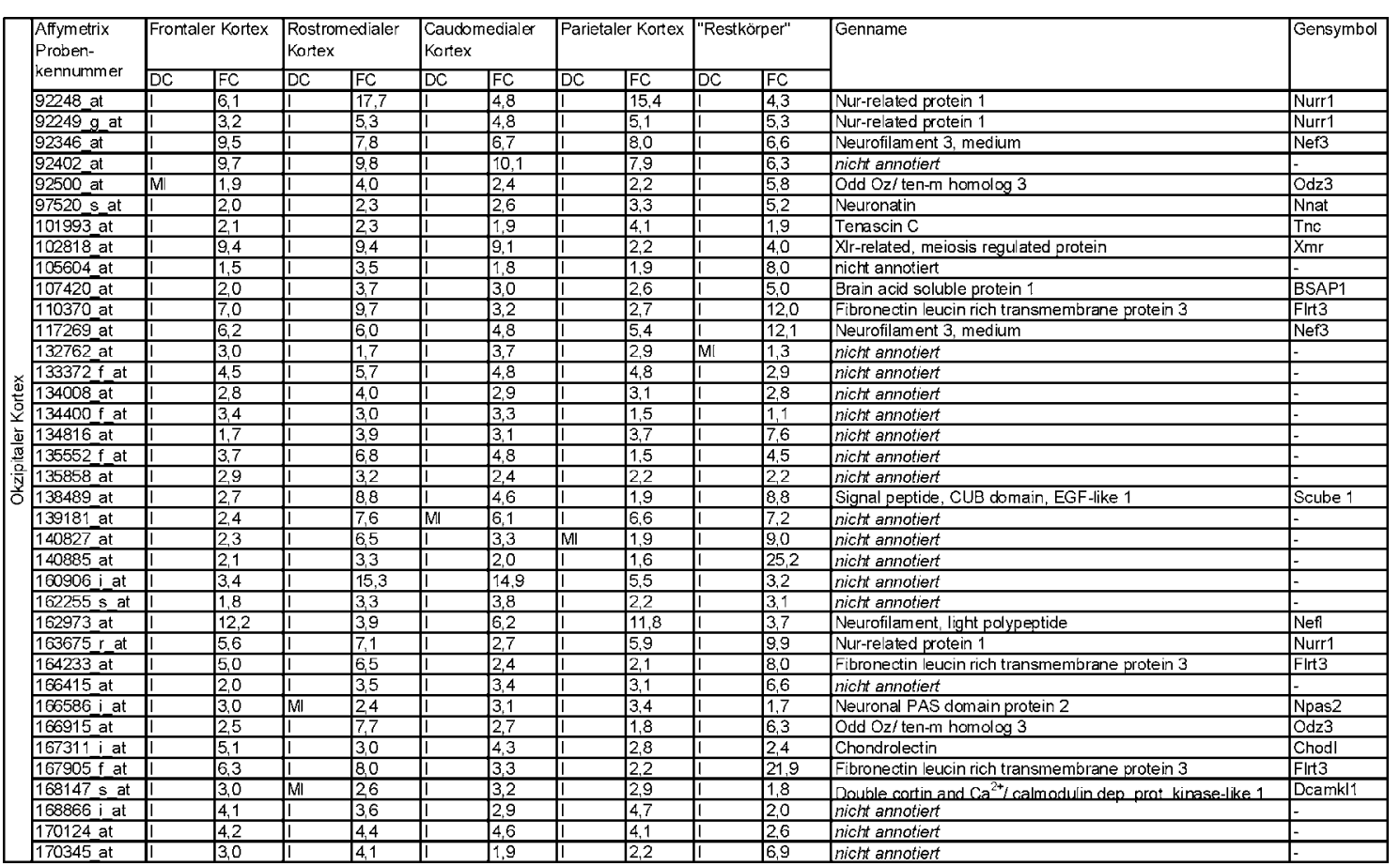




\section{Sequenzen der cDNA-Klone und RNA-Sonde von Hop}

Hop, kodierende Sequenz (AF492704)

Hop, cDNA-KIon 1

Hop, cDNA-KIon 2

Hop, RNA-Sonde

Hop, Targetsequenz (96672_at)

Hop, kodierende Sequenz (AF492704)

Hop, cDNA-KIon 1

Hop, cDNA-KIon 2

Hop, RNA-Sonde

Hop, Targetsequenz (96672_at)

Hop, kodierende Sequenz (AF492704)

Hop, cDNA-KIon 1

Hop, cDNA-KIon 2

Hop, RNA-Sonde

Hop, Targetsequenz (96672_at)

Hop, kodierende Sequenz (AF492704) Hop, cDNA-KIon 1

Hop, cDNA-KIon 2

Hop, RNA-Sonde

Hop, Targetsequenz (96672_at)

Hop, kodierende Sequenz (AF492704) Hop, cDNA-Klon 1

Hop, cDNA-KIon 2 Hop, RNA-Sonde

Hop, Targetsequenz (96672_at)

\section{Ende Homeodomäne}

Hop, kodierende Sequenz (AF492704) Hop, cDNA-KIon 1

Hop, cDNA-KIon 2 Hop, RNA-Sonde

Hop, Targetsequenz (96672_at)

Hop, kodierende Sequenz (AF492704) Hop, cDNA-KIon 1

Hop, cDNA-KIon 2 Hop, RNA-Sonde

Hop, Targetsequenz (96672_at)

Hop, kodierende Sequenz (AF492704)

Hop, cDNA-KIon 1

Hop, cDNA-KIon 2

Hop, RNA-Sonde

Hop, Targetsequenz (96672 at)
Beginn Exon 2

--AGCTCCGGATCTCCGGAGGCAGCACTTGAGGCGCTTCCTCAGTATACTGTCCCCTCG 57 ----GCTCCGGATCTCCGGAGGCAGCACTTGAGGCGCTTCCTCAGTATACTGTCCCCTCG 56 GGCAGCTCCGGATCTCCGGAGGCAGCACTTGAGGCGCTTCCTCAGTATACTGTCCCCTCG 60

(--1-

Beginn Exon 3

GAGTGTCAGGCGGGAGGCGTCTTCTTCCTCCTCTCCATCCTTAGTCAGACGCGCACGGAC 117 GAGTGTCAGGCGGGAGGCGTCTTCTTCCTCCTCTCCATCCTTAGTCAGACGCGCACGGAC 116 GAGTGTCAGGCGGGAGGCGTCTTCTTCCTCCTCTCCATCCTTAGTCAGACGCGCACGGAC 120

AGTGTCAGGCGGGAGCGTCTCTTCCCCTCTCCATCCTTAGTCAGACCGCACGGAC 1

\section{Beginn Homeodomäne}

CATGTCGGCGCAGACCGCGAGCGGCCCĆACGGAGGACCAGGTGGAGATCCTGGAGTACAA 177 CATGTCGGCGCAGACCGCGAGCGGCCCCACGGAGGACCAGGTGGAGATCCTGGAGTACAA 176 CATGTCGGCGCAGACCGCGAGCGGCCCACGGAGGACCAGGTGGAGATCCTGGAGTACAA 180

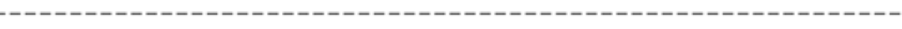

(1)

CTTCAACAAGGTCAACAAGCACCCGGACCCCACCACGCTGTGCCTCATCGCAGCCGAGGC 237 CTTCAACAAGGTCAACAAGCACCCGGACCCCACCACGCTGTGCCTCATCGCAGCCGAGGC 236 CTTCAACAAGGTCAACAAGCACCCGGACCCCACCACGCTGTGCCTCATCGCAGCCGAGGC 240

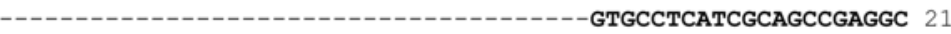
(1)

Beginn Exon 4

GGGTCTCACGGAGGAGCAGACG'CAGAAATGGTTTAAGCAGCGCCTGGCAGAGTGGCGGCG 297 GGGTCTCACGGAGGAGCAGACGCAGAAATGGTTTAAGCAGCGCCTGGCAGAGTGGCGGCG 296 GGGTCTCACGGAGGAGCAGACGCAGAAATGGTTTAAGCAGCGCCTGGCAGAGTGGCGGCG 300 GGGTCTCACGGAGGAGCAGACGCAGAAATGGTTTAAGCAGCGCCTGGCAGAGTGGCGGCG 81

ÍTCAGAAGGCTTGCCTTCGGAATGCAGATCTGTTACGGACTAGGGAGCCAGGCCCTTGAG 357 GTCAGAAGGCTTGCCTTCGGAATGCAGATCTGTTACGGACTAGGGAGCCAGGCCCTTGAG 356 GTCAGAAGGCTTGCCTTCGGAATGCAGATCTGTTACGGACTAGGGAGCCAGGCCCTTGAG 360 GTCAGAAGGCTTGCCTTCGGAATGCAGATCTGTTACGGACTAGGGAGCCAGGCCCTTGAG 141

CTTGCTCTTGGAACTCCATCTCTTCTTCCTTCCCTCGGCTTACCCAGGCTGTTTTGATGT 417 CTTGCTCTTGGAACTCCATCTCTTCTTCCTTCCCTCGGCTTACCCAGGCTGTTTTGATGT 416 CTTGCTCTTGGAACTCCATCTCTTCTTCCTTCCCTCGGCTTACCCAGGCTGTTTTGATGT 420 CTTGCTCTTGGAACTCCATCTCTTCTTCCTTCCCTCGGCTTACCCAGGCTGTTTTGATGT 201

TTCAGTGCAGTGTTGAATGTCTCATTGTTTTGCTGTCCTGCTATTTAACACAATGTGTTT 477 TTCAGTGCAGTGTTGAATGTCTCATTGTTTTGCTGTCCTGCTATTTAACACAATGTGTTT 476 TTCAGTGCAGTGTTGAATGTCTCATTGTTTTGCTGTCCTGCTATTTAACACAATGTGTTT 480 TTCAGTGCAGTGTTGAATGTCTCATTGTTTTGCTGTCCTGCTATTTAACACAAT--:--- 255

Abb. 29: Gegenüberstellung der Sequenzen von Hop-cDNA-Klonen.

Zwei cDNA-Klone des Genes Hop (cDNA-Klone 1 und 2) wurden durch Screenen einer cDNA-Bibliothek (E14,5; Gehirn) identifiziert. Sie entsprechen hinsichtlich ihrer Sequenz dem Genbank-Eintrag AF 492704, also der Spleißvariante, welche für die Exonabfolge 2-3-4, nicht 1-3-4, kodiert. Die translatierte Sequenz ist fett gedruckt. In der Sequenzanordnung sind auch die klonierte Hop-RNA-Sonde sowie die Microarray-Targetsequenz des Hop-Gens aufgeführt.

- Diese Abbildung ist auf der nächsten Seite fortgesetzt. - 
Hop, kodierende Sequenz (AF492704) Hop, cDNA-KIon 1 Hop, cDNA-KIon 2 Hop, RNA-Sonde Hop, Targetsequenz (96672_at)

Hop, kodierende Sequenz (AF492704) Hop, cDNA-KIon 1 Hop, cDNA-KIon 2 Hop, RNA-Sonde

Hop, Targetsequenz (96672_at)

Hop, kodierende Sequenz (AF492704) Hop, cDNA-KIon 1 Hop, cDNA-Klon 2 Hop, RNA-Sonde

Hop, Targetsequenz (96672_at)

Hop, kodierende Sequenz (AF492704) Hop, cDNA-Klon Hop, cDNA-Klon 2 Hop, RNA-Sonde

Hop, Targetsequenz (96672 at)

Hop, kodierende Sequenz (AF492704) Hop, cDNA-Klon

Hop, cDNA-KIon 2 Hop, RNA-Sonde

Hop, Targetsequenz (96672 at)

Hop, kodierende Sequenz (AF492704) Hop, cDNA-KIon 1

Hop, cDNA-KIon 2 Hop, RNA-Sonde

Hop, Targetsequenz (96672_at)

Hop, kodierende Sequenz (AF492704) Hop, cDNA-Klon 1

Hop, cDNA-KIon 2 Hop, RNA-Sonde

Hop, Targetsequenz (96672_at)

Hop, kodierende Sequenz (AF492704) Hop, cDNA-KIon Hop, cDNA-KIon 2 Hop, RNA-Sonde

Hop, Targetsequenz (96672_at)

Hop, kodierende Sequenz (AF492704)

Hop, cDNA-KIon 1 Hop, cDNA-KIon 2 Hop, RNA-Sonde

Hop, Targetsequenz (96672 at)

Hop, kodierende Sequenz (AF492704)

Hop, cDNA-KIon 1

Hop, cDNA-KIon 2

Hop, RNA-Sonde

Hop, Targetsequenz (96672_at)

Hop, kodierende Sequenz (AF492704)

Hop, cDNA-KIon 1

Hop, cDNA-KIon 2

Hop, RNA-Sonde

Hop, Targetsequenz (96672_at)
TTTTTTTTTATGTATATAACTAAAAAAAAAAAAATCCAAAATAACAGGGAGCTAAATGCA 537 TTTTTTTTTATGTATATAACTAAAAAAAAAAAAATCCAAAATAACAGGGAGCTAAATGCA 536 TTTTTTTTTATGTATATAACTAAAAAAAAAAAAATCCAAAATAACAGGGAGCTAAATGCA 540

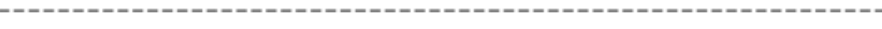

GTTCTGTGTAAAGTGATGGCTGGGGGCAGGGGTGTGGCTTGCCTTTGGATTTTAATGAAA 597 GTTCTGTGTAAAGTGATGGCTGGGGGCAGGGGTGTGGCTTGCCTTTGGATTTTAATGAAA 596 GTTCTGTGTAAAGTGATGGCTGGGGGCAGGGGTGTGGCTTGCCTTTGGATTTTAATGAAA 600 -

GATGATGTGGGAACCGTCTTCGTTTGCCCTTGGCCATCACCTTCCAGTAGTAATTCATAT 657 GATGATGTGGGAACCGTCTTCGTTTGCCCTTGGCCATCACCTTCCAGTAGTAATTCATAT 656 GATGATGTGGGAACCGTCTTCGTTTGCCCTTGGCCATCACCTTCCAGTAGTAATTCATAT 660

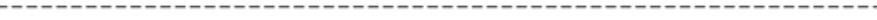

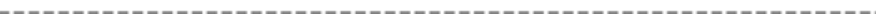

GGACCATCCCCTTCAGAGCTGCCTGGCTTCTATTGAAAAGATAACAGAAACAGGCAGGGG 717 GGACCATCCCCTTCAGAGCTGCCTGGCTTCTATTGAAAAGATAACAGAAACAGGCAGGGG 716 GGACCATCCCCTTCAGAGCTGCCTGGCTTCTATTGAAAAGATAACAGAAACAGGCAGGGG 720

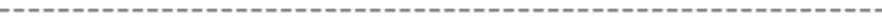
-.--n--1TCAGAGCTGCCTGGCTTCTATTGAAAAGATAACAGAA-CAGGCAGGGG 48

AACACCTCCTGAGTTCACTTCCCTGTGCTCCCTTCCTTCTGCTTCACTAAACACACTGGT 777 AACACCTCCTGAGTTCACTTCCCTGTGCTCCCTTCCTTCTGCTTCACTAAACACACTGGT 776 AACACCTCCTGAGTTCACTTCCCTGTGCTCCCTTCCTTCTGCTTCACTAAACACACTGGT 780

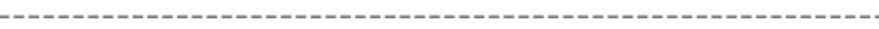
AACACCTCCTGAGTTCACTTCCCTGTGCTCCCT-СCTTCTGCTTCACTAAACACACTGGT 107

GGTTGAATGAGAACGTGGGTGTATTTGAGTCATTCAAATTATATATATATATATATATAT 837 GGTTGAATGAGAACGTGGGTGTATTTGAGTCATTCAAATTATATATATATATATATATAT 836 GGTTGAATGAGAACGTGGGTGTATTTGAGTCATTCAAATTATATATATATATATATATAT 840 GGTTGAATGAGAACGTGGGTGTATTTGAGTCATTCAAATTATATATATATATATATATAT GGTTGAATGAGAACGTGGGTGTATTTGAGTCATTCAAATTATATATATATATATATATAT 167

ATATATATATATATATATATGAATGAATGAACAGTTCCTTCCCTTACAGCTGTGTTACCT 897 ATATATATATATATATATATGAATGAATGAACAGTTCCTTCCCTTACAGCTGTGTTACCT 896 ATATATATATATATATATATGAATGAATGAACAGTTCCTTCCCTTACAGCTGTGTTACCT 900 ATATATATATATATATATATGAATGAATGAACAGTTCCTCCCTTACAGCTGTGTACCT ATATATATATATATATATATGAATGAATGAACAGTTCCTTCCCTTACAGCTGTGTTACCT 227

TGGAAAGCAACCTAGTATAGCAGCTATGGATTCCAAGGGGCAGAAAAGCAAGTAGCTAAG 957 TGGAAAGCAACCTAGTATAGCAGCTATGGATTCCAAGGGGCAGAAAAGCAAGTAGCTAAG 956 TGGAAAGCAACCTAGTATAGCAGCTATGGATTCCAAGGGGCAGAAAAGCAAGTAGCTAAG 960 TGGAAAGCAACCTAGTATAGCAGCTATGGATTCCAAGGGGCAGAAAGCAAGTAGCTAG TGGAAAGCAACCTAGTATAGCAGCTATGGATTCCAAGGGGCAGAAAAGCAAGTA------ 281

GAAAAAAAAAGTTACAGAGTCTAGAATTTACCTTATTTAAATGAACTTGTTAAATTTATT 1017 GAAAAAAAAAGTTACAGAGTCTAGAATTTACCTTATTTAAATGAACTTGTTAAATTTATT 1016 GAAAAAAAAAGTTACAGAGTCTAGAATTTACCTTATTTAAATGAACTTGTTAAATTTATT 1020 -

TTGCTGAATAAAATGAACTGCTTTTGTGTTAAAAATTATATTCTAAAATTAAAAAAAACG 1077 TTGCTGAATAAAATGAACTGCTTTTGTGTTAAAAATTATATTCTAAAATTAAAAAAAACG 1076 TTGCTGAATAAAATGAACTGCTTTTGTGTTAAAAATTATATTCTAAAATTAAAAAAAACG 1080

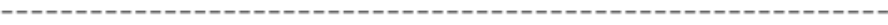

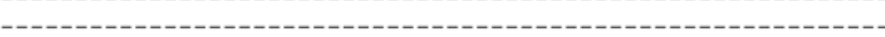

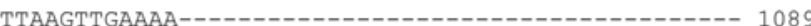
TTAAGTTGAAAAAAAAAAAAAAAAAAAAAAAAAAAAAAAAAA------- 1118 TTAAGTTGAAAAAAAAAAAAAAAAAAAAAAAAAAAAAAAAAAAAAAA 1130

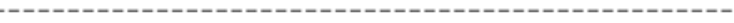




\section{Nomenklatur und Abkürzungen}

Kursiv geschrieben sind Gennamen, die Namen zugehöriger mRNAs sowie wissenschaftliche Bezeichnungen für anatomische Begriffe, die aus dem Lateinischen oder Griechischen entlehnt sind. Für Gennamen wurden die international standardisierten Abkürzungen verwendet.

Neben den konventionellen physikalischen Einheiten und chemischen Symbolen fanden folgende Abkürzungen Anwendung (einige auch im Text erkärt):

$\begin{array}{ll}\text { Abb. } & \text { Abbildung } \\ \text { ATP } & \text { Adenosintriphosphat } \\ \text { bp } & \text { Basenpaar } \\ \text { BrdU } & \text { 5'-Bromo-2'-deoxyuridin } \\ \text { BSA } & \text { bovine serum albumine (Rinderserumalbumin) } \\ \text { cDNA } & \text { complementary DNA (komplementäre DNA) } \\ \text { CI } & \text { Chloroform/Isoamylalkohol (24:1) } \\ \text { CIP } & \text { calf intestinal phosphatase (Phosphatase aus Kälberdarm) } \\ \text { CMV } & \text { Cytomegalovirus } \\ \text { cpm } & \text { counts per minute (radioaktive Zerfälle pro Minute) } \\ \text { CTP } & \text { Cytidintriphosphat } \\ \text { dCTP } & \text { desoxy-Cytidintriphosphat } \\ \text { DEPC } & \text { Diethylpyrocarbonat } \\ \text { d. h. } & \text { das heißt } \\ \text { DIG } & \text { Digoxygenin } \\ \text { DNA } & \text { desoxy ribonucleic acid (Desoxyribonukleinsäure) } \\ \text { DNase } & \text { Desoxyribonuklease } \\ \text { dNTP } & \text { desoxy-Nukleotidtriphosphate } \\ \text { DTT } & \text { Dithiothreitol } \\ \text { En } & \text { Embryonaltag } n \text { (E1 = 24 h nach der Befruchtung) } \\ \text { EBSS } & \text { Earle's balanced salt solution (Salzlösung nach Earle) } \\ \text { EDTA } & \text { Ethylendiamintetraacetat } \\ \text { EGFP } & \text { Enhanced green fluorescent protein (verstärktes grün fluoreszierendes } \\ \text { engl. } & \text { englisch } \\ \text { griech. } & \text { GTiechisch } \\ \text { GTP } & \text { Guanosintriphosphat } \\ & \end{array}$




$\begin{array}{ll}\text { LacZ } & \beta \text {-Galaktosidase } \\ \text { MOPS } & \text { Morpholinopropansulfonsäure } \\ \text { mRNA } & \text { messenger RNA } \\ \text { OD } & \text { optische Dichte } \\ \text { PBS } & \text { Phosphat-gepufferte Salzlösung } \\ \text { PCI } & \text { Phenol/ Chloroform/ Isoamylalkohol (25:24:1) } \\ \text { RNA } & \text { ribonucleic acid (Ribonukleinsäure) } \\ \text { RNase } & \text { Ribonuklease } \\ \text { rpm } & \text { rounds per minute (Umdrehungen pro Minute) } \\ \text { RT } & \text { Raumtemperatur } \\ \text { SDS } & \text { sodiumdodecylsulfate (Natriumdodecylsulfat) } \\ \text { STI } & \text { Standard-I Nährmedium } \\ \text { SSC } & \text { standard saline citrate solution (Standard-NaCl/ NaCitrat-Lösung) } \\ \text { Tab. } & \text { Tabelle } \\ \text { TBE } & \text { Tris-Borat-EDTA-Puffer } \\ \text { TE } & \text { Tris-EDTA-Puffer } \\ \text { ü.N. } & \text { über Nacht } \\ \text { UV } & \text { ultraviolettes Licht } \\ \text { vol } & \text { Volumenanteile } \\ \text { X-Gal } & \text { 5-Bromo-4-chloro-3-indolyl- } \beta \text {-D-galaktosid } \\ \text { z. B. } & \text { zum Beispiel }\end{array}$




\section{Literaturverzeichnis}

J. Adu, F. T. Leong, N. R. Smith, J. P. Leek, A. F. Markham, P. A. Robinson und A. J. Mighell. Expression of mOb1, a novel atypical 73 amino acid K50-homeodomain protein, during mouse development. Mech Dev 119 Suppl 1: S43-47. (2002)

S. Agarwala, T. A. Sanders und C. W. Ragsdale. Sonic hedgehog control of size and shape in midbrain pattern formation. Science 291: 2147-2150. (2001)

A. Agathon, C. Thisse und B. Thisse. The molecular nature of the zebrafish tail organizer. Nature 424: 448-452. (2003)

A. Aguzzi und F. Theuring. Improved in situ beta-galactosidase staining for histological analysis of transgenic mice. Histochemistry 102: 477-481. (1994)

C. Akazawa, Y. Sasai, S. Nakanishi und R. Kageyama. Molecular characterization of a rat negative regulator with a basic helix-loop-helix structure predominantly expressed in the developing nervous system. J Biol Chem 267: 21879-21885. (1992)

P. Alifragis, A. Liapi und J. G. Parnavelas. Lhx6 regulates the migration of cortical interneurons from the ventral telencephalon but does not specify their GABA phenotype. $\mathrm{J}$ Neurosci 24: 5643-5648. (2004)

K. L. Allendorfer und C. J. Shatz. The subplate, a transient neocortical structure: its role in the development of connections between thalamus and cortex. Annu Rev Neurosci 17: 185-218. (1994)

J. Altman und S. A. Bayer. Mosaic organization of the hippocampal neuroepithelium and the multiple germinal sources of dentate granule cells. J Comp Neurol 301: 325-342. (1990)

J. Altman und G. D. Das. Autoradiographic and histological evidence of postnatal hippocampal neurogenesis in rats. J Comp Neurol 124: 319-335. (1965)

S. L. Ang, O. Jin, M. Rhinn, N. Daigle, L. Stevenson und J. Rossant. A targeted mouse Otx2 mutation leads to severe defects in gastrulation and formation of axial mesoderm and to deletion of rostral brain. Development 122: 243-252. (1996)

T. E. Anthony, C. Klein, G. Fishell und N. Heintz. Radial glia serve as neuronal progenitors in all regions of the central nervous system. Neuron 41: 881-890. (2004)

D. N. Arnosti, S. Barolo, M. Levine und S. Small. The eve stripe 2 enhancer employs multiple modes of transcriptional synergy. Development 122: 205-214. (1996)

K. Asanoma, T. Matsuda, H. Kondo, K. Kato, T. Kishino, N. Niikawa, N. Wake und H. Kato. NECC1, a candidate choriocarcinoma suppressor gene that encodes a homeodomain consensus motif. Genomics 81: 15-25. (2003) 
M. Ashburner, C. A. Ball, J. A. Blake, D. Botstein, H. Butler, J. M. Cherry, A. P. Davis, K. Dolinski, S. S. Dwight, J. T. Eppig, M. A. Harris, D. P. Hill, L. Issel-Tarver, A. Kasarskis, S. Lewis, et al. Gene ontology: tool for the unification of biology. The Gene Ontology Consortium. Nat Genet 25: 25-29. (2000)

S. Assimacopoulos, E. A. Grove und C. W. Ragsdale. Identification of a Pax6-dependent epidermal growth factor family signaling source at the lateral edge of the embryonic cerebral cortex. J Neurosci 23: 6399-6403. (2003)

A. Bach, Y. Lallemand, M. A. Nicola, C. Ramos, L. Mathis, M. Maufras und B. Robert. Msx1 is required for dorsal diencephalon patterning. Development 130: 4025-4036. (2003)

J. Bai, R. L. Ramos, J. B. Ackman, A. M. Thomas, R. V. Lee und J. J. LoTurco. RNAi reveals doublecortin is required for radial migration in rat neocortex. Nat Neurosci 6: 1277-1283. (2003)

P. Baldi und A. D. Long. A Bayesian framework for the analysis of microarray expression data: regularized $t$-test and statistical inferences of gene changes. Bioinformatics 17: 509-519. (2001)

J. Banerji, S. Rusconi und W. Schaffner. Expression of a beta-globin gene is enhanced by remote SV40 DNA sequences. Cell 27: 299-308. (1981)

M. F. Barbe und P. Levitt. The early commitment of fetal neurons to the limbic cortex. Neurosci 11: 519-533. (1991)

S. A. Bayer und J. Altman. Neocortical development. Raven Press, New York (1991)

R. S. Beddington und E. J. Robertson. Anterior patterning in mouse. Trends Genet 14: 277-284. (1998)

G. Bernier, W. Vukovich, L. Neidhardt, B. G. Herrmann und P. Gruss. Isolation and characterization of a downstream target of Pax6 in the mammalian retinal primordium. Development 128: 3987-3994. (2001)

B. Bettler, J. Boulter, I. Hermans-Borgmeyer, A. O'Shea-Greenfield, E. S. Deneris, C. Moll, U. Borgmeyer, M. Hollmann und S. Heinemann. Cloning of a novel glutamate receptor subunit, GluR5: expression in the nervous system during development. Neuron 5: 583-595. (1990)

K. M. Bishop, G. Goudreau und D. D. O'Leary. Regulation of area identity in the mammalian neocortex by Emx2 and Pax6. Science 288: 344-349. (2000)

K. M. Bishop, J. L. Rubenstein und D. D. O'Leary. Distinct actions of Emx1, Emx2, and Pax6 in regulating the specification of areas in the developing neocortex. J Neurosci 22: 7627-7638. (2002)

J. Bolz, D. Uziel, S. Muhlfriedel, A. Gullmar, C. Peuckert, K. Zarbalis, W. Wurst, M. Torii und P. Levitt. Multiple roles of ephrins during the formation of thalamocortical projections: maps and more. J Neurobiol 59: 82-94. (2004)

R. T. Bottcher, N. Pollet, H. Delius und C. Niehrs. The transmembrane protein XFLRT3 forms a complex with FGF receptors and promotes FGF signalling. Nat Cell Biol 6: 38-44. (2004) 
T. Bouwmeester, S. Kim, Y. Sasai, B. Lu und E. M. De Robertis. Cerberus is a head-inducing secreted factor expressed in the anterior endoderm of Spemann's organizer. Nature 382: 595601. (1996)

M. M. Braun, A. Etheridge, A. Bernard, C. P. Robertson und H. Roelink. Wnt signaling is required at distinct stages of development for the induction of the posterior forebrain.

Development 130: 5579-5587. (2003)

J. Briscoe, Y. Chen, T. M. Jessell und G. Struhl. A hedgehog-insensitive form of patched provides evidence for direct long-range morphogen activity of sonic hedgehog in the neural tube. Mol Cell 7: 1279-1291. (2001)

J. Briscoe und J. Ericson. Specification of neuronal fates in the ventral neural tube. Curr Opin Neurobiol 11: 43-49. (2001)

K. Brodmann. Vergleichende Lokalisationslehre der Großhirnrinde in ihren Prinzipien dargestellt auf Grund des Zellbaues. JA Barth, Leipzig (1909)

S. Bulchand, E. A. Grove, F. D. Porter und S. Tole. LIM-homeodomain gene Lhx2 regulates the formation of the cortical hem. Mech Dev 100: 165-175. (2001)

M. Bylund, E. Andersson, B. G. Novitch und J. Muhr. Vertebrate neurogenesis is counteracted by Soxl-3 activity. Nat Neurosci 6: 1162-1168. (2003)

Q. P. Cao und W. R. Crain. Expression of SGP-1 mRNA in preimplantation mouse embryos. Dev Genet 17: 263-271. (1995)

M. Carey. The enhanceosome and transcriptional synergy. Cell 92: 5-8. (1998)

V. S. Caviness, Jr. Neocortical histogenesis in normal and reeler mice: a developmental study based upon [3H] thymidine autoradiography. Brain Res 256: 293-302. (1982)

F. Chen, H. Kook, R. Milewski, A. D. Gitler, M. M. Lu, J. Li, R. Nazarian, R. Schnepp, K. Jen, C. Biben, G. Runke, J. P. Mackay, J. Novotny, R. J. Schwartz, R. P. Harvey, et al. Hop is an unusual homeobox gene that modulates cardiac development. Cell 110: 713-723. (2002)

C. Chiang, Y. Litingtung, E. Lee, K. E. Young, J. L. Corden, H. Westphal und P. A. Beachy. Cyclopia and defective axial patterning in mice lacking Sonic hedgehog gene function. Nature 383: 407-413. (1996)

J. M. Claverie. Computational methods for the identification of differential and coordinated gene expression. Hum Mol Genet 8: 1821-1832. (1999)

J. C. Corbo, T. A. Deuel, J. M. Long, P. LaPorte, E. Tsai, A. Wynshaw-Boris und C. A. Walsh. Doublecortin is required in mice for lamination of the hippocampus but not the neocortex. $\mathrm{J}$ Neurosci 22: 7548-7557. (2002)

F. Crick. What mad pursuit: a personal view of scientific discovery. Basic Books, New York (1988)

C. Dehay, P. Savatier, V. Cortay und H. Kennedy. Cell-cycle kinetics of neocortical precursors are influenced by embryonic thalamic axons. J Neurosci 21: 201-214. (2001) 
N. B. Elkind, N. Goldfinger und V. Rotter. Spot-1, a novel NLS-binding protein that interacts with $p 53$ through a domain encoded by $p(C A) n$ repeats. Oncogene 11: 841-851. (1995)

J. Ericson, J. Muhr, M. Placzek, T. Lints, T. M. Jessell und T. Edlund. Sonic hedgehog induces the differentiation of ventral forebrain neurons: a common signal for ventral patterning within the neural tube. Cell 81: 747-756. (1995)

A. A. Fienberg, N. Hiroi, P. G. Mermelstein, W. Song, G. L. Snyder, A. Nishi, A. Cheramy, J. P. O'Callaghan, D. B. Miller, D. G. Cole, R. Corbett, C. N. Haile, D. C. Cooper, S. P. Onn, A. A. Grace, et al. DARPP-32: regulator of the efficacy of dopaminergic neurotransmission. Science 281: 838-842. (1998)

A. C. Foley und C. D. Stern. Evolution of vertebrate forebrain development: how many different mechanisms? J Anat 199: 35-52. (2001)

G. A. Foster, M. Schultzberg, T. Hokfelt, M. Goldstein, H. C. Hemmings, Jr., C. C. Ouimet, S. I. Walaas und P. Greengard. Development of a dopamine- and cyclic adenosine 3':5'monophosphate-regulated phosphoprotein (DARPP-32) in the prenatal rat central nervous system, and its relationship to the arrival of presumptive dopaminergic innervation. J Neurosci 7: 1994-2018. (1987)

F. Francis, A. Koulakoff, D. Boucher, P. Chafey, B. Schaar, M. C. Vinet, G. Friocourt, N. McDonnell, O. Reiner, A. Kahn, S. K. McConnell, Y. Berwald-Netter, P. Denoulet und J. Chelly. Doublecortin is a developmentally regulated, microtubule-associated protein expressed in migrating and differentiating neurons. Neuron 23: 247-256. (1999)

M. Fromm und P. Berg. Transcription in vivo from SV40 early promoter deletion mutants without repression by large T antigen. J Mol Appl Genet 2: 127-135. (1983)

T. Fukuchi-Shimogori und E. A. Grove. Emx2 patterns the neocortex by regulating FGF positional signaling. Nat Neurosci 6: 825-831. (2003)

T. Fukuchi-Shimogori und E. A. Grove. Neocortex patterning by the secreted signaling molecule FGF8. Science 294: 1071-1074. (2001)

N. Funatsu, T. Inoue und S. Nakamura. Gene Expression Analysis of the Late Embryonic Mouse Cerebral Cortex Using DNA Microarray: Identification of Several Region- and Layer-specific Genes. Cereb Cortex (2004)

Y. Furuta, D. W. Piston und B. L. Hogan. Bone morphogenetic proteins (BMPs) as regulators of dorsal forebrain development. Development 124: 2203-2212. (1997)

J. Galceran, E. M. Miyashita-Lin, E. Devaney, J. L. Rubenstein und R. Grosschedl. Hippocampus development and generation of dentate gyrus granule cells is regulated by LEF 1 . Development 127: 469-482. (2000)

S. Garel, K. J. Huffman und J. L. Rubenstein. Molecular regionalization of the neocortex is disrupted in Fgf8 hypomorphic mutants. Development 130: 1903-1914. (2003)

S. Garel, F. Marin, M. G. Mattei, C. Vesque, A. Vincent und P. Charnay. Family of Ebf/Olf-1related genes potentially involved in neuronal differentiation and regional specification in the central nervous system. Dev Dyn 210: 191-205. (1997) 
S. K. Garel, J. Huffmann und J. L. Rubenstein. Molecular regionalization of the neocortex is disrupted in Fgf8 hypomorphic mutants. Development 130: 1903-1914. (2003)

B. J. Gavin, J. A. McMahon und A. P. McMahon. Expression of multiple novel Wnt-1/int-1related genes during fetal and adult mouse development. Genes Dev 4: 2319-2332. (1990)

S. F. Gilbert. Developmental biology. Sinauer Associates, Inc, Sunderland 7 (2003)

C. Gillen, M. Gleichmann, P. Spreyer und H. W. Muller. Differentially expressed genes after peripheral nerve injury. J Neurosci Res 42: 159-171. (1995)

Y. Gitton, M. Cohen-Tannoudji und M. Wassef. Specification of somatosensory area identity in cortical explants. J Neurosci 19: 4889-4898. (1999)

J. G. Gleeson, P. T. Lin, L. A. Flanagan und C. A. Walsh. Doublecortin is a microtubuleassociated protein and is expressed widely by migrating neurons. Neuron 23: 257-271. (1999a)

J. G. Gleeson, S. R. Minnerath, J. W. Fox, K. M. Allen, R. F. Luo, S. E. Hong, M. J. Berg, R. Kuzniecky, P. J. Reitnauer, R. Borgatti, A. P. Mira, R. Guerrini, G. L. Holmes, C. M. Rooney, S. Berkovic, et al. Characterization of mutations in the gene doublecortin in patients with double cortex syndrome. Ann Neurol 45: 146-153. (1999b)

G. Gradwohl, C. Fode und F. Guillemot. Restricted expression of a novel murine atonal-related bHLH protein in undifferentiated neural precursors. Dev Biol 180: 227-241. (196)

R. Grosschedl, K. Giese und J. Pagel. HMG domain proteins: architectural elements in the assembly of nucleoprotein structures. Trends Genet 10: 94-100. (1994)

E. A. Grove und T. Fukuchi-Shimogori. Generating the cerebral cortical area map. Annu Rev Neurosci 26: 355-380. (2003)

E. A. Grove und S. Tole. Patterning events and specification signals in the developing hippocampus. Cereb Cortex 9: 551-561. (1999)

E. A. Grove, S. Tole, J. Limon, L. Yip und C. W. Ragsdale. The hem of the embryonic cerebral cortex is defined by the expression of multiple Wnt genes and is compromised in Gli3-deficient mice. Development 125: 2315-2325. (1998)

D. A. Grueneberg, K. J. Simon, K. Brennan und M. Gilman. Sequence-specific targeting of nuclear signal transduction pathways by homeodomain proteins. Mol Cell Biol 15: 3318-3326. (1995)

L. Guyonneau, F. Murisier, A. Rossier, A. Moulin und F. Beermann. Melanocytes and pigmentation are affected in dopachrome tautomerase knockout mice. Mol Cell Biol 24: 33963403. (2004)

Y. Hamamori und M. D. Schneider. HATs off to Hop: recruitment of a class I histone deacetylase incriminates a novel transcriptional pathway that opposes cardiac hypertrophy. Clin Invest 112: 824-826. (2003)

E. Hartfuss, R. Galli, N. Heins und M. Gotz. Characterization of CNS precursor subtypes and radial glia. Dev Biol 229: 15-30. (2001) 
T. L. Haynes, M. B. Thomas, M. R. Dusing, M. T. Valerius, S. S. Potter und D. A. Wiginton. An enhancer LEF-1/TCF-1 site is essential for insertion site-independent transgene expression in thymus. Nucleic Acids Res 24: 5034-5044. (1996)

X. He, R. Gerrero, D. M. Simmons, R. E. Park, C. J. Lin, L. W. Swanson und M. G. Rosenfeld. Tst-1, a member of the POU domain gene family, binds the promoter of the gene encoding the cell surface adhesion molecule P0. Mol Cell Biol 11: 1739-1744. (1991)

J. M. Hebert, Y. Mishina und S. K. McConnell. BMP signaling is required locally to pattern the dorsal telencephalic midline. Neuron 35: 1029-1041. (2002)

C. P. Heisenberg, C. Houart, M. Take-Uchi, G. J. Rauch, N. Young, P. Coutinho, I. Masai, L. Caneparo, M. L. Concha, R. Geisler, T. C. Dale, S. W. Wilson und D. L. Stemple. A mutation in the Gsk3-binding domain of zebrafish Masterblind/Axin1 leads to a fate transformation of telencephalon and eyes to diencephalon. Genes Dev 15: 1427-1434. (2001)

M. Hiraiwa, J. Liu, A. G. Lu, C. Y. Wang, R. Misasi, T. Yamauchi, I. Hozumi, T. Inuzuka und J. S. O'Brien. Regulation of gene expression in response to brain injury: enhanced expression and alternative splicing of rat prosaposin (SGP-1) mRNA in injured brain. J Neurotrauma 20: 755-765. (2003)

S. E. Hong, Y. Y. Shugart, D. T. Huang, S. A. Shahwan, P. E. Grant, J. O. Hourihane, N. D. Martin und C. A. Walsh. Autosomal recessive lissencephaly with cerebellar hypoplasia is associated with human RELN mutations. Nat Genet 26: 93-96. (2000)

C. Houart, L. Caneparo, C. Heisenberg, K. Barth, M. Take-Uchi und S. Wilson. Establishment of the telencephalon during gastrulation by local antagonism of Wnt signaling. Neuron 35: 255265. (2002)

C. Houart, M. Westerfield und S. W. Wilson. A small population of anterior cells patterns the forebrain during zebrafish gastrulation. Nature 391: 788-792. (1998)

J. Huelsken und J. Behrens. The Wnt signalling pathway. J Cell Sci 115: 3977-3978. (2002)

T. Inoue, T. Tanaka, S. C. Suzuki und M. Takeichi. Cadherin-6 in the developing mouse brain: expression along restricted connection systems and synaptic localization suggest a potential role in neuronal circuitry. Dev Dyn 211: 338-351. (1998)

N. Itasaki, S. Bel-Vialar und R. Krumlauf. 'Shocking' developments in chick embryology: electroporation and in ovo gene expression. Nat Cell Biol 1: 203-207. (1999)

A. Iwahori, D. Fraidenraich und C. Basilico. A conserved enhancer element that drives FGF4 gene expression in the embryonic myotomes is synergistically activated by GATA and bHLH proteins. Dev Biol 270: 525-537. (2004)

K. Jin, J. Chen, S. H. Graham und R. P. Simon. Global ischemia induced gene. US-Patent $\underline{5968771-\mathrm{B}}$ (1999)

K. Jin, M. Minami, J. Q. Lan, X. O. Mao, S. Batteur, R. P. Simon und D. A. Greenberg. Neurogenesis in dentate subgranular zone and rostral subventricular zone after focal cerebral ischemia in the rat. Proc Natl Acad Sci U S A 98: 4710-4715. (2001) 
A. Kerlavage, V. Bonazzi, M. di Tommaso, C. Lawrence, P. Li, F. Mayberry, R. Mural, M. Nodell, M. Yandell, J. Zhang und P. Thomas. The Celera Discovery System. Nucleic Acids Res 30: 129-136. (2002)

J. S. Kerley, S. L. Olsen, S. J. Freemantle und M. J. Spinella. Transcriptional activation of the nuclear receptor corepressor RIP140 by retinoic acid: a potential negative-feedback regulatory mechanism. Biochem Biophys Res Commun 285: 969-975. (2001)

I. Klatzo. Cecile \& Oskar Vogt: the significance of their contributions in modern neuroscience. Acta Neurochir Suppl 86: 29-32. (2003)

J. D. Kohtz, D. P. Baker, G. Corte und G. Fishell. Regionalization within the mammalian telencephalon is mediated by changes in responsiveness to Sonic Hedgehog. Development 125: 5079-5089. (1998)

H. Kook und J. A. Epstein. Hopping to the beat. Hop regulation of cardiac gene expression. Trends Cardiovasc Med 13: 261-264. (2003)

S. E. Lacy, C. G. Bonnemann, E. A. Buzney und L. M. Kunkel. Identification of FLRT1, FLRT2, and FLRT3: a novel family of transmembrane leucine-rich repeat proteins. Genomics 62: 417-426. (1999)

E. S. Lander, L. M. Linton, B. Birren, C. Nusbaum, M. C. Zody, J. Baldwin, K. Devon, K. Dewar, M. Doyle, W. FitzHugh, R. Funke, D. Gage, K. Harris, A. Heaford, J. Howland, et al. Initial sequencing and analysis of the human genome. Nature 409: 860-921. (2001)

R. Lathe, J. L. Vilotte und A. J. Clark. Plasmid and bacteriophage vectors for excision of intact inserts. Gene 57: 193-201. (1987)

C. H. Lee, C. Chinpaisal und L. N. Wei. Cloning and characterization of mouse RIP140, a corepressor for nuclear orphan receptor TR2. Mol Cell Biol 18: 6745-6755. (1998)

K. J. Lee, P. Dietrich und T. M. Jessell. Genetic ablation reveals that the roof plate is essential for dorsal interneuron specification. Nature 403: 734-740. (2000)

K. J. Lee, M. Mendelsohn und T. M. Jessell. Neuronal patterning by BMPs: a requirement for GDF7 in the generation of a discrete class of commissural interneurons in the mouse spinal cord. Genes Dev 12: 3394-3407. (1998)

S. M. Lee, S. Tole, E. Grove und A. P. McMahon. A local Wnt-3a signal is required for development of the mammalian hippocampus. Development 127: 457-467. (2000)

S. Lei, A. Dubeykovskiy, A. Chakladar, L. Wojtukiewicz und T. C. Wang. The murine gastrin promoter is synergistically activated by TGF-beta/Smad and Wnt signaling pathways. J Biol Chem (2004)

K. F. Liem, Jr., G. Tremml und T. M. Jessell. A role for the roof plate and its resident TGFbetarelated proteins in neuronal patterning in the dorsal spinal cord. Cell 91: 127-138. (1997)

K. F. Liem, Jr., G. Tremml, H. Roelink und T. M. Jessell. Dorsal differentiation of neural plate cells induced by BMP-mediated signals from epidermal ectoderm. Cell 82: 969-979. (1995) 
G. Liu, A. E. Loraine, R. Shigeta, M. Cline, J. Cheng, V. Valmeekam, S. Sun, D. Kulp und M. A. Siani-Rose. NetAffx: Affymetrix probesets and annotations. Nucleic Acids Res 31: 82-86. (2003)

D. J. Lockhart und E. A. Winzeler. Genomics, gene expression and DNA arrays. Nature 405: 827-836. (2000)

L. Luo, X. Yang, Y. Takihara, H. Knoetgen und M. Kessel. The cell-cycle regulator geminin inhibits Hox function through direct and polycomb-mediated interactions. Nature 427: 749-753. (2004)

M. B. Luskin und C. J. Shatz. Studies of the earliest generated cells of the cat's visual cortex: cogeneration of subplate and marginal zones. J Neurosci 5: (1985)

M. A. Mackenzie, S. A. Jordan, P. S. Budd und I. J. Jackson. Activation of the receptor tyrosine kinase Kit is required for the proliferation of melanoblasts in the mouse embryo. Dev Biol 192: 99-107. (1997)

D. Mahony, S. Karunaratne und J. A. Rothnagel. Improved detection of lacZ reporter gene expression in transgenic epithelia by immunofluorescence microscopy. Exp Dermatol 11: 153158. (2002)

O. Marin und J. L. Rubenstein. Cell migration in the forebrain. Annu Rev Neurosci 26: 441483. (2003)

A. McCormick, H. Brady, L. E. Theill und M. Karin. Regulation of the pituitary-specific homeobox gene GHF1 by cell-autonomous and environmental cues. Nature 345: 829-832. (1990)

G. Meyer, C. G. Perez-Garcia, H. Abraham und D. Caput. Expression of $p 73$ and Reelin in the developing human cortex. J Neurosci 22: 4973-4986. (2002)

J. H. Millonig, K. J. Millen und M. E. Hatten. The mouse Dreher gene Lmxla controls formation of the roof plate in the vertebrate CNS. Nature 403: 764-769. (2000)

R. J. Milner und J. G. Sutcliffe. Gene expression in rat brain. Nucleic Acids Res 11: 5497-5520. (1983)

T. Miyamoto, S. Hasuike, K. Sengoku, N. Takuma, H. Hayashi, Y. Sasaki, T. Yamashita und M. Ishikawa. Molecular cloning and expression analysis of the mouse Spot-2 gene in pituitary development. Dev Genes Evol 213: 199-202. (2003)

E. M. Miyashita-Lin, R. Hevner, K. M. Wassarman, S. Martinez und J. L. Rubenstein. Early neocortical regionalization in the absence of thalamic innervation. Science 285: 906-909. (1999)

T. Miyata, A. Kawaguchi, K. Saito, M. Kawano, T. Muto und M. Ogawa. Asymmetric production of surface-dividing and non-surface-dividing cortical progenitor cells. Development 131: 3133-3145. (2004)

E. S. Monuki, F. D. Porter und C. A. Walsh. Patterning of the dorsal telencephalon and cerebral cortex by a roof plate-Lhx2 pathway. Neuron 32: 591-604. (2001) 
I. Munoz-Sanjuan und A. H. Brivanlou. Neural induction, the default model and embryonic stem cells. Nat Rev Neurosci 3: 271-280. (2002)

D. M. Mutch, A. Berger, R. Mansourian, A. Rytz und M. A. Roberts. The limit fold change model: a practical approach for selecting differentially expressed genes from microarray data. BMC Bioinformatics 3: 17. (2002)

L. Muzio, B. DiBenedetto, A. Stoykova, E. Boncinelli, P. Gruss und A. Mallamaci. Conversion of cerebral cortex into basal ganglia in Emx2(-/-) Pax6(Sey/Sey) double-mutant mice. Nat Neurosci 5: 737-745. (2002a)

L. Muzio, B. DiBenedetto, A. Stoykova, E. Boncinelli, P. Gruss und A. Mallamaci. Emx2 and Pax6 control regionalization of the pre-neurogenic cortical primordium. J Neurosci 19: 877885. (2002b)

J. H. Nadeau. Modifier genes in mice and humans. Nat Rev Genet 2: 165-174. (2001)

Y. Nakagawa, J. E. Johnson und D. D. O'Leary. Graded and areal expression patterns of regulatory genes and cadherins in embryonic neocortex independent of thalamocortical input. $\underline{\mathrm{J}}$ Neurosci 19: 10877-10885. (1999)

D. Niessing, W. Driever, F. Sprenger, H. Taubert, H. Jackle und R. Rivera-Pomar. Homeodomain position 54 specifies transcriptional versus translational control by Bicoid. Mol Cell 5: 395-401. (2000)

S. C. Noctor, A. C. Flint, T. A. Weissman, R. S. Dammerman und A. R. Kriegstein. Neurons derived from radial glia cells establish radial units in neocortex. Nature 409: 714-720. (2001)

U. Nordstrom, T. M. Jessell und T. Edlund. Progressive induction of caudal neural character by graded Wnt signaling. Nat Neurosci 5: 525-532. (2002)

W. F. Odenwald, J. Garbern, H. Arnheiter, E. Tournier-Lasserve und R. A. Lazzarini. The Hox1.3 homeo box protein is a sequence-specific DNA-binding phosphoprotein. Genes Dev 3: 158172. (1989)

M. Ogawa, T. Miyata, K. Nakajima, K. Yagyu, M. Seike, K. Ikenaka, H. Yamamoto und K. Mikoshiba. The reeler gene-associated antigen on Cajal-Retzius neurons is a crucial molecule for laminar organization of cortical neurons. Neuron 14: 899-912. (1995)

D. D. O'Leary. Do cortical areas emerge from a protocortex? Trends Neurosci 12: 400-406. (1989)

D. D. O'Leary und Y. Nakagawa. Patterning centers, regulatory genes and extrinsic mechanisms controlling arealization of the neocortex. Curr Opin Neurobiol 12: 14-25. (2002)

N. Osumi und T. Inoue. Gene transfer into cultured mammalian embryos by electroporation. Methods 24: 35-42. (2001)

D. M. Panchision, J. M. Pickel, L. Studer, S. H. Lee, P. A. Turner, T. G. Hazel und R. D. McKay. Sequential actions of BMP receptors control neural precursor cell production and fate. Genes Dev 15: 2094-2110. (2001) 
C. M. Parras, C. Schuurmans, R. Scardigli, J. Kim, D. J. Anderson und F. Guillemot. Divergent functions of the proneural genes Mash1 and Ngn2 in the specification of neuronal subtype identity. Genes Dev 16: 324-338. (2002)

M. Pellegrini, A. Mansouri, A. Simeone, E. Boncinelli und P. Gruss. Dentate gyrus formation requires Emx2. Development 122: 3893-3898. (1996)

R. G. Perez und R. M. Lewis. Regional distribution of DARPP-32 (dopamine- and adenosine 3',5'-monophosphate-regulated phosphoprotein of $\mathrm{Mr}=32,000) \mathrm{mRNA}$ in mouse brain. $\mathrm{J}$ Comp Neurol 318: 304-315. (1992)

P. L. Pfeffer, M. Bouchard und M. Busslinger. Pax2 and homeodomain proteins cooperatively regulate a $435 \mathrm{bp}$ enhancer of the mouse Pax 5 gene at the midbrain-hindbrain boundary. Development 127: 1017-1028. (2000)

N. Picard-Riera, B. Nait-Oumesmar und A. Baron-Van Evercooren. Endogenous adult neural stem cells: limits and potential to repair the injured central nervous system. J Neurosci Res 76: 223-231. (2004)

S. Piccolo, E. Agius, L. Leyns, S. Bhattacharyya, H. Grunz, T. Bouwmeester und E. M. De Robertis. The head inducer Cerberus is a multifunctional antagonist of Nodal, BMP and Wnt signals. Nature 397: 707-710. (1999)

O. Pozzoli, A. Bosetti, L. Croci, G. G. Consalez und M. L. Vetter. Xebf3 is a regulator of neuronal differentiation during primary neurogenesis in Xenopus. Dev Biol 233: 495-512. (2001)

K. Quandt, K. Frech, H. Karas, E. Wingender und T. Werner. MatInd and MatInspector: new fast and versatile tools for detection of consensus matches in nucleotide sequence data. Nucleic Acids Res 23: 4878-4884. (1995)

D. Rajagopalan. A comparison of statistical methods for analysis of high density oligonucleotide array data. Bioinformatics 19: 1469-1476. (2003)

P. Rakic. Mode of cell migration to the superficial layers of fetal monkey neocortex. J Comp Neurol 145: 61-83. (1972)

P. Rakic. Neurons in rhesus monkey visual cortex: systematic relation between time of origin and eventual disposition. Science 183: 425-427. (1974)

P. Rakic. Specification of cerebral cortical areas. Science 241: 170-176. (1988)

O. Reiner, R. Carrozzo, Y. Shen, M. Wehnert, F. Faustinella, W. B. Dobyns, C. T. Caskey und D. H. Ledbetter. Isolation of a Miller-Dieker lissencephaly gene containing G protein betasubunit-like repeats. Nature 364: 717-721. (1993)

K. Y. Reznikov. Cell proliferation and cytogenesis in the mouse hippocampus. Adv Anat Embryol Cell Biol 122: 1-74. (1991)

H. Roelink, A. Augsburger, J. Heemskerk, V. Korzh, S. Norlin, A. Ruiz i Altaba, Y. Tanabe, M. Placzek, T. Edlund, T. M. Jessell und et al. Floor plate and motor neuron induction by vhh-1, a vertebrate homolog of hedgehog expressed by the notochord. Cell 76: 761-775. (1994) 
H. Roelink und R. Nusse. Expression of two members of the Wnt family during mouse development--restricted temporal and spatial patterns in the developing neural tube. Genes Dev 5: 381-388. (1991)

J. Rusch und M. Levine. Threshold responses to the dorsal regulatory gradient and the subdivision of primary tissue territories in the Drosophila embryo. Curr Opin Genet Dev 6: 416-423. (1996)

F. Sambroock, E. F. Fritsch und T. Maniatis. Molecular Cloning. A Laborytory Manual. Cold Spring Harbor Laborytory, Cold Spring Harbor 2 (1989)

F. Sanger, S. Nicklen und A. R. Coulsen. DNA sequencing with chaintermination inhibitors. Proc Natl Acad Sci U S A 74: 5463-5467. (1977)

T. Sapir, M. Elbaum und O. Reiner. Reduction of microtubule catastrophe events by LIS1, platelet-activating factor acetylhydrolase subunit. Embo J 16: 6977-6984. (1997)

R. Scardigli, N. Baumer, P. Gruss, F. Guillemot und I. Le Roux. Direct and concentrationdependent regulation of the proneural gene Neurogenin2 by Pax6. Development 130: 32693281. (2003)

B. L. Schlaggar und D. D. O'Leary. Potential of visual cortex to develop an array of functional units unique to somatosensory cortex. Science 252: 1556-1560. (1991)

D. E. Schmechel und P. Rakic. A Golgi study of radial glial cells in developing monkey telencephalon: morphogenesis and transformation into astrocytes. Anat Embryol (Berl) 156: 115-152. (1979)

H. Z. Sheng, S. Bertuzzi, C. Chiang, W. Shawlot, M. Taira, I. Dawid und H. Westphal. Expression of murine Lhx5 suggests a role in specifying the forebrain. Dev Dyn 208: 266-277. (1997)

T. Shibata, K. Yamada, M. Watanabe, K. Ikenaka, K. Wada, K. Tanaka und Y. Inoue. Glutamate transporter GLAST is expressed in the radial glia-astrocyte lineage of developing mouse spinal cord. J Neurosci 17: 9212-9219. (1997)

K. Shimamura und J. L. Rubenstein. Inductive interactions direct early regionalization of the mouse forebrain. Development 124: 2709-2718. (1997)

C. H. Shin, Z. P. Liu, R. Passier, C. L. Zhang, D. Z. Wang, T. M. Harris, H. Yamagishi, J. A. Richardson, G. Childs und E. N. Olson. Modulation of cardiac growth and development by HOP, an unusual homeodomain protein. Cell 110: 725-735. (2002)

K. Shinozaki, M. Yoshida, M. Nakamura, S. Aizawa und Y. Suda. Emxl and Emx2 cooperate in initial phase of archipallium development. Mech Dev 121: 475-489. (2004)

A. Simeone, M. Gulisano, D. Acampora, A. Stornaiuolo, M. Rambaldi und E. Boncinelli. Two vertebrate homeobox genes related to the Drosophila empty spiracles gene are expressed in the embryonic cerebral cortex. EMBO J 11: 2541-2550. (1992)

H. Skala, A. Porteu, M. Thomas, M. F. Szajnert, H. Okazawa, A. Kahn und F. Phan-Dinh-Tuy. Upstream elements involved in vivo in activation of the brain-specific rat aldolase $C$ gene. Role of binding sites for POU and winged helix proteins. J Biol Chem 273: 31806-31814. (1998) 
D. Spieler, N. Baumer, J. Stebler, M. Koprunner, M. Reichman-Fried, U. Teichmann, E. Raz, M. Kessel und L. Wittler. Involvement of Pax6 and Otx2 in the forebrain-specific regulation of the vertebrate homeobox gene ANF/Hesx1. Dev Biol 269: 567-579. (2004)

K. P. Steel, D. R. Davidson und I. J. Jackson. TRP-2/DT, a new early melanoblast marker, shows that steel growth factor (c-kit ligand) is a survival factor. Development 115: 1111-1119. (1992)

A. Stoykova, D. Treichel, M. Hallonet und P. Gruss. Pax6 modulates the dorsoventral patterning of the mammalian telencephalon. J Neurosci 20: 8042-8050. (2000)

A. Streit, A. J. Berliner, C. Papanayotou, A. Sirulnik und C. D. Stern. Initiation of neural induction by FGF signalling before gastrulation. Nature 406: 74-78. (2000)

J. L. Stringer, N. S. Belaguli, D. Iyer, R. J. Schwartz und A. Balasubramanyam. Developmental expression of serum response factor in the rat central nervous system. Brain Res Dev Brain Res 138: 81-86. (2002)

T. Stühmer, S. A. Anderson, M. Ekker und J. L. Rubenstein. Ectopic expression of the Dlx genes induces glutamic acid decarboxylase and Dlx expression. Development 129: 245-252. (2002)

M. L. Sutherland, T. A. Delaney und J. L. Noebels. Glutamate transporter mRNA expression in proliferative zones of the developing and adult murine CNS. J Neurosci 16: 2191-2207. (1996)

N. Suzuki, H. Rohdewohld, T. Neuman, P. Gruss und H. R. Scholer. Oct-6: a POU transcription factor expressed in embryonal stem cells and in the developing brain. Embo J 9: 3723-3732. (1990)

S. C. Suzuki, T. Inoue, Y. Kimura, T. Tanaka und M. Takeichi. Neuronal circuits are subdivided by differential expression of type-II classic cadherins in postnatal mouse brains. Mol Cell Neurosci 9: 433-447. (1997)

P. Svenningsson, A. Nishi, G. Fisone, J. A. Girault, A. C. Nairn und P. Greengard. DARPP-32: an integrator of neurotransmission. Annu Rev Pharmacol Toxicol 44: 269-296. (2004)

$\mathrm{H}$. Tabata und K. Nakajima. Efficient in utero gene transfer system to the developing mouse brain using electroporation: visualization of neuronal migration in the developing cortex. Neuroscience 103: 865-872. (2001)

M. Takahashi und N. Osumi. Pax6 regulates specification of ventral neurone subtypes in the hindbrain by establishing progenitor domains. Development 129: 1327-1338. (2002)

M. Takahashi, K. Sato, T. Nomura und N. Osumi. Manipulating gene expressions by electroporation in the developing brain of mammalian embryos. Differentiation 70: 155-162. (2002)

K. Takebayashi, C. Akazawa, S. Nakanishi und R. Kageyama. Structure and promoter analysis of the gene encoding the mouse helix-loop-helix factor HES-5. Identification of the neural precursor cell-specific promoter element. J Biol Chem 270: 1342-1349. (1995) 
K. Takiguchi-Hayashi, M. Sekiguchi, S. Ashigaki, M. Takamatsu, H. Hasegawa, R. SuzukiMigishima, M. Yokoyama, S. Nakanishi und Y. Tanabe. Generation of reelin-positive marginal zone cells from the caudomedial wall of telencephalic vesicles. J Neurosci 24: 2286-2295. (2004)

The International Human Genome Sequencing Consortium. New release: International Consortium Completes Human Genome Project, www.genome.gov/11006929. (2003)

T. Theil, S. Aydin, S. Koch, L. Grotewold und U. Ruther. Wnt and Bmp signalling cooperatively regulate graded Emx2 expression in the dorsal telencephalon. Development 129: 3045-3054. (2002)

J. Timmer, J. Johnson und L. Niswander. The use of in ovo electroporation for the rapid analysis of neural-specific murine enhancers. Genesis 29: 123-132. (2001)

S. Tole, G. Goudreau, S. Assimacopoulos und E. A. Grove. Emx2 is required for growth of the hippocampus but not for hippocampal field specification. J Neurosci 20: 2618-2625. (2000a)

S. Tole und E. A. Grove. Detailed field pattern is intrinsic to the embryonic mouse hippocampus early in neurogenesis. J Neurosci 21: 1580-1589. (2001)

S. Tole, C. W. Ragsdale und E. A. Grove. Dorsoventral patterning of the telencephalon is disrupted in the mouse mutant extra-toes(J). Dev Biol 217: 254-265. (2000b)

A. D. Tramontin, J. M. Garcia-Verdugo, D. A. Lim und A. Alvarez-Buylla. Postnatal development of radial glia and the ventricular zone (VZ): a continuum of the neural stem cell compartment. Cereb Cortex 13: 580-587. (2003)

T. Y. Tsong. Electroporation of cell membranes. Biophys J 60: 297-306. (1991)

L. Tsuji, T. Yamashita, T. Kubo, T. Madura, H. Tanaka, K. Hosokawa und M. Tohyama. FLRT3, a cell surface molecule containing LRR repeats and a FNIII domain, promotes neurite outgrowth. Biochem Biophys Res Commun 313: 1086-1091. (2004)

R. Tur-Kaspa, L. Teicher, B. J. Levine, A. I. Skoultchi und D. A. Shafritz. Use of electroporation to introduce biologically active foreign genes into primary rat hepatocytes. Mol Cell Biol 6: 716-718. (1986)

D. Uziel, S. Muhlfriedel, K. Zarbalis, W. Wurst, P. Levitt und J. Bolz. Miswiring of limbic thalamocortical projections in the absence of ephrin-A5. J Neurosci 22: 9352-9357. (2002)

P. Vanderhaeghen, Q. Lu, N. Prakash, J. Frisen, C. A. Walsh, R. D. Frostig und J. G. Flanagan. A mapping label required for normal scale of body representation in the cortex. Nat Neurosci 3: 358-365. (2000)

J. C. Venter, M. D. Adams, E. W. Myers, P. W. Li, R. J. Mural, G. G. Sutton, H. O. Smith, M. Yandell, C. A. Evans, R. A. Holt, J. D. Gocayne, P. Amanatides, R. M. Ballew, D. H. Huson, J. R. Wortman, et al. The sequence of the human genome. Science 291: 1304-1351. (2001)

O. Vogt und C. Vogt. Ergebnisse unserer Hirnforschung. J Psychol Neurol 25: 277-462. (1919) 
T. Von Ohlen, D. Lessing, R. Nusse und J. E. Hooper. Hedgehog signaling regulates transcription through cubitus interruptus, a sequence specific DNA binding protein. Proc Natl Acad Sci U S A 94: 2404-2409. (1997)

B. Wasylyk, C. Wasylyk, P. Augereau und P. Chambon. The SV40 72 bp repeat preferentially potentiates transcription starting from proximal natural or substitute promoter elements. Cell 32: 503-514. (1983)

L. N. Wei, X. Hu, D. Chandra, E. Seto und M. Farooqui. Receptor-interacting protein 140 directly recruits histone deacetylases for gene silencing. J Biol Chem 275: 40782-40787. (2000)

R. White, G. Leonardsson, I. Rosewell, M. Ann Jacobs, S. Milligan und M. Parker. The nuclear receptor co-repressor nrip1 (RIP140) is essential for female fertility. Nat Med 6: 1368-1374.

(2000)

J. Wijnholds, K. Chowdhury, R. Wehr und P. Gruss. Segment-specific expression of the neuronatin gene during early hindbrain development. Dev Biol 171: 73-84. (1995)

S. W. Wilson und C. Houart. Early steps in the development of the forebrain. Dev Cell 6: 167181. (2004)

K. S. Wittman und M. Hamburgh. The development and effect of genetic background on expressivity and penetrance of the Brachyury mutation in the mouse: a study in developmental genetics. J Exp Zool 168: 137-145. (1968)

P. L. Woodhams, M. R. Celio, N. Ulfig und M. P. Witter. Morphological and functional correlates of borders in the entorhinal cortex and hippocampus. Hippocampus 3 Spec No: 303311. (1993)

M. Yoshida, Y. Suda, I. Matsuo, N. Miyamoto, N. Takeda, S. Kuratani und S. Aizawa. Emx I and Emx2 functions in development of dorsal telencephalon. Development 124: 101-111. (1997)

W. J. Young, Y. F. Lee, S. M. Smith und C. Chang. A bidirectional regulation between the TR2/TR4 orphan receptors (TR2/TR4) and the ciliary neurotrophic factor (CNTF) signaling pathway. J Biol Chem 273: 20877-20885. (1998)

R. H. Zetterstrom, L. Solomin, L. Jansson, B. J. Hoffer, L. Olson und T. Perlmann. Dopamine neuron agenesis in Nurr1-deficient mice. Science 276: 248-250. (1997)

R. H. Zetterstrom, R. Williams, T. Perlmann und L. Olson. Cellular expression of the immediate early transcription factors Nurrl and NGFI-B suggests a gene regulatory role in several brain regions including the nigrostriatal dopamine system. Brain Res Mol Brain Res 41: 111-120. (1996)

S. Zhao und P. A. Overbeek. Tyrosinase-related protein 2 promoter targets transgene expression to ocular and neural crest-derived tissues. Dev Biol 216: 154-163. (1999) 


\title{
Lebenslauf und Publikationen
}

\author{
Persönliche Daten: \\ Sven Mühlfriedel \\ geboren am 1. November 1973 in Schleiz \\ Schulbildung: \\ $1980-1983$ \\ 1983 - 1988 \\ Oberschule, Möschlitz \\ 1988 - 1992 \\ Polytechnische Oberschule "Dr. Konrad Duden", Schleiz \\ Juli 1992 \\ Spezialschule mathematisch-naturwissenschaftlich-technischer Richtung "Carl Zeiss", Jena \\ Abitur, Note "sehr gut" \\ Zivildienst: \\ $1992-1994$ \\ Landwirtschaft und Gärtnerei der Lebenshilfe e.V., Konradsreuth

\section{Studium:} \\ $1994-2000$ \\ $1999-2000$ \\ Januar 2000 \\ Publikationen: \\ Studium der Biologie (Diplom), Friedrich-Schiller-Universität, Jena \\ Diplomarbeit, Thema: \\ "Die Bedeutung von Ephrin A5 für die Entwicklung thalamocorticaler Projektionen" \\ AG Prof. Dr. J. Bolz, Friedrich-Schiller-Universität, Jena \\ Diplom, Note "mit Auszeichnung" \\ Uziel D, Mühlfriedel S, Zarbalis K, Wurst W, Levitt P, Bolz J. \\ Miswiring of limbic thalamocortical projections in the absence of ephrin-A5. \\ J Neurosci. 2002 Nov 1;22(21):9352-7 \\ Bolz J, Uziel D, Mühlfriedel S, Gullmar A, Peuckert C, Zarbalis K, Wurst W, Torii M, Levitt P. \\ Multiple roles of ephrins during the formation of thalamocortical projections: maps and more. \\ J Neurobiol. 2004 59(1):82-94. Review.
}

Auslandspraktikum:

März - August 2000 Auslandspraktikum, Thema:

"Effects of HGF/ Scatter factor on neurite outgrowth of embryonic mouse thalamus and somatosensory cortex in vitro."

AG Prof. Pat Levitt, Ph.D., University of Pittsburgh School of Medicine, Pittsburgh, USA

Publikation:

Powell EM, Mühlfriedel S, Bolz J, Levitt P.

Differential regulation of thalamic and cortical axonal growth by hepatocyte growth factor/scatter factor: Dev Neurosci. 2003 Mar-Aug;25(2-4):197-206.

Promotion:

$2000-2004$

Promotion, Thema:

"Mechanismen der Entwicklung des zerebralen Kortex"

AG Prof. Dr. P. Gruss, Max-Planck-Institut f. biophysikalische Chemie, Göttingen

Publikationen:

Sven Mühlfriedel/ F. Kirsch et al.

A microarray large scale analysis of gene expression in E16.5 cerebral cortex.

in Vorbereitung

Sven Mühlfriedel et al.

A roof dependent enhancer element drives Hop expression in cerebral cortex.

in Vorbereitung 